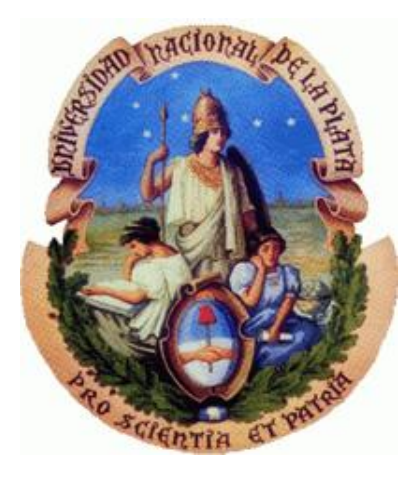

FACULTAD DE INFORMÁTICA UNIVERSIDAD NACIONAL DE LA PLATA

\title{
Un enfoque de modelado de Actividades Educativas Posicionadas que contemplan Elementos Concretos
} TESIS PRESENTADA PARA OBTENER EL GRADO DE MAGISTER EN
TECNOLOGÍA INFORMÁTICA APLICADA EN EDUCACIÓN

Autor: Esp. Alejandra Beatriz Lliteras

Directora: Dra. Silvia E. Gordillo

Codirectora: Dra. Cecilia Challiol

- Agosto 2015 - 
Página 2 de 167 


\section{Índice}

Índice

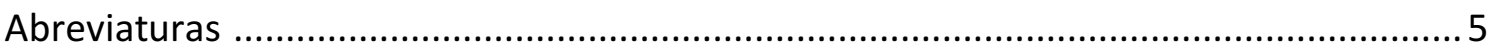

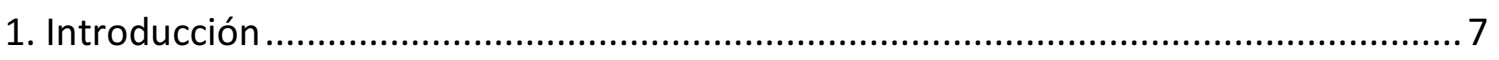

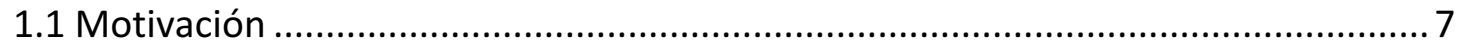

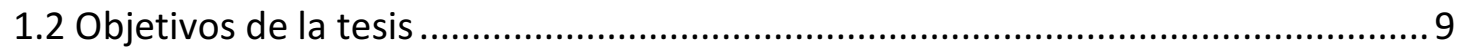

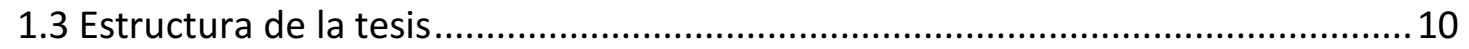

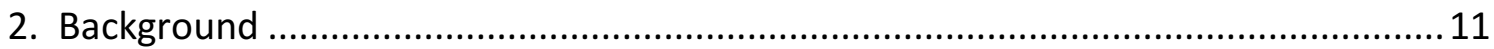

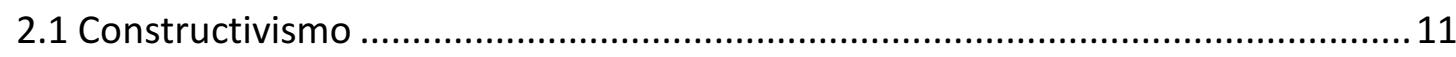

2.1.1 El constructivismo desde la perspectiva de Jean Piaget............................... 12

2.1.2 El constructivismo desde la perspectiva de Lev Vygotsky ..........................13

2.1.3 Algunas observaciones sobre las perspectivas de Piaget y Vygotsky.............. 14

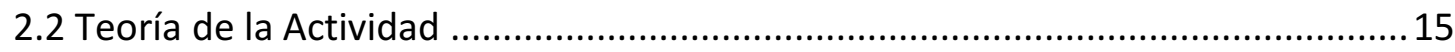

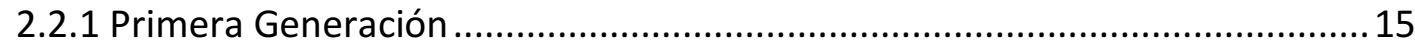

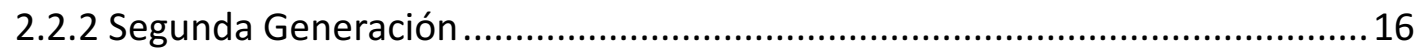

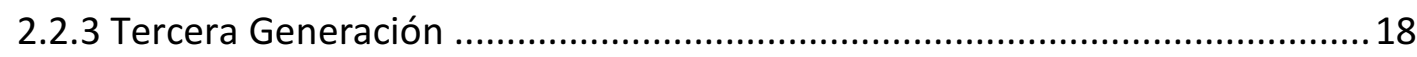

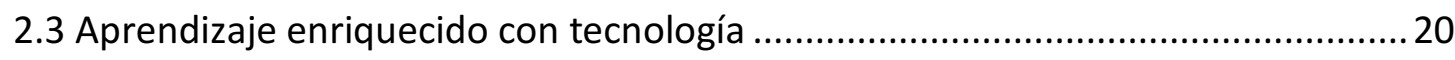

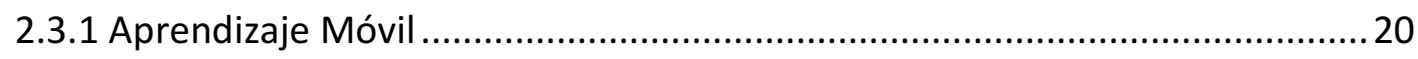

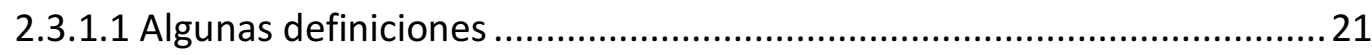

2.3.1.2 Aprendizaje Móvil basado en posicionamiento .................................. 23

2.3.1.3 La TA en Aprendizaje Móvil ................................................................ 23

2.3.1.4 Estándares usados en Aprendizaje Móvil ........................................... 25

2.3.1.5 Uso de objetos del mundo real........................................................ 27

2.4 Aspectos relacionados a la Ingeniería de Software ..........................................29

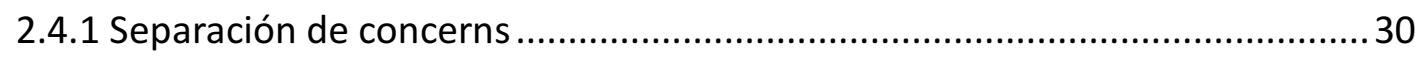

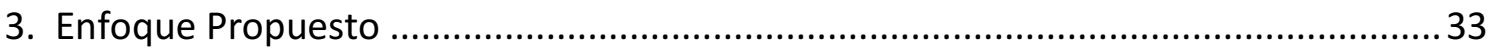

3.1 Caracterización de la problemática a resolver ..................................................... 33

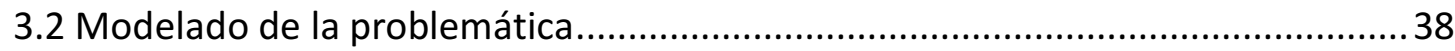

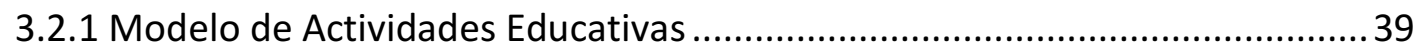

3.2.2 Modelo de Actividades Educativas Posicionadas ................................... 47 


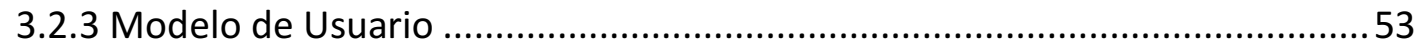

3.3 Análisis del reuso en los modelos del enfoque propuesto ..................................57

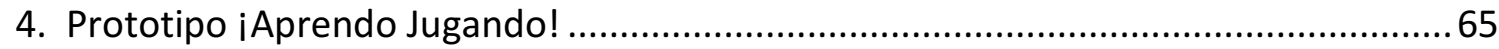

4.1 Extensión del modelo en base al dominio particular ........................................65

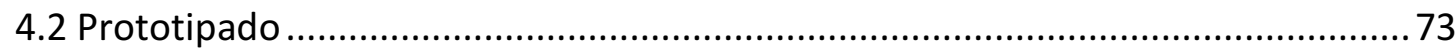

4.2.1 Definición de la AEP utilizada en el prototipo ............................................ 73

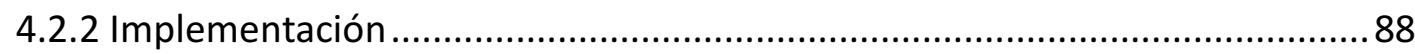

4.3 Cómo configurar el espacio físico para poner en práctica el prototipo .................95

5. Casos de Estudio: Presentación, Análisis y Discusión .............................................99

5.1 Aspectos comunes para las puestas en práctica en los casos de estudio. .............99

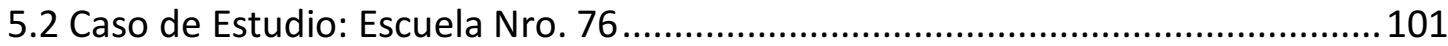

5.3 Caso de Estudio: Escuela Manantiales.................................................................. 107

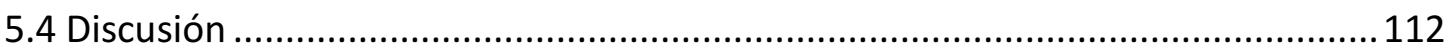

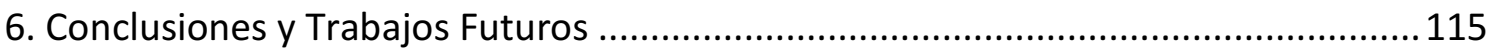

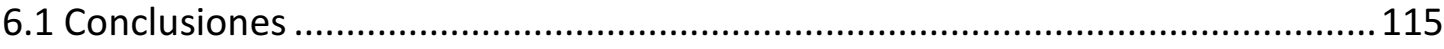

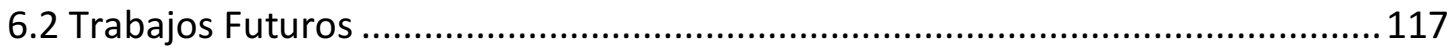

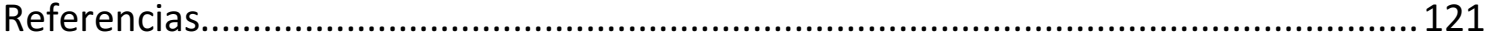

Anexo A: Cómo instalar el prototipo ¡Aprendo Jugando! en un dispositivo móvil ....... 131

A.1 Instalación de un Lector de QR ......................................................................... 131

A.2 Instalación del prototipo ¡Aprendo Jugando! ..................................................... 134

Anexo B: Simulación de uso del prototipo ¡Aprendo jugando!.................................. 141

Anexo C: Planilla de observación para la Escuela Nro. 76 ........................................ 159

Anexo D: Planilla de observación para la Escuela Manantiales.................................... 161

Publicaciones realizadas relacionadas a la temática de la tesis ................................ 165 


\section{Abreviaturas}

AE - Actividad Educativa

AEP - Actividad Educativa Posicionada

GPS - Global Positioning System

IEEE LTEC - Institute of Electrical and Electronics Engineers Learning Technology Estándards Committee

IMS - Instructional Management Systems

IMS-LD - IMS Learning Design

ISO - International Organization for Standardization

LMS - Learning Management System

PDA - Personal Digital Assistant

QR - Quick Response

QTI - Question \& Test Interoperabilty

RFID - Radio-Frequency Identification

SCORM - Sharable Content Object Reference Model

TA - Teoría de la Actividad

TEL - Technology Enhanced Learning

UML - Unified Modeling Language 
Página 6 de 167 


\section{Introducción}

\subsection{Motivación}

El avance de la tecnología móvil y la masificación de los dispositivos móviles (como por ejemplo, teléfonos inteligentes y tablets), ha permitido su inclusión como parte del uso cotidiano en diferentes aspectos de la vida de los individuos. Por ejemplo, aspectos sociales, entretenimiento, educación (como se destaca en [Hyo-Jeong et al., 2008]), entre otros.

El Aprendizaje Móvil, para los autores [Kukulska-Hulme et al., 2011] y [Traxler, 2009] puede definirse como el proceso de enseñanza-aprendizaje que ocurre con el uso de dispositivos móviles, proveyendo acceso bajo demanda a los recursos de aprendizaje, desde cualquier lugar. Sin embargo, la definición de Aprendizaje Móvil aún no está totalmente unificada, para algunos autores esto implica focalizarse solo en el uso de tecnología móvil, mientras que para otros implica además la movilidad del usuario. En particular, en [Lu et al., 2010] se hace distinción del concepto de Aprendizaje Móvil en relación a otros tipos de aprendizaje mencionando que se asume que el alumno está permanentemente en movimiento, esto implica que la posición del alumno cambia de un lugar a otro. Siguiendo esta línea, en [Brown, 2010] se plantea que este tipo de aprendizaje puede conducir al alumno a una nueva experiencia de aprendizaje. Con este tipo de aprendizaje es posible: situar a los alumnos en escenarios del mundo real [Bamberger and Tal, 2007]; así como combinar recursos de aprendizaje del mundo digital y del mundo real (algunos ejemplos de esta combinación son mencionados en [Rogers et al., 2005] y [Vogel et al., 2010]). Incluir la manipulación de objetos del mundo real según [McNeil and Jarvin, 2007], implica otro procesamiento de la información, constituyendo la manipulación de los mismos, un canal de información adicional para el alumno. A los objetos del mundo real que pueden ser manipulados, los llamaremos en este trabajo: elementos concretos.

El Aprendizaje Móvil que contempla la movilidad del alumno, permite llevar a cabo actividades educativas posicionadas. En particular, en [Chu et al., 2010] y en [Liu et al., 2014] se presentan ejemplos de este tipo de actividades, en el marco de las ciencias naturales (para educación primaria). Estas actividades contemplan al mismo tiempo la observación de elementos del mundo real (plantas) y del mundo digital; y donde se le indica al alumno un recorrido que debe realizar para completar una tarea. En estas actividades, los autores abordan la inclusión de elementos del mundo real desde la observación y no desde la posibilidad de manipulación de los mismos. Por otro lado, en [Santos 2011], se plantean actividades educativas posicionadas tomando como base el estándar de "Tecnología educativa para la evaluación de preguntas e interoperabilidad de pruebas" (conocido como IMS Question \& Test Interoperabilty -QTI [IMS, 2006]), las preguntas allí formuladas, no contemplan elementos del mundo real. 
La mayoría de las aplicaciones que plantean actividades educativas posicionadas, se crean ad-hoc, existiendo muchos prototipos propuestos, por ejemplo MobiMath (matemática) [Wijers et al., 2010], Savannah (comportamiento animal) [Facer et al., 2004], Frequency 1550 (historia) [Raessens, 2007] , Explore! (arqueología) [Costabile et al., 2008], $\mathrm{T}^{3} \mathrm{G}$ (ciencias naturales) [Chu et al., 2010] y en [Liu et al., 2014] en el que se presenta un prototipo para trabajar sobre la morfología de las hojas de plantas (para ciencias naturales). Estos prototipos solo se pueden usar para el lugar o con el contenido con el que fueron creados, en particular, estos autores no presentan ningún modelo asociado que permita algún grado de flexibilidad.

Existen en la bibliografía algunos autores que proponen modelos relacionados con Aprendizaje Móvil, por ejemplo en [Hansen et al., 2012] se presenta un modelo orientado a aplicaciones de hipermedia sensibles al contexto y en particular lo usan instanciado para educación creando la aplicación Haslelnteractive [Hansen and Bouvin, 2009]. Este modelo permite representar narraciones y recolectar datos del ambiente, no contempla la manipulación de elementos del mundo real.

En [Gomez et al., 2014] se usa el modelo de IMS-LD [IMS-LD, 2003] para crear actividades educativas que contemplan el contexto del usuario. En particular, el contexto de posición lo mencionan de manera simbólica solo como marco de referencia (por ejemplo: escuela, casa) y no como una posición del mundo real. Los posibles valores contextuales se especifican en tiempo de diseño, y junto a los mismos se definen las reglas que se aplicarán a los mismos. Por ejemplo, si el alumno puede estudiar entre 15 y 30 minutos y está en la casa se asume que este tendrá un alto nivel de concentración y en consecuencia se le brinda la actividad.

En [Santos et al., 2011], emplean un modelo que se basa en el IMS Question \& Test Interoperability (QTI) [IMS, 2006] para brindar preguntas posicionadas, ligando el contenido de las mismas a la posición para la cual se crea. Los prototipos presentados solo permiten posiciones GPS ya que la creación es mediante el mapa de Google Maps. Este modelo ha sido probado en diferentes dominios.

En los modelos mencionados en [Gomez et al., 2014] y [Santos et al., 2011], no se propone separación en capas como se hace conceptualmente en [Lliteras et al., 2012], en particular para contenido educativo y posicionamiento. En ninguno de estos dos modelos se contempla la manipulación de elementos concretos como parte de las actividades educativas posicionadas.

El presente trabajo de tesis adopta la separación en capas, en particular de posicionamiento y contenido como se propone en [Lliteras et al., 2012] para presentar un enfoque de modelado que permita representar actividades educativas posicionadas que involucren elementos concretos. Se considerará la representación del espacio físico en el que se realizan estas actividades como un aspecto destacado de este enfoque.

Página 8 de 167 
Cabe destacar que, en el trabajo propuesto para esta tesis, los elementos concretos, son aquellos objetos que existen en el mundo real y de los cuales el alumno contará además con alguna representación en el mundo digital. Dichos elementos estarán presentes en las actividades educativas posicionadas del alumno para poder ser manipulados por él y se los identificará de alguna manera para poder ser relacionados con su representación digital (por ejemplo, empleando códigos QR [Kato et al., 2010]). Estos elementos concretos, estarán ubicados en el lugar en el que se plantee cada actividad educativa posicionada y podrán guardar alguna relación con lo que enuncie dicha actividad.

\subsection{Objetivos de la tesis}

A continuación se enuncian los objetivos particulares del presente trabajo

- Definir los conceptos principales relacionados con las actividades educativas posicionadas.

- Proponer un enfoque de modelado de actividades educativas posicionadas que contempla elementos concretos y la representación del espacio físico de uso, separando los aspectos de actividad educativa y posición en el que dicha actividad se brinda.

- Presentar mediante un prototipo un caso de instanciación particular del enfoque propuesto. El cual será puesto en práctica en escuelas.

- Exponer observaciones generadas a partir de casos de estudio del prototipo, en temas como por ejemplo: el uso del prototipo, el comportamiento de los actores involucrados (rol del docente y de los alumnos) y de la interacción con los elementos concretos y con el espacio físico en el que se usó.

El aporte novedoso de la tesis es la definición de un enfoque de modelado flexible y extensible de actividades educativas posicionadas que contemplan elementos concretos. Lo que implica, por ejemplo, que las actividades educativas puedan realizarse en diferentes espacios físicos. La mismas tareas puedan ser usadas en distintas planificaciones y empleadas en distintas actividades educativas posicionadas al igual que los elementos concretos. Se considerará la representación del espacio físico en el que se realizan estas actividades como un aspecto destacado de este enfoque. La instanciación del enfoque propuesto permitirá llevar a cabo diferentes experiencias móviles en el marco del Aprendizaje Móvil.

Como una consecuencia del dominio del prototipo implementado se propuso una extensión del enfoque propuesto para brindar soporte a actividades educativas posicionadas que involucren la recolección y depósito de elementos concretos. 


\subsection{Estructura de la tesis}

En esta sección se enumeran y describen brevemente los capítulos de la tesis.

En el Capítulo 2, se presenta el background de esta tesis, en donde contemplando un enfoque constructivista del aprendizaje, y en particular el enfoque socio-cultural introducido por Vygotsky, se decidió explorar la teoría de la actividad para el trabajo propuesto. Por otro lado se presenta el aprendizaje enriquecido con tecnología, para explorar en particular, el Aprendizaje Móvil, haciendo foco en aquel Aprendizaje Móvil que es basado en posicionamiento. Luego de esto, se analizan estándares para el Aprendizaje Móvil. Además, se describe el uso de objetos del mundo real en educación. Para dar sustento al enfoque propuesto, desde la perspectiva de la ingeniería de software, y las buenas prácticas de modelado, se introduce en este capítulo una breve descripción acerca de la evolución del software, en particular de la separación en concerns.

En el Capítulo 3, se caracteriza la problemática a resolver en este trabajo y luego se propone un enfoque de modelado orientado a objetos para dar una posible solución a dicha problemática. Los modelos del enfoque fueron especificados para que sean flexibles y extensibles para considerar otros aspectos relevantes que puedan surgir al considerar otras características más allá de la problemática en cuestión.

En el Capítulo 4, se presenta un análisis de un dominio particular y en base a este análisis se propone una extensión de los modelos del enfoque propuesto en el Capítulo 3. En base a estas extensiones, se implementó un prototipo llamado ¡Aprendo Jugando!.

En el Capítulo 5, se presentan dos casos de estudio, en los que se realizaron diferentes puestas en práctica del prototipo presentado en el Capítulo 4. De cada uno se realiza la presentación, análisis y discusión de aquellos aspectos relevantes que surgieron durante los mismos.

En el Capítulo 6, se presentan las conclusiones obtenidas en relación al trabajo presentado y se mencionan posibles trabajos futuros. 


\section{Background}

Contemplando un enfoque constructivista del aprendizaje, y en particular el enfoque socio-cultural introducido por Vygotsky, se decidió explorar la teoría de la actividad para el trabajo propuesto. Por otro lado se presentará en el marco del aprendizaje enriquecido con tecnología, para explorar en particular el Aprendizaje Móvil, haciendo foco en aquel Aprendizaje Móvil que es basado en posicionamiento. Se analizarán estándares para el Aprendizaje Móvil para luego describir el uso de objetos del mundo real en educación.

Para dar sustento al enfoque propuesto, desde la perspectiva de la ingeniería de software, y las buenas prácticas de modelado, se introduce en este capítulo una breve descripción acerca de la evolución del software, en particular del concepto de separación en concerns.

\subsection{Constructivismo}

El constructivismo, de acuerdo a lo expuesto en [Carretero, 1993], "es la idea de que individuo, tanto en los aspectos cognitivos y sociales del comportamiento como en los afectivos, no es un simple producto del ambiente ni resultado de sus disposiciones internas, sino una construcción propia; que se produce día a día como resultado de la interacción entre esos dos factores". Este autor, menciona además que "el conocimiento no es una copia de la realidad, sino una construcción del ser humano (...)" la cual realiza "(...) fundamentalmente con los esquemas propios". Además, "La posición constructivista hace hincapié en que el conocimiento nuevo sólo se adquiere mediante una interacción con los esquemas que ya posee el sujeto" [Camilloni et al., 2001].

De acuerdo a [Carretero, 1997], "un esquema es una representación de una situación concreta $o$ de un concepto que permite manejarlos internamente y enfrentarse a situaciones iguales o parecidas en la realidad"..."Los esquemas pueden ser muy simples o muy complejos... muy generales o muy especializados". Un ejemplo de esquema simple citado por el autor, es el que construye un niño cuando aprende a "tomar con sus manos un objeto" (conocido como esquema de prensión), otro esquema es de "irse a la cama" el cual construye el niño pequeño mediante el ritual de acostarse (por ejemplo con la lectura de un cuento por parte de alguno de sus padres).

Los autores [Camilloni et al., 2001], [Carretero, 1993], [González-Tejero, 2011] y [Powell and Kalina, 2009] mencionan dos grandes perspectivas del constructivismo, por un lado la representada por Piaget (relacionado con lo individual), y por otro lado, la representada por Vygotsky (relacionado a lo social). De acuerdo a lo expuesto en [Carretero, 1993], "la aportación de Piaget y Vygotsky ha sido fundamental en la elaboración de un pensamiento constructivista en el ámbito educativo". Para el presente trabajo, se hará una breve presentación del constructivismo desde la perspectiva de los 
dos autores mencionados, con el fin de poder introducir una base conceptual de la temática. Esta no es exhaustiva, sino que constituye una mera descripción introductoria.

\subsubsection{El constructivismo desde la perspectiva de Jean Piaget $^{1}$}

El principal foco en la perspectiva de constructivismo propuesta por Piaget, de acuerdo a lo mencionado en [Powell and Kalina, 2009], está relacionado a lo individual y a la manera en la que los individuos construyen el conocimiento. Para Piaget la inteligencia pasa por etapas diferentes a lo largo de la vida de un individuo $\mathrm{y}$, los esquemas de los individuos se construyen a través del proceso de asimilación y acomodación en cada etapa y a medida que éste pasa por ellas. Las etapas por las que pasa el individuo de acuerdo a Piaget [Piaget, 1952], son las siguientes:

- Sensoria motora.

- Pre operacional.

- Operacional concreta.

- Operacional formal.

A continuación, se hará una breve descripción de cada una estas etapas de desarrollo en el individuo propuestas por el autor, de acuerdo a su trabajo [Piaget, 1952]:

- Sensoria motora: comprendida desde el nacimiento y hasta los dos años de edad. En esta etapa el niño descubre su entorno a través de sus sentidos, movimientos y lenguaje. De acuerdo al autor, los primeros esquemas se relacionan a los reflejos, como por ejemplo el esquema de succión para alimentarse. Luego estos reflejos se adaptan con el entorno pasando a ser auto generados y no producto de un acto reflejo, es decir, existe una intencionalidad.

- Pre operacional: entre los dos y los siete años. En esta etapa el niño adquiere la habilidad del lenguaje propio, sin embargo aun no puede comprender los pensamientos de los demás individuos y se la asocia a un pensamiento intuitivo. El niño puede hacer representaciones mentales de un objeto que no está viendo sin embargo no puede usar un pensamiento deductivo.

- Operacional concreta: abarca de los siete a los once años. En esta etapa, el niño se encuentra en un punto crucial en el desarrollo de su cerebro en cuanto al desarrollo lógico. Comienza a reemplazar el pensamiento intuitivo por su propio razonamiento lógico. En esta etapa el niño puede diferenciar su perspectiva de la de otras personas y puede aplicar pensamiento deductivo.

\footnotetext{
${ }^{1}$ Jean Piaget, nació en 1934 y falleció en 1980.
} 
- Operacional formal: desde los once años hasta que el individuo es adulto. Etapa en la que el niño comienza a usar niveles de pensamiento superiores, trabajando con ideas abstractas para resolver problemas.

En cuanto a los procesos de asimilación y acomodación, Piaget en su trabajo [Piaget, 1952] menciona que se dan cuando el niño está aprendiendo y describe a cada proceso de la siguiente manera:

- Asimilación: sucede cuando el niño aporta nuevos conocimientos a sus propios esquemas.

- Acomodación: se da cuando el niño debe "acomodar" sus esquemas a la nueva información o conocimiento.

En [Wadsworth, 1996], el autor menciona que, para Piaget, la inteligencia es una forma de adaptación, en el que el conocimiento de cada individuo se construye mediante los dos procesos complementarios previamente descriptos. Cuando un niño se enfrenta a una situación nueva, la debe asimilar mediante un esquema existentes o crear uno nuevo.

El constructivismo de Piaget, de acuerdo a [Powell and Kalina, 2009], incorpora la importancia de comprender que necesita cada individuo para obtener conocimiento y aprender a su propio ritmo.

\subsubsection{El constructivismo desde la perspectiva de Lev Vygotsky2 3}

La perspectiva de constructivismo propuesta por Vygotsky, de acuerdo a [Powell and Kalina, 2009], es conocida como constructivismo socio-cultural y se basa en la relevancia de la interacción social como parte del aprendizaje. Se basa en las interacciones sociales de los alumnos en el proceso de aprendizaje. De acuerdo a [Carretero, 1997], esta perspectiva hace que "el aprendizaje no sea considerado como una actividad individual, sino mas bien social". El citado autor, menciona además que "una de las contribuciones esenciales de Vygotsky ha sido la de concebir al sujeto como un ser eminentemente social, en la línea del pensamiento marxista, y al conocimiento mismo como un producto social".

${ }^{2}$ Lev Vygotsky nació en 1896 y falleció en 1934.

${ }^{3}$ En [Ivić, 1994] se menciona: "En Moscú, durante un prodigioso decenio (1924-1934), Vygotsky, rodeado de un grupo de colaboradores tan apasionados como él por la elaboración de una verdadera reconstrucción de la psicología, crea su teoría histórico-cultural de los fenómenos psicológicos. Ignorados durante largo tiempo, los escritos fundamentales de Vygotsky y sus actividades profesionales, sólo se han redescubierto y reconstituidos recientemente, y poco a poco". De acuerdo a la cita mencionada, es posible acceder a sus trabajos a través de otros autores o bien, por antologías realizadas de sus textos y postulados. Por este motivo, las fechas de los textos citados en relación al autor, son posteriores al período histórico en el que el autor realiza sus postulaciones, inclusive, posteriores a su fallecimiento.

Página 13 de 167 
En [Carretero, 1997], el autor, presenta a Vygotsky como un pionero por algunos de sus postulados, entre los que destaca dos en particular. Los mismos se describen a continuación en base a lo presentado en [Vygotsky, 1978]:

- Los procesos psicológicos superiores se adquieren primero en un contexto social y luego se internalizan: "un proceso interpersonal queda transformado en otro intrapersonal. En el desarrollo cultural del niño, toda función aparece dos veces: primero, a escala social, y más tarde, a escala individual; primero, entre personas (interpsicológica), y después, en el interior del propio niño (intrapsicológica). Esto puede aplicarse igualmente a la atención voluntaria, a la memoria lógica y a la formación de conceptos. Todas las funciones psicológicas superiores se originan como relaciones entre seres humanos."

- La zona de desarrollo próximo: "es la distancia entre el nivel real de desarrollo, determinado por la capacidad de resolver independientemente un problema, y el nivel de desarrollo potencial, determinado a través de la resolución de un problema bajo la guía de un adulto o en colaboración con un compañero más capaz. El estado del desarrollo mental de un niño puede determinarse únicamente si se lleva a cabo una clasificación de sus dos niveles: el nivel real de desarrollo y de la zona de desarrollo potencial".

Mediante los dos postulados de Vygotsky mencionados anteriormente, en [Carretero, 1997] se indica que se cambia la visión que existió por mucho tiempo y se implanta la idea de que "lo que un individuo puede aprender no sólo depende de su actividad individual".

\subsubsection{Algunas observaciones sobre las perspectivas de Piaget y Vygotsky}

En base al trabajo de [Carretero, 1997], se destacan algunas discrepancias entre las perspectivas de Piaget y Vygotsky, "mientras que Piaget sostiene que lo que un niño puede aprender está determinado por su nivel de desarrollo cognitivo, Vygotsky piensa que es este último el que está condicionado por el aprendizaje". Otro aspecto de discrepancia entre los autores, es sobre "la influencia del lenguaje en el desarrollo cognitivo en general y más concretamente en relación al pensamiento". En [Vygotsky, 2012], se indican estas diferencias de la función del lenguaje egocéntrico. De acuerdo a [Carretero, 1997], mientras que para Piaget el lenguaje de la etapa Pre Operatoria se toma como elemento para mostrar la incapacidad del niño para comprender el punto de vista de otro, para Vygotsky este lenguaje (entre los dos y siete años aproximadamente) realiza contribuciones importantes en el desarrollo cognitivo del niño. En primer lugar, porque es un paso para que se produzca el lenguaje interiorizado, que resulta esencial en etapas posteriores y en segundo lugar, porque dicho lenguaje posee posibilidades comunicativas mucho mayores de lo que Piaget había postulado.

Continuando con lo expuesto en [Carretero, 1997], el autor menciona que "se ha comprobado como el alumno aprende de forma más eficaz cuando lo hace en un contexto 
de colaboración e intercambio con sus compañeros. Igualmente, se han precisado algunos de los mecanismos de carácter social que estimulan y favorecen el aprendizaje, como son las discusiones en grupo y el poder de la argumentación en la discrepancia entre los alumnos que poseen distintos grados de conocimiento de un tema".

\subsection{Teoría de la Actividad}

Tomando como base del trabajo, el enfoque socio-cultural del aprendizaje propuesto por Vygotsky, se aborda en esta sección la Teoría de la Actividad (TA). Esta teoría toma como unidad de análisis a la actividad y surge como una herramienta intelectual enfrentando los postulados del psicoanálisis y el conductismo de los años 20. En [Engeström, 2001] (el autor, citando su trabajo previo [Engeström and Escalante, 1996]) propone la visión de una evolución en tres generaciones para la TA, donde la última generación es propuesta por el citado autor.

- Primera generación: se centró en el hecho de que un acto humano no es solo la respuesta a un estimulo sino que es mediado por un componente cultural. Siendo Vygotsky [Vygotsky, 1978] quien sienta estas bases.

- Segunda generación: el foco está en que la actividad es un acto colectivo y en la división del trabajo. Generación asociada fundamentalmente a Leontev [Leontev, 1978].

- Tercera generación: surge como la necesidad de desarrollar marcos conceptuales para entender el diálogo, las múltiples perspectivas de diferentes voces y las redes de sistemas de actividad que interactúan entre ellos. Cuyo fundamental referente ha sido Engeström [Engeström, 2001].

A continuación se describirá cada una de estas generaciones desde lo presentado en [Engeström, 2001].

\subsubsection{Primera Generación}

Como se mencionó anteriormente, la TA se origina en los años 20 y el primer acercamiento fue formulado por Vygotsky para explicar el desarrollo humano desde la teoría marxista, en contraposición a las corrientes del psicoanálisis y del conductismo vigente en ese momento. Esta última, postulaba que dado un estimulo se obtenía una respuesta solamente a partir de reflejos innatos. Vygotsky, introduce el concepto de artefacto mediador. De este modo, el individuo, de acuerdo a Vygotsky, no reacciona directamente al ambiente, sino que existe una relación entre el agente humano (sujeto) y los objetos del ambiente. Esta relación se encuentra mediada por factores culturales, herramientas y señales. De este modo, Vygotsky propone como unidad de análisis un "acto mediado" y propone una figura triangular para la acción humana, la cual se presenta en la Figura 2.1.a. En dicha figura, se presenta un triángulo donde la conexión entre el estímulo condicionado (S) y la respuesta (R) se encuentra mediada por un componente

Página 15 de 167 
cultural (X). Por otro lado, en la Figura 2.1.b, se muestra su reformulación más común en la bibliografía (ambas figuras, fueron extraídas de [Engeström, 2001].
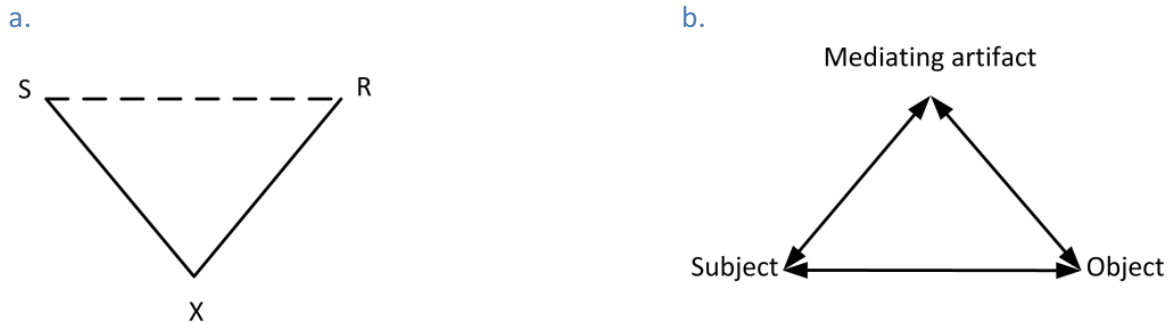

Figura 2.1: Fundamentos de la TA [Engeström, 2001]

En [Engeström, 2001], el autor, citando su trabajo previo [Engeström and Escalante, 1996], menciona que "la inserción de un componente cultural en las acciones humanas fue revolucionaria" y que a partir de esto "el individuo ya no se podía entender sin sus medios culturales; y la sociedad, ya no se podía entender sin la intervención de las personas que usan y producen artefactos". Esta generación, de acuerdo lo mencionado por el autor citado, se focalizó en la acción individual y esto fue una limitante.

\subsubsection{Segunda Generación}

La segunda generación de la TA, comienza con Leontev y se caracteriza por la expansión de la unidad de análisis de lo individual a lo colectivo y la introducción del concepto de división de tareas. Este autor introduce en [Leontev, 1978] la idea de actividad colectiva explicando la diferencia entre una acción individual y una actividad colectiva mediante la división de tareas. Para esto, el autor en el citado trabajo propone un ejemplo de caza colectiva e indica "Cuando los miembros de una tribu están cazando, cada uno de ellos tiene unos objetivos separados y está a cargo de distintas acciones. Algunos espantan a una manada de animales para que corra hacia otros cazadores (...) y otros miembros tienen otras tareas. Estas acciones tienen unos objetivos inmediatos, pero el motivo real se encuentra más allá de la caza. El objetivo común de esas personas es obtener comida y vestimenta: sobrevivir. Para comprender por qué son significativas unas acciones separadas es necesario comprender el motivo que hay detrás de toda la actividad. La actividad está guiada por un motivo".

Lo expuesto por Leontev, es retomado en [Engeström, 1987] para presentar una expansión del modelo triangular de la primera generación. En esta expansión, se incluyen los elementos colectivos del sistema de actividad: comunidad, reglas y división del trabajo, mencionando la importancia de analizar sus interacciones y conflictos, su intención con esto, fue la de analizar la actividad desde lo colectivo en lugar de hacerlo exclusivamente a 
nivel de agente individual. El modelo expandido propuesto en [Engeström, 1987], se visualiza en la Figura 2.2.

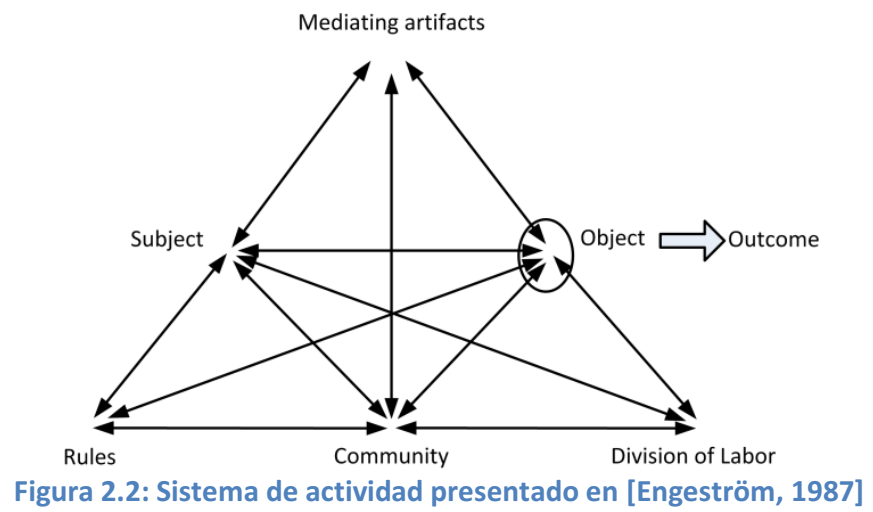

Los elementos enunciados en la Figura 2.2, se describen a continuación:

- Sujeto: es un individuo o subgrupo involucrado en una actividad, el cual es elegido como punto de vista del análisis

- Objeto: es el "espacio de problema" al que la actividad se dirige y a partir del cual se llegará, mediante una transformación (con la ayuda de Artefactos de mediación) a los resultados. Constituye el foco de la actividad

- Artefactos de mediación: es cualquier cosa que medie la acción entre el sujeto y el objeto

- Comunidad: es el grupo de individuos o de subgrupos involucrados en la actividad (en su totalidad), todos ellos comparten el mismo objeto. Cada Sujeto es parte de una Comunidad.

- División del trabajo: indica la manera en la que el sujeto actúa en el objeto, por ejemplo las personas pueden adoptar diferentes roles

- Reglas: las reglas definen la interacción entre el sujeto y los Artefactos de mediación para con el objeto. Constituyen regulaciones explícitas y/o implícitas, normas, valores y convenciones

- Resultado: es la transformación del objeto luego de que el sujeto aplica Artefactos de mediación sobre él.

De acuerdo a [Engeström, 2001], el triángulo superior de la Figura 2.2, "se puede ver como la punta del iceberg, que representa acciones grupales o individuales embebidas en un sistema de actividades colectivas". En el citado trabajo, se menciona además que "al objeto se lo describe con un óvalo, el cual indica que, las acciones orientadas al objeto están siempre caracterizadas de manera explícita o implícita por la ambigüedad, la sorpresa, la interpretación, la comprensión y el potencial para el cambio".

Por otro lado, como se mencionó anteriormente, Engeström expone la importancia de las contradicciones en los sistemas de actividad como fuerza impulsora del cambio y el

Página 17 de 167 
desarrollo. Indicando en [Engeström, 1987] que el sistema de actividad "está constantemente trabajando con contradicciones dentro de los elementos y entre ellos".

De acuerdo a [Uden, 2007] "una contradicción es una falta de adaptación dentro o entre elementos o entre diferentes actividades. La Teoría de la Actividad, no ve a las contradicciones como un problema, sino que las considera una fuente de evolución."

La Teoría de la Actividad de esta generación, fue adoptada internacionalmente ya que a partir de los 70, se la re contextualiza en occidente. Con esto llegaron nuevos desafíos, tales como el cuestionamiento y la diversidad entre diferentes tradiciones o perspectivas. En [Cole and Engeström, 2001] se menciona que el problema de esta generación es la falta de sensibilidad para la diversidad cultural.

\subsubsection{Tercera Generación}

La tercera generación de esta teoría es formulada en [Engeström, 2001]. Esta generación surge como la necesidad de desarrollar herramientas conceptuales para entender el diálogo, las múltiples perspectivas de diferentes voces y las redes de sistemas de actividad que interactúan entre ellos. El modelo de esta generación, toma a dos sistemas de actividad (que interactúan entre sí) como unidad mínima de análisis posibilitando capturar tensiones y contradicciones que se producen intra e inter sistemas de actividades además de estudiar procesos de aprendizaje inter-organizacionales.

En [Daniels, 2001] se cita el trabajo presentado en [Engeström et al., 1999]), y en referencia a esto, Daniels define que "la actividad se realiza mediante una constante negociación, orquestación y lucha entre las distintas metas y perspectivas de los participantes. El objeto y el motivo de una actividad colectiva son como un mosaico en constante evolución, una pauta que nunca se establece por completo". Se menciona además que "...la construcción de objetos mediada por artefactos (...) es un proceso dialogal y en colaboración donde distintas perspectivas (...) y voces (...) se encuentran, chocan $y$ se fusionan. Estas distintas perspectivas están arraigadas en distintas comunidades y prácticas que siguen coexistiendo dentro del mismo sistema de actividad colectiva".

El modelo para esta generación de la TA se presenta en la Figura 2.3.

De acuerdo a lo citado en [Daniels, 2001] (en relación al trabajo [Engeström et al., 1999]), y aquí aplicable a la Figura 2.3, "el objeto pasa de un estado inicial de material en bruto, dado por la situación y que no ha sido tema de reflexión (objeto 1; por ejemplo un paciente concreto que entra en la consulta de un médico) a ser un objeto colectivamente significativo construido por el sistema de actividad (objeto 2; por ejemplo, el paciente como espécimen de una categoría de enfermedad/salud) hasta convertirse en un objeto potencialmente compartido o construido conjuntamente (objeto 3; por ejemplo, una comprensión construida en colaboración de la situación vital y del plan de asistencia del 
paciente). El objeto de la actividad es un blanco en movimiento que no es reducible a objetivos conscientes a corto plazo".

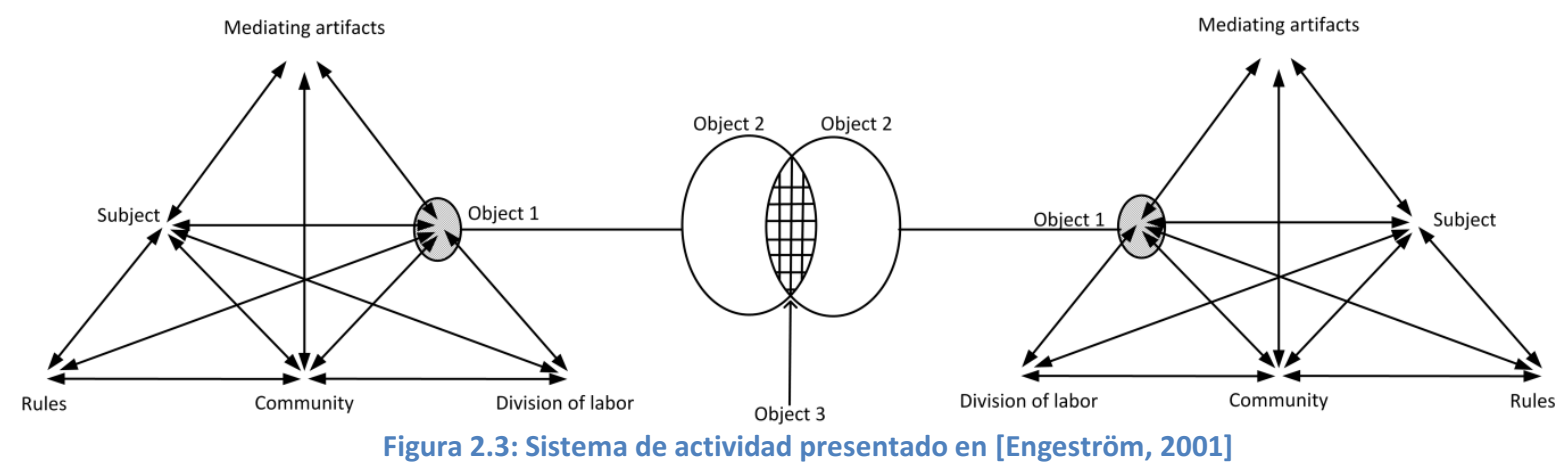

En [Daniels, 2001] se menciona que "para Engeström, la TA es la base teórica para el análisis del aprendizaje innovador", y luego cita a [Engeström et al., 1999], donde se menciona que este último lo justifica indicando que la TA :

- "es contextual y está orientada hacia la comprensión de prácticas locales históricamente específicas, sus objetos, sus artefactos mediadores y su organización social".

- "está basada en una teoría dialéctica del conocimiento y del pensamiento centrada en el potencial creativo de la cognición humana".

- "es una teoría del desarrollo que intenta explicar los cambios cualitativos que se dan con el tiempo en las prácticas humanas e influir en ellos".

En [Engeström, 2001], el autor resume a la tercera generación de la TA, en cinco principios a ser considerados para el estudio de los sistemas de actividad en su dinámica interna y su interrelación:

- Primer principio: indica que la unidad mínima de análisis es un sistema de actividad colectivo el cual es mediado por herramientas y está orientado hacia objetos, en el contexto de sus relaciones de red con otros sistemas de actividad

- Segundo principio: se basa en la multiplicidad de voces de los sistemas de actividad. Un sistema de actividad es una comunidad con múltiples puntos de vista, intereses y tradiciones. La división de tareas, en una actividad, crea diferentes posiciones en los participantes, los cuales a su vez poseen sus propias historias personales. Cuanto mayor sea la red de sistemas interconectados, mayor será la cantidad de voces.

- Tercer principio: contempla la historia de los sistemas de actividad, los que se conforman y transforman durante largos períodos de tiempo. Sus potenciales y problemas solo pueden ser comprendidos respecto de su propia historia. La historia en si misma necesita ser estudiada como la historia local de la actividad y 
sus objetos y como la historia de las ideas teóricas y de las herramientas que le han dado forma a la actividad

- Cuarto principio: enuncia el rol central de las contradicciones como fuente de cambio y evolución. Las contradicciones no son problemas o conflictos. Las contradicciones son tensiones estructurales acumuladas históricamente dentro y entre sistemas de actividades. Cuando un sistema de actividad adopta un nuevo elemento desde el exterior (por ejemplo, una nueva tecnología), usualmente sufre una contradicción con algún elemento pre existente (por ejemplo, las reglas o la división de tareas). Estas contradicciones generan disturbios pero también intentos innovadores para cambiar a la actividad.

- Quinto principio: expresa la posibilidad de transformaciones expansivas en los sistemas de actividad, mediante las cuales, algunas veces, se llega a un objetivo colectivo nuevo conllevando a que el objeto y la motivación de la actividad se re conceptualicen para adoptar un horizonte de posibilidades más amplio que de la manera anterior. De acuerdo a lo expresado por Engeström, "un ciclo completo de transformación expansiva se puede pensar como un viaje colectivo por la zona de desarrollo próximo de la actividad".

\subsection{Aprendizaje enriquecido con tecnología}

En [Chan et al., 2006], se menciona que el aprendizaje enriquecido con tecnología (conocido por sus siglas en ingles: TEL, Technology Enhanced Learning), es aquel en el que usando tecnología digital, se da soporte al aprendizaje humano. En este marco, se presentan en esta sección dos estándares existentes desde el foco de la tesis, es decir, desde el posicionamiento. Se analizarán algunos autores que emplean dichos estándares contemplando de alguna manera este concepto y se introduce al Aprendizaje Móvil como un caso particular de aprendizaje enriquecido con tecnología, en este caso, móvil. Además, se describe el uso de objetos del mundo real en educación.

\subsubsection{Aprendizaje Móvil}

El Aprendizaje Móvil involucra el uso de dispositivos móviles como artefacto mediador en el proceso de enseñanza. En [Ng, 2013], el autor menciona que cuando el aprendizaje es mediado por dispositivos móviles se requiere de nuevas competencias cognitivas, técnicas y sociales de una manera holística para que los alumnos alcancen los resultados esperados. De acuerdo a [Cochrane and Bateman, 2010] un factor clave para emplear Aprendizaje Móvil es que enriquece el proceso de enseñanza-aprendizaje facilitando la pedagogía constructivista social centrada en el alumno. Estos mismos autores mencionan que, en educación superior, este tipo de aprendizaje incluye los siguientes beneficios:

- Exploración de prácticas innovadoras de enseñanza y aprendizaje.

- Permite realizar "aprendizaje auténtico", por ejemplo facilitando el aprendizaje en cualquier lugar y en cualquier momento.

Página 20 de 167 
- Permite involucrar a los estudiantes con los potenciales de la tecnología móvil de la Web 2.0: conectividad, movilidad, geo-localización, redes sociales, etc.

- Permite acortar la brecha digital proveyendo acceso a contextos de aprendizaje y a herramientas de creación de contenido.

- Se paso de un modelo de computadoras puramente fijo (por ejemplo, PCs conectadas físicamente a internet) a un paradigma de computación wireless y móvil, convirtiendo cualquier espacio en un potencial espacio de aprendizaje.

De acuerdo a [Ng, 2015], debido a la movilidad en este tipo de aprendizaje, es posible realizar experiencias de Aprendizaje Móvil situado ${ }^{4}$ ya que estas resultan más motivadoras para los alumnos permitiéndoles percibir el aprendizaje como auténtico y relevante.

\subsubsection{Algunas definiciones}

El Aprendizaje Móvil, para los autores [Kukulska-Hulme et al., 2011] y [Traxler, 2009] puede definirse como el proceso de enseñanza-aprendizaje que ocurre con el uso de dispositivos móviles, proveyendo acceso bajo demanda a los recursos de aprendizaje, desde cualquier lugar. Sin embargo, la definición de Aprendizaje Móvil aún no está totalmente unificada. En [Keskin and Metcalf, 2011] se destacan tres perspectivas del término desde:

- lo tecnológico,

- el aprendizaje electrónico y

- la movilidad

Algunos autores, emplean más de una perspectiva en su definición. Una invariante en las mismas es la inclusión del concepto de dispositivos móviles (o de mano), según el año en la que la misma se presenta. A continuación se enuncian algunas definiciones del término desde las tres perspectivas mencionadas.

- En la definición presentada en [Quinn, 2000], el autor lo introduce desde las perspectivas tecnológica y la del aprendizaje electrónico. La misma se presenta a continuación:

"elearning through mobile computational devices: Palms, Windows CE machines, even your digital cell phone" [Quinn, 2000]

\footnotetext{
${ }^{4}$ En el trabajo presentado por [Lave and Wenger, 1991], se dice que el aprendizaje situado es un aspecto inseparable e integral de cualquier práctica social. La noción de aprendizaje situado indica el carácter contextualizado del aprendizaje donde el alumno participa en un contexto cultural (comunidad de práctica), social, y en donde adquiere los conocimientos necesarios no solo para transformar dicho contexto, sino que además, para transformarse a sí mismo
} 
- Los autores [Traxler, 2005] y [Wexler et al., 2007], introducen el término solo desde la perspectiva tecnológica, a continuación se presentan sus respectivas definiciones:

"any educational provision where the sole or dominant technologies are handheld or palmtop devices " [Traxler, 2005]

"any activity that allows individuals to be more productive when consuming, interacting with, or creating information, mediated through a compact digital portable device that the individual carries on a regular basis, has reliable connectivity, and fits in a pocket or purse" [Wexler et al., 2007]

- En [Kadirire, 2009] se lo define solo desde la perspectiva del aprendizaje electrónico, como una extensión de esta clase de aprendizaje, su enunciación es la siguiente:

"a form of e-Learning, which can take place anytime, anywhere with the help of a mobile communication device such as a mobile phone, a personal digital assistant (PDA), iPod or any such small portable device" [Kadirire, 2009]

- Las definiciones presentadas en [O'Malley et al., 2003] y en [Woodill, 2012] introducen el término desde la perspectiva de la movilidad, cada uno de la siguiente manera:

"any sort of learning that happens when the learner is not at a fixed, predetermined location, or learning that happens when the learner takes advantage of learning opportunities offered by mobile technologies" [O'Malley et al., 2003]

"Where a learner can be physically mobile while at the same time remaining connected to non-proximate sources of information, instruction, and data communications technology" [Woodill, 2012]

Una vez presentadas algunas definiciones de "Aprendizaje Móvil" y habiendo relacionado las mismas con las perspectivas mencionadas en [Keskin and Metcalf, 2011], se presentará la perspectiva adoptada en este trabajo.

Si bien una de las perspectiva es la de analizar al Aprendizaje Móvil como una extensión del aprendizaje electrónico, en particular, aquellos basados en mover sistemas existentes de aprendizaje electrónico (en sistemas de gestión de aprendizaje, conocido por su sigla en inglés $L M S$ ) a Aprendizaje Móvil; según lo planteado en [Parson, 2014], estos no aprovechan las posibilidades adicionales que otorgan los dispositivos móviles tal como es, por ejemplo, el posicionamiento.

Página 22 de 167 
En el presente trabajo, se hará foco en aquel Aprendizaje Móvil que usa el posicionamiento del alumno como parte de la experiencia educativa. En particular, a este tipo de aprendizaje se lo conoce como "Aprendizaje Móvil basado en posicionamiento" y será abordado en la siguiente sección.

\subsubsection{Aprendizaje Móvil basado en posicionamiento}

Al contemplar el movimiento del alumno, de acuerdo a [Scanlon, 2014], existen dos contextos ${ }^{5}$ relevantes a considerar, por un lado la posición del alumno y por otro su entorno. De acuerdo a lo expresado en [Brown et al., 2010a], lo que distingue al Aprendizaje Móvil de otros aprendizajes es que el alumno está continuamente en movimiento y esto no implica solamente su movilidad física, sino que además, los alumnos están activos en diferentes contextos, los cuales pueden cambiar de acuerdo a su posición individual.

En [Brown et al., 2010b], los autores mencionan que las actividades de aprendizaje que contemplan el entorno físico, pueden constituir un enfoque prometedor para diversas teorías de aprendizaje y teorías cognitivas. Los autores mencionan además que de acuerdo a la teoría de procesamiento de la información ([Miller, 1956]) y a la teoría de carga cognitiva ([Sweller, 1988]), la memoria de trabajo humana tiene capacidad limitada por lo que el contenido de aprendizaje debe ser estructurado de forma tal que, la carga de información no abrume al alumno. Por otro lado, también los citados autores mencionan que la teoría de aprendizaje multimedia (acorde a [Moreno and Mayer, 2000] y [Moreno and Mayer, 2001)], indica que cada canal sensorial (visual y auditivo) posee capacidad de procesamiento limitado y que el aprendizaje es óptimo cuando la información que se presenta más aumentada en un canal sensorial es menos destacada en el otro canal. Además, dada la capacidad reducida de procesamiento, la información que se le presenta a los alumnos, debe estar limitada a lo relevante en su contexto de aprendizaje actual. Una implicancia en el aprendizaje contextual, es que la información con y a través de los contextos debe estar estructurada de manera apropiada con el fin de reducir la carga cognitiva, y de este modo, maximizar la retención.

\subsubsection{La TA en Aprendizaje Móvil}

En [Sharples et al., 2005], los autores, presentan una adaptación de la Teoría de la Actividad (descripta en la Sección 2.2), en el marco del Aprendizaje Móvil, donde para

\footnotetext{
${ }^{5}$ El contexto, de acuerdo a [Dey, 2001] es "cualquier información que puede ser usada para caracterizar la situación de una entidad", donde el término entidad se define como cualquier cosa relevante (por ejemplo, una persona, un lugar o un objeto) que participa en la interacción entre un usuario y un sistema y el término información, se define como cualquier elemento o dato que permite la descripción de cualquier condición o estado de las entidades participantes. En el marco de educación enriquecida con tecnología, en [Luckin, 2010] se define como "la situación actual de una persona en relación a una actividad educativa"
}

Página 23 de 167 
explicar el rol de la tecnología en el aprendizaje, la separan en dos perspectivas o capas:

- Capa semiótica ${ }^{6}$ : describe al aprendizaje como un sistema semiótico en donde las acciones orientadas al objeto del alumno son mediadas por herramientas culturales y signos.

- Capa tecnológica: muestra al aprendizaje comprometido con la tecnología, en donde herramientas como la computadora o los dispositivos móviles actúan como agentes interactivos entre otras cosas para ayudar a los alumnos a reflexionar y recordar.

Los autores citados, mencionan que el aprendizaje ocurre en un sistema socio-cultural en el que muchos alumnos interactúan para crear una actividad colectiva enmarcada por las limitaciones culturales y las prácticas históricas. Estos autores, señalan que Engeström (para la TA) analiza la actividad colectiva a través de un marco ampliado que muestra las interacciones entre la actividad mediada por herramientas y las reglas culturales, la comunidad y la división del trabajo. Debido a la adaptación presentada en el citado trabajo, y para mostrar una relación dialéctica entre la tecnología y la semiótica, cambiaron el nombre de los factores culturales por los términos: Control, Contexto y Comunicación. Para que esto no genere una ambigüedad de interpretación entre las personas afines a la educación, en relación a las personas afines a la tecnología, los introducen de la siguiente manera:

- Control: El control del aprendizaje puede corresponder principalmente a una persona, generalmente el docente, puede ser compartido entre los alumnos, o bien, puede compartirse entre los alumnos y la tecnología (por ejemplo, en un diálogo basado en la instrucción por computadora). El beneficio en este caso, queda de manifiesto en la forma en la que el aprendizaje es entregado: por ejemplo, el alumno puede acceder al contenido cuando le resulta conveniente y puede controlar el ritmo con el que lo accede.

Sin embargo, el uso de la tecnología se produce dentro de un sistema social que incluye a otras personas y a otras tecnologías. Rigiendo normas y convenciones (por ejemplo cuándo, cómo y a quién se le puede enviar un mail). Por otro lado, la forma en la que una persona usa la tecnología, se puede ver influenciada por otras personas y por su propia predisposición a usarla, pudiendo a la vez, las personas y los grupos imponer reglas informales de cómo les gusta trabajar y aprender.

- Contexto: este término tiene muchas connotaciones, por ejemplo desde la perspectiva tecnológica se ha debatido si es algo emergente o si puede ser

\footnotetext{
${ }^{6}$ Semiótica: Ciencia que estudia los diferentes sistemas de signos que permiten la comunicación entre individuos, sus modos de producción, de funcionamiento y de recepción.
} 
modelado. Contexto, también abarca a las múltiples comunidades de actores (personas y tecnologías) que interactúan en torno de un objetivo en común.

- Comunicación: La relación dialéctica entre la capa tecnológica y semiótica es quizás la más fácil de ver en relación con la comunicación. Si un sistema tecnológico permite ciertas formas de comunicación (como el correo electrónico o mensajes de texto), los alumnos comienzan a adaptar sus actividades de comunicación y de aprendizaje en consecuencia (por ejemplo, mediante redes sociales, mensajes de texto, etc.) fusionando actividades de ocio y deberes. A medida que los alumnos se familiarizan con la tecnología, inventan nuevas formas de interactuar (por ejemplo con emoticones, o el lenguaje propio de los mensajes de texto), creando nuevas reglas y comunidades. Esta apropiación de la tecnología no sólo conduce a nuevas formas de aprendizaje y de trabajo, sino que también establece una tensión entre las tecnologías y las prácticas existentes. Por lo tanto, hay una continua co-evolución entre la tecnología y la comunicación humana.

A partir de lo antes expuesto, los autores citados en esta sección ([Sharples et al., 2005]), proponen una nueva figura triangular para presentar su adaptación de la TA, como la que se visualiza en la Figura 2.4 (esta figura fue extraída de [Sharples et al., 2005]).

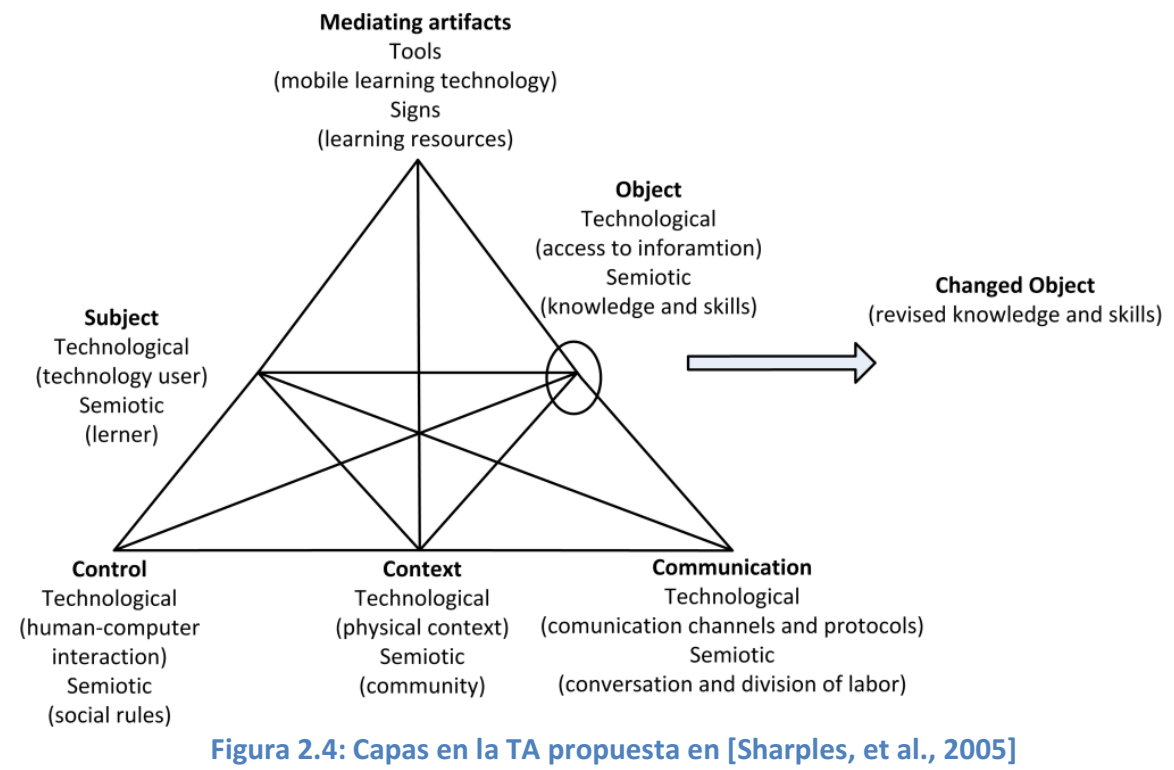

\subsubsection{Estándares usados en Aprendizaje Móvill}

En [Devedžić et al., 2007], los autores mencionan que en el aprendizaje enriquecido con tecnología, la palabra estándar es usada para describir los siguientes conceptos: 
- Estándar oficial: Describe un conjunto de requerimientos y guías de diseño para sistemas de aprendizaje enriquecido con tecnología o sus componentes arquitecturales aprobado por una organización de estandarización (como por ejemplo ISO ${ }^{7}$ e IEEE LTSC $^{8}$ ).

- Estándar de hecho: es igual a un estándar oficial, pero altamente aceptado por la comunidad de aprendizaje enriquecido por tecnología y la industria.

- Especificación: Es lo mismo que un estándar de hecho, generalmente creado y promocionado por alguna organización o consortium de la academia o de la industria. Es comúnmente usado en la comunidad de aprendizaje enriquecido por tecnología pero no está consensuado por sus miembros.

- Modelo de referencia: Es una versión adaptada y reducida de una combinación de estándares y especificaciones focalizadas en aspectos arquitecturales de un sistema de aprendizaje enriquecido por tecnología, definiciones de una parte o más de un sistema y de sus interacciones.

Por lo antes expuesto, usaremos en este trabajo el término estándar de manera general para cualquiera de estos cuatro conceptos previamente descriptos.

En [Zervas and Sampson, 2014], se indica que los estándares SCORM ${ }^{9}$ [Dodds and Thropp, 2006] e IMS-LD ${ }^{10}[$ IMS-LD, 2003] permiten que los cursos online puedan ser diseñados y empaquetados en un formato uniforme, comprensible por máquinas, pudiéndose usar estos cursos en diferentes sistemas. Estos autores, mencionan que la principal diferencia entre ambos estándares es que SCORM se basa en un modelo de aprendizaje individual, mientras que IMS-LD permite modelar tanto situaciones de aprendizaje individual como aprendizaje grupal y colaborativo. En [Devedžić et al., 2007], los autores mencionan a ambos, entre otros, como estándares en aprendizaje electrónico.

En el marco del Aprendizaje Móvil, los autores [Sarrab et al., 2012] mencionan que no hay aun estándares propios, como los hay para aprendizaje electrónico. Sin embargo, indican que, para Aprendizaje Móvil, se pueden emplear los estándares existentes para aprendizaje electrónico.

Por otro lado en [Neumann et al., 2009], los autores indican que IMS-LD presenta problemas de reusabilidad, adaptabilidad y flexibilidad. Los autores, mencionan también que es complejo de usar y que presenta problemas de expresividad. Por ejemplo, en [König and Paramythis, 2012] los autores, señalan que no está contemplado el concepto de grupo. Por otro lado, en [Paramythis, 2008] el autor cita deficiencias del IMS-LD. En particular, menciona que no permite crear artefactos como por ejemplo una pregunta,

\footnotetext{
${ }^{7}$ ISO: International Organization for Standardization

${ }^{8}$ IEEE LTEC: Institute of Electrical and Electronics Engineers Learning Technology Standards Committee

${ }^{9}$ SCORM: Sharable Content Object Reference Model. SCORM es un modelo de referencia.

${ }^{10}$ IMS-LD: Instructional Management System -Learning Design. IMS-LD, es una especificación.
} 
pudiéndolos solo modelar a través de una propiedad, por ejemplo, de la persona o del rol que lo crea. Este autor señala además, la deficiencia en el soporte para modelar flujos de control complejos.

Respecto a SCORM, en [Hatakka et al., 2007] los autores señalan que usarlo es complejo e insume mucho tiempo, requiriendo mucho conocimiento de los metadatos para poder configurar un curso.

\subsubsection{Uso de objetos del mundo real}

De acuerdo a lo expuesto en [McNeil and Jarvin, 2007], el uso de objetos concretos en educación data de largo tiempo, en el trabajo citado, los autores refieren en relación a esto, a los siguientes trabajo y autores: [Piaget and Szeminska, 1995], [Bruner, 1996] y [Montessori, 1964]. En los últimos tres trabajos citados, y de acuerdo a lo expresado en [McNeil and Jarvin, 2007], los niños no llegan al mundo con capacidad de pensamiento abstracto. En cambio, estos pueden construir conceptos abstractos a través de sus interacciones con objetos concretos de su entorno (en adelante los llamaremos unificadamente como objetos del mundo físico). Estos autores, identifican tres principales razones para incluir este tipo objetos:

- Incluyen un canal adicional para incorporar información.

- Activan el conocimiento del mundo real.

- Mejoran la memoria a través de la acción física.

En [McNeil and Jarvin, 2007], los autores también mencionan que lo anteriormente expuesto continua en el tiempo, y ha inspirado a los docentes a usar este tipo de objetos en sus clases.

En relación a su incorporación en el aprendizaje enriquecido con tecnología, en [Manches and O'Malley, 2011], los autores mencionan la existencia de diversos estudios realizados para comparar los efectos del uso de objetos del mundo real en relación al mundo virtual. En relación a lo identificado por los autores en [McNeil and Jarvin, 2007], señalan que quizás la información más relevante que los objetos del mundo físico proveen, es su posición espacial. Los autores en [Manches and O'Malley, 2011], citan a [Larkin and Simon, 1987], quienes describen como las relaciones espaciales pueden ayudar a disminuir la tarea cognitiva de tener que relacionar piezas de información esquemáticas, pudiendo esto, ser de gran relevancia para objetos donde los niños son capaces de cambiar fácilmente la posición relativa de dichos objetos. En los objetos del mundo físico, su ubicación no está limitada por el tamaño de una hoja o por el tamaño de la pantalla de una computadora. Otro aspecto importante es que las relaciones espaciales 
pueden ser procesadas a través del tacto (esto es por el sistema propioceptivo ${ }^{11}$ del ser humano que permite conocer la posición relativa de los objetos en relación al cuerpo). Lo que permite a los niños hacer un seguimiento de la posición de los objetos a través del tacto y por tanto, liberar la atención visual de otros objetos.

Los autores en [Manches and O'Malley, 2011] citan además que, las propiedades visuales y táctiles de los objetos del mundo físico pueden ayudar a focalizar la atención de los niños en ciertas propiedades de un problema. Por otro lado, estos objetos proveen información en tres dimensiones, lo que puede brindar soporte al procesamiento perceptual de factores como la forma, la distancia relativa y contemplar objetos colocados encima de otros. Esto puede ser significativo para jóvenes cuando exploran conceptos en los que la tridimensionalidad es importante, como por ejemplo, figuras geométricas y el concepto de volumen.

Por otro lado, en [Zacharia and Olympiou, 2011] en relación a los objetos del mundo físico, los autores citando el trabajo de [Loomis and Lederman, 1986] mencionan que mediante el tacto o lo sensación háptica ${ }^{12}$, es posible percibir características de los objetos como por ejemplo, la dureza, textura, peso, inercia, suavidad, deslizamiento y la temperatura.

En el marco del Aprendizaje Móvil, en [Liu et al., 2014], los autores han introducido como un recurso mas, el uso de plantas reales en un estudio de la morfología de sus hojas en el nivel primario. Para analizar el impacto en la incorporación de este elemento del mundo físico versus reemplazarlo por una foto digital, tomaron dos grupos de alumnos e hicieron que resuelvan una actividad. Un grupo empleaba las plantas reales, y el otro las

${ }^{11}$ El sistema propioceptivo incluye a cualquier receptor sensorial o terminación nerviosa que aporta sensibilidad interna o propioceptiva del cuerpo. Los propioceptores están localizados en los músculos, articulaciones, tendones y en el aparato vestibular. Mediante su estimulación, podemos conocer la posición o la velocidad y aceleración ligada a los movimientos del cuerpo. Por consiguiente, los propioceptores se pueden considerar como un subsistema de interorreceptores, que además de los receptores vinculados al equilibrio y movimiento corporal, incluye a los receptores sensibles a la presión sanguínea o quimiorreceptores sensibles al pH, a la concentración de oxígeno y a la de dióxido de carbono. También son interorreceptores aquéllos que nos permiten percibir la temperatura corporal, el dolor, el hambre y la sed, entre otros.

${ }^{12}$ Se define el sistema háptico como "la percepción del individuo del mundo adyacente a su cuerpo mediante el uso de su propio cuerpo". El sistema de percepción háptica es especial porque puede incluir los receptores sensoriales ubicados en todo el cuerpo y está estrechamente relacionado con el movimiento del cuerpo, de forma que puede tener un efecto directo sobre el mundo que está percibiendo. De igual forma, el concepto de percepción háptica está muy relacionado con el concepto de contacto activo que establece que se obtiene más información cuando un plan motor (movimiento) está asociado al sistema sensorial; y al concepto de propiocepción psicológica extendida que dice que al utilizar una herramienta nuestra percepción se extiende, tal como cuando usamos un bastón: nuestra percepción es transferida transparentemente hacia el final del bastón. Se ha descubierto que la percepción háptica se apoya en las fuerzas que se experimentan durante el contacto.

Página 28 de 167 
fotos digitales. Los resultados mostraron que el grupo que empleo las plantas reales, obtuvo mejores resultados y comprensión que los que no las usaron.

\subsection{Aspectos relacionados a la Ingeniería de Software}

Relacionados a la Ingeniería de Software hay una variada gama de aspectos, en esta sección solo se hará foco en aquellos relevantes para esta tesis, como son la evolución del software y en particular el concepto de separación de concerns.

Desde hace ya más de cuatro décadas, la evolución del software en general es una problemática que se intenta resolver. La modularización en el modelado de software, según lo presentado en el año 1972 en [Parnas, 1972], constituye un mecanismo para mejorar la flexibilidad y comprensión de un sistema. Dicho autor, hace hincapié en que la eficacia de la modularización se ve afectada según el criterio usado para la misma. Concluyendo que, un sistema se puede volver no flexible a cambios si se aplicó un mal criterio de modularización.

En el año 1976 se plantea en [Lehman, 1976] leyes relacionadas con la evolución del software, estas leyes al analizarlas aún están vigentes, a continuación se enuncian las más relevantes acorde a la temática de la tesis:

- Cambio Continuo: un sistema debe adaptarse a nuevas situaciones para no convertirse en obsoleto. Es decir, concebir el sistema para poder incorporar nuevas situaciones al mismo.

- Crecimiento Continuo: Las necesidades de los usuarios pueden variar en el tiempo, el sistema debe estar preparado para poder incorporar la funcionalidad para satisfacer las mismas, sin impactar en el sistema.

- Aumento de la Complejidad: los cambios continuos en un sistema hacen que este se complejice y hay que trabajar para mantenerlo o bien para reducir dicha complejidad.

- Disfunción de la Calidad: el no poder incorporar cambios en el sistema en base al entorno operativo, este se vuelve obsoleto y disminuye su calidad.

Este aspecto crítico, como es la evolución, es tratado más recientemente por [Madhavji et al., 2006], donde se refuerza el concepto que plantea que, si en un sistema de software no está presente la posibilidad de incorporar cambios, la evolución del mismo se ve perjudicada.

A continuación se plantea el concepto de separación de concerns como una posible solución para lograr que el software evolucione. 


\subsubsection{Separación de concerns}

En [Tarr et al., 1999] se contempla lo planteado en [Parnas, 1972], en relación a la relevancia de la modularización en la evolución del software, y se propone el concepto de separación de concerns multidimensional. Los autores en [Tarr et al., 1999] analizan que para reducir la complejidad del software es necesario contar con dos mecanismos, estos son:

- Mecanismos de Descomposición: esto permite contar con unidades de software manejables.

- Mecanismos de Composición: las unidades de software se deben de conectar bajo algún criterio para lograr en si el software en cuestión.

Acorde a esto, los actores (según lo presentado en [Tarr et al., 1999]) definen a un concern como una unidad de software. De esta manera, ellos sostienen que usar concerns, reduce la complejidad, mejora la reusabilidad y disminuye el impacto en el mantenimiento y la evolución del software.

Los autores describen en [Ossher and Tarr, 2000] que una clara separación de concerns permite reducir la complejidad y comprensión del software como así también promover la trazabilidad del mismo. Un aspecto que destacan los autores es que una adecuada separación de concerns permite limitar el impacto que provocan los cambios del software, facilitando de esta manera la evolución y la adaptación no invasiva. Por otro lado, los autores mencionan que otro beneficio es facilitar el reuso como así también simplificar la integración entre componentes. Una vez definidos los concerns existentes, incorporar uno nuevo en cualquier etapa del ciclo de vida del software no debe impactar en los ya existentes.

Tomando como base los autores [Parnas, 1972] y a [Tarr et al., 1999], se presenta en [Sutton and Rouvellou, 2002] un esquema de modelado de concern-space de propósito general Ilamado Cosmos (COncern-Space MOdeling Schema). Los autores representan los concerns como clases, indicando que estas deben ser independientes de cualquier artefacto de software. Estos autores definen dos tipos de concerns:

- Los concerns lógicos representan los conceptos de interés del sistema, como por ejemplo, características o propiedades.

- Los concerns físicos representan elementos del sistema que se aplican a los concerns lógicos.

Esta categorización que se realiza en [Sutton and Rouvellou, 2002], de concerns lógicos y físicos, les permite a los autores modelarlos de manera independiente entre sí. 
Otro enfoque relacionado con la separación de concerns es presentado en [Hafedh et al., 2004], en donde se plantea esta separación como una técnica que permite la resolución de un problema general considerando lo siguiente:

- Primero resolver sus restricciones por separado. Definiendo así los concerns, los cuales deben ser tratados de manera independiente entre sí para que no se interfieran.

- Luego combinar las soluciones parciales, buscando que estas partes se puedan componer logrando una solución óptima. En esta etapa se componen los concerns.

Los autores también plantean en [Hafedh et al., 2004] un framework conceptual basado en transformaciones del software, pudiendo distinguir entre requerimientos separables e inseparables. Este framework se basa en la separación de concerns.

Un modelo de separación de concerns multidimensional a nivel de requerimientos es planteado en [Moreira et al., 2005]. En este modelo los concerns son una colección de requerimientos, independientemente de si estos son funcionales o no. Para identificar las relaciones existentes entre los diferentes concerns, los autores crean una matriz que les permite identificar de esta manera cuales son concerns transversales (crosscutting concerns).

En [Challiol et al., 2012] se describe un enfoque de modelado que usa el concepto de separación de concerns para aplicaciones móviles sensibles al contexto. Los autores identifican los concerns como paquetes UML en los cuales se definen las clases de dicho concerns, en particular, cuentan con un concern para representar todos los aspectos relacionados al posicionamiento, denominando a este "concern físico". De esta manera, logran desacoplar aquellos aspectos propios del dominio del posicionamiento. La relación entre concerns está dada por el concepto de "rol" entre clases. Los autores mencionan que dicho enfoque de modelado les permite reusar cada uno de los modelos involucrados. 
Página 32 de 167 


\section{Enfoque Propuesto}

En este capítulo se caracterizará la problemática a resolver en este trabajo y luego se propondrán tres modelos orientado a objetos para dar una posible solución a dicha problemática. El enfoque será especificado para que sea flexible y extensible para considerar otros aspectos relevantes que puedan surgir al considerar otras características más allá de la problemática en cuestión.

\subsection{Caracterización de la problemática a resolver}

De manera general, la problemática a resolver, consiste en representar actividades educativas posicionadas para ser puestas en práctica en el marco de un sistema educativo. Se usará indistintamente en este documento la sigla AE para indicar Actividades Educativas (sin posicionar) y AEP para hacer referencia a Actividades Educativas Posicionadas. A continuación se presentará una descripción de algunos de los conceptos relacionados al abordaje de actividades educativas, luego se describen características del posicionamiento de las mismas para finalmente profundizar en ciertos aspectos de ambas temáticas considerados relevantes para este trabajo. Estos conceptos permitirán delimitar el alcance de la problemática y, para mayor legibilidad, se los ha organizado de la siguiente manera:

- Conceptos generales de las AE.

- Estructuración de AE.

- Posicionamiento de AE.

- Qué se le brinda al alumno en las AEP.

- Uso de elementos concretos en las AEP.

- Puesta en práctica de las AEP.

A continuación se detalla cada ítem mencionado anteriormente.

\section{- Conceptos generales de las AE}

Una actividad educativa, es definida en [Lompscher, 1999] como una clase específica de actividad que posee intencionalidad de aprendizaje y está dirigida hacia, y se basa en, objetivos de aprendizaje.

El concepto de actividad educativa en el marco de aprendizaje electrónico (e-learning) es contemplado por el estándar IMS $^{13}$ (IMS Global Learning Consortium, Inc.). En particular, en [IMS, 2003] se define a la actividad educativa como una unidad pedagógica neutral de instrucción, conocimiento o evaluación que puede estar compuesta por subactividades y cada actividad se realiza en el contexto de una actividad padre. Esta

\footnotetext{
${ }^{13} \mathrm{http}: / /$ www.imsglobal.org/specifications.html
} 
definición, es utilizada de base por diferentes autores tanto en aprendizaje electrónico como en Aprendizaje Móvil (por ejemplo, [Jesse and Chang, 2012]).

En el marco del Aprendizaje Móvil (m-learning) las actividades educativas son abordadas por varios autores considerando diferentes aspectos. En [Kukulska-Hulme et al., 2007] se indica que las $A E$ necesitan ser diseñadas contemplando características particulares de dicho aprendizaje, pero no se brinda más detalle al respecto. De acuerdo a [Uden, 2007] estas pueden ser usadas en diferentes lugares y en diferentes momentos, incorporando de esta manera el ambiente dónde ellas se llevan a cabo. En ambos casos, tanto [Kukulska-Hulme et al., 2007] como [Uden, 2007], hacen una caracterización conceptual de las actividades educativas sin entrar en detalle de aspectos puntuales de cómo definirlas. En este marco, diversos autores, por ejemplo, [Conole, 2008], [Sollervall et al., 2012] y [Huang etal., 2012] definen que una actividad educativa está compuesta por tareas. Estos últimos enfoques mencionados, permiten tener una caracterización más específica de cómo se podría definir una actividad educativa (en el marco de Aprendizaje Móvil).

En este trabajo se seguirá la línea mencionada anteriormente, la cual define que una actividad educativa está compuesta por tareas ([Conole, 2008], [Sollervall et al., 2012] y [Huang et al., 2012]). Veamos ahora una caracterización de las tareas para comprender mejor los aspectos a considerar en el diseño de las mismas. En [Riestra, 2004] se define que una tarea posee una consigna, cada consigna es especificada mediante un enunciado el cual plantea al desarrollo de la tarea específica. En cuanto a lo pragmático de las consignas, en el trabajo presentado por [González, 2012] se indica que su propósito varía en relación con el objetivo que se propone quien la formula; puede requerir una respuesta para dar cuenta de conocimientos adquiridos previamente, elaborar nuevos conocimientos o llevar a cabo alguna tarea práctica. Acorde a este último autor, se puede identificar, en algunos casos, el concepto de respuesta asociada a una consigna, a partir, por ejemplo, de una pregunta brindada al alumno.

\section{- Estructuración de AE}

La manera en la que se planifica una actividad para ser presentada al alumno, es otro aspecto a contemplar en este tipo de aplicaciones. De acuerdo a los autores [Lallerana and McGrinn, 1981], la planificación determina los objetivos y metas de una actividad educativa a partir de los cuales se determinan los recursos y estrategias. En [Britain, 2004] se menciona que la organización y la presentación de la actividad es un factor importante en el proceso de enseñanza. En [Reigeluth, 2007] se presentan diferentes formas de secuenciar temas o tareas: linealmente o tipo grafo (a partir de condiciones). En particular, sugiere que cuando no existe relación (entre los temas o tareas) no es necesaria la secuenciación, pero de existir, ésta se puede realizar de manera cronológica, por tema o en espiral. 
En el marco de Aprendizaje Móvil, en [Frohberg et al., 2009] se analiza la incidencia en la formas de estructurar las actividades en relación a la libertad del alumno para realizarla. En dicho trabajo se caracterizan aplicaciones móviles educativas puntuales en base a este análisis.

En [Lliteras et al., 2012] ${ }^{14}$ se propone una estructuración de contenido educativo en el marco de los juegos educativos móviles basados en posicionamiento. En dichos trabajo se identifican tres estructuras particulares, las cuales se describen brevemente a continuación:

- Secuencial lineal: el contenido educativo se organiza de modo de que exista un contenido inicial y uno final y que los contenidos intermedios están antecedidos y precedidos por exactamente un contenido educativo.

- Secuencial con bifurcación: el contenido educativo se organiza con contenidos iniciales (uno en particular o más de uno) y uno o más contenidos educativos finales. Los contenidos intermedios pueden ser antecedidos o precedidos por más de un contenido educativo

- Conjunto: No se establece un orden para el contenido educativo, pudiendo iniciar y terminar en cualquiera de ellos. A priori, no se establece que contenidos educativos anteceden ni preceden a otro.

En la Figura 3.1 se presenta una ejemplificación gráfica de las estructuras presentadas en [Lliteras et al., 2012], con las tres estructuras introducidas previamente.

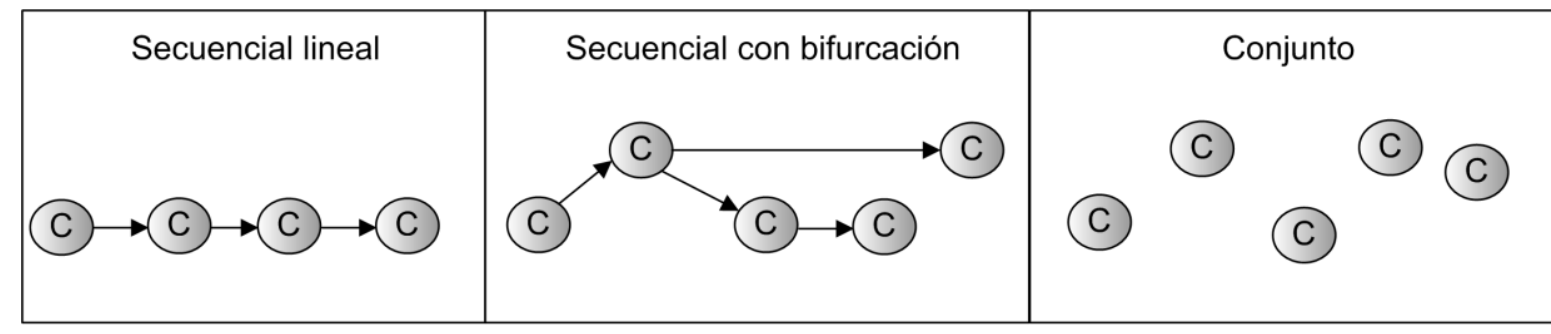

Notación gráfica

(C) Contenido educativo $\rightarrow$ Relación entre contenidos educativos

Figura 3.1: Estructuración del contenido educativo

\footnotetext{
${ }^{14}$ Este trabajo se basa en formas más generales de organizar contenidos, en particular considerando las características de las aplicaciones móviles basadas en posicionamiento. Algunas de estas organizaciones son descriptas en [Kjeldskov and Paay, 2004] y posteriormente al trabajo citado fue abordado por [Millard et al., 2013] para la organización de contenido hipertextual.
} 
Las estructuras mencionadas en [Lliteras et al., 2012] podrían ser aplicadas a la estructuración de actividades educativas en particular, ya que se definen en general para cualquier contenido educativo. En el caso particular de nuestra problemática serían tareas y actividades educativas. Es decir, la generalidad presentada en dicho trabajo, permite beneficiarse de las ventajas del enfoque propuesto para contenido educativo y aplicarlo, en este trabajo, en las actividades educativas y tareas.

\section{- Posicionamiento de AE}

Un aspecto a considerar en las actividades educativas (en el marco de este trabajo), es el lugar donde las mismas serán presentadas al alumno, surgiendo así el concepto de posicionamiento ${ }^{15}$ de las mismas. Este aspecto de posicionamiento en Aprendizaje Móvil, ha sido abordado por diferentes autores. En relación a esto, en [Frohberg et al., 2009] se presenta que una característica a considerar en el Aprendizaje Móvil es el espacio físico en el que se brinda el contenido. De acuerdo a lo definido en [Jesse and Chang, 2012], la posición forma parte de la actividad en sí. Sin embargo, acorde a lo definido en [Uden, 2007] se destaca que una actividad podría realizarse en diferentes lugares, esto no sería posible usando un enfoque como el propuesto en [Jesse and Chang, 2012]. Para poder representar que una actividad se podría llevar a cabo en diferentes lugares físicos se podría usar lo propuesto en [Lliteras et al., 2012], que plantea desacoplar el contenido educativo de la posición, en el marco de este trabajo el contenido está representado por las actividades educativas y las tareas, por esto en este trabajo se propone desacoplar las $A E$ y las tareas, de la posición en la que se lleven a cabo. Cabe desatacar que el concepto de posición se da en el marco de un espacio físico. Notar que, como se menciona en [Lliteras et al., 2012], el reuso de contenido en diferentes espacios físicos, es posible solamente cuando el mismo no depende de un espacio físico específico (es decir, no son dependientes de la posición o situadas [Santos et al., 2014]).

\section{- Qué se le brinda al alumno en las AEP}

La forma en la que se le brindan al alumno las actividades educativas, en su dispositivo móvil, es otro aspecto relevante en el Aprendizaje Móvil. Según lo especificado en [Huang et al., 2012], el alumno recibe actividades en forma de audio, imágenes, video y texto. La adopción de una de estas formas o de una combinación de ellas, dependerá del grupo de alumnos destinatarios, de las habilidades cognitivas que el equipo de expertos en educación planifique que los alumnos pongan de manifiesto al recibirlo y dependerá además, de las características tecnológicas del dispositivo móvil a utilizar durante la actividad, por ejemplo, el tamaño de la pantalla, su resolución, la posibilidad de uso de audio, etc. En [Yen et al., 2012] se presenta un trabajo que aborda la importancia en la

\footnotetext{
${ }^{15}$ El concepto de posicionamiento en aplicaciones sensibles al contexto, es abordado en [Leonhardt, 1998] identificando dos tipos de posicionamiento: Simbólico y Geométrico.
} 
manera en la que se presentan las tareas al alumno, ya que de acuerdo a los autores, esto incide en la apropiación del conocimiento. Mientras que en [Ali et al., 2012] se destaca la importancia de aspectos de usabilidad en el impacto que tiene en el proceso de aprendizaje. En [Lliteras et al., 2013] se presenta la separación del contenido educativo de la presentación visual de los mismos, este mismo concepto podría aplicarse para las actividades educativas.

Otro aspecto destacado a contemplar en este tipo de aplicaciones es el de posicionamiento, y en base a esto, brindarle asistencia al alumno para que pueda ir desde una tarea hacia otra, dentro del espacio físico en el que éstas se llevan a cabo. Es decir, asistirlo en la movilidad, por ejemplo brindándole un mapa con las indicaciones de donde se debe realizar cada tarea y como llegar de una tarea a otra. Brindar asistencia para la movilidad, es una problemática común en aplicaciones móviles basadas en posicionamiento. Una forma posible de asistencia fue propuesta en [Lliteras et al., 2011].

\section{- Uso de elementos concretos en las AEP}

De acuerdo a lo presentado en el Capítulo 2, los objetos del mundo real han sido empleados en educación desde hace ya muchos años. En particular, para este trabajo nos interesa lo propuesto en [Zhang, 1997]. El autor menciona que al trabajar con representaciones externas (por ejemplo elementos concretos), se cuenta con información que puede ser percibida directamente, cambiando de este modo, la naturaleza de las tareas desde la perspectiva de la persona que las realiza. Estos elementos pueden ser tomados con las manos y analizados. En [Zacharia and Olympiou, 2011] se indica que al manipular elementos concretos, algunas de sus características, como por ejemplo textura, peso, forma y temperatura, pueden ser percibidos por el alumno. En el marco del Aprendizaje Móvil, los autores presentan en [Liu et al., 2014] un estudio, en el que al alumno se le proponen tareas que involucran plantas reales (elementos concretos) en un espacio físico. Los autores indican que al incluir estos elementos se logro mejor desempeño de los alumnos en las tareas propuestas. Acorde a lo mencionado anteriormente, los elementos concretos, pueden ser incluidos como parte de la actividad a presentarle al alumno en un determinado espacio físico. Estos elementos podrían ser desplazados por el alumno de un lugar a otro como parte de la consigna, cobrando relevancia además de los elementos concretos, el lugar. Para ejemplificar, se podría tener una actividad asociada con el ajedrez, en la que el elemento sea una pieza del juego y el lugar un casillero dentro del tablero [Zhang, 1997].

\section{- Puesta en práctica de las AEP}

Otro aspecto relevante a contemplar en el marco del Aprendizaje Móvil es el rol del docente en las AEP. En general, en diversos trabajos (por ejemplo en [Huang et al., 2012] y en [Al Hamdani, 2013]), se menciona un cambio de rol del docente, pasando del tradicional modelo "top-down" (el docente dirige el aprendizaje) a un modelo "botton-up" 
donde el docente es un facilitador de contenidos para sus alumnos. Este modelo ya fue introducido en [Vygotsky, 1978], en donde se indica que un rol para el docente es el de proveer una guía a los alumnos para motivarlos a mejorar (por ejemplo activando su zona de desarrollo próximo) y con esta perspectiva, los alumnos son vistos como constructores de su conocimiento.

Si bien las actividades educativas se pueden plantear para ser resueltas de manera individual, en [Ryu and Parson, 2009] se menciona que cuando los alumnos trabajan en grupo, tienden a aprender más y a retener por más tiempo lo que se les enseña que si el mismo contenido es presentado de manera individual.

A partir de los conceptos introducidos previamente, se puede pensar en la existencia de participantes (o usuarios) de las AEP que poseen diferentes roles durante la experiencia de uso o puesta en práctica, y retomando lo mencionado cuando se presentaron los conceptos generales de las actividades educativas, éstos pueden brindar respuestas acordes a su rol.

\subsection{Modelado de la problemática}

Debido a que todavía no hay estándares para Aprendizaje Móvil, acorde a la introducido en la Sección 2.3.1.4, se decidió presentar un enfoque de modelado considerando lo descripto en la Sección 2.4 .

En esta sección se presenta un enfoque de modelado orientado a objetos [Rumbaugh et al., 1991], para representar Actividades Educativas Posicionadas que involucren Elementos Concretos. De acuerdo a lo descripto en la Sección 3.1, se identificaron principalmente los siguientes conceptos a modelar:

- Actividad educativa compuesta por tareas.

- Tarea, la cual posee una consigna (acorde a lo definido en [Riestra,2004]) con un enunciado que puede implicar diferentes recursos (por ejemplo texto o video).

- Posible relación entre las diferentes tareas involucradas en una actividad educativa.

- Posicionamiento de actividades educativas, tareas y elementos concretos, considerando que la posición de estos últimos puede variar a lo largo de la actividad.

- Los participantes (usuarios) que bajo algún rol forman parte de la puesta en práctica de la actividad educativa posicionada y brindan respuestas.

Cada modelo propuesto será definido mediante diagramas de clases UML [UML], en donde básicamente, los conceptos se representarán mediante clases, interfaces y relaciones entre estas dos últimas. Para el diseño, se emplearán buenas prácticas de 
modelado orientado a objetos, como por ejemplo, el uso de Patrones de Diseño [Gamma et al., 1994] y Separación de Concerns [Challiol et al., 2012].

Contemplando lo presentado en el Capítulo 2 respecto a la Evolución del Software y a la Separación de Concerns con el enfoque propuesto por [Challiol et al., 2012] en donde se hace foco en el reuso y la flexibilidad de los modelos que contemplan este concepto, y considerando lo presentado en [Lliteras et al., 2012] para desacoplar los conceptos de contenido educativo y posicionamiento, se identificaron tres capas conceptuales para resolver la problemática caracterizada en la Sección 3.1. Dichas capas son:

- Actividades Educativas: Capa que involucra todo lo referido al planteo de las actividades educativas y sus tareas, sus relaciones y conceptos afines.

- Actividades Educativas Posicionadas: En esta capa se modelan los conceptos relacionados a la posición en la que se realizan las actividades educativas y sus tareas.

- Usuario: mediante esta capa, se agrupan los conceptos que representan datos relevantes del usuario, su actividad, y la manera en la que resuelven las tareas propuestas en cada posición.

Las capas identificadas se representarán definiendo (para este trabajo) un modelo de clases particular para cada una de ella. Cada modelo se presenta mediante paquetes UML [UML_DP]. En la Figura 3.2, se visualizan dichos paquetes y la relación entre ellos.

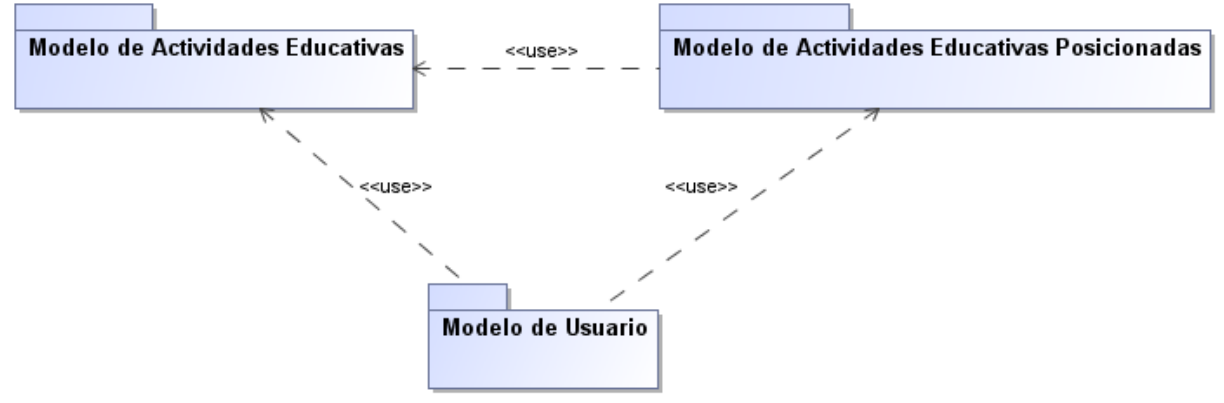

Figura 3.2: Modelos propuestos presentados en paquetes

Cada modelo propuesto en la Figura 3.2, es presentado en las siguientes sub-secciones. Por una cuestión de legibilidad, estos serán presentados de manera incremental.

\subsubsection{Modelo de Actividades Educativas}

Como ya se mencionó anteriormente, dentro del paquete Modelo de Actividades Educativas, se representan los conceptos relacionados a Actividades Educativas.

De acuerdo a lo introducido en la Sección 3.1, una actividad educativa, en este trabajo, se define con ciertos objetivos y está compuesta por tareas. Una primera representación 
de estos conceptos se introducen en la Figura 3.3. Se puede apreciar que la clase ActividadEducativa tiene una o varias tareas (Tarea). Es responsabilidad del experto en educación, crear y organizar las actividades educativas con tareas acordes para lograr el objetivo global.

\begin{tabular}{|c|c|c|}
\hline ActividadEducativa & \multirow{2}{*}{ tareas } & Tarea \\
\hline \multirow[b]{2}{*}{$\begin{array}{l}\text {-objetivo } \\
\text {-preRequisitos } \\
\text {-tematicasRelacionadas } \\
\text {-resultadoEsperado } \\
\text {-rangoDeEdad }\end{array}$} & & \multirow{2}{*}{$\begin{array}{l}\text {-objetivo } \\
\text {-preRequisitos } \\
\text {-tematicasRelacionadas } \\
\text {-resultadoEsperado } \\
\text {-rangoDeEdad } \\
\text {-consigna }\end{array}$} \\
\hline & \multirow[t]{2}{*}{$1 . .^{*}$} & \\
\hline $\begin{array}{l}\text { +iniciar Actividad() } \\
\text { +siguientesTareas() } \\
\text { +finalizarActividad() }\end{array}$ & & \\
\hline
\end{tabular}

Figura 3.3: Primer modelado de Actividad Educativa y sus Tareas

A continuación se describen brevemente cada uno de los atributos presentes en ambas clases, ActividadEducativa y Tarea y la semántica que le da cada una de ellas:

- objetivo: se contemplan objetivos en dos niveles, por un lado el objetivo de cada tarea (Tarea) y por otro, el objetivo general de la actividad educativa (ActividadEducativa). En ambos casos, se refiere al enfoque, la dirección y los propósitos que hay detrás de la Tarea o de la ActividadEducativa desde el punto de vista del profesor [Kennedy, 2006]. Notar que el objetivo de una ActividadEducativa, puede englobar los objetivos de cada una de sus tareas.

- preRequisitos: en cuanto a los preRequisitos, se especifican a nivel de cada Tarea y a nivel general de la ActividadEducativa. En ambos casos, permite indicar los requisitos necesarios que se deben cumplir para que los participantes puedan realizar cada Tarea y la ActividadEducativa en sí misma.

- tematicasRelacionadas: el atributo tematicasRelacionadas, indica los diferentes temas curriculares relacionados a la ActividadEducativa en general o bien a una Tarea en particular.

- resultadoEsperado (outcome): presente tanto en la ActividadEducativa como en la Tarea, de acuerdo a [Kennedy, 2006], permite identificar lo que se espera que el alumno sepa, comprenda y sea capaz de hacer al término de la correspondiente ActividadEducativa o Tarea. De acuerdo a lo expresado en [Kennedy, 2006], la "taxonomía de Bloom" [Bloom and Krathwohl, 1956] se usa frecuentemente para escribir los resultados esperados, indicando que también se puede emplear la "taxonomía de Bloom revisada" presentada en [Anderson et al., 2001].

- rangoDeEdad: atributo presente tanto en la Tarea como en la ActividadEducativa, refiere al rango de edad para la cual es sugerida la Tarea o la ActividadEducativa. 
Este rango podría guardar relación con los rangos de edades identificados por Piaget para proponer las etapas de desarrollo intelectual en los niños [Piaget, 1965] o bien en los adolescentes hasta adultos [Piaget, 1972].

Por último, la Tarea, posee el atributo consigna. La consigna será la que le indique al alumno que hacer (este concepto será retomado más adelante).

Supongamos ahora que dado un conjunto de tareas, llamadas T1, T2 y T3, queremos estructurarlas de maneras diferentes (Figura 3.4), por ejemplo por un lado de manera secuencial lineal (Figura 3.4.a) y por otro de manera bifurcada (Figura 3.4.b).

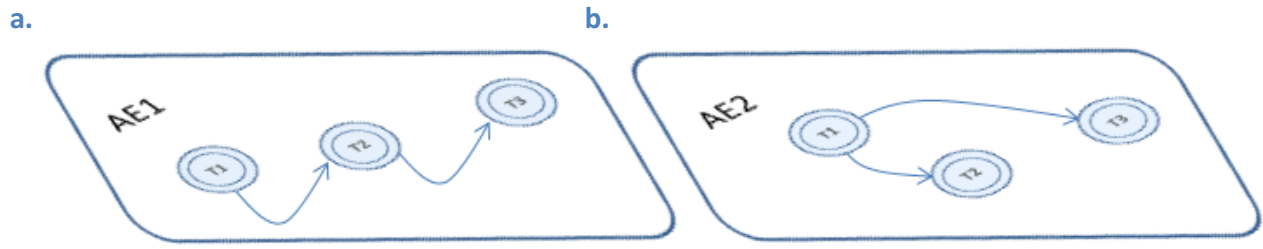

Figura 3.4: Las mismas tareas estructuradas de manera diferente

Con el modelo propuesto en la Figura 3.3, no es posible representar que una tarea puede estar siendo usada en dos formas de estructuración diferente. La relación tareas (dada entre las clases ActividadEducativa y Tarea), no puede tener dos semánticas simultáneamente, es decir, no se puede usar para interpretar que las tareas son secuenciadas lineales o secuenciadas con bifurcación al mismo tiempo. Esto nos lleva a desacoplar este concepto para incluir mas expresividad en el modelo. Acorde a lo mencionado anteriormente, se decidió modelar la planificación, la cual puede ser, por ejemplo, aleatoria o secuenciada. La clase PlanificaciónAleatoria, solo necesita conocer el conjunto de tareas que la componen, mientras que en el caso de la clase PlanificaciónSecuenciada, es necesario representar la semántica de cada tarea involucrada en la secuenciación, sin perder la posibilidad de reusar la Tarea en diferentes planificaciones. De este modo, se representan los conceptos de tarea secuenciada inicial, final o intermedia. Siendo necesario, en los dos primeros casos representar cuál o cuáles son las tareas siguientes. En la Figura 3.5 se pueden observar las clases incorporadas para representar estos conceptos. 


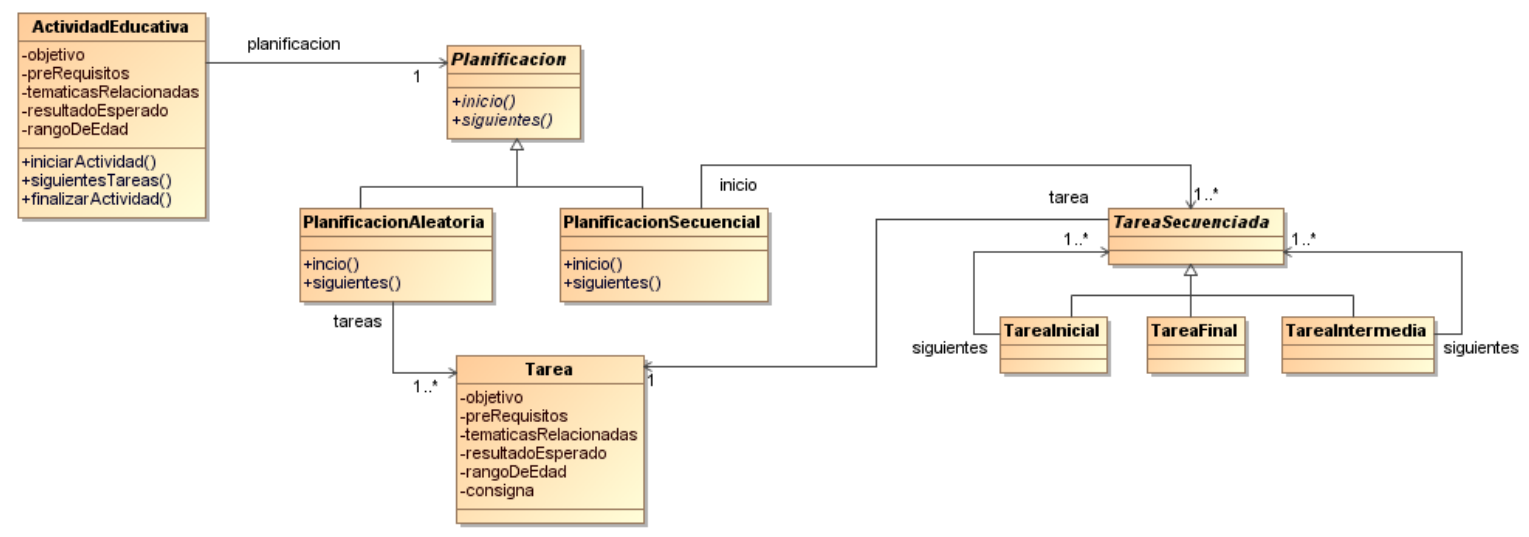

Figura 3.5: Modelado de la Planificación

Notar que, acorde a lo propuesto en la Figura 3.5, la misma Tarea, puede estar en diferentes planificaciones, independientemente de que esta sea aleatoria o secuencial.

Como se mencionó en la Sección 3.1, la Tarea tiene una consigna. Analizaremos ahora, de qué manera se podría definir su enunciado. En la Figura 3.6 se ejemplifican diferentes enunciados de consignas (acorde a lo mencionado en [Huang et al., 2012]). En la Figura 3.6.a el participante recibe un enunciado con texto y un audio (para reproducir). En la Figura 3.6.b, recibe un texto y un video. Mientras que en la Figura 3.6.c recibe texto e imagen.

a.

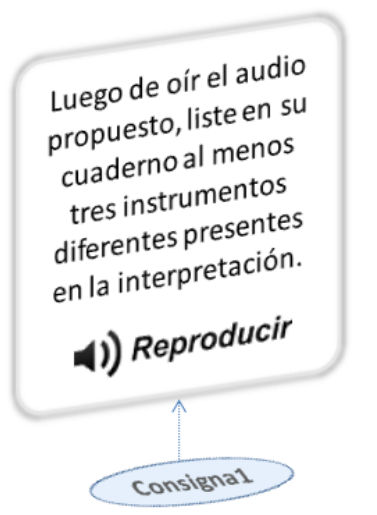

b.

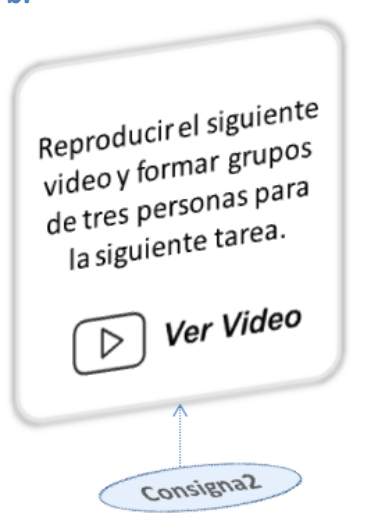

c.

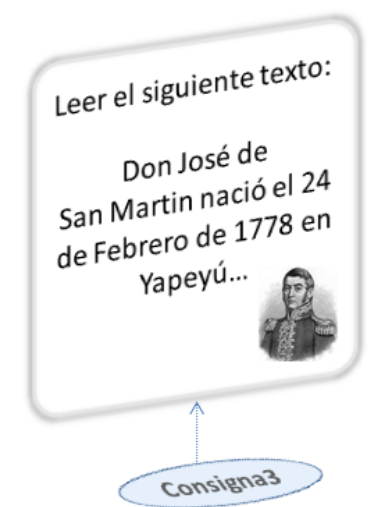

Figura 3.6: Ejemplos de enunciados de consignas

Acorde a la Figura 3.6 se identifican al menos los siguientes componentes para definir un enunciado: texto, imagen, audio, video y una combinación de estos obteniendo una componente compuesta. Para poder representar esto, se propone el modelo de la Figura 3.7. Se puede apreciar que se representó la Consigna como una clase en si misma con el fin de obtener mayor expresividad. Y el enunciado se define a partir de la jerarquía de Componente, la cual se basa en el patrón de diseño Composite [Gamma et al., 1994]. De este modo existen componentes "simples" representados con la jerarquía Estandar y a 
partir de ellos mediante la clase ComponenteCompuesto se brinda la posibilidad de composición.

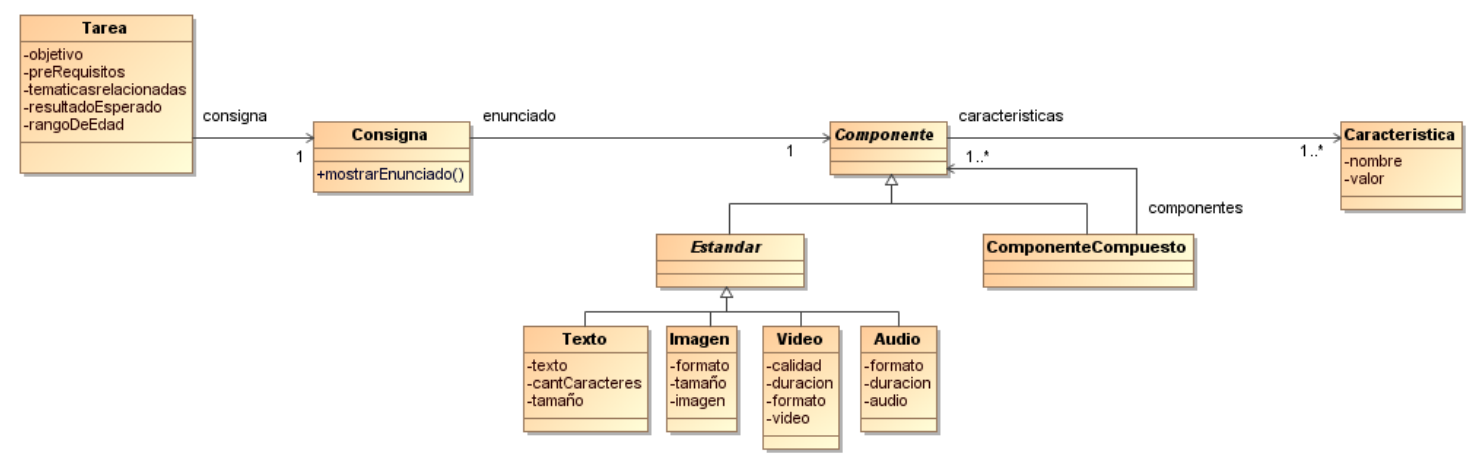

Figura 3.7: Modelado de la jerarquía de Componente

Cabe destacar que, para los componentes Estandar (ver Figura 3.7), se decidió representar un conjunto finito de atributos que los caracteriza, sin embargo para proveer flexibilidad en la representación de las componentes en general, se decidió incluir la clase Caracteristica, mediante la cual, dinámicamente, se pueden definir otros "atributos o cualidades" de los componentes cuando éstos son instanciados. Estas características, se definen con un nombre y un valor (por ejemplo: nombre="textura" y valor="rugosa", donde "textura" y "rugosa" son textos). Tener en cuenta que como valor, se podría guardar un objeto complejo.

A continuación se presenta en la Figura 3.8, otros tipos de enunciado, por ejemplo aquellos que involucran alguna respuesta por parte del alumno. En la Figura 3.8.a se presenta un enunciado que involucra que el alumno ingrese texto para responder, en la Figura 3.8.b se define un enunciado donde el alumno debe tomar una foto (imagen) mientras que en la Figura 3.8.c el alumno deberá seleccionar alguna de las opciones propuestas, donde la última de ellas además del nombre y la imagen del instrumento provee un audio en el que se ejecuta el instrumento.
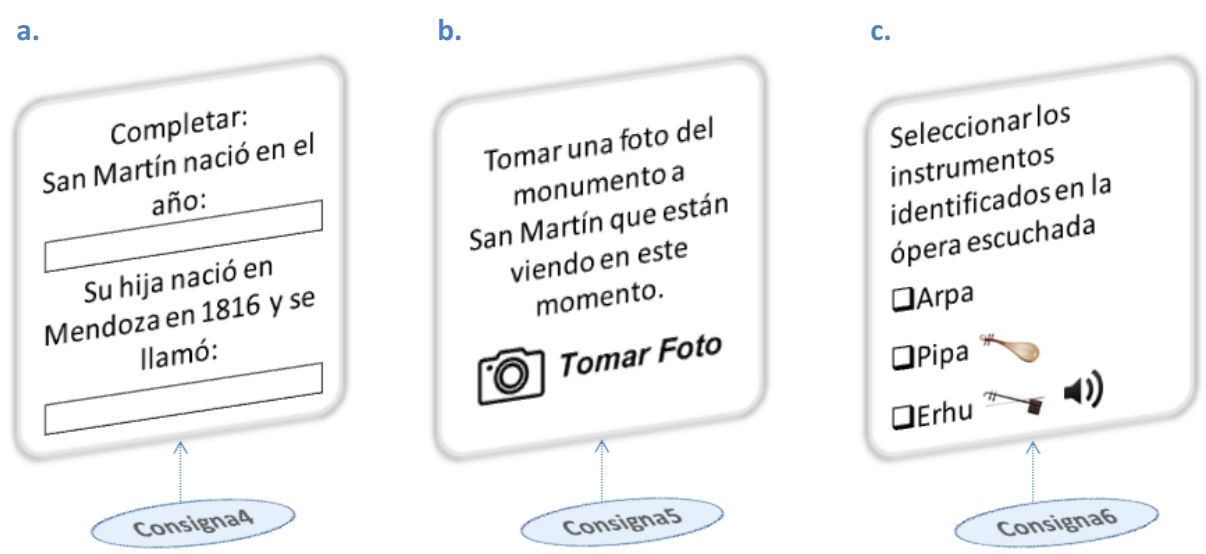

Figura 3.8: Ejemplos de enunciados con más componentes

Página 43 de 167 
Para representar los enunciados de la Figura 3.8, es necesario agregar mayor expresividad a la jerarquía de Componente, incorporando por un lado la posibilidad de generación (por parte del participante) de componentes y por otro lado, los de opción. La clase DeGeneracion conoce el tipo de componente a generar (componente Estandar). En el caso de las opciones, éstas pueden estar compuestas por diferentes componentes, debido a esto, se decidió representarla como una especialización del ComponenteCompuesto. Estos conceptos, son modelados en la Figura 3.9.

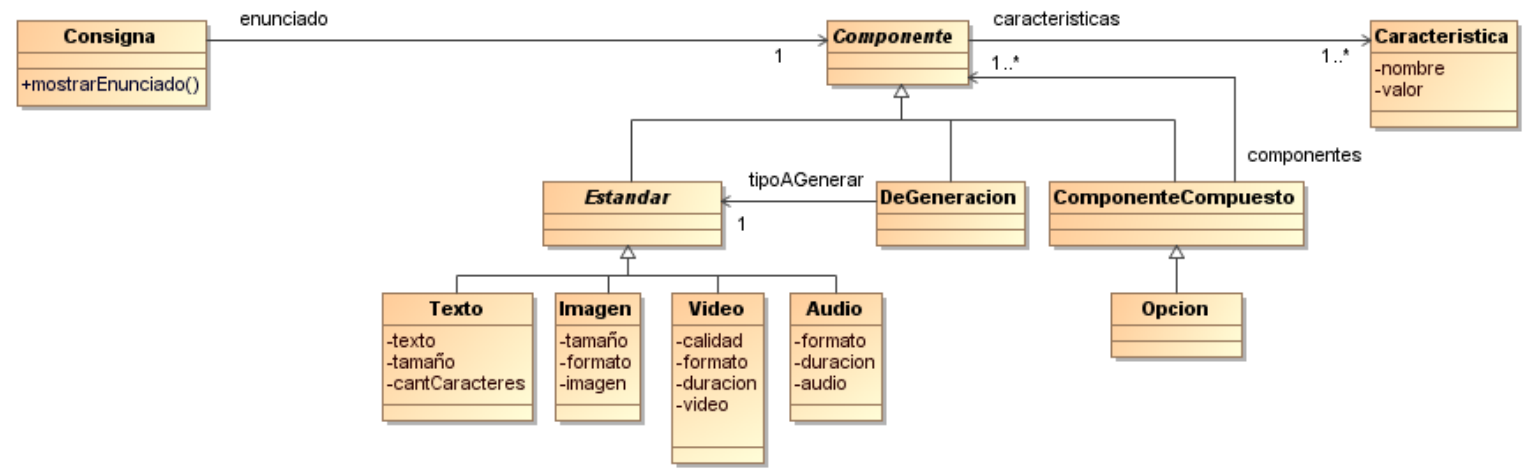

Figura 3.9: Modelado de generación de componentes y opciones

Para poder brindarle al alumno una corrección automática de consignas cuyo enunciado involucra opciones, se deben conocer aquellas opciones que son correctas. Esto se puede expresar con un tipo de consigna específica que mantenga este conocimiento. Esto se puede apreciar en la Figura 3.10. Se extendió la clase Consigna mediante la clase ConsignaConOpcion. Esta última clase conoce las opciones correctas. Cabe destacar que todas las opciones involucradas son conocidas como parte del enunciado.

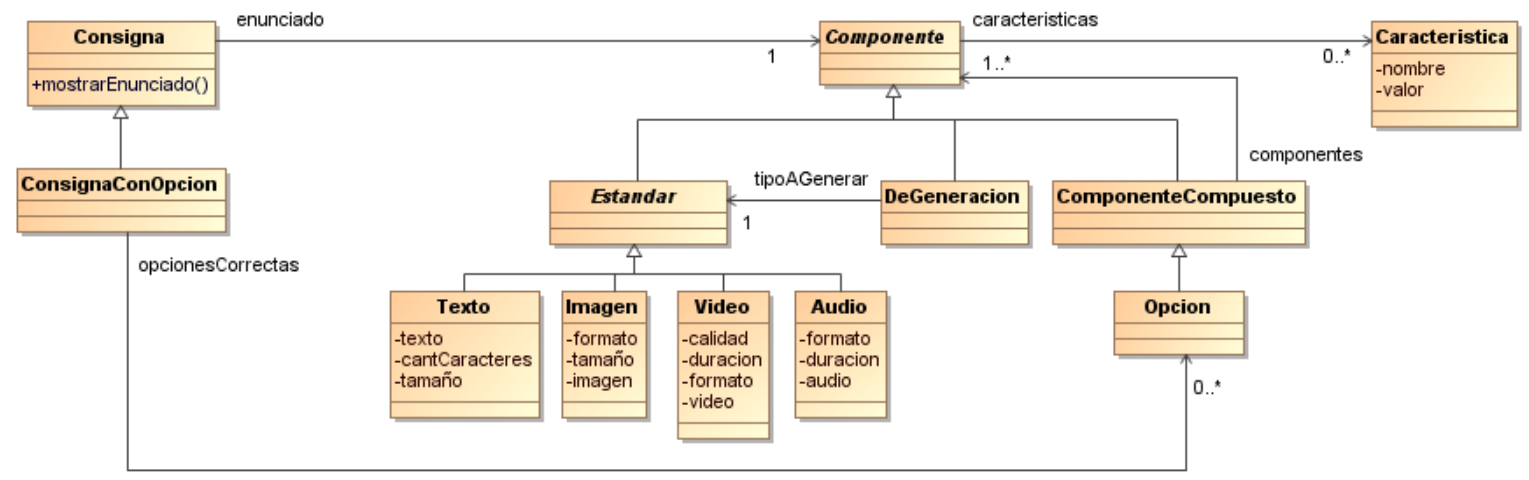

Figura 3.10: Modelado de consignas con opciones

Algunas veces, al redactar enunciados, es posible querer destacar ciertos conceptos y no presentarlos como simples textos. Por ejemplo, supongamos que en un enunciado queremos incluir un lugar determinado, como por ejemplo una biblioteca. Donde de esa biblioteca se conocen determinadas características como, por ejemplo, su nombre, 
horario de apertura y la capacidad para lectores en sala. Supongamos ahora que se quiere incluir dentro del enunciado un elemento propio del dominio que se está describiendo, como podría ser un libro en el caso de la biblioteca. Ese libro que se incluye en la redacción, al igual que lo mencionado para el lugar, puede contar con características, como por ejemplo su nombre, el número de ISBN y la cantidad de páginas. En la Figura 3.11, se presentan ejemplos de lo antes mencionado.

a.

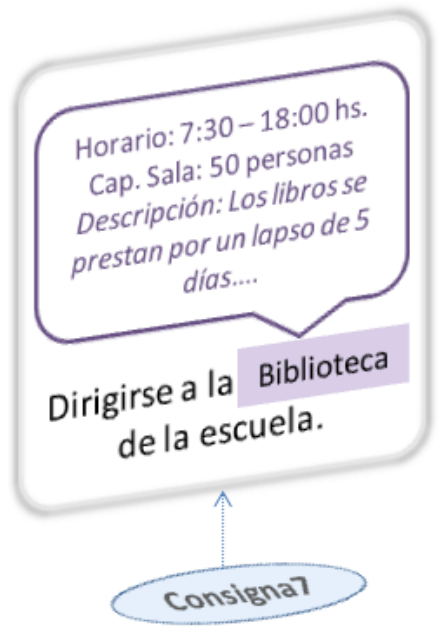

b.

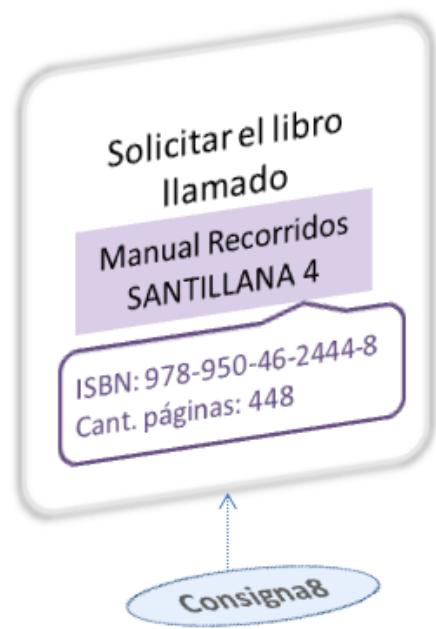

Figura 3.11: Ejemplos de enunciados de consignas con lugar y elemento

Para representar enunciados de la forma presentada en la Figura 3.11, se ha decidido incorporar estos conceptos como componentes, definiendo las clases Lugar y Elemento las cuales se visualizan en la Figura 3.12. Notar que cada característica adicional del Lugar o del Elemento, serán representadas mediante la clase Caracteristica.

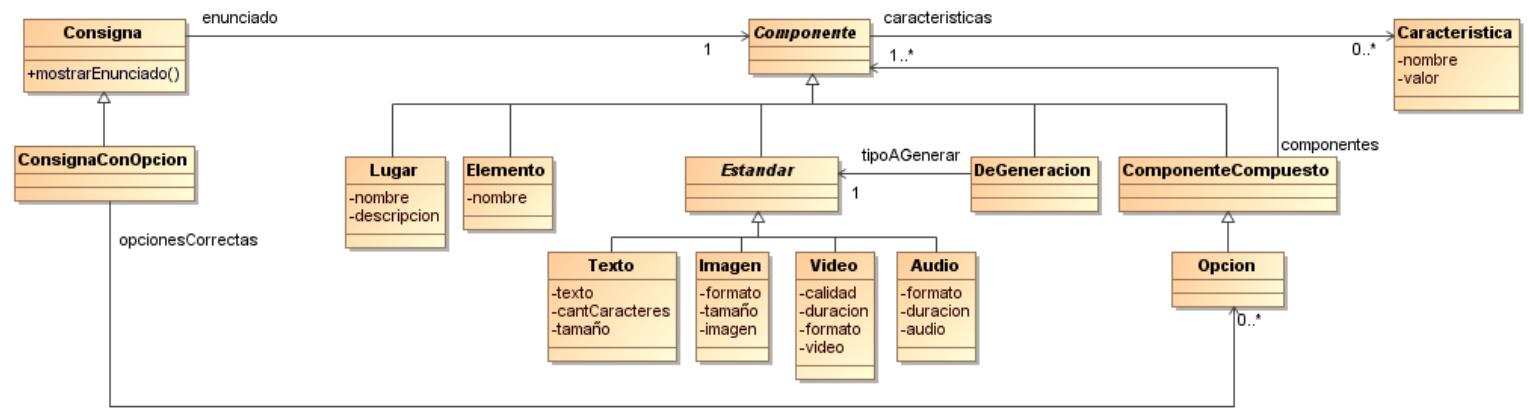

Figura 3.12: Modelado del Lugar y el Elemento como Componente

En la Figura 3.13 se presenta el modelo propuesto de Actividades Educativas. Con todas las clases que se fueron presentando anteriormente. 


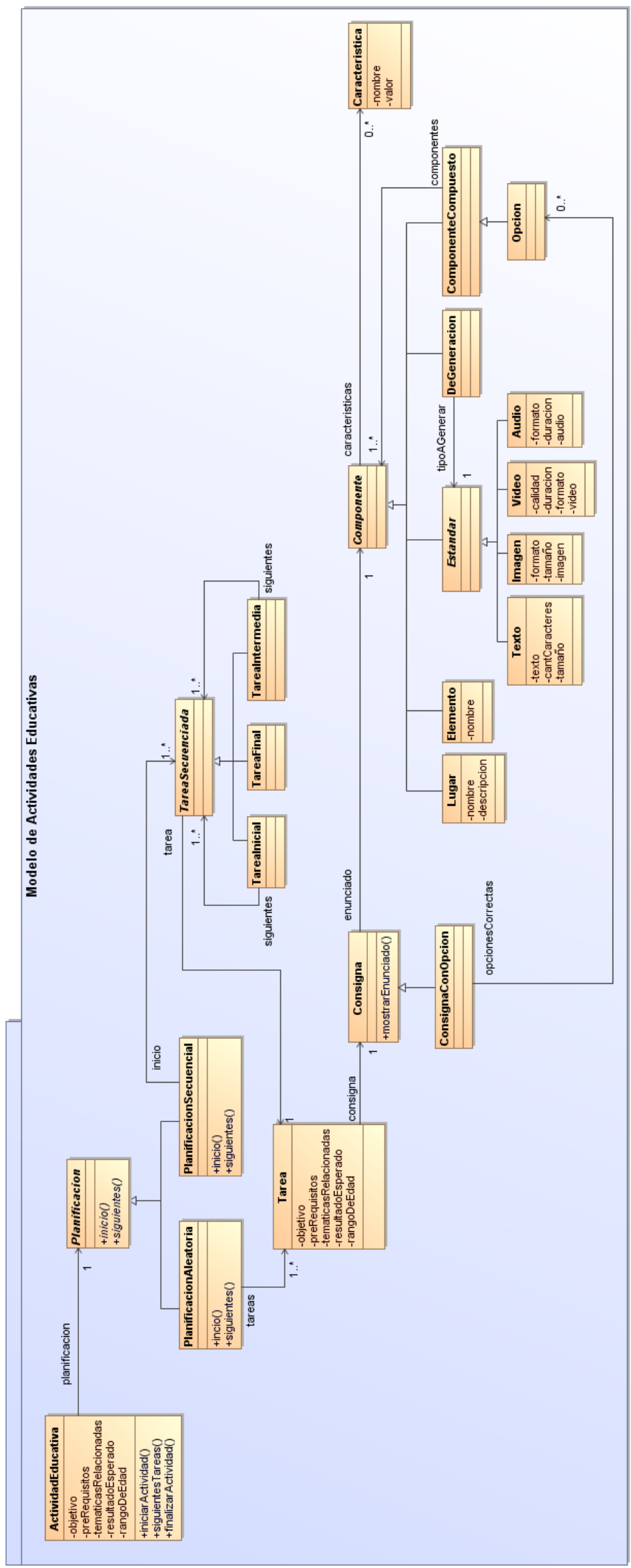

Figura 3.13: Modelo propuesto de Actividades Educativas 


\subsubsection{Modelo de Actividades Educativas Posicionadas}

Con el fin de continuar presentando los conceptos introducidos en la Figura 3.2 (presentada al inicio del Capítulo 3), aquí se aborda el modelo de Actividades Educativas Posicionadas. Dicho modelo se define en base a los conceptos descriptos en la Sección 3.2.1 e incorpora el concepto de posicionamiento.

Las actividades educativas planteadas en la Sección 3.2.1, se pueden poner en práctica en un espacio físico particular, es decir posicionarse. Posicionar una Actividad Educativa, conlleva a posicionar a cada una de sus tareas, puesto que éstas se pueden llevar a cabo en diferentes lugares entre sí. Dado que algunas tareas pueden involucrar elementos concretos, éstos se deberán posicionar también dentro del espacio físico en el que la AEP se llevará a cabo. Estos elementos concretos en el modelo de AEP, tendrán su definición general como elementos en el modelo de AE y podrán además sumar características concretas. En la Figura 3.14, se ejemplifican tres libros concretos (por ejemplo, inventariados en una Biblioteca particular), que se relacionan con el mismo elemento Libro. Se puede apreciar que los tres libros concretos cuentan con una característica adicional como es el número de inventario. Cabe destacar que esta característica tiene sentido solo a nivel concreto y no a nivel general del libro.

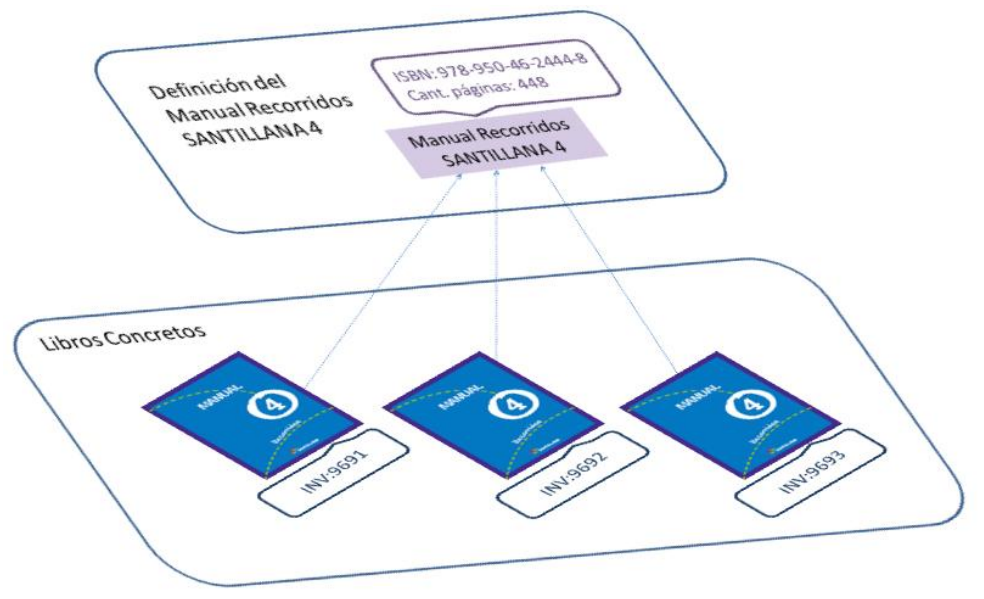

Figura 3.14: Ejemplo de elemento concreto

En base a los conceptos mencionados anteriormente, una primera aproximación de modelado se presenta en la Figura 3.15, en donde las clases ActividadEducativa, Tarea y Elemento del modelo de $\mathrm{AE}$ han sido posicionadas mediante la representación de las clases ActividadEducativaPosicionada, TareaPosicionada y ElementoConcreto respectivamente. En el modelo presentado en dicha figura, se puede apreciar que la ActividadEducativaPosicionada conoce a sus tareas posicionadas (TareaPosicionada) y a su vez, éstas pueden tener asociados, elementos concretos posicionados (ElementoConcreto), los cuales podrían adicionar características nuevas (como se 
ejemplifico en la Figura 3.14). Notar que, en esta figura, se han incluido solamente las clases relevantes del Modelo de Actividades Educativas por una cuestión de legibilidad.

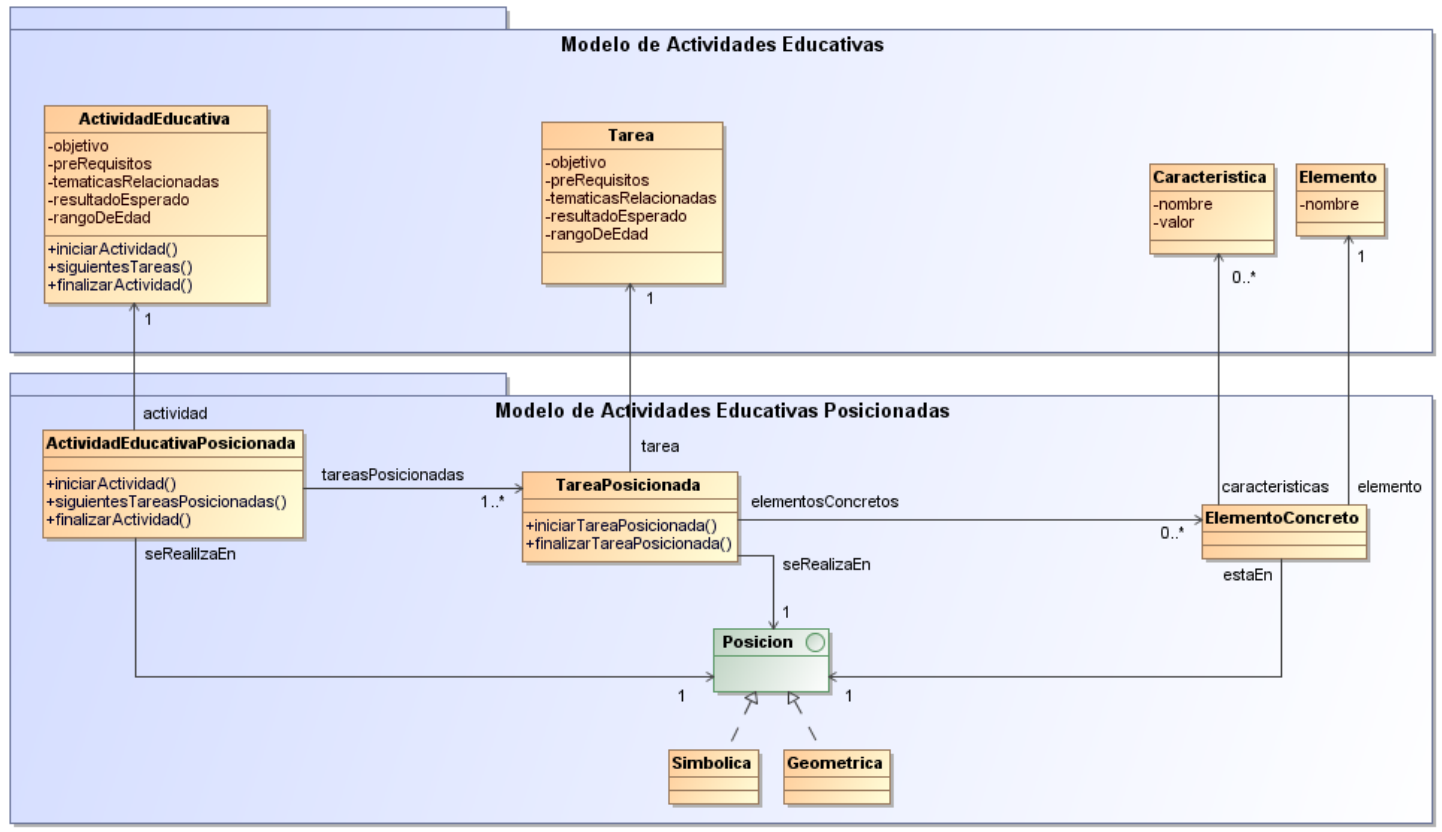

Figura 3.15: Posicionamiento de la actividad educativa, tarea y elemento

Como se pudo apreciar en la Figura 3.15, tanto las clases ActividadEducativaPosicionada, TareaPosicionada como ElementoConcreto, poseen una posición (Posicion). Para la representación de la posición, en este trabajo se adoptó lo expuesto por [Leonhardt, 1998], en donde se expresa que, al menos, existen dos formas de indicar una posición, una es mediante un conjunto de símbolos (por ejemplo, un nombre) y la otra es mediante un sistema de coordenadas (como por ejemplo, la terna (latitud, longitud, altura) considerando la esfera terrestre o bien pares ( $x, y)$ en el plano). En el primer caso, el autor citado las enuncia como posiciones simbólicas, en el segundo caso, posiciones geométricas. La posición se modelo utilizando el concepto de Interfaz [UML_DC] (ver Figura 3.15), con el fin de definir en ella el comportamiento básico de cualquier posición. En particular, se proponen las clases Simbolica y Geometrica que implementan dicha interfaz.

Con el modelo propuesto en la Figura 3.15, es posible representar tareas posicionadas en un espacio físico como se muestra en la Figura 3.16. Se puede apreciar que las posiciones (en el ejemplo $(x 1, y 1),(x 2, y 2)$ y $(x 3, y 3))$, están desacopladas de las tareas posicionadas (TP1, TP2 y TP3) y éstas de las tareas (T1, T2 y T3). Notar que la forma en la que se planificaron dichas tareas está establecida en la Actividad Educativa (en este ejemplo denominada AE1). 


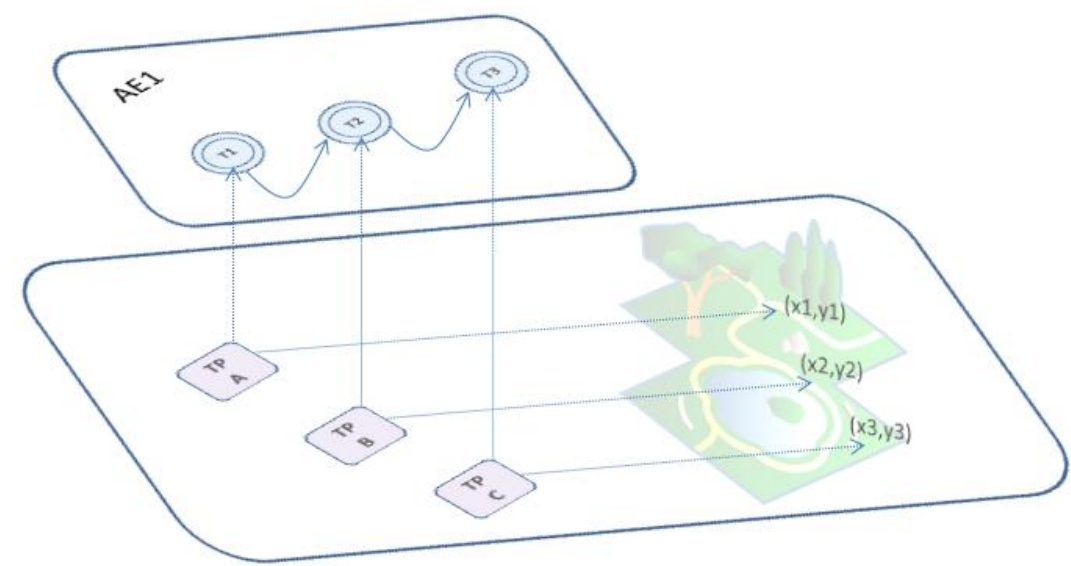

Figura 3.16: Tarea posicionada en un espacio físico

Con el modelo propuesto en la Figura 3.15, si bien, es posible reusar las tareas (T1, T2 y T3) en diferentes posiciones no se logra la expresividad suficiente para poder representar características propias de cada lugar dentro del espacio físico. Se podría pensar en definir lugares posicionados con características propias. Un ejemplo de este nuevo concepto se presenta esquemáticamente en la Figura 3.17. En dicha figura, se destacan dos lugares posicionados, L1 y L2, considerando que ambos lugares posicionados hacen referencia (en este ejemplo particular) al mismo lugar definido conceptualmente mediante el atributo nombre="Bosque" y descripcion="El bosque posee un lago y forestación variada...".

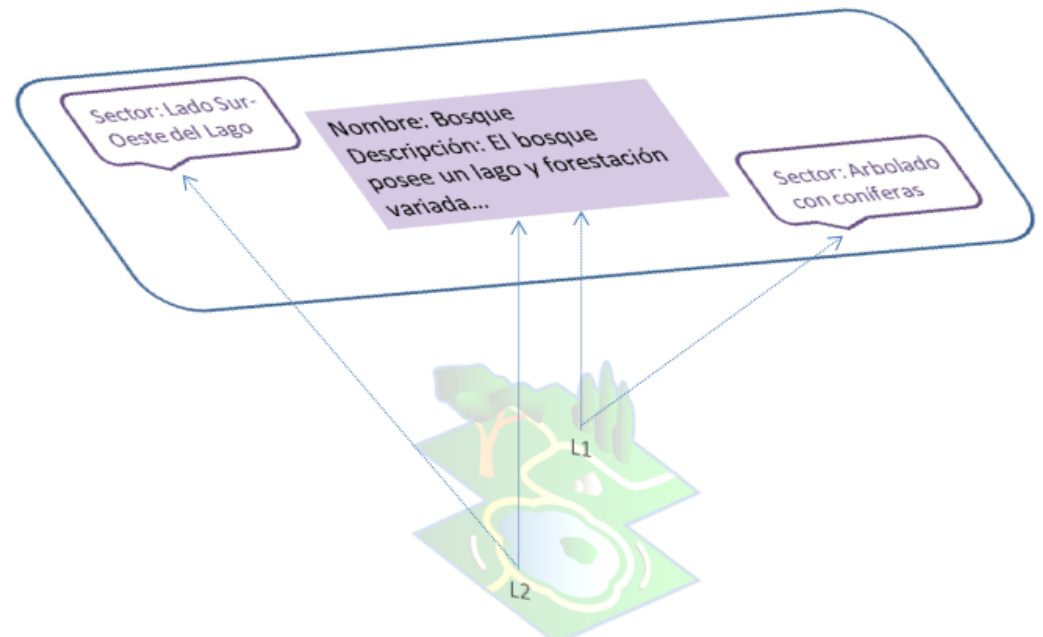

Figura 3.17: Identificación de lugares en el espacio físico

Notar que en la Figura 3.17, en el caso del lugar posicionado L1, se ha definido una característica para sumar semántica a dicho lugar, indicándola con clave="Sector" y valor="Arbolado con coníferas", mientras que para el lugar posicionado L2, se le definió una característica con clave="Sector" y valor="Lado Sur-Oeste del Lago". 
Luego de este análisis presentado en la Figura 3.17, se genera la necesidad de tener más nivel de expresividad en el modelo presentado en la Figura 3.15. Es por esto que se opto, en este trabajo, por modelar la clase LugarPosicionado, la cual conoce su Posicion y además conoce un Lugar (el cual contendrá características que lo describen). Cada LugarPosicionado puede además definir características propias. Al incorporar esta nueva clase (LugarPosicionado) ahora las ActividadEducativaPosicionada y TareaPosicionada se realizan en un LugarPosicionado (relaciones llamadas seRealizanEn respectivamente) mientras que el ElementoConcreto está en un LugarPosicionado (relación estaEn). En la Figura 3.18 se visualizan los cambios mencionados para agregar mayor expresividad al modelo.

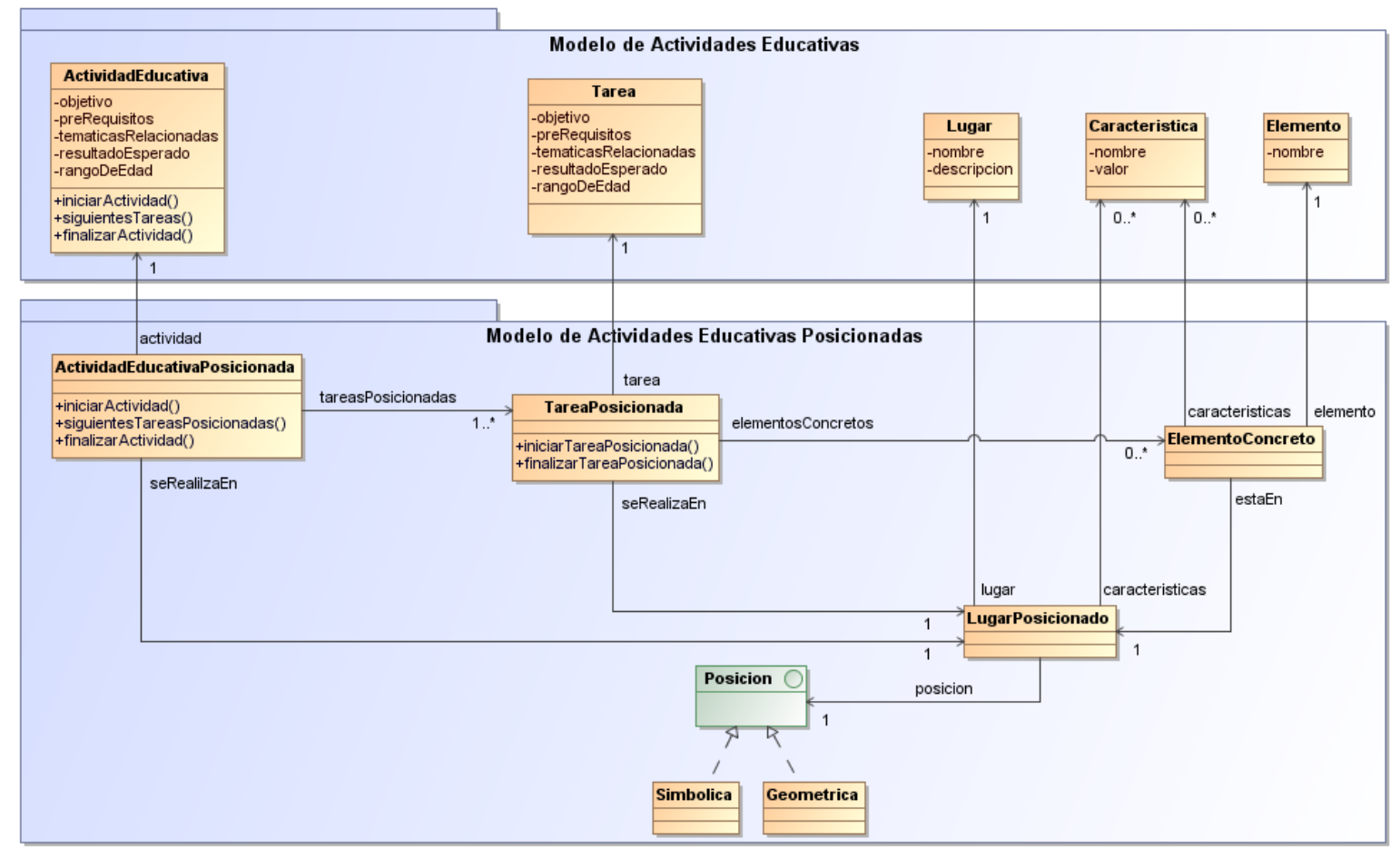

Figura 3.18: Modelado del lugar posicionado

A continuación se describirán algunas características que posee cada ElementoConcreto. Al poder ser manipulado y transportado durante la puesta en práctica de la actividad, el lugar en el que se encuentra el elemento concreto puede cambiar durante la misma. Esto conlleva a que un elemento concreto pueda o no estar disponible para el siguiente alumno que llega a realizar la tarea posicionada. Con el fin de poder conocer la disponibilidad del ElementoConcreto en un lugar determinado, se decidió modelar la misma con el patrón de diseño "State" [Gamma et al., 1994]. Se consideraron, hasta el momento, dos clases concretas para modelar los estados Disponible y NoDisponible. Como se quiere mantener un registro de al menos, todos los lugares por los que fue pasando un elemento concreto, como así de sus estados, se decidió modelar el 
historial de eventos asociado a cada elemento concreto mediante la clase HistorialElemento. Cabe destacar que en el historial del elemento concreto, se registran los eventos asociados al mismo. En particular, CambioEstado y CambioDeLugar. Estos conceptos mencionados se incorporan en el modelo propuesto en la Figura 3.19.

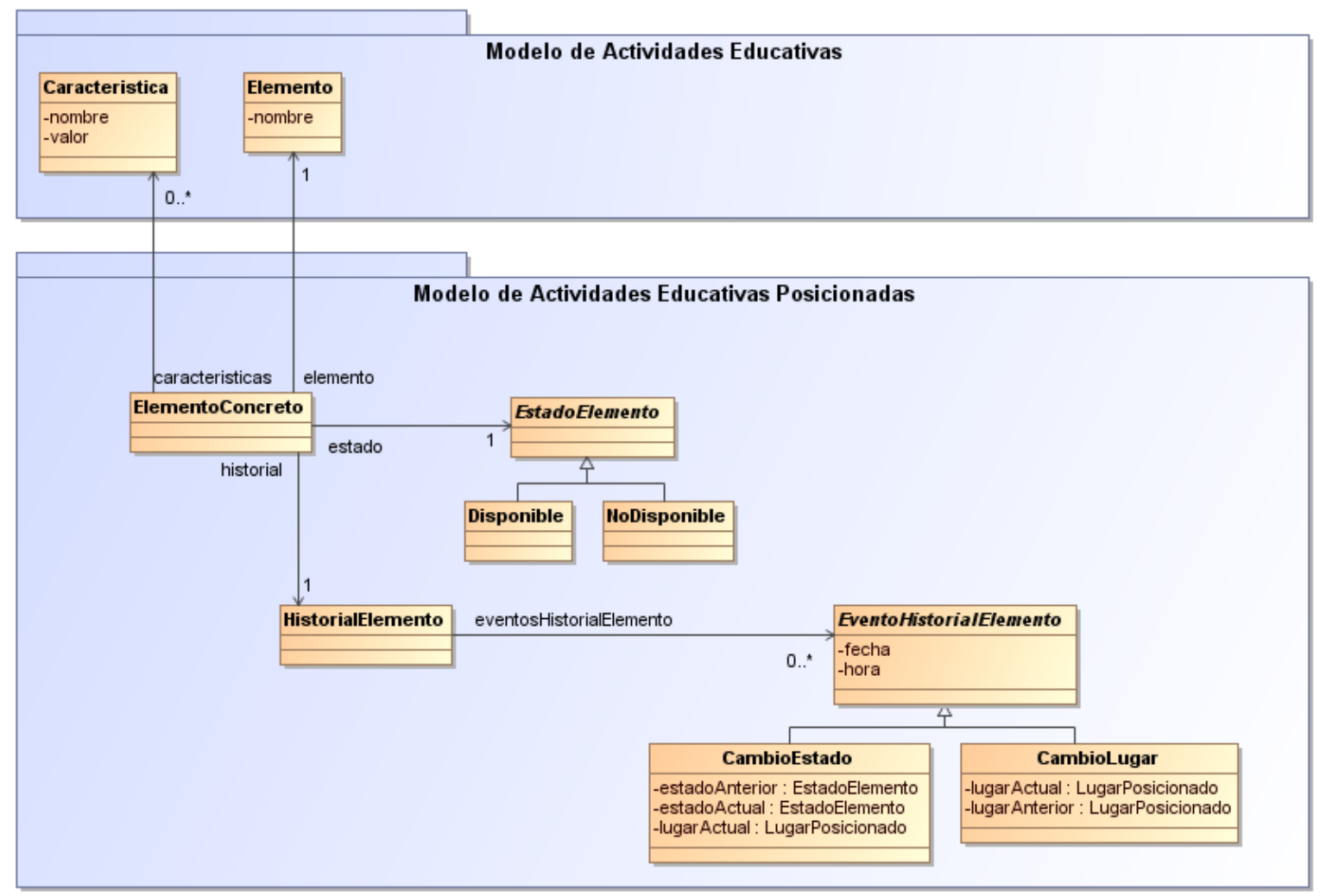

Figura 3.19: Modelado del estado y el historial para un elemento concreto

Notar que, se decidió que una vez definida una actividad educativa posicionada el lugar en el que se realizará, al igual que para las tareas, no cambie. Esto fue una decisión a nivel de diseño de modelo propuesto.

En la Figura 3.20, se presenta el modelo propuesto para Actividades Educativas Posicionadas; con todas las clases que se fueron presentando anteriormente. En esta figura, quedan explícitas las relaciones de conocimiento relevantes entre los modelos de Actividades Educativas y de Actividades Educativas Posicionadas. 


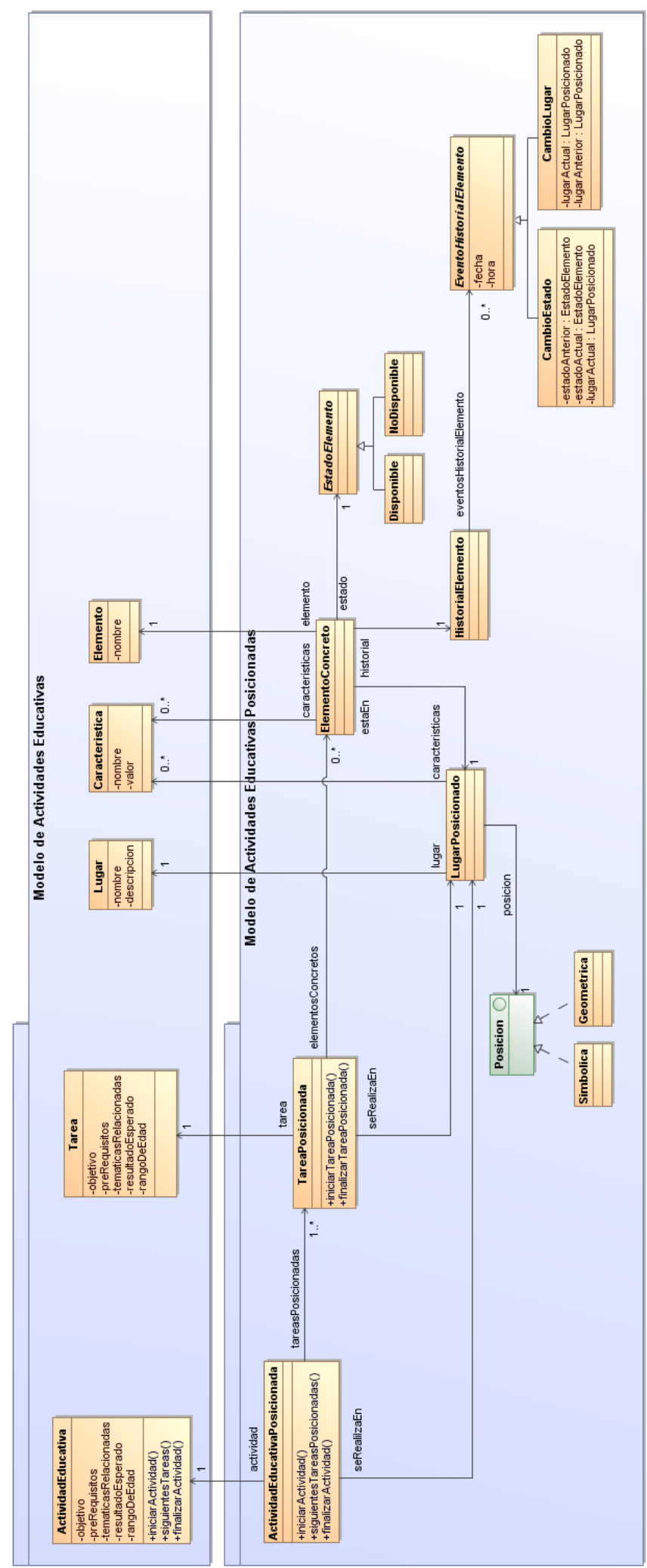

Figura 3.20: Modelo propuesto para actividades educativas posicionadas

Página 52 de 167 


\subsubsection{Modelo de Usuario}

De acuerdo a lo presentado en la Figura 3.2 (descripta al inicio del Capítulo 3) se introduce en esta sección el modelo de Usuario, el cual se basa en los conceptos definidos en los modelos de Actividades Educativas y Actividades Educativas Posicionadas.

Se decidió modelar el concepto de grupo. Un grupo se conforma para la puesta en práctica de la AEP, es decir, en el caso de que estén involucradas personas que observan y tutores, éstos acompañan a los alumnos desplazándose con ellos de tarea en tarea. Es decir, que hay diferentes participantes con diferentes roles. Estos conceptos se presentan en la Figura 3.21. En esta figura, se representa al participante, desacoplando la idea del rol que puede desempeñar, esto se debe a que una persona (participante) podría desempeñar diferentes roles en la misma puesta en práctica o en diferentes. El concepto de rol, se modeló empleando el patrón de diseño "RoleObject" [Bäumer et al., 1998]. De los participantes (con un rol particular) se mantiene información del equipamiento asignado. La clase Equipamiento se define con un nombre y una descripción del mismo (por ejemplo: nombre="celular" descripcion="con cámara y gps", en donde "celular y "con cámara y gps", en particular, son textos).

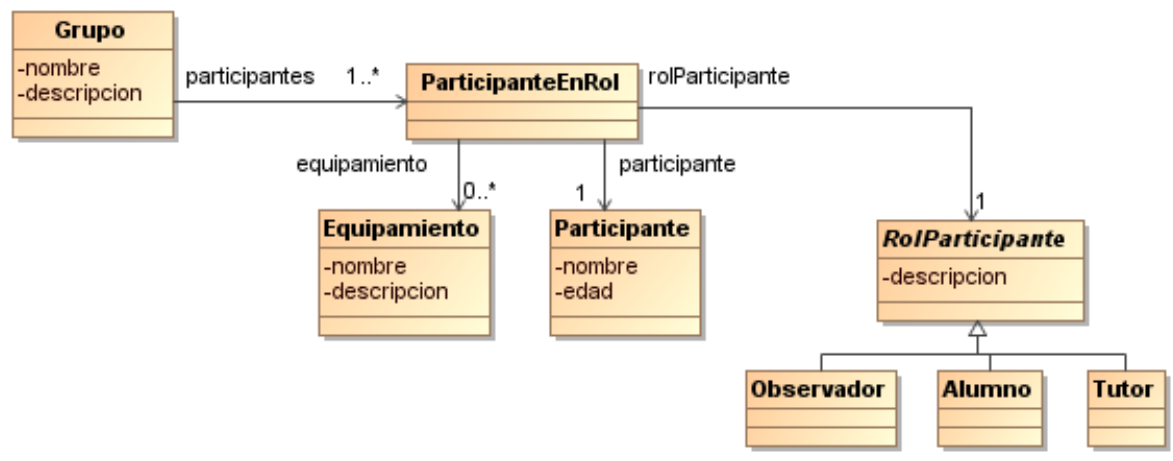

Figura 3.21: Modelado del Grupo

Cada grupo puede generar respuestas a medida que recibe las tareas. Cada respuesta generada se asocia a la ActividadEducativaPosicionada y a la TareaPosicionada (ambas clases definidas en el modelo de Actividades Educativas Posicionadas) que se está respondiendo. Registrándose además quien o quienes la responden y bajo que rol (por ejemplo, la responden alumnos o la responde un tutor o bien, ambos). Acorde a la forma de enunciar las consignas propuesta en la Sección 3.2.1, se modelaron dos tipos de respuestas, por un lado las respuestas de generación (RespuestaDeGeneracion) y por otro las de selección (RespuestaDeSeleccion). En el primer caso, la respuesta se asocia a un Componente Estandar (definido en el modelo de Actividades Educativas) con el fin de asociar el contenido generado (por ejemplo, un video o un texto). En el caso de la RespuestaDeSeleccion, se asocian las opciones (clase Opcion definida en el modelo de 
Actividades Educativas) que han sido seleccionadas para esa tarea. Estos conceptos se presentan en la Figura $3.22^{16}$.

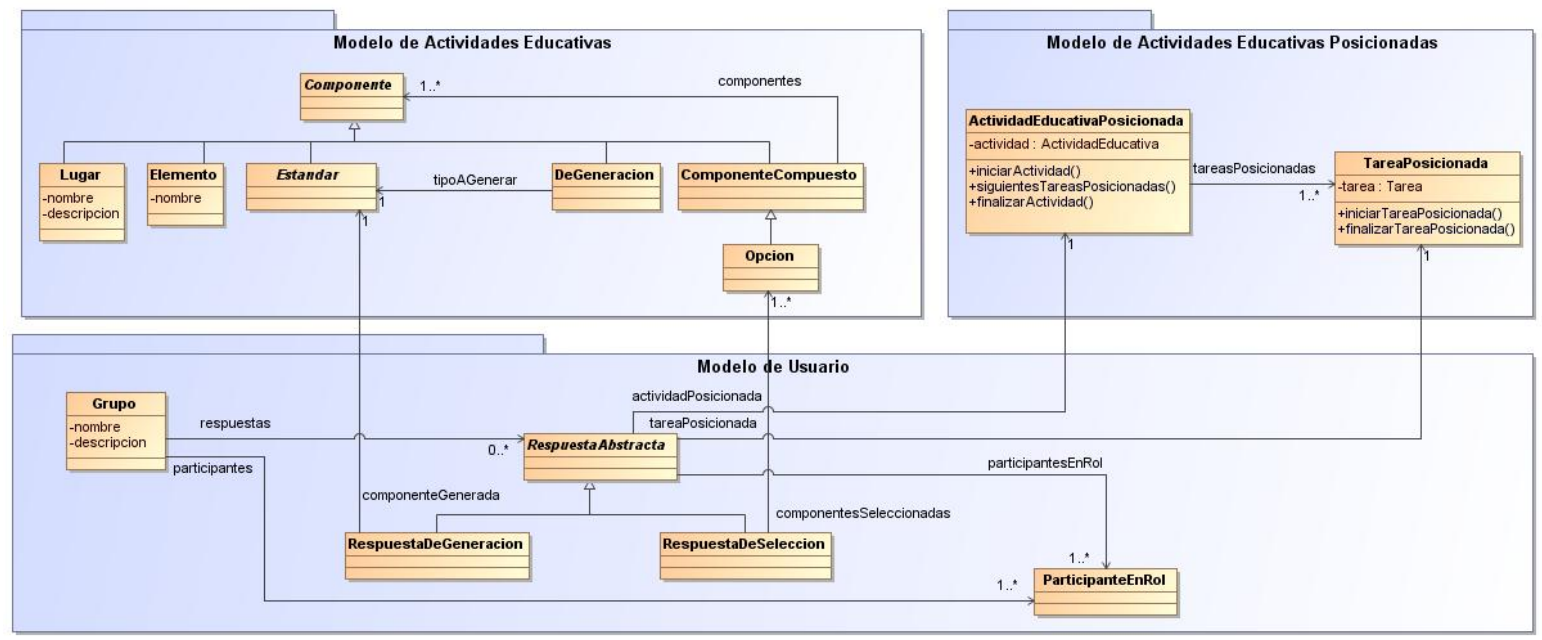

Figura 3.22: Modelado de las respuestas del grupo

En la puesta en práctica de la AEP, puede suceder que, un grupo de alumnos no responda ante una consigna que así lo requiera. Con el modelo propuesto en la Figura 3.22, no es posible representar esta particularidad. Por este motivo, se decidió modelar, empleando el patrón de diseño "Null Object" [Woolf, 1997] una NoRespuesta por parte de un participante (con un rol) del grupo. En la Figura 3.23, se presenta el modelo que contempla este concepto.

${ }^{16}$ Por una cuestión de legibilidad en la presentación del modelo, se omitió la representación explícita entre las clases del Modelo de Actividades Educativas Posicionadas y el Modelo de Actividades Educativas. En su reemplazo, se incluyó el atributo actividad en la clase ActividadEducativaPosicionada y el atributo tarea en la clase TareaPosicionada. Solo las clases relevantes en ambos modelos mencionados fueron incluidas en la figura. 


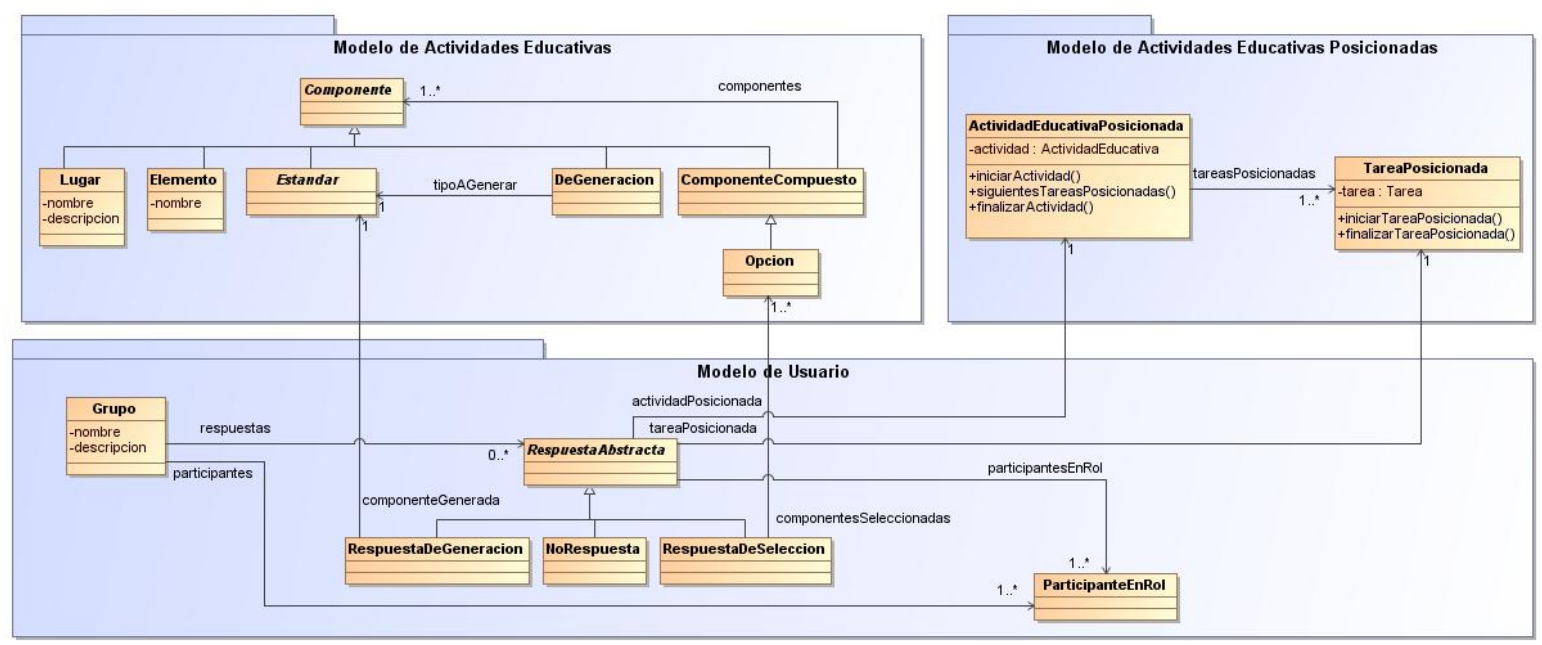

Figura 3.23: Modelado de la NoRespuesta

Otra decisión de diseño que surge a partir de la puesta en práctica, ha sido la de registrar ciertas actividades del grupo. Por ejemplo, cuando el grupo está en la posición de inicio de la actividad, en qué lugar se encuentra, si está realizando una tarea en particular, o si se está desplazando hacia una tarea o lugar determinado. Para esto se decidió modelar la actividad del grupo mediante una jerarquía (ActividadDeGrupo), cuyas clases concretas son: Inicial, EnLugar, EnTarea, CaminandoALugar y CaminandoASiguienteTarea. Todas las actividades de grupo, son registradas mediante la clase HistorialGrupo. Estos conceptos son presentados en la Figura 3.24.

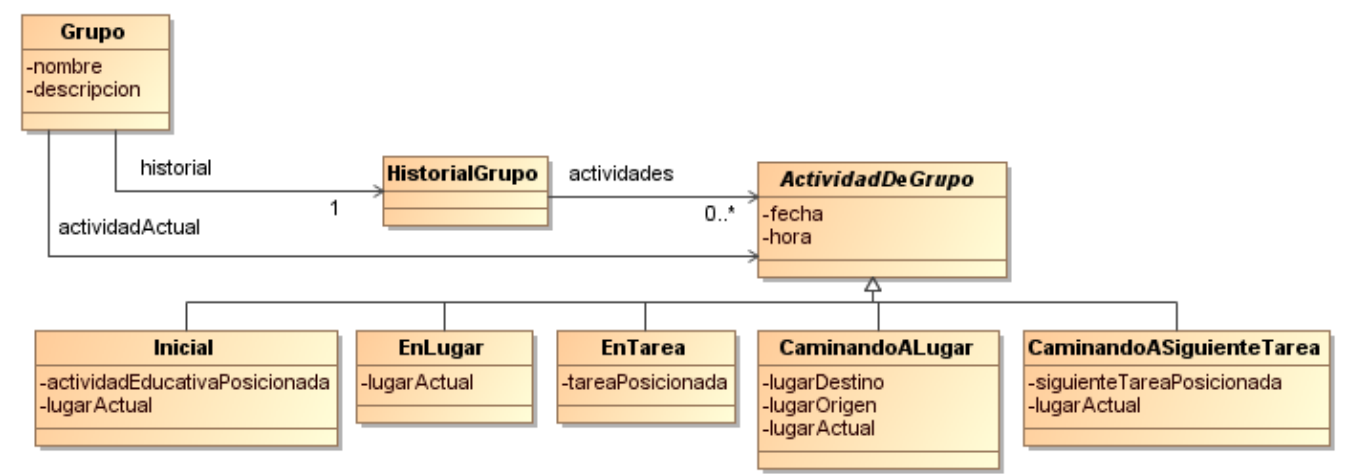

Figura 3.24: Modelado del historial del grupo

En la Figura 3.25, se presenta el modelo propuesto para el Usuario. Con todas las clases que se fueron presentando anteriormente. En esta figura, quedan explícitas las relaciones de conocimiento relevantes entre los modelos de Actividades Educativas, de Actividades Educativas Posicionadas y de Usuario. De esta forma, se han presentado los tres modelos propuestos en la Figura 3.2. 


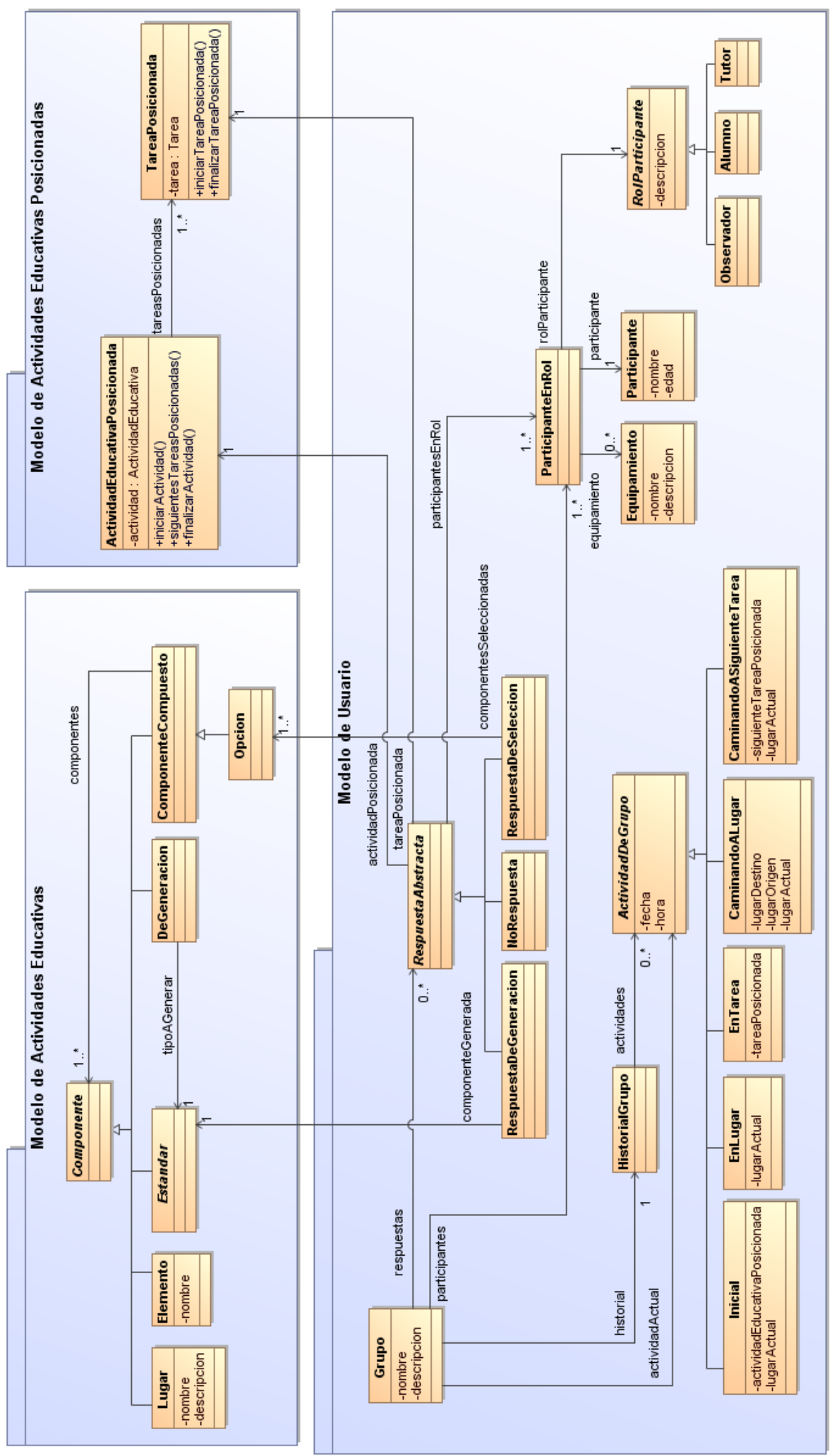

Figura 3.25: Modelo propuesto de usuario 


\subsection{Análisis del reuso en los modelos del enfoque propuesto}

En esta sección se presentan algunos ejemplos de actividades educativas posicionadas que permiten visualizar esquemáticamente la posibilidad de reuso alcanzada con los modelos del enfoque propuesto y luego se presentan diagramas de secuencia UML [UML_DS], para mostrar la obtención de la siguiente tarea posicionada para cada caso de ejemplo propuesto.

Para introducir esquemáticamente los conceptos presentados en los modelos de $A E$ y de $A E P$, se propone una serie de ejemplos que permiten destacar el reuso propuesto en este trabajo, en particular, con los modelos mencionados.

- Ejemplo 1

Supongamos tener la actividad educativa AE1, definida anteriormente en la Figura 3.4.a, la cual fue planificada linealmente con las tareas T1, T2 y T3. Se definió además un espacio físico para la actividad educativa posicionada (AEP1) en el cual se crearon tres lugares posicionados (L1, L3 y L4). Las tareas posicionadas TP1, TP2 y TP3 se definieron relacionando las tareas y los lugares mencionados anteriormente. Esto se muestra en la Figura 3.26.

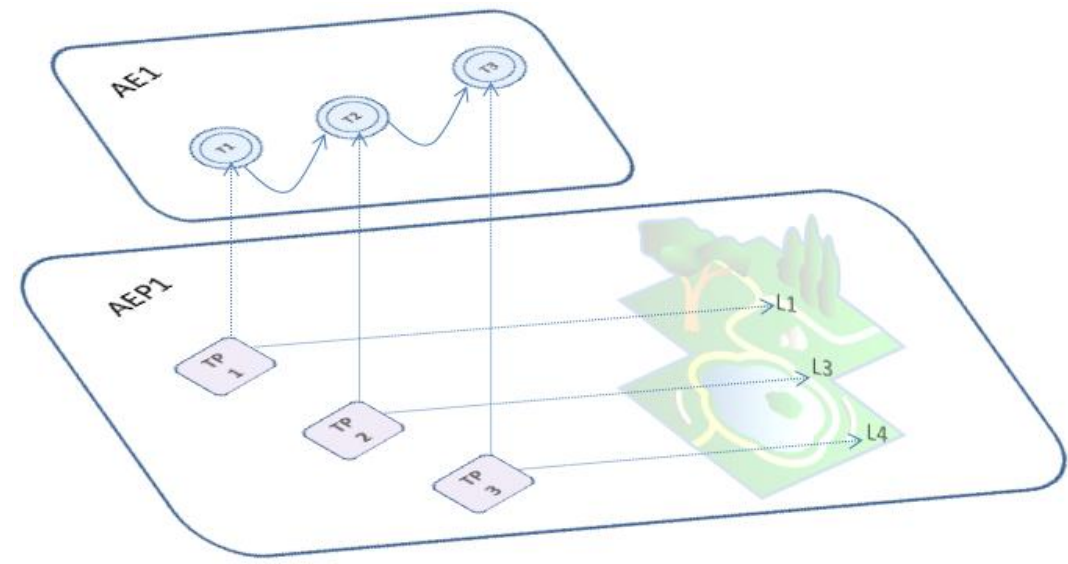

Figura 3.26: Ejemplo de actividad educativa posicionada AEP1

- Ejemplo 2

Supongamos ahora que se quiere reusar la AE1 (presentado en la Figura 3.26) en otros lugares posicionados del mismo espacio físico del ejemplo anterior. Esto se representa en la Figura 3.27. Notar que, esto implica definir una nueva actividad educativa posicionada (AEP2) la cual cuenta con tres nuevas tareas posicionadas (TP4, TP5 y TP6) donde cada tarea posicionada, conoce el lugar posicionado (L5, L6 y $L 2)$ respectivamente. 


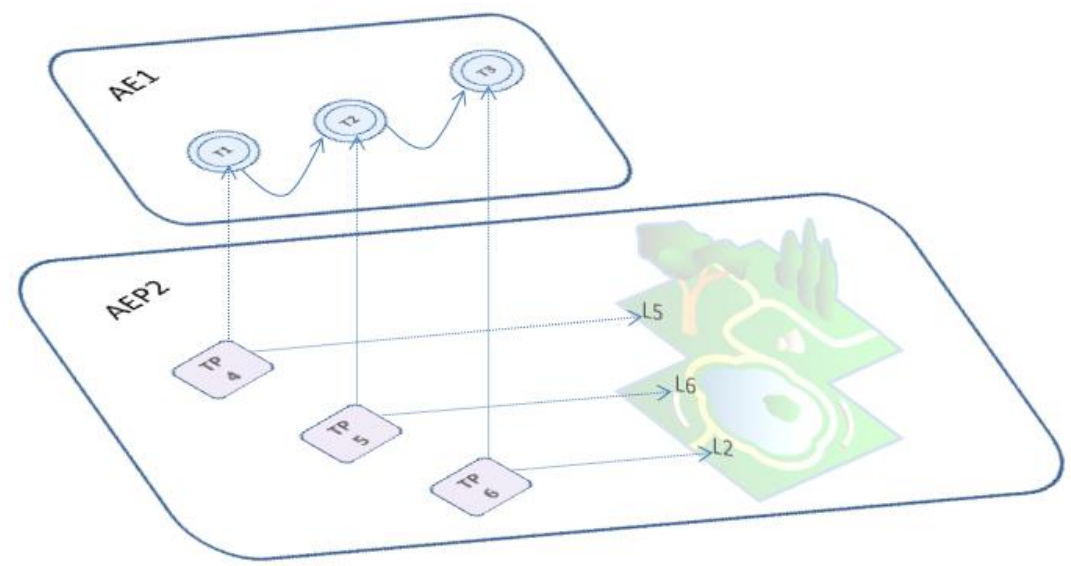

Figura 3.27: Ejemplo de actividad educativa posicionada AEP2

- Ejemplo 3

Veamos ahora un ejemplo donde se reusa nuevamente la actividad educativa AE1, pero en este caso, en otro espacio físico. Esto se visualiza en la Figura 3.28. Se puede apreciar que para la AEP3 se definieron tres lugares posicionados (L7, L8 y L9). Notar que se relacionó cada tarea posicionada (TP7, TP8 y TP9) con su tarea correspondiente (T1, T2 y T3) y su lugar posicionado (L7, L8 y L9).

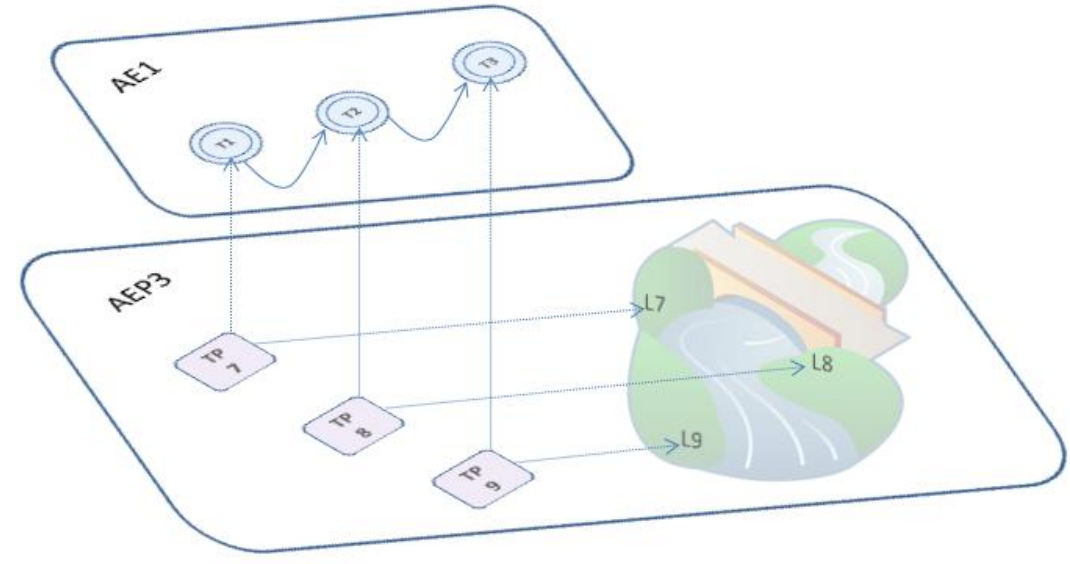

Figura 3.28: Ejemplo de actividad educativa posicionada AEP3

- Ejemplo 4

En este nuevo ejemplo visualizado en la Figura 3.29, se reusa la AE2. De este modo, se tiene la AE2, planificada secuenciada con bifurcación, donde se reusan las tareas (T1, T2 y T3). Por otro lado, se decidió reusar los lugares posicionados definidos en el espacio físico para las AEP1 y AEP2, creando la AEP4, con las tareas posicionadas TP10, TP11 y TP12 que relacionan las tareas (T1, T2 y T3) con los lugares posicionados previamente definidos (L1, L6 y L4) respectivamente. 


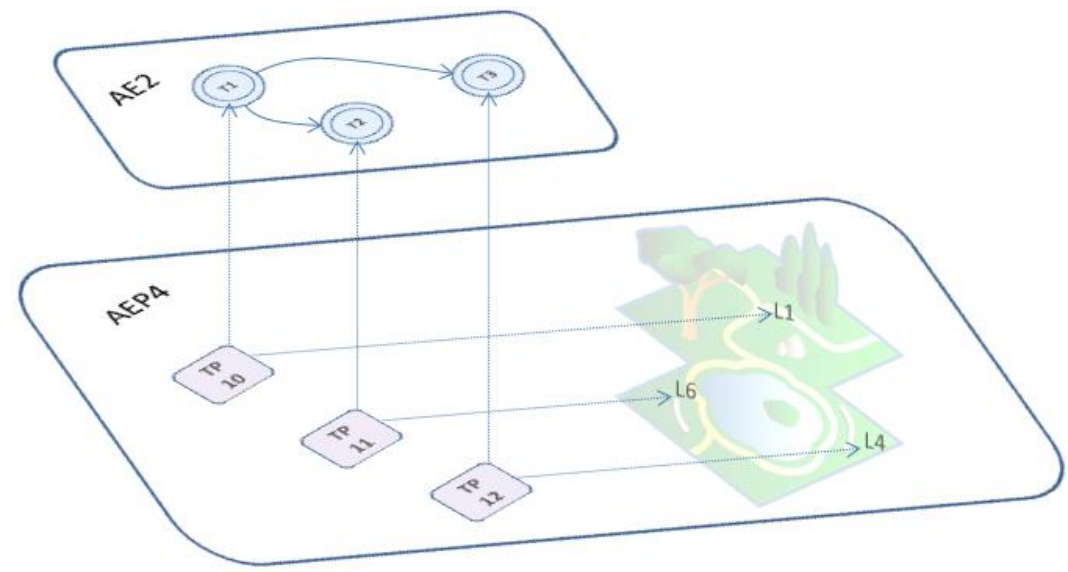

Figura 3.29: Ejemplo de actividad educativa posicionada AEP4

- Ejemplo 5

A continuación, en la Figura 3.30 se presenta un nuevo ejemplo, en el que el reuso se presenta a nivel de actividad educativa (AE2) y de lugares posicionados. En este ejemplo, se reusa el mismo lugar posicionado (L3) para más de una tarea posicionada de la actividad educativa posicionada (AEP5). Se puede apreciar que la TP13 y la TP15 se llevan a cabo en el mismo lugar posicionado L3.

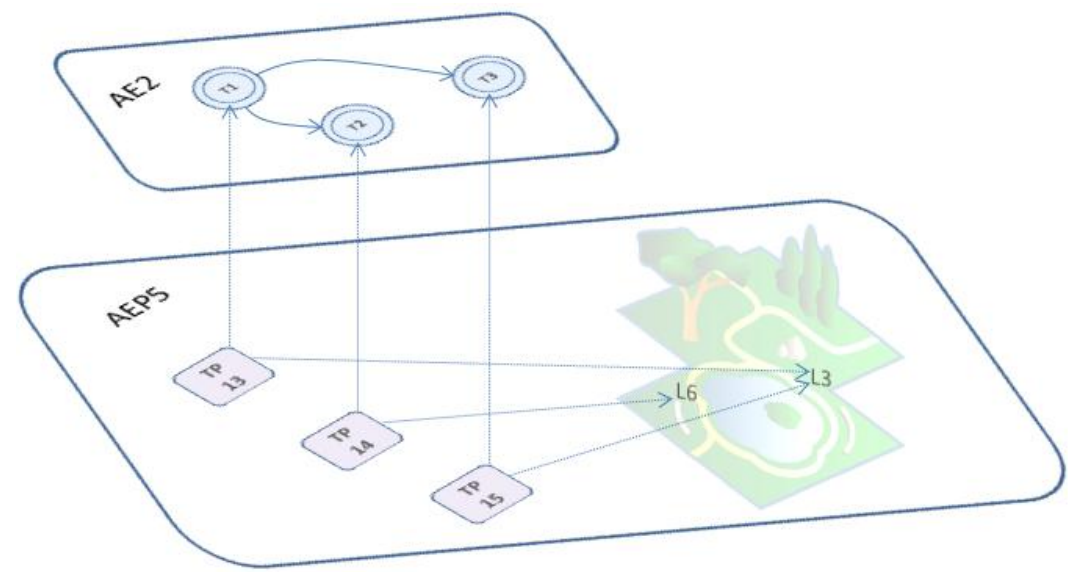

Figura 3.30: Ejemplo de actividad educativa posicionada AEP5

En base a los ejemplos introducidos previamente, se puede destacar el reuso en los siguientes conceptos:

- Tarea: Diferentes planificaciones involucrando a las mismas tareas propuestas en dos actividades educativas (AE1 y AE2)

- Actividad Educativa: Se mostró como usar la misma actividad educativa AE1 en diferentes actividades educativas posicionadas AEP1, AEP2 y AEP3. Y además como usar la EA2 para las actividades educativas posicionadas AEP4 y AEP5. 
- Lugar Posicionado: Se emplearon los mismos lugares posicionados definidos en el espacio físico para más de una tarea posicionada. Se mostró además mediante el ejemplo 5, que en el mismo lugar posicionado (L3), es posible realizar más de una tarea posicionada (T13 y T15) en el marco de la AEP5. Se pudo apreciar que el mismo lugar posicionado puede ser usado en tareas posicionadas de diferentes AEP (por ejemplo L1 en los ejemplos 1 y 4 ).

Supongamos que a partir de los ejemplos presentados se instancian los modelos propuestos en la Sección 3.2. A continuación se muestra como sería la secuencia de mensajes, en la puesta en práctica, una vez que se respondió la primera tarea posicionada (de cada AEP) de cada ejemplo. Esto permitirá clarificar cómo se comportan los modelos propuestos para distintas instanciaciones de los mismos. En todos los diagramas de secuencia propuestos, se partirá desde la invocación del método siguientesTareasPosicionadas(), el cual es enviado a la actividad educativa posicionada. El objetivo es mostrar que ante la misma secuencia de mensajes desencadenada a partir del método mencionado, la respuesta obtenida puede diferir dependiendo de cómo se instanciaron los modelos propuestos.

Supongamos que se instanciaron los modelos propuestos a partir del ejemplo 1 . Al ser puesto en práctica, y ante la invocación del método siguientesTareasPosicionadas() luego de haber realizado la primera tarea de la AEP1, se obtiene como respuesta una tarea posicionada, en particular, tp2. Esto se puede apreciar en la Figura 3.31.

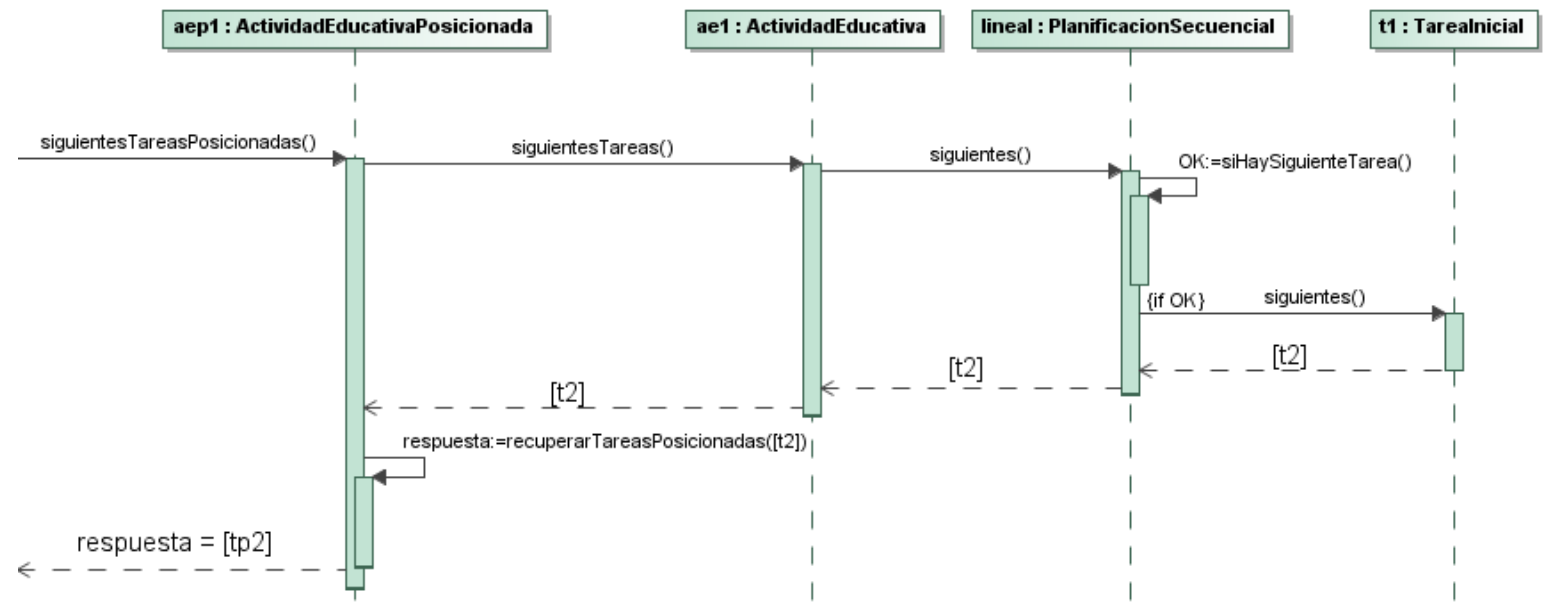

Figura 3.31: Diagrama de secuencia para obtener las siguientesTareasPosicionadas para la AEP1

El método recuperarTareasPosicionadas(tareas) devuelve las tareas posicionadas, asociadas a las tareas recibidas como parámetro. Esto se repite para los diagramas de secuencia subsiguientes. 
Supongamos ahora que se instanciaron los modelos propuestos a partir del ejemplo 2. Al ser puesto en práctica luego de haber realizado la TP4, y ante la invocación del método siguientesTareasPosicionadas(), se obtiene como respuesta una tarea posicionada, en particular, tp5. Esto se puede apreciar en la Figura 3.32.

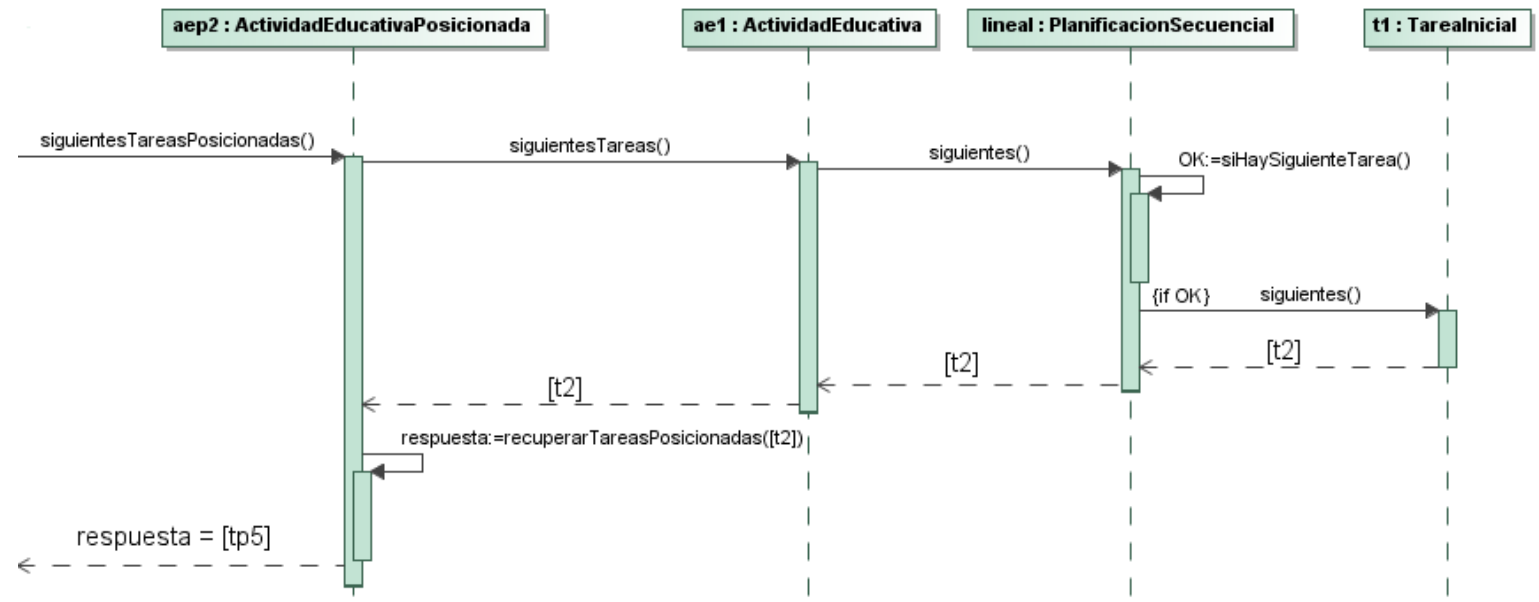

Figura 3.32: Diagrama de secuencia para obtener las siguientesTareasPosicionadas para la AEP2

Veamos ahora cómo se comporta, durante la puesta en práctica, el método siguientesTareasPosicionadas() cuando los modelos han sido instanciados a partir del ejemplo 3. En la Figura 3.33, se puede apreciar que la respuesta obtenida es tp8.

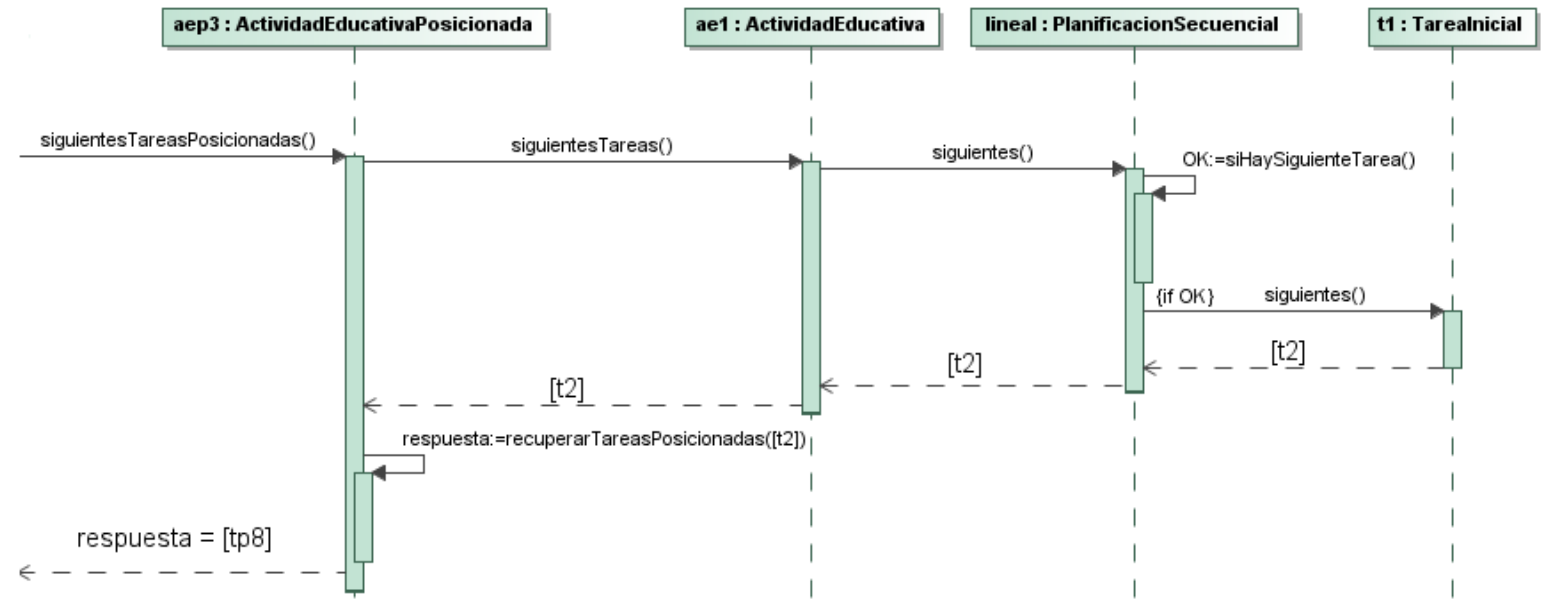

Figura 3.33: Diagrama de secuencia para obtener las siguientesTareasPosicionadas para la AEP3

Se puede apreciar en las Figuras 3.31, 3.32 y 3.33, que al tener todas la misma $A E$, el método siguientesTareas(), genera el mismo resultado (t2), en estas figuras, solamente varía la tarea posicionada acorde a cada AEP.

El diagrama de secuencia presentado en la Figura 3.34, muestra la invocación del método siguientesTareasPosicionadas(). Los modelos en este caso, fueron instanciados 
con el ejemplo 4. La respuesta obtenida durante la puesta en práctica, luego de haber realizado la tarea posicionada TP10, es en este caso, una colección con dos tareas posicionadas: tp11 y tp12. Esto se debe a que la AE2, tiene una planificación secuencial con bifurcación. En este caso, la tarea t1, posee como siguientes tareas a t2 y t3.

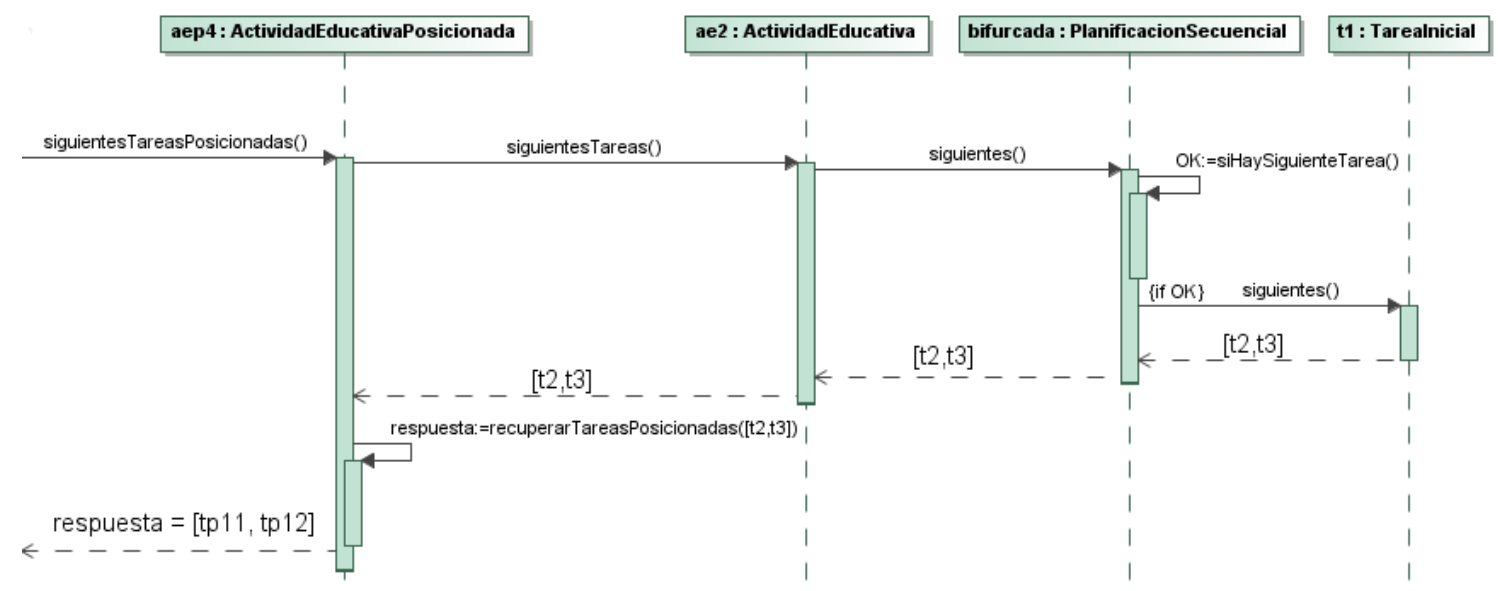

Figura 3.34: Diagrama de secuencia para obtener las siguientesTareasPosicionadas para la AEP4

Por último, en la Figura 3.35, se presenta el último diagrama de secuencia. En este caso, los modelos fueron instanciados con el ejemplo 5. La figura muestra la secuencia ante la invocación del método siguientesTareasPosicionadas() luego de haber realizado la TP13 durante una puesta en práctica. Como resultado se obtienen dos tareas posicionadas: tp14 y tp15.

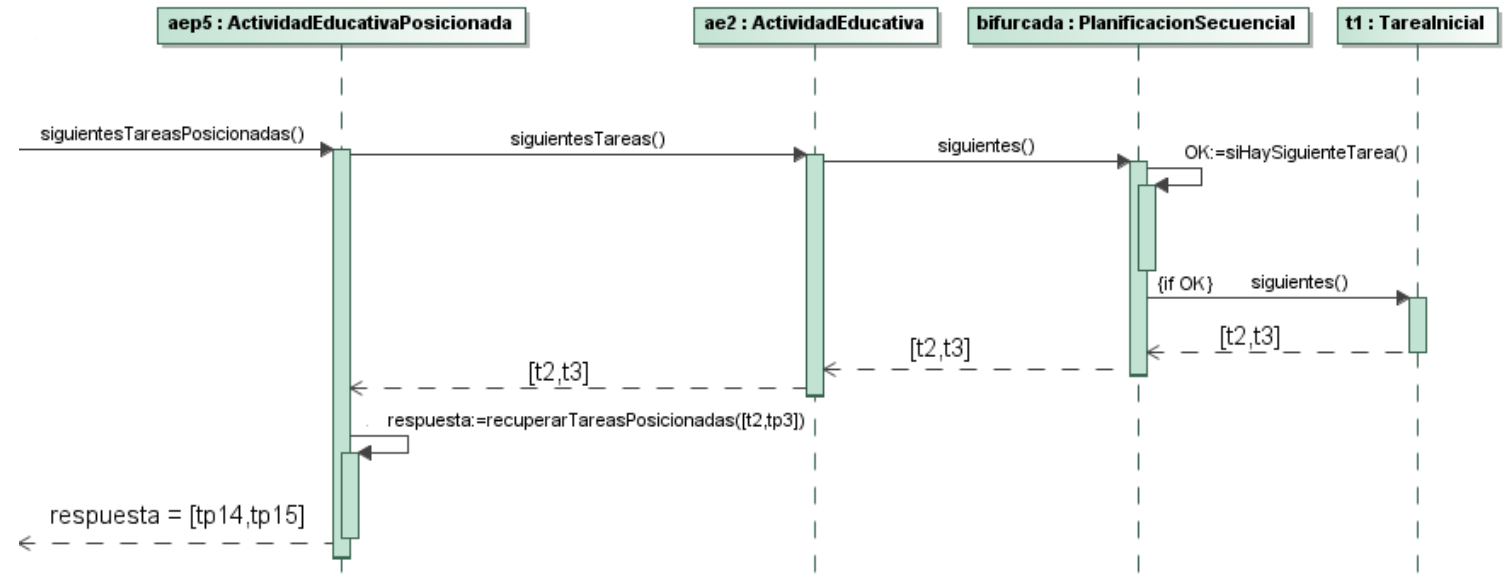

Figura 3.35: Diagrama de secuencia para obtener las siguientesTareasPosicionadas para la AEP5

Se puede apreciar en las Figuras 3.34 y 3.35, que al tener ambas la misma AE (ae2), el método siguientesTareas(), genera como resultado una colección con las tareas t2 y t3. La diferencia entre ambas figuras, se manifiesta en las tareas posicionadas resultantes.

En los diagramas de secuencia introducidos previamente, se puede apreciar el comportamiento polimórfico. Se puede observar que ante diferentes instanciaciones de 
los modelos, se obtienen tareas posicionadas como respuesta del método siguientesTareasPosicionadas().

Cabe mencionar que el contenido para la instanciación de los modelos, es responsabilidad del experto en educación. Dependerá de esta instanciación lo que se le brinde al alumno durante la puesta en práctica de la actividad. 
Página 64 de 167 


\section{Prototipo ¡Aprendo Jugando!}

En este capítulo se presenta el análisis de un dominio particular para la instanciación del enfoque propuesto en el Capítulo 3. Dicho dominio contempla AEP en las que las tareas posicionadas involucran elementos concretos que el alumno debe recolectar y posteriormente depositar de acuerdo a un criterio (en particular, relacionado el tipo de material). A partir de este análisis se decidió extender los modelos propuestos en el Capítulo 3, para sumar expresividad. En base a esta extensión, se implementó un prototipo (en Android) que en particular instancia la extensión del modelo propuesto con una AEP cuya $A E$ posee una planificación secuenciada con bifurcación que contempla tareas en las que el alumno debe recolectar elementos y otras tareas, en las que se deben depositar los elementos recolectados. El prototipo fue planteado como una actividad lúdica, para poner en práctica los conocimientos construidos en el ámbito escolar.

\subsection{Extensión del modelo en base al dominio particular}

En esta sección se presenta un dominio que contempla una AEP en la que las tareas posicionadas involucran elementos concretos que el alumno debe recolectar y posteriormente depositar de acuerdo a un criterio. A partir del mismo, se analizará si el enfoque propuesto en el Capítulo 3 debe ser extendido para lograr mayor expresividad.

A continuación se van a presentar de manera incremental los conceptos relevantes para este dominio.

Se identificaron consignas que involucran recolectar elementos como también consignas que involucran depositarlos. En la Figura 4.1, se presentan ejemplos de posibles consignas que, en su enunciado, indican la recolección o depósito de elementos. En la Figura 4.1.a, se presenta una consigna que involucra recolectar elementos, mientras que en la Figura 4.1.b se visualiza una consigna que involucra depositar elementos previamente recolectados.

a.

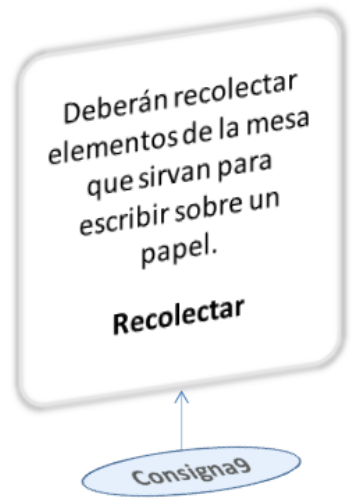

b.

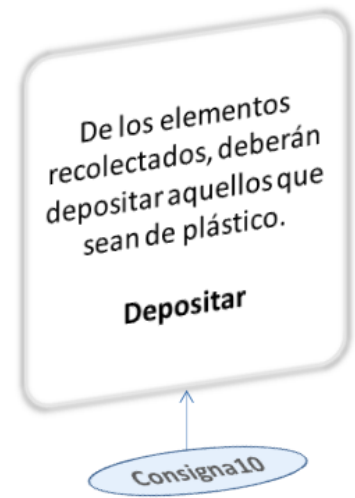

Figura 4.1: Ejemplo de enunciados de consignas que involucran recolectar o depositar elementos 
Acorde al enfoque propuesto en el Capítulo 3, se podrían enunciar los ejemplos de la Figura 4.1 empleando componentes textuales (Texto), sin embargo, las acciones de recolectar o depositar implican la necesidad de interacción por parte del alumno similar a lo que ocurre con el componente DeGeneracion. Por esta razón, se decidió modelar la clase abstracta componente DeManipulacion y dos clases concretas: Recolectar y Depositar. Esta extensión, se puede visualizar en la Figura 4.2.

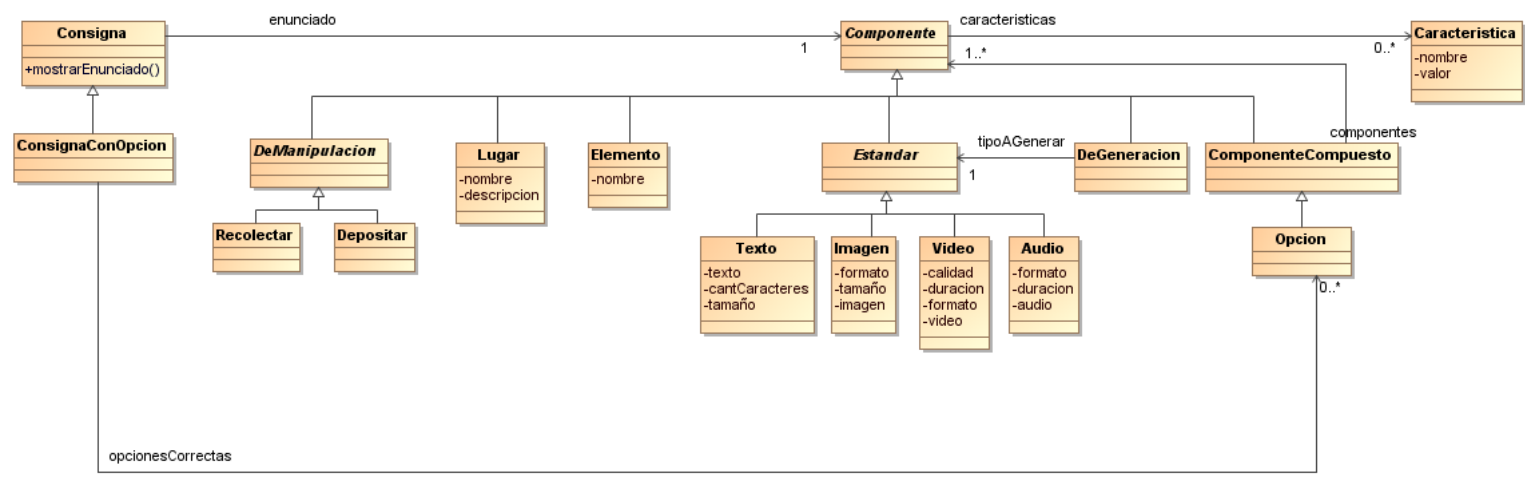

Figura 4.2: Modelado de las componentes DeManipulacion

Cuando el enunciado de una consigna (de una tarea) involucra depositar elementos, puede requerir, adicionalmente, indicar en qué lugar se debe realizar dicho depósito. Se puede pensar al depósito como un lugar destacado, para el cual se conoce, entre otras cosas, los tipos de material que pueden ser depositados en él. Por otro lado, los elementos podrían conocer los tipos de materiales con los que están elaborados (por ejemplo, plástico). De este modo, se podrían tener enunciados de consignas como las que se presentan en la Figura 4.3. En la Figura 4.3.a, se indica que el tipo de material que se puede dejar en ese depósito es plástico, mientras que en la Figura 4.3.b se indica que el elemento está elaborado con plástico.

a.

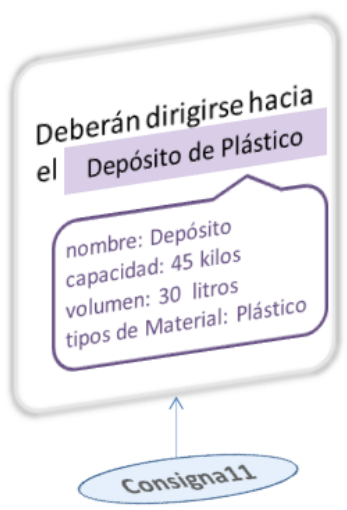

b.

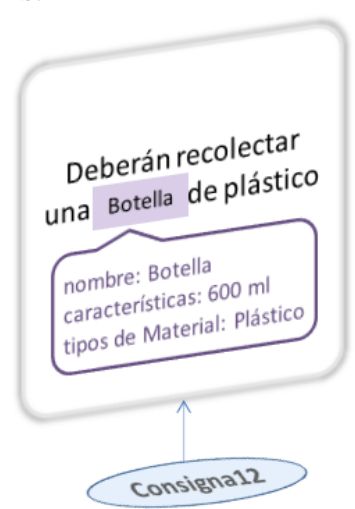

Figura 4.3: Ejemplo de enunciados de consignas que destacan el tipo de material tanto del depósito como del elemento 
Si bien el tipo de material (tanto del depósito como del elemento en la Figura 4.3) podría ser representado, con el modelo del Capítulo 3, como una característica, sería deseable, poder realizar validaciones respecto al tipo de material que acepta un depósito en relación al tipo de material del elemento dejado en el mismo. Por esto, se decidió, modelar la clase TipoDeMaterial. Para lograr expresividad, se decidió además, modelar la clase Deposito como una subclase de Lugar. Lo antes descripto se puede apreciar en la Figura 4.4. Notar que el Deposito conoce los tipos de materiales que pueden ser depositados en él. Mientras que cualquier Elemento conoce a los tipos de material con los que está elaborado.

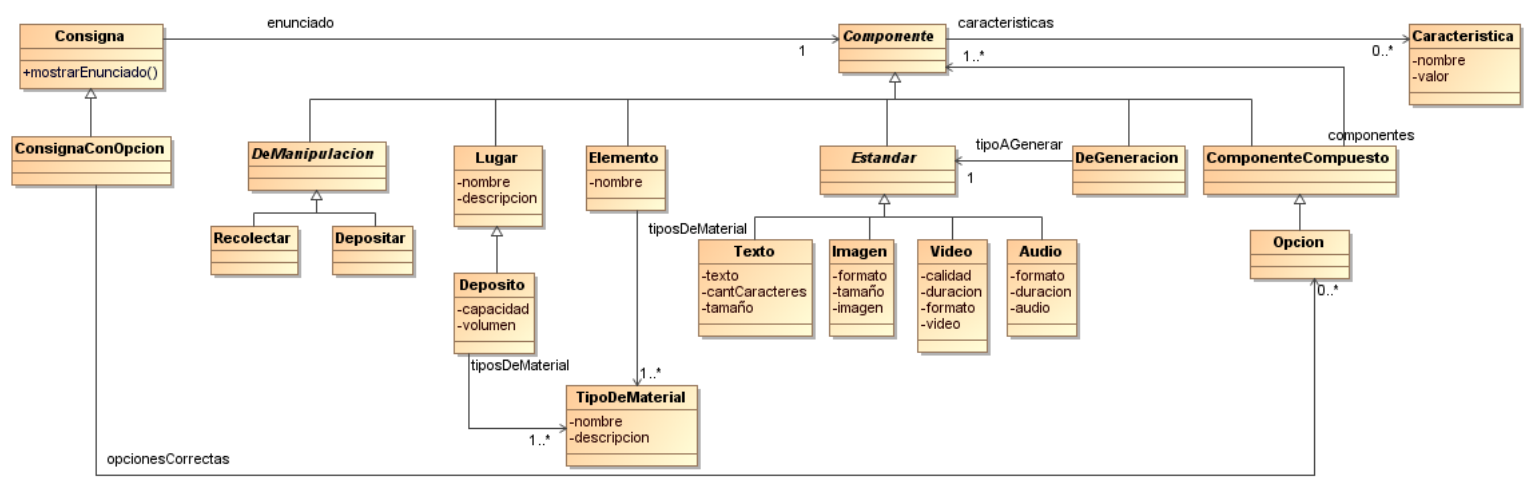

Figura 4.4: Modelado del lugar de depósito y el tipo de material

Analicemos ahora que conceptos deben ser representados en el modelo de AEP acorde al dominio que se quiere instanciar en este capítulo.

Al incorporar el concepto de lugar de depósito al modelo de $A E$, este mismo se puede extrapolar para las AEP. En este caso, un depósito posicionado, conocerá la definición general del depósito y además podrá tener características propias. En la Figura 4.5 se visualiza un ejemplo de un depósito posicionado, se puede apreciar que éste posee una característica particular que está relacionada con la capacidad disponible.

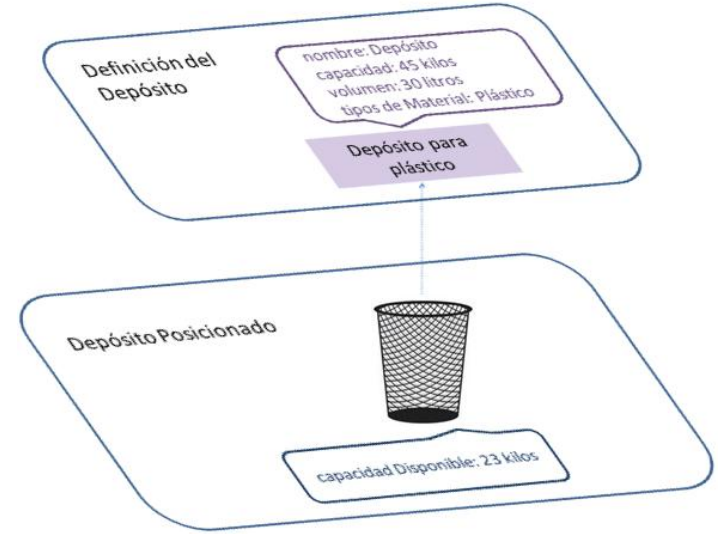

Figura 4.5: Ejemplo de depósito posicionado 
Acorde a lo mostrado en la Figura 4.5, se decidió modelar el DepositoPosicionado, como una extensión del LugarPosicionado. Esto se puede apreciar en la Figura 4.6. Notar en esta figura, que la clase DepositoPosicionado hereda las relaciones lugar y caracteristicas. En particular, al momento de su instanciación, la relación lugar tomará como valor una instancia de la clase Deposito.

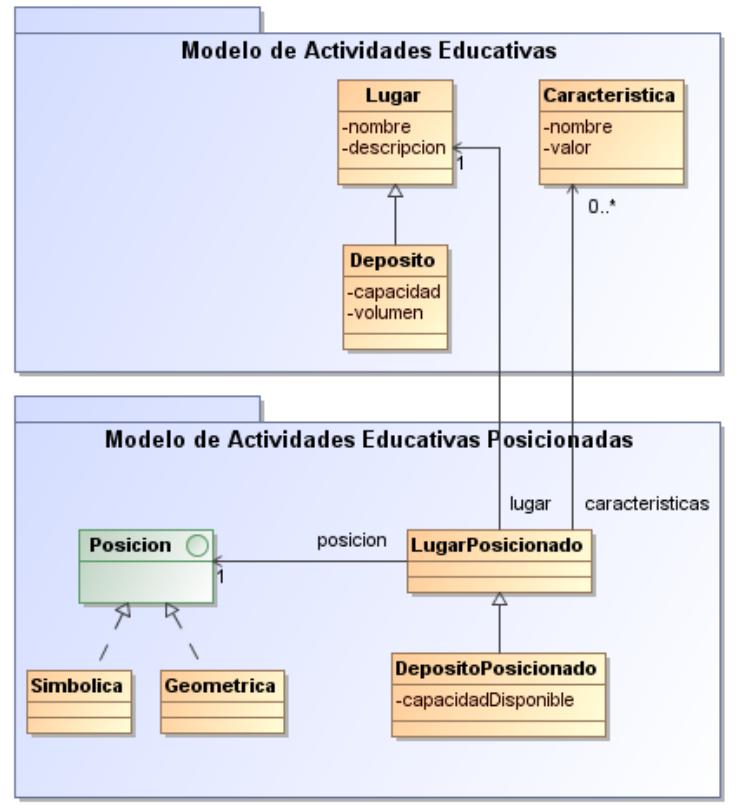

Figura 4.6: Modelado del DepositoPosicionado

En el modelo de AEP no es necesario representar ningún otro concepto adicional, solo se incorporó el DepositoPosicionado. Analicemos ahora el modelo del usuario, para ver que conceptos se deben representar en el dominio que se viene presentando.

Acorde a las nuevas componentes para enunciar consignas de tareas (incorporadas en el modelo de $A E$ ), surgen nuevas formas de responder por parte del grupo. Se decidió modelar las respuestas de manipulación con el objetivo de poder registrar que recolecta o que deposita en cada caso. De este modo se propone la extensión de RespuestaAbstracta, con la clase RespuestaDeManipulacion. En la Figura 4.7, se presenta la extensión mencionada. Notar que, para las respuestas que involucran manipulación por parte del grupo, se registran los elementos concretos involucrados en cada caso. 


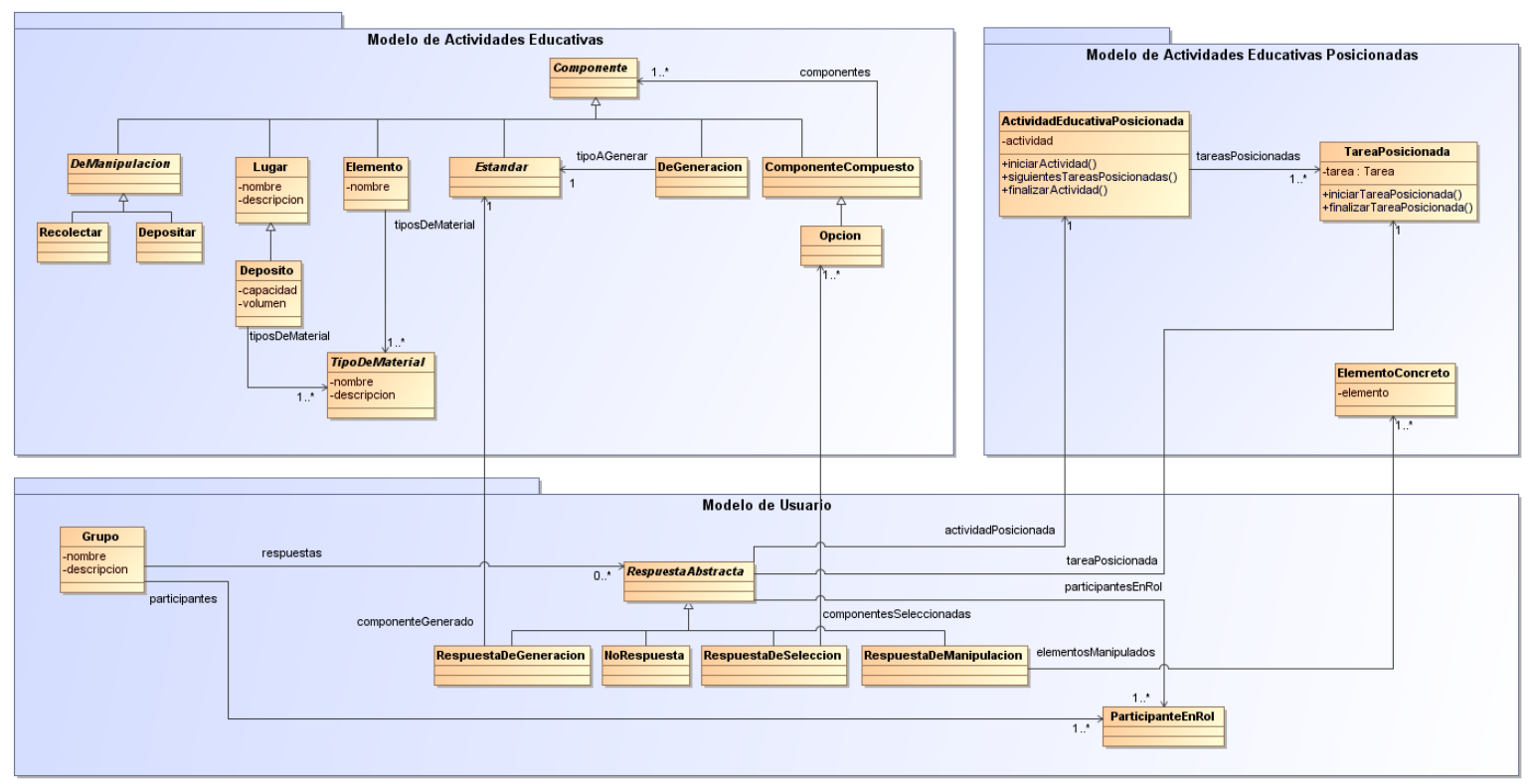

Figura 4.7: Modelado de la RespuestaDeManipulacion

Notar que en la Figura 4.7, si bien existe la respuesta de manipulación desde una perspectiva general, es posible saber si los elementos asociados fueron recolectados o depositados a través del enunciado de la consigna de la tarea que se está respondiendo.

A continuación se presentarán los tres modelos extendidos destacando los conceptos incorporados que se fueron mencionando anteriormente. Cabe destacar que el modelo extendido permite instanciar cualquier actividad educativa posicionada que involucre recolección y depósito de elementos concretos. Esto es posible porque dicho modelo esta expresado de manera general.

En la Figura 4.8, se presenta el modelo de AE extendido, en la Figura 4.9 el modelo de AEP extendido mientras que en la Figura 4.10 el modelo de Usuario extendido. En cada uno de ellos se destacan las clases introducidas en la extensión propuesta para el dominio presentado. 


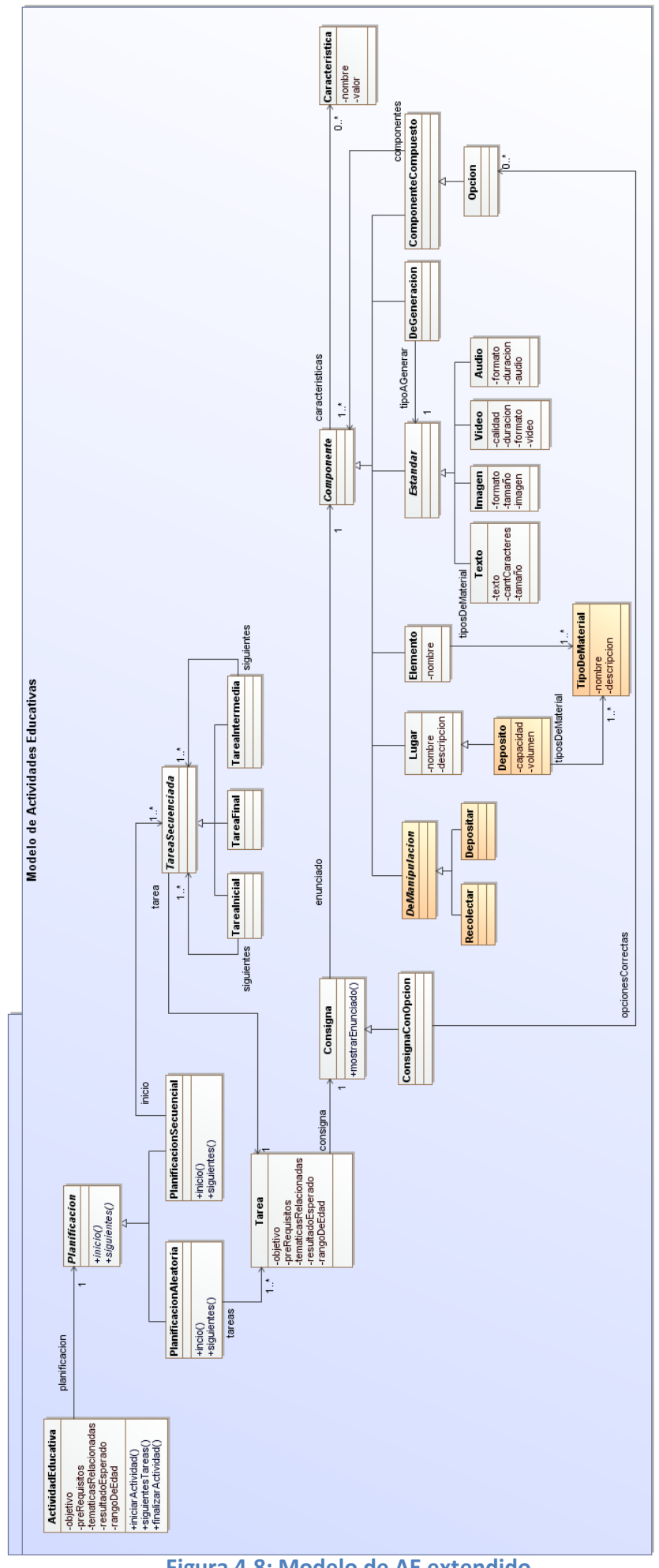

Figura 4.8: Modelo de AE extendido 


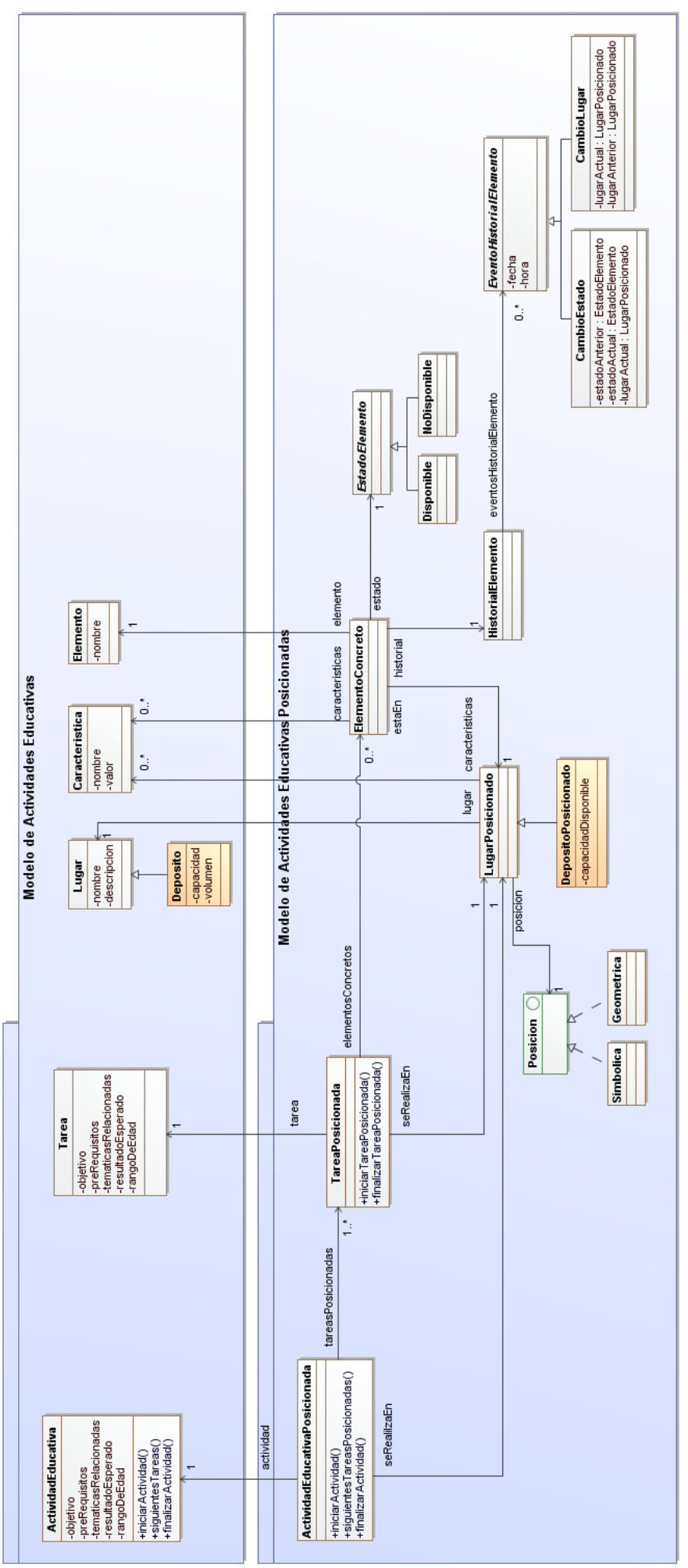

Figura 4.9: Modelo de AEP extendido 


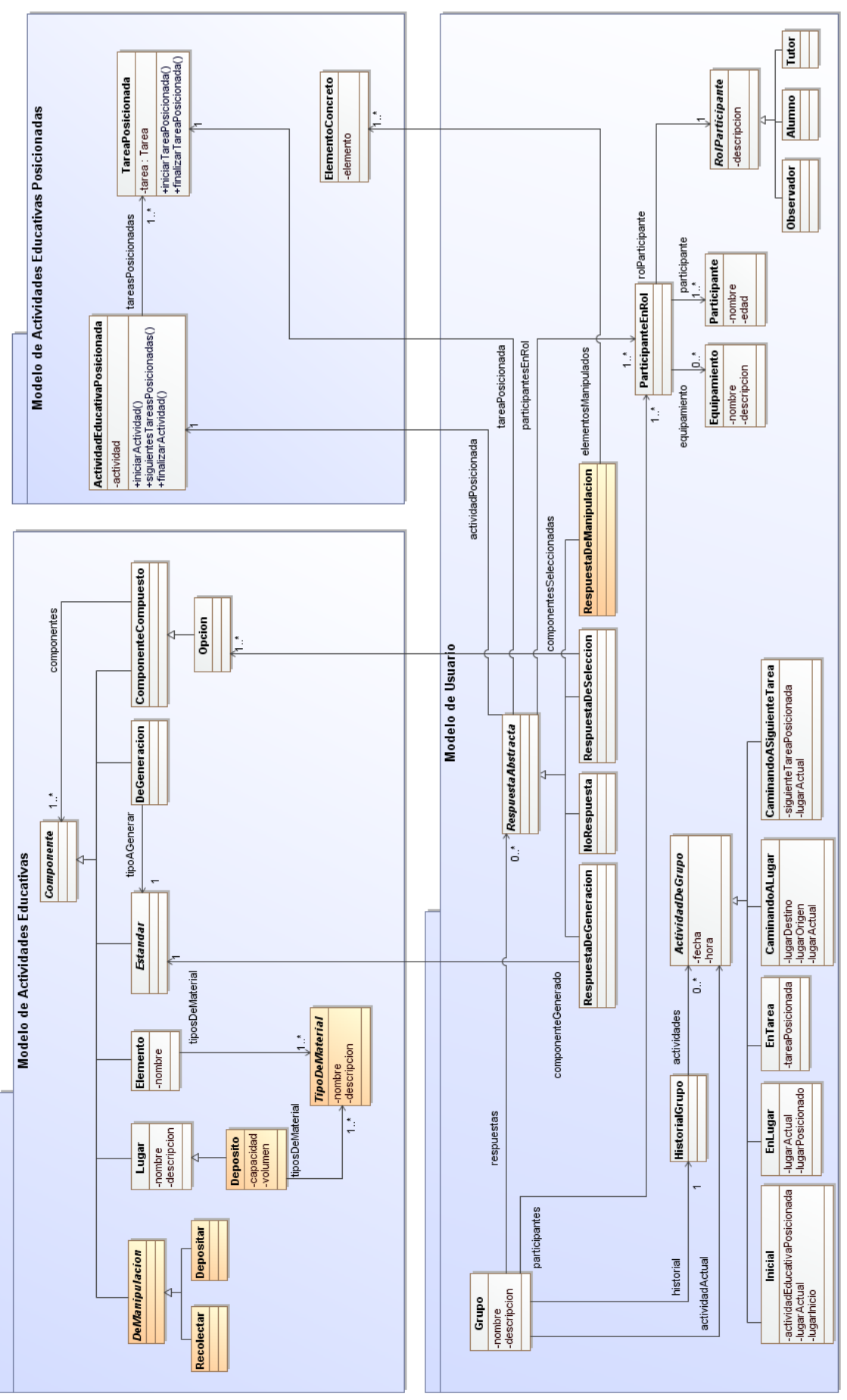

Figura 4.10: Modelo del Usuario extendido 


\subsection{Prototipado}

En esta sección, se realiza una descripción de los conceptos más relevantes que serán empleados para instanciar una AEP con el modelo propuesto en la Sección 4.1. Luego se presentará el prototipo que utiliza esta instanciación y se mostrarán algunas interacciones del mismo.

El prototipo está presentado como un juego, esto se realizó en base a lo planteado en [Ying et al., 2009], donde los autores mencionan que una problemática de las aplicaciones móviles educativas es la motivación del alumno al usarlas. Como una solución a esta problemática, estos autores proponen plantear este tipo de aplicaciones como juegos. Esta solución tiene sustento en el trabajo presentado por [Malone and Lepper, 1987] y [Prensky, 2001] donde se destaca la relevancia del uso de juegos para motivar a los alumnos en el proceso de aprendizaje.

\subsubsection{Definición de la AEP utilizada en el prototipo}

En esta sección, como se mencionó anteriormente, se describirán aquellos conceptos usados para instanciar el modelo propuesto en la Sección 4.1.

En relación al modelo de $A E$, se decidió instanciar el modelo propuesto en la Sección 4.1, con una ActividadEducativa (siendo una actividad educativa de recolección y depósito, Ilamada $A E-R D$ ) con las siguientes características:

- objetivo: Que el alumno recupere y enriquezca la noción de tipos de material (cartón/papel, plástico y metal), a partir del reconocimiento de elementos de su vida diaria (por ejemplo una hoja de cuaderno), reconociendo y trabajando la idea de que los elementos de la vida diaria están constituidos por materiales que condicionan sus usos. Facilitar la distinción entre elemento y uso. Fomentar la discusión y la manipulación de elementos para su análisis y clasificación.

- preRequisitos: Previo a esta actividad, al alumno se le presentaron ejemplos en los que se les mostró la diferencia entre el uso de un elemento y el elemento en sí mismo. Se le presentaron ejemplos de elementos elaborados con diferentes tipos de materiales y se le facilitó el espacio para que explore y construya estos conceptos.

- tematicasRelacionadas: Los Materiales y sus Cambios $^{17}$; Geometría y

\footnotetext{
17 "Los Materiales y sus Cambios" (área Ciencias Naturales): Eje temático extraído de la Dirección Nacional de Gestión Curricular y Formación Docente, Ministerio de Educación, Presidencia de la Nación. http://www.me.gov.ar/curriform
} 
Medidas ${ }^{18}$.

- resultadoEsperado: Que el alumno pueda identificar elementos que cumplan una consigna, considerando el uso que se le puede dar al elemento. Que el alumno pueda determinar el o los tipos de materiales predominantes en la elaboración de un elemento para su clasificación en el depósito correcto. Que el alumno pueda discutir con sus pares para arribar a una decisión conjunta. COMPRENSION, ANÁLISIS Y APLICACION ${ }^{19}$.

- rangoDeEdad: de siete a once años (etapa operacional concreta ${ }^{20}$ ).

Se destaca que, el criterio usado en la $A E-R D$ para definir los valores de tematicasRelacionadas, resultadoEsperado y rangoDeEdad, también es empleado para todas las tareas definidas a continuación.

Se decidió instanciar tres tareas que involucran la recolección de elementos, tres tareas para depositar dichos elementos y una tarea de finalización de la AE-RD.

Para la primera tarea de recolección, llamémosla TR1, se definieron las siguientes características:

- objetivo: Facilitar la distinción entre elemento y uso. Fomentar la discusión y la observación de elementos para el análisis de su potencial uso. Acompañar al alumno para que reconozca que elementos puede usar como materia prima para elaborar papel reciclado. Mostrar las bondades del reciclado acercando al alumno a su naturalización en su ámbito directo, por ejemplo, su casa.

- preRequisitos: Previo a esta tarea, al alumno se le presentaron ejemplos en los que se les mostró la diferencia entre el uso de un elemento y el elemento en sí mismo. Se le presentaron ejemplos de elementos elaborados con diferentes tipos de materiales y se le facilitó el espacio para que explore y construya estos conceptos. Es deseable poder experimentar en el aula como hacer papel reciclado.

- tematicasRelacionadas: Los Materiales y sus Cambios.

- resultadoEsperado: Identificar los elementos que pueden ser usados en la elaboración de papel reciclado Que el alumno pueda discutir con sus pares para arribar a una decisión conjunta. COMPRENSION, APLICACIÓN Y ANÁLISIS.

\footnotetext{
18 "Geometría y Medida" (área Matemática): Eje temático extraído de la Dirección Nacional de Gestión Curricular y Formación Docente, Ministerio de Educación, Presidencia de la Nación. http://www.me.gov.ar/curriform

${ }^{19}$ Conceptos definidos en base a la taxonomía de Bloom [Bloom and Krathwohl, 1956].

${ }^{20}$ Contemplando lo definido por Piaget [Piaget, 1965]
} 
- rangoDeEdad: de siete a once años (etapa operacional concreta).

El enunciado de la consigna con opción de la tarea de recolección TR1, se presenta en la Figura 4.11. Notar que, el mismo está compuesto por las componentes Texto y Recolectar. Se decidió representar la consigna con opción (ConsignaConOpcion), ya que se desea poder controlar, posteriormente durante una puesta en práctica, si los elementos recolectados son los correctos para dicha consigna.

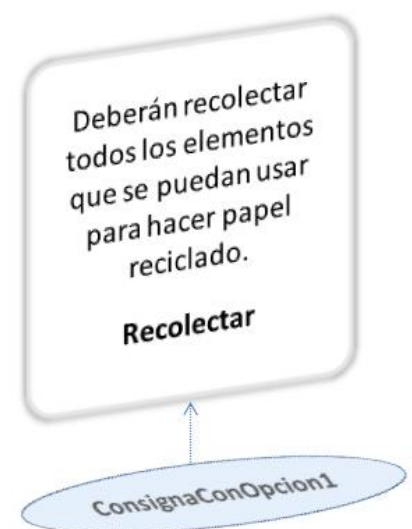

Figura 4.11: Enunciado de la consigna para la tarea TR1

Como se mencionó anteriormente, para poder validar posteriormente la respuesta a la consigna de la TR1, es necesario saber cuáles de los elementos recolectados son correctos. Es por esto, que las opcionesCorrectas de la clase ConsignaConOpcion, se instancian con los elementos correctos. Para cada elemento se indica en este caso, el nombre del elemento y el tipo de material con el que está elaborado. En la Figura 4.12 se presentan los elementos correctos para la consigna con opción de la tarea TR1 (introducida en la Figura 4.11).

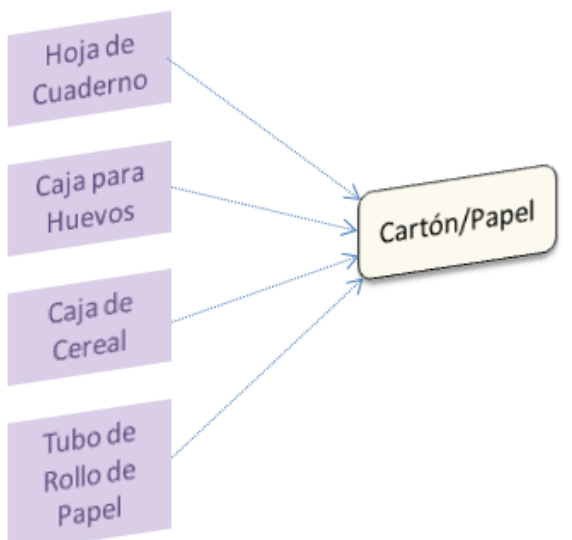

Figura 4.12: Descripción de los elementos que conforman opciones correctas en la TR1 
Notar en la Figura 4.12 que el tipo de material se reusa para la definición de los diferentes elementos. Esto mismo sucederá para todos los elementos que se definan para todas las tareas.

En la segunda tarea de recolección, a la cual llamaremos TR2, se definieron las siguientes características:

- objetivo: Facilitar la distinción entre elemento y uso. Fomentar la discusión y la observación de elementos para el análisis de su potencial uso. Reconocer y trabajar la idea de que los elementos de la vida diaria están constituidos por materiales que condicionan sus usos.

- preRequisitos: Previo a esta tarea, al alumno se le presentaron ejemplos en los que se les mostró la diferencia entre el uso de un elemento y el elemento en sí mismo. Se le presentaron ejemplos de elementos elaborados con diferentes tipos de materiales y se le facilitó el espacio para que explore y construya estos conceptos.

- tematicasRelacionadas: Los Materiales y sus Cambios.

- resultadoEsperado: Identificar los elementos que pueden ser usados para contener líquidos. Que el alumno pueda discutir con sus pares para arribar a una decisión conjunta. COMPRENSIÓN, APLICACIÓN Y ANÁLISIS.

- rangoDeEdad: de siete a once años (etapa operacional concreta).

El enunciado de la consigna con opción de la TR2, se presenta en la Figura 4.13. Este enunciado también se genera a partir de las componentes de Texto y Recolectar. En dicha figura, se muestran los elementos que el grupo debería recolectar para resolverla correctamente. Notar que en este caso, se representan dos tipos de material diferente.

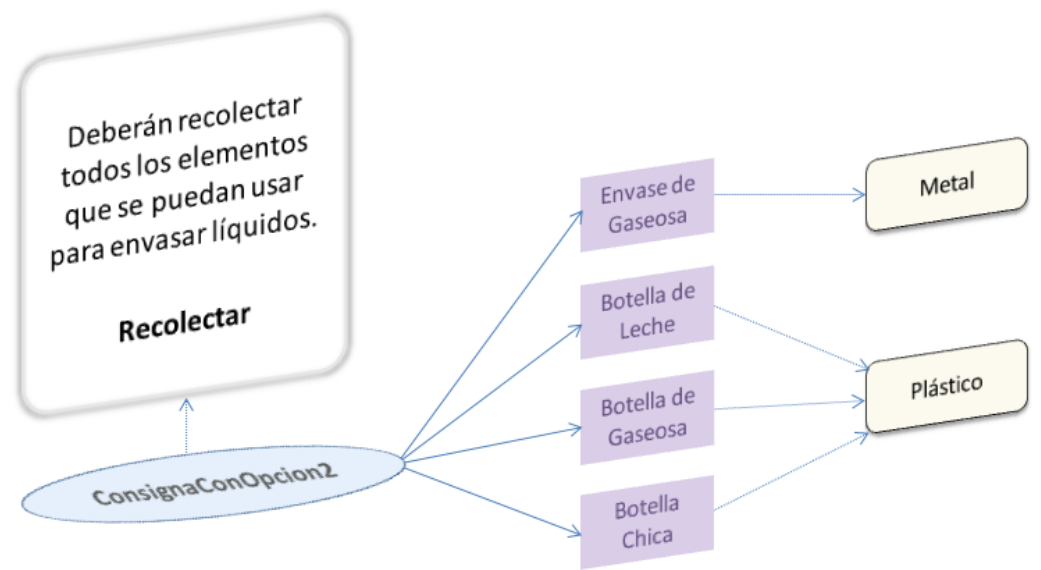

Figura 4.13: Enunciado de la consigna para la tarea TR2 y sus elementos 
La tercera tarea de recolección, denominada TR3, tiene las siguientes características:

- objetivo: Facilitar la distinción entre elemento y uso. Fomentar la discusión y la observación de elementos para el análisis de su potencial uso.

- preRequisitos: Previo a esta tarea, al alumno se le presentaron ejemplos en los que se les mostró la diferencia entre el uso de un elemento y el elemento en sí mismo. Se le presentaron ejemplos de elementos elaborados con diferentes tipos de materiales y se le facilitó el espacio para que explore y construya estos conceptos.

- tematicasRelacionadas: Los Materiales y sus Cambios ; Geometría y Medida.

- resultadoEsperado: Identificar los elementos que pueden ser usados para medir (de forma directa) empleando la unidad de medida centímetros. Que el alumno pueda discutir con sus pares para arribar a una decisión conjunta. COMPRENSIÓN, APLICACIÓN Y ANÁLISIS.

- rangoDeEdad: de siete a once años (etapa operacional concreta).

El enunciado de la consigna con opción de la tarea TR3, se presenta en la Figura 4.14. Dicho enunciado está compuesto por componentes de Texto y Recolectar. En dicha figura, se presentan además los elementos para las opciones correctas de la consigna con opción.

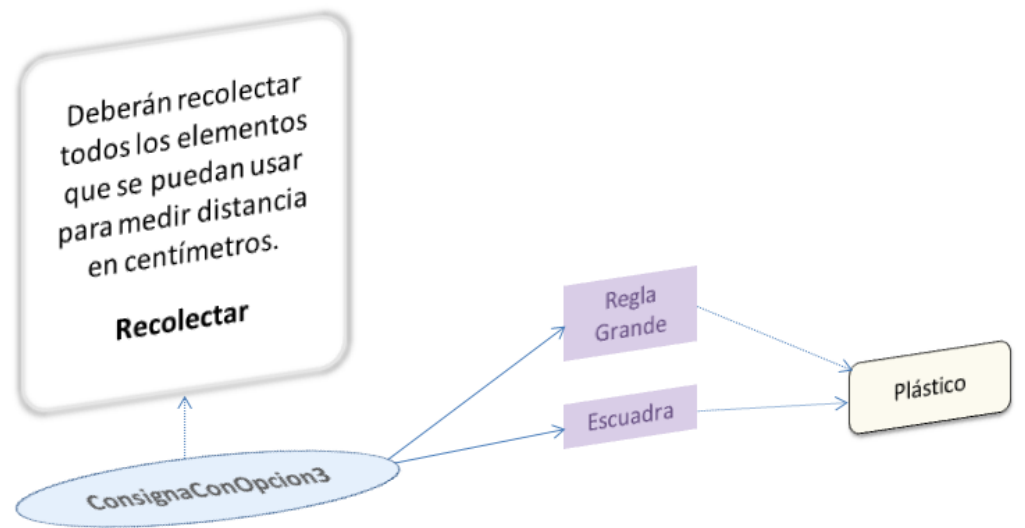

Figura 4.14: Enunciado de la consigna para la tarea TR3

A continuación se describirán las tres tareas para depositar definidas para la AE-RD.

Las características de una de las tareas para depositar definida y llamada TD1 son:

- objetivo: Que el alumno recupere y enriquezca la noción de tipos de material (cartón/papel), a partir del reconocimiento de elementos de su vida diaria (por ejemplo una hoja de cuaderno), reconociendo el tipo de material para agruparlos. 
- preRequisitos: Previo a esta tarea, al alumno se le presentaron ejemplos en los que se les mostró la diferencia entre el uso de un elemento y el elemento en sí mismo. Se le presentaron ejemplos de elementos elaborados con diferentes tipos de materiales y se le facilitó el espacio para que explore y construya estos conceptos.

- tematicasRelacionadas: Los Materiales y sus Cambios.

- resultadoEsperado: Que el alumno pueda determinar el o los tipos de materiales predominantes en la elaboración de un elemento para su clasificación en el depósito de cartón/papel. Que el alumno pueda discutir con sus pares para arribar a una decisión conjunta. COMPRENSIÓN, APLICACIÓN Y ANÁLISIS.

- rangoDeEdad: a partir de siete años.

Para las tareas de depositar, se decidió componer los enunciados empleando componentes de Deposito, Texto y Depositar. Notar que, en las tareas para depositar, la consigna no cuenta con opciones, sino que se hará una validación en base a lo que un grupo posteriormente responda para resolverla. Esta validación se realizará acorde al tipo de depósito involucrado. El enunciado de la consigna para la tarea TD1, se presenta en la Figura 4.15. En este enunciado, se emplea un Deposito que admite el TipoDeMaterial "Cartón/Papel".

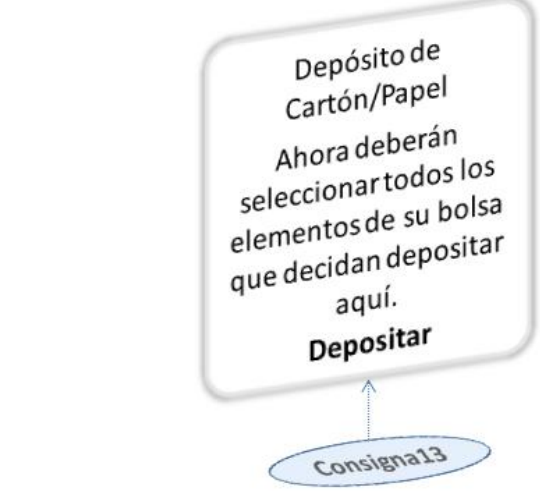

Figura 4.15: Enunciado de la consigna para la tarea TD1

La segunda tarea para depositar, denominada TD2, se definió con las siguientes características:

- objetivo: Que el alumno recupere y enriquezca la noción de tipos de material (plástico), a partir del reconocimiento de elementos de su vida diaria (por ejemplo una botella de gaseosa plástica), reconociendo el tipo de material para agruparlos. 
- preRequisitos: Previo a esta tarea, al alumno se le presentaron ejemplos en los que se les mostró la diferencia entre el uso de un elemento y el elemento en sí mismo. Se le presentaron ejemplos de elementos elaborados con diferentes tipos de materiales y se le facilitó el espacio para que explore y construya estos conceptos.

- tematicasRelacionadas: Los Materiales y sus Cambios.

- resultadoEsperado: Que el alumno pueda determinar el o los tipos de materiales predominantes en la elaboración de un elemento para su clasificación en el depósito de plástico. Que el alumno pueda discutir con sus pares para arribar a una decisión conjunta. COMPRENSIÓN, APLICACIÓN Y ANÁLISIS.

- rangoDeEdad: a partir de siete años.

El enunciado de la consigna para la tarea TD2, se presenta en la Figura 4.16. En este enunciado, se emplea un Deposito que admite el TipoDeMaterial "Plástico".

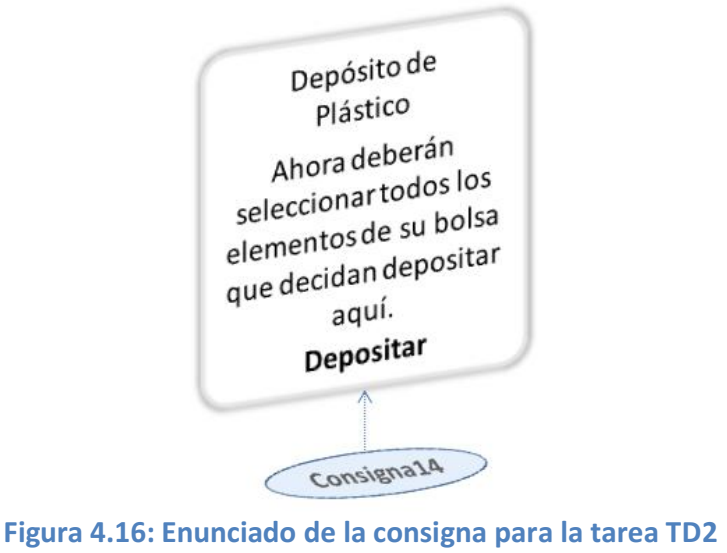

Por último, se presentan las características de la tercera tarea para depositar, llamada TD3.

- objetivo: Que el alumno recupere y enriquezca la noción de tipos de material (metal), a partir del reconocimiento de elementos de su vida diaria (por ejemplo una lata de tomate), reconociendo el tipo de material para agruparlos.

- preRequisitos: Previo a esta tarea, al alumno se le presentaron ejemplos en los que se les mostró la diferencia entre el uso de un elemento y el elemento en sí mismo. Se le presentaron ejemplos de elementos elaborados con diferentes tipos de materiales y se le facilitó el espacio para que explore y construya estos conceptos. 
- tematicasRelacionadas: Los Materiales y sus Cambios.

- resultadoEsperado: Que el alumno pueda determinar el o los tipos de materiales predominantes en la elaboración de un elemento para su clasificación en el depósito de metal Que el alumno pueda discutir con sus pares para arribar a una decisión conjunta. COMPRENSIÓN, APLICACIÓN Y ANÁLISIS.

- rangoDeEdad: a partir de siete años.

El enunciado de la consigna para la tarea TD3, se muestra en la Figura 4.16. En este enunciado, se emplea un Deposito que admite el TipoDeMaterial "Metal".

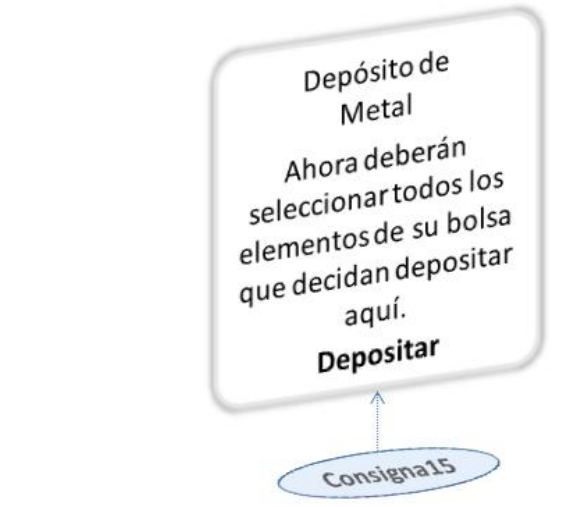

Figura 4.17: Enunciado de la consigna para la tarea TD3

La tarea de finalización de la $A E-R D$, llamada $T F$, se definió con las siguientes características:

- objetivo: Mostrarle al alumno su desempeño durante la puesta en práctica de la $A E$, para que esto pueda ser usado para conocer sus debilidades y fortalezas en la temática y en base a esto, revisitar conceptos en el aula.

- preRequisitos: Haber visitado, al menos, las diferentes tareas de recolección propuestas.

- tematicasRelacionadas: Los Materiales y sus Cambios; Geometría y Medidas.

- resultadoEsperado: Que el alumno pueda identificar sus fortalezas y debilidades en las temáticas relacionadas. COMPRENSIÓN.

- rangoDeEdad: a partir de siete.

Respecto a la planificación de la AE-RD, se decidió, realizar una PlanificacionSecuencial bifurcada, relacionando las tareas previamente enunciadas. Para una mejor presentación de la planificación, se decidió presentarla considerando una tarea de inicio y las transiciones válidas a otras tareas previamente definidas. Notar que, la planificación secuencial, se realiza a partir de instancias de la clase TareasSecuenciada. 
La planificación para la $A E-R D$, posee una única tarea secuenciada inicial, que conoce a la TR1. Se comenzará a describir las transiciones válidas ${ }^{21}$, a partir de esta tarea. En la Figura 4.18, se visualizan las transiciones válidas desde TR1. A partir de esta figura, se visualiza que desde la TR1 existen cuatro transiciones válidas.

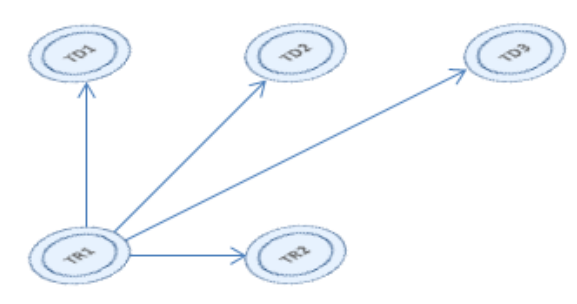

Figura 4.18: Transiciones válidas desde la TR1

Veamos en detalle cada una de las cuatro transiciones visualizadas en la Figura 4.18. Primero se analizan las tres transiciones que van a tareas de depósito para luego analizar la transición que va a la tarea de recolección TR2.

- Transición TR1 a la TD1. Al tomar esta opción pasan a ser válidas las transiciones visualizadas en la Figura 4.19. Desde la TD1 es posible ir hacia la TD2, o bien hacia la TD3 y en caso de realizar la TD1 y finalizarla, es posible volver a realizar dicha tarea (TD1). Otra transición válida es desde la TD1 hacia la TR2, es decir seguir recolectando.

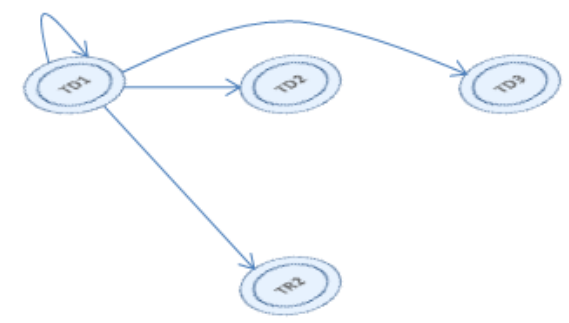

Figura 4.19: Transiciones válidas desde TD1 luego de haber realizado TR1

- Transición TR1 a la TD2. Al tomar esta opción pasan a ser válidas las transiciones visualizadas en la Figura 4.20. Desde la TD2 es posible ir hacia la TD1, o bien hacia la TD3 y en caso de realizar la TD2 y finalizarla, es posible volver a realizar dicha tarea (TD2). Otra transición válida es desde la TD2 hacia la TR2 la que habilita para continuar recolectando.

\footnotetext{
${ }^{21}$ Notar que por simplicidad en la redacción, se hace abuso del lenguaje y se habla de la tarea cuando se debería hablar de la tarea secuenciada.
} 


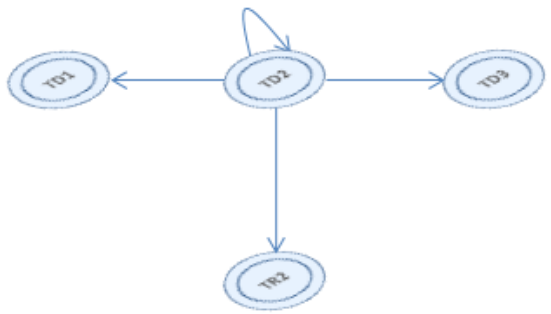

Figura 4.20: Transiciones válidas desde TD2 luego de haber realizado TR1

- Transición TR1 a la TD3. Al tomar esta opción pasan a ser válidas las transiciones visualizadas en la Figura 4.21. Desde la TD3 es posible ir hacia la TD1, o bien hacia la TD2 y en caso de realizar la TD3 y finalizarla, es posible volver a realizar dicha tarea (TD3). Otra transición válida es desde la TD3 hacia la TR2 para seguir con las tareas de recolección.

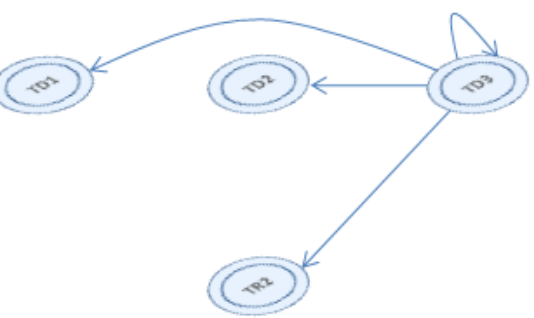

Figura 4.21: Transiciones válidas desde TD3 luego de haber realizado TR1

- Transiciones a la TR2. Independientemente de la manera que en la que se llegue a la tarea de recolección TR2 (es decir, ya sea porque se viene de la TR1 o bien desde alguna de las tareas de depósito), las transiciones válidas desde la TR2 se muestran en la Figura 4.22.

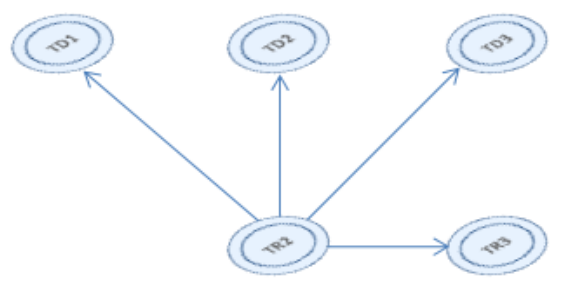

Figura 4.22: Transiciones válidas desde TR2

Una vez realizada la TR2, en la Figura 4.22 se mostraron las opciones que constituyen transiciones válidas, veamos en detalle cada una de estas, primero analizando las tres que van a tareas de depósito para luego analizar la transición que va a la TR3.

- Transición TR2 a la TD1. Al tomar esta opción pasan a ser válidas las transiciones visualizadas en la Figura 4.23. Desde la TD1 es posible ir hacia la TD2, o bien hacia la TD3 y en caso de realizar la TD1 y finalizarla, es posible volver a realizar 
dicha tarea. Otra transición válida es desde la TD1 hacia la TR3 para seguir recolectando.

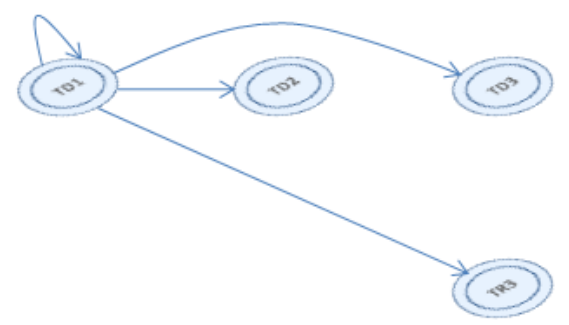

Figura 4.23: Transiciones válidas desde TD1 luego de haber realizado TR2

- Transición TR2 a la TD2. Al tomar esta opción pasan a ser válidas las transiciones visualizadas en la Figura 4.24. Desde la TD2 es posible ir hacia la TD1, o bien hacia la TD3 y en caso de realizar la TD2 y finalizarla, es posible volver a realizar dicha tarea. Otra transición válida es desde la TD2 hacia la TR3, para continuar recolectando.

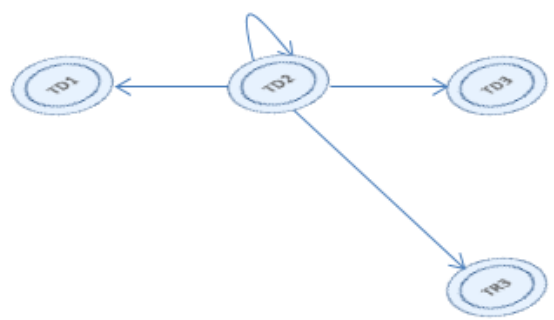

Figura 4.24: Transiciones válidas desde TD2 luego de haber realizado TR2

- Transición TR2 a la TD3. Al tomar esta opción pasan a ser válidas las transiciones visualizadas en la Figura 4.25. Desde la TD3 es posible ir hacia la TD1, o bien hacia la TD2 y en caso de realizar la TD3 y finalizarla, es posible volver a realizar dicha tarea. Otra transición válida es desde la TD3 hacia la TR3, la cual permite seguir recolectando.

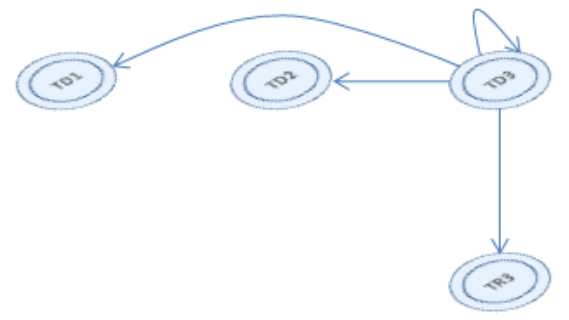

Figura 4.25: Transiciones válidas desde TD3 luego de haber realizado TR2 
- Transiciones a la TR3. Independientemente de la manera en la que se llegue a la tarea de recolección TR3 (es decir, ya sea porque se viene de la TR2 o bien desde alguna de las tareas de depósito), las transiciones válidas desde la TR3 se muestran en la Figura 4.26 .

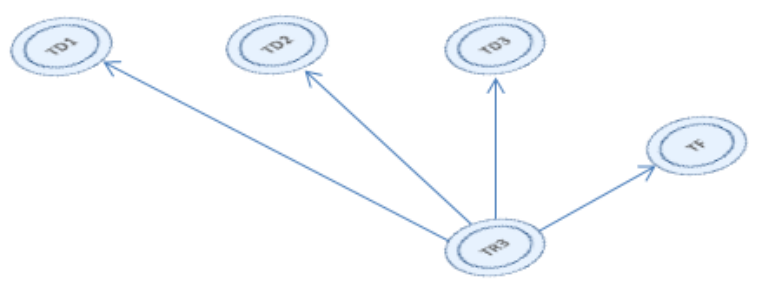

Figura 4.26: Transiciones válidas desde la TR3

Una vez realizada la TR3, se podrá optar por la tarea de finalización (TF) o bien dirigirse hacia alguna de las tareas de depositar como se mostró en la Figura 4.26. Veamos en detalle las transiciones válidas desde TR3.

- Transición TR3 a la TD1. Al tomar esta opción pasan a ser válidas las transiciones visualizadas en la Figura 4.27. Desde la TD1 es posible ir hacia la TD2, o bien hacia la TD3 y en caso de realizar la TD1 y finalizarla, es posible volver a realizar dicha tarea. Luego de realizar la tarea TD1, el grupo podrá optar la TF.

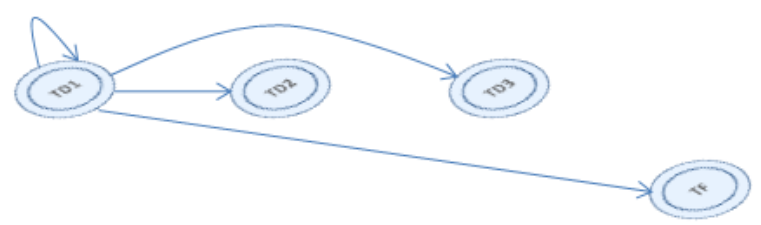

Figura 4.27: Transiciones válidas desde la TD1 luego de haber realizado la TR3

- Transición TR3 a la TD2. Al tomar esta opción pasan a ser válidas las transiciones visualizadas en la Figura 4.28. Desde la TD2 es posible ir hacia la TD1, o bien hacia la TD3 y en caso de realizar la TD2 y finalizarla, es posible volver a realizar dicha tarea. Luego de realizar la tarea TD2, el grupo podrá optar por realizar la TF.

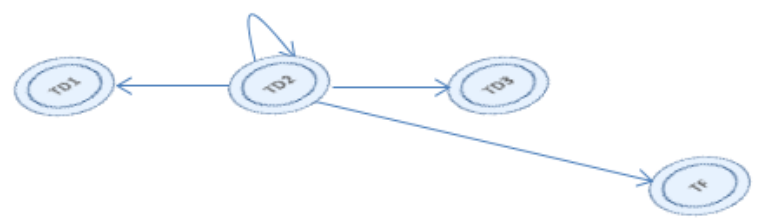

Figura 4.28: Transiciones válidas desde la TD2 luego de haber realizado la TR3 
- Transición TR3 a la TD3. Al tomar esta opción pasan a ser válidas las transiciones visualizadas en la Figura 4.29. Desde la TD3 es posible ir hacia la TD1, o bien hacia la TD2 y en caso de realizar la TD3 y finalizarla, es posible volver a realizar dicha tarea. Luego de realizar la tarea TD3, el grupo podrá optar por realizar la TF.

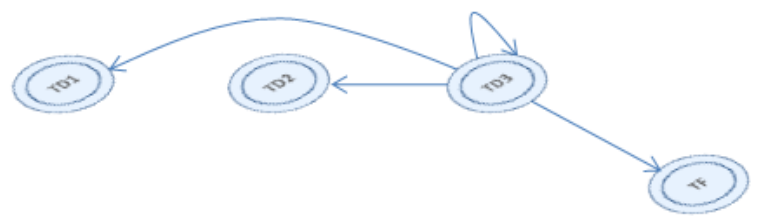

Figura 4.29: Transiciones válidas desde la TD3 luego de haber realizado la TR3

- Transiciones a la TF. Independientemente de la manera en la que se llegue a la tarea final (es decir, ya sea porque se viene de la TR3 o bien desde alguna de las tareas de depósito) aquí se finaliza con la AEP-RD. Esta tarea, fue creada con fines informativos para mostrar el desempeño durante la puesta en práctica de la AE-RD.

A partir de la PlanificacionSecuenciada propuesta, puede haber más de una manera de finalizar la planificación, dependiendo del flujo del grafo que se siga. Esto le permite al grupo, durante la puesta en práctica, ser artífice de su experiencia, eligiendo entre los puntos de decisión posibles.

En cuanto a la instanciación del modelo de AEP, a continuación en la Figura 4.30 se muestran los lugares identificados en el espacio físico y las tareas posicionadas en dicho espacio. La AEP, será denominada AEP-RD. En esta figura se muestran tres mesas una en cada lugar del espacio en el que se realiza cada tarea educativa posicionada para recolectar y los tres cestos de depósito indicando cada lugar para tal fin.

Notar que para poder identificar el lugar donde cada depósito posicionado es ubicado, previamente fue necesario definir tres instancias de DepositoPosicionado, una para cada tarea de depositar. 


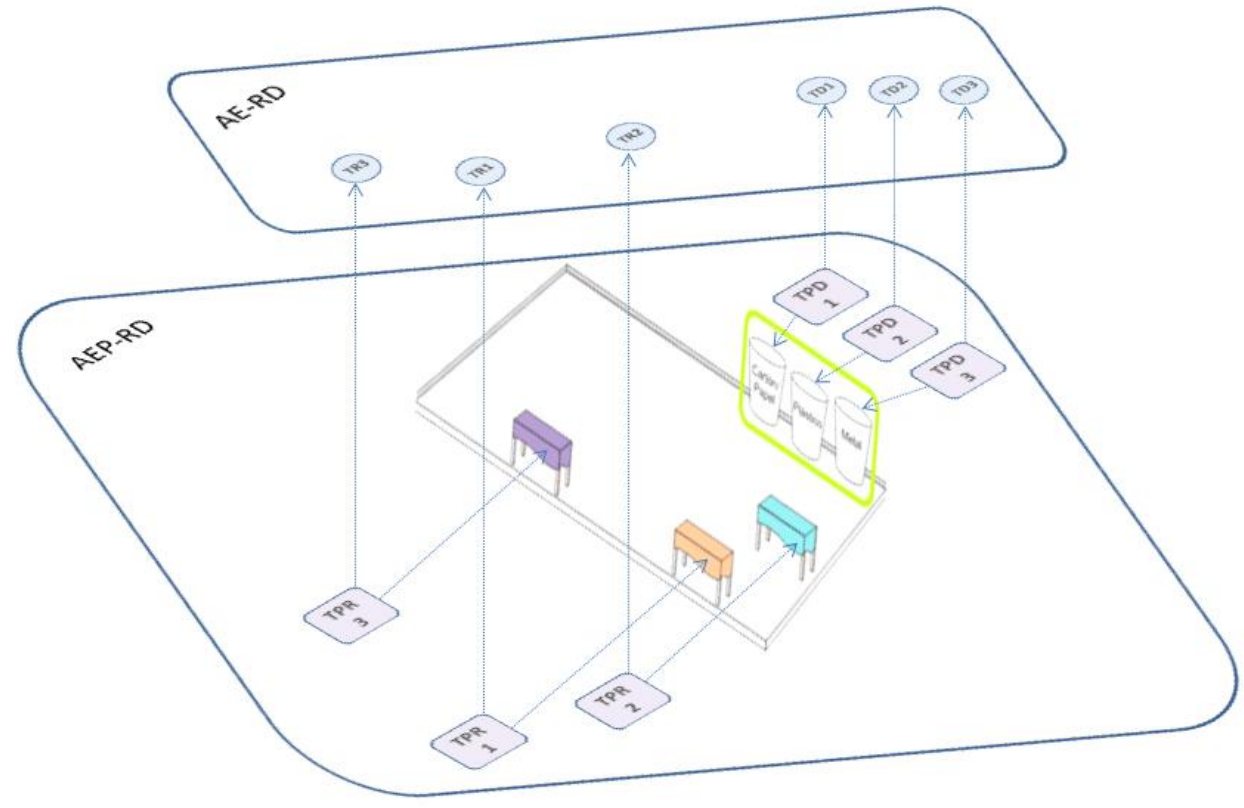

Figura 4.30: Tareas posicionadas

Al instanciar las tres tareas posicionadas para recolectar (TPR1, TPR2, TPR3), es necesario definir los elementos concretos involucrados, es decir, aquellos elementos del mundo real, que el grupo podrá manipular para decidir si forman parte o no de lo que posteriormente dará como respuesta. Para cada elemento correcto relacionado con la consigna con opción de cada tarea, es necesario instanciar un elemento concreto. De esta manera tenemos los elementos concretos correctos. Adicionalmente, se deben instanciar elementos concretos que permitirán al grupo analizar si cumplen con la consigna recibida. Estos últimos elementos concretos instanciados, tendrán sus correspondientes elementos generales definidos.

En la Figura 4.31, se muestran los elementos concretos instanciados para la TPR1. Notar que para dicha tarea los elementos concretos correctos son:"Hoja de Cuaderno", "Caja para Huevos", "Caja de Cereal" y "Tubo de Rollo de Papel". 


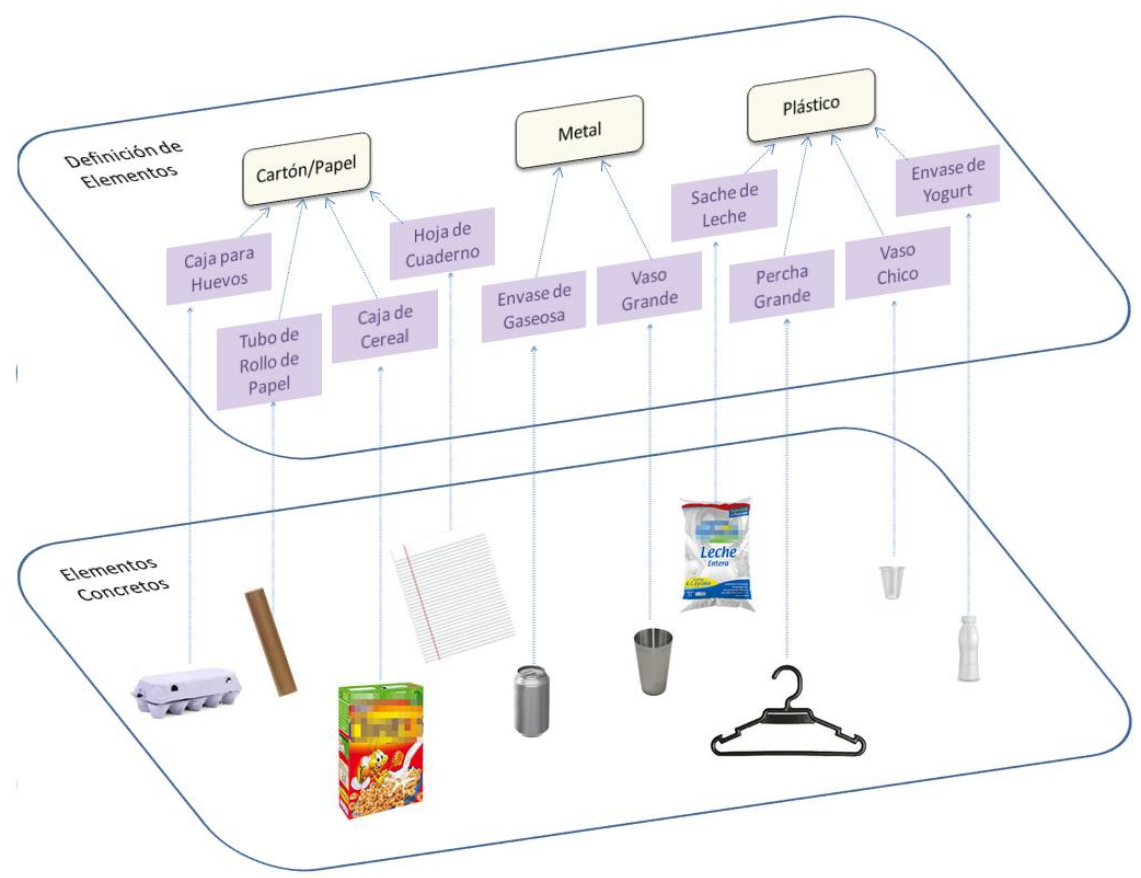

Figura 4.31: Elementos concretos de la TPR1

En la Figura 4.32, se muestran los elementos concretos para la TPR2. Notar que para dicha tarea los elementos concretos correctos son: "Envase de Gaseosa", "Botella de Leche", "Botella de Gaseosa" y "Botella Chica".

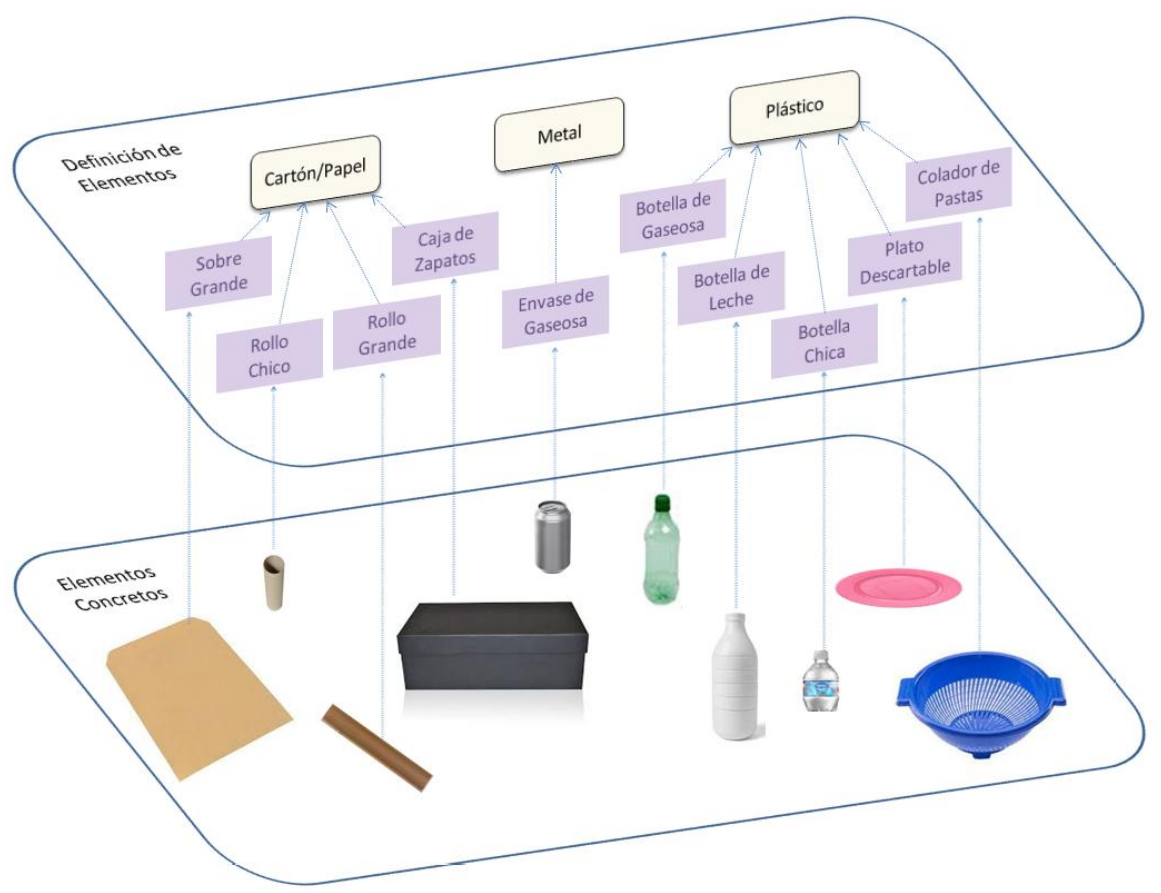

Figura 4.32: Elementos concretos de la TPR2 
En la Figura 4.33, se muestran los elementos concretos para la TPR3. Notar que para dicha tarea los elementos concretos correctos son: "Regla Grande" y "Escuadra".

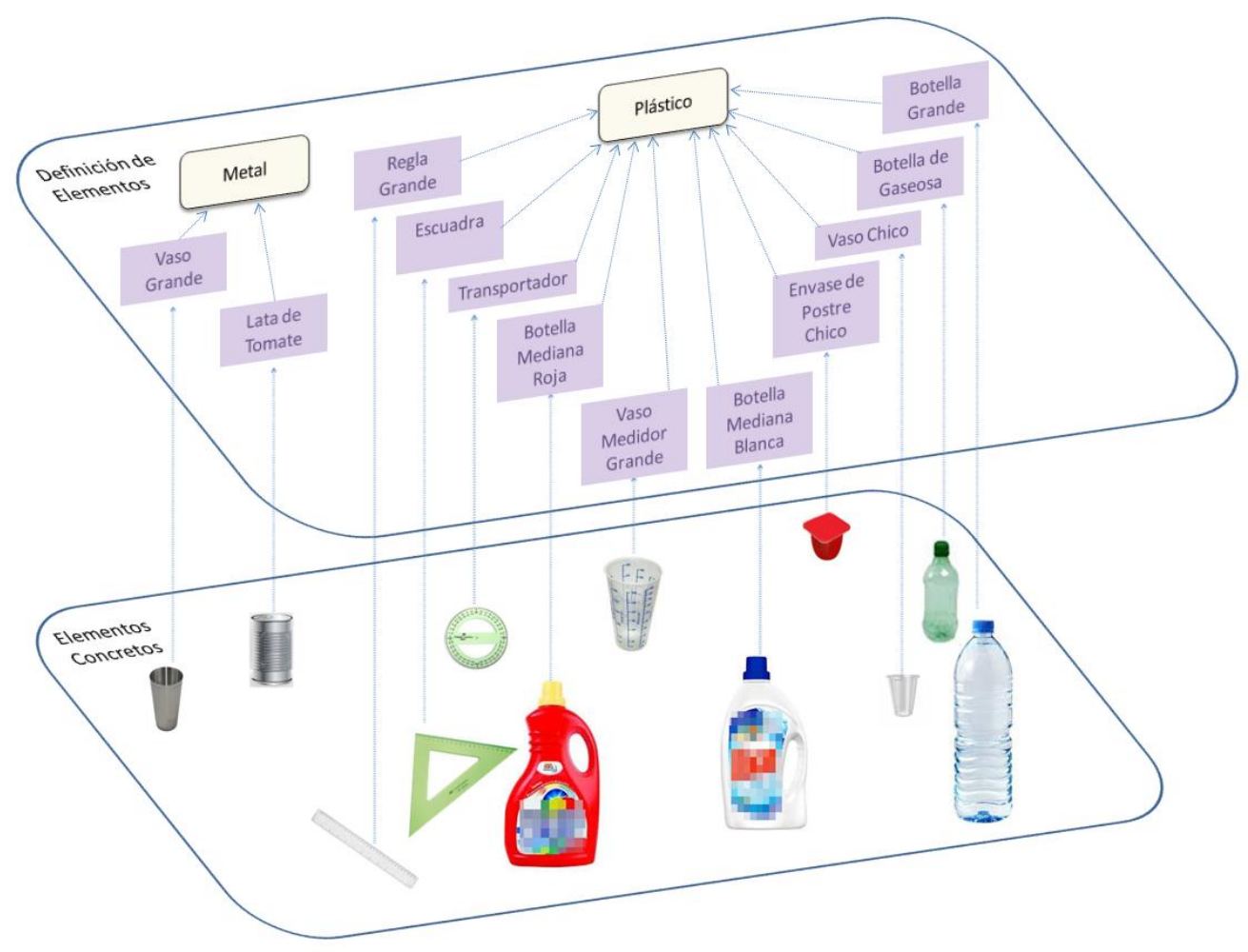

Figura 4.33: Elementos concretos de la TPR3

A todos los elementos concretos instanciados para las diferentes tareas de recolección, se les definió el estado "Disponible". Y se les indicó como lugar posicionado inicial el mismo lugar que la tarea posicionada que los contiene.

\subsubsection{Implementación}

El prototipo, llamado ¡Aprendo Jugando!, se implementó como una aplicación Android que no requiere de conectividad a internet para su ejecución. La misma, hace uso de un lector de código $\mathrm{QR}^{22}$ externo, el cual debe estar instalado previamente en el mismo dispositivo que el prototipo desarrollado. Este lector, permitirá reconocer códigos QR, los cuales serán usados para identificar los lugares en los que se brinden tareas de recolección y de depósito. Se usan además, estos códigos, para identificar los elementos concretos recolectados o depositados. En la Figura 4.34 se presenta un ejemplo de código QR.

\footnotetext{
${ }^{22}$ Código QR: El código QR (Quick Response) es un código bidimensional matricial que posee patrones de detección de posición en tres esquinas [Kato et al., 2010].
} 


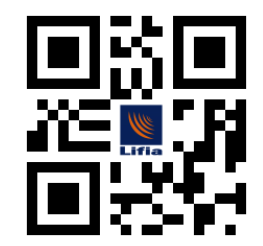

Figura 4.34: Ejemplo de QR

En el Anexo A, se presentan los pasos necesarios para instalar el prototipo en un dispositivo móvil particular. A continuación se mostrarán las pantallas más relevantes del prototipo desarrollado, tomadas a partir de una simulación de puesta en práctica. Dichas pantallas serán introducidas brevemente para comprender la interacción de los alumnos con el mismo. Para mayor detalle, en el Anexo B, se muestra una simulación completa del uso del prototipo.

En la Figura 4.35.a, se presenta la pantalla de bienvenida a la AEP-RD, en donde se le presenta al alumno el objetivo del juego y se le describe brevemente la dinámica del mismo. Cuando el alumno presiona el botón "iA Jugar!" de dicha pantalla, visualiza la pantalla que se muestra en la Figura 4.35.b. En esta pantalla, el alumno recibe un mapa esquemático del espacio físico, en donde se le muestran las ubicaciones de las diferentes tareas y en particular, se le indica a cual deberá dirigirse. Al llegar al lugar indicado, el alumno presiona en el botón "Leer Código", se le abre el lector de códigos QR (Figura 4.35.c)
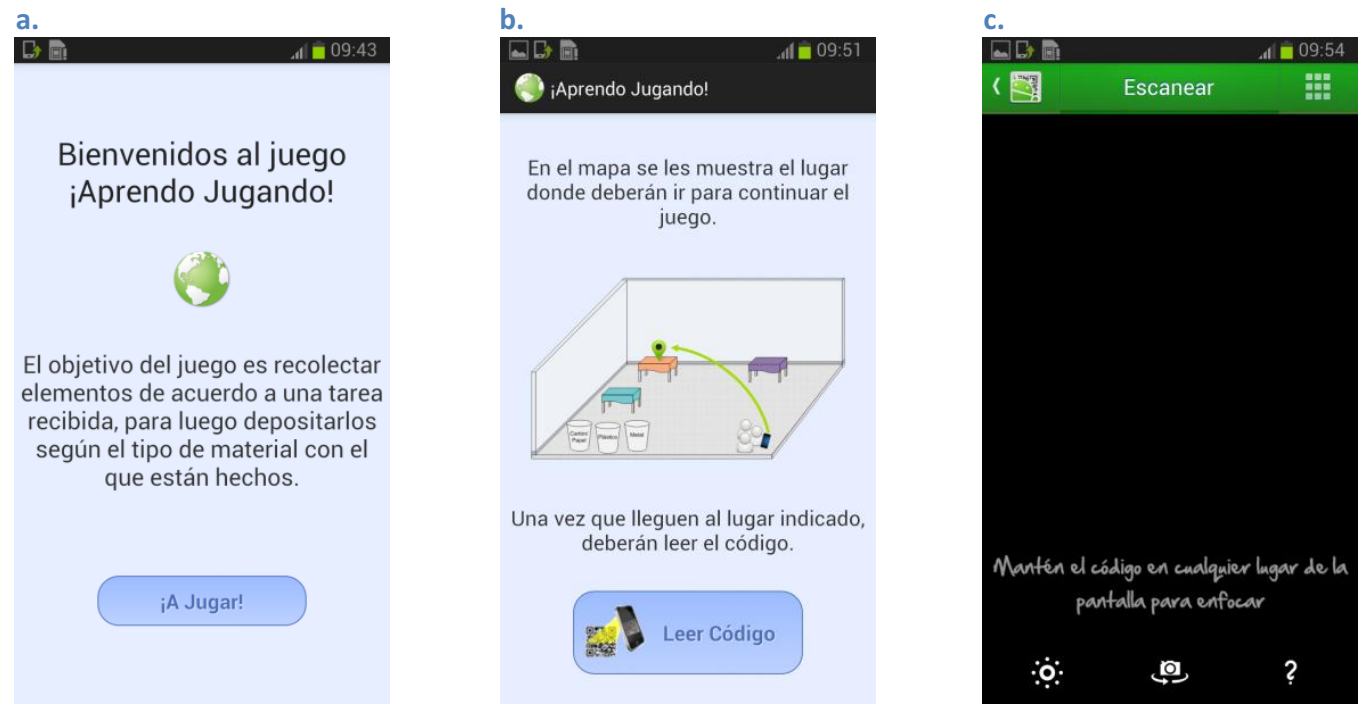

Figura 4.35: Pantallas del prototipo

Una vez abierto el lector de código QR, se debe hacer foco en el código QR de la tarea que se quiere realizar, para recibir de este modo su consigna. En particular, en la Figura 4.36, se muestra el código QR de la TPR1. El lugar donde se realiza la tarea tiene el color naranja que la identifica y en la misma se visualizan los elementos concretos. 


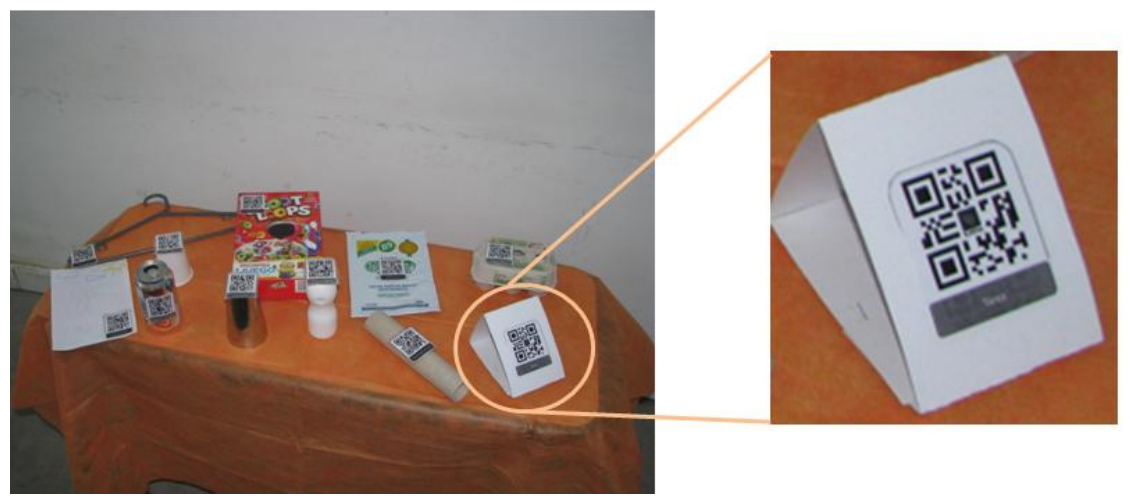

Figura 4.36: Código QR de una tarea

Los enunciados de consignas para las tareas de recolección, se presentan en la Figura 4.37. La Figura 4.37.a muestra el enunciado de la consigna para la tarea posicionada TPR1, la Figura 4.37.b muestra el enunciado de la consigna para la tarea posicionada TPR2, mientras que la Figura 4.37.c, muestra el enunciado de la consigna para la tarea posicionada TPR3.
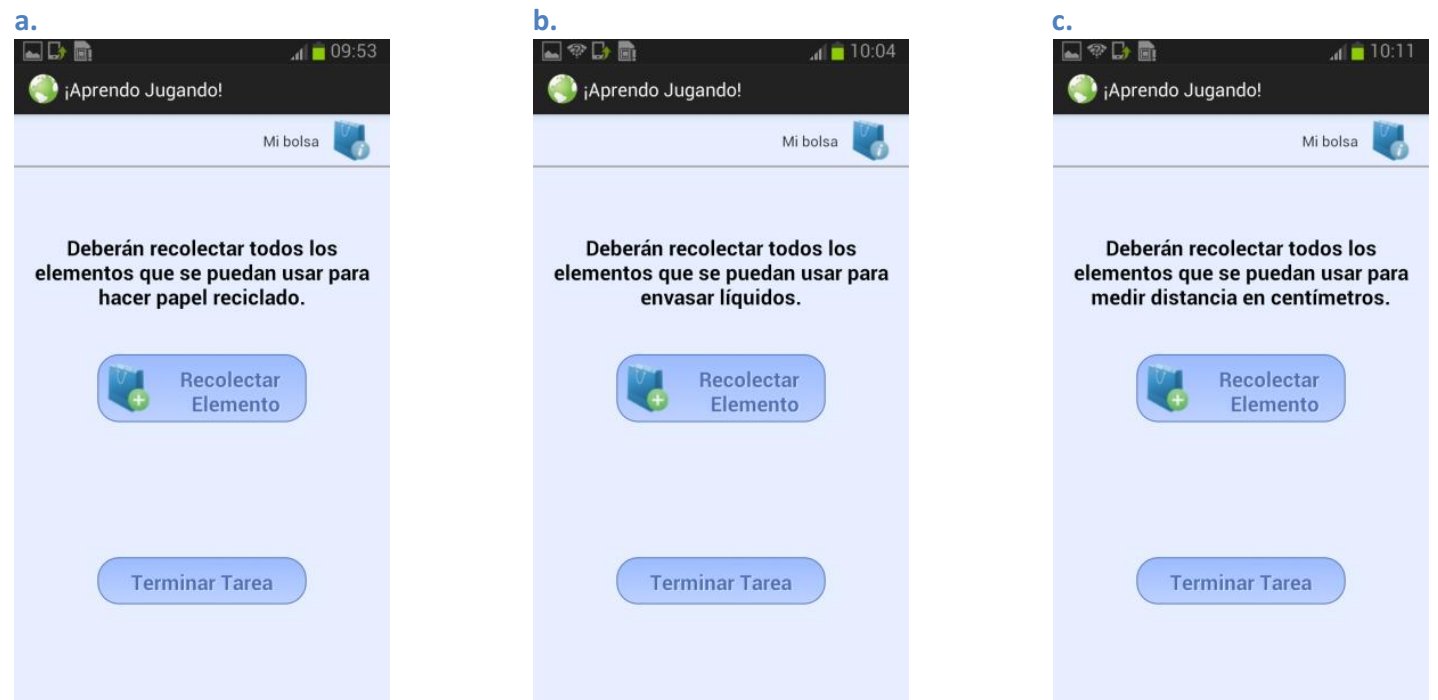

Figura 4.37: Enunciados de consignas de tareas de recolección

Cuando el grupo presiona el botón de "Recolectar Elemento", para cualquiera de las tres tareas presentadas en las pantallas de las Figura 4.37, se abre el lector de código QR y el grupo deberá recolectar un elemento que considere apropiado para resolver la consigna, leer su código QR y luego colocarlo en la canasta disponible para transportarlo consigo. En particular, suponiendo que el grupo está realizando la TPR1 (cuyo enunciado se presentó en la Figura 4.37.a) y selecciona el botón "Recolectar Elemento" y lee el código QR de la hoja de cuaderno, pasa a visualizar la pantalla que se presenta en la Figura 4.38.a, En la Figura 4.38.b, se muestra la lista de elementos concretos luego de haber continuado con la recolección de dos elementos más, ambos correspondientes a la TPR1. 

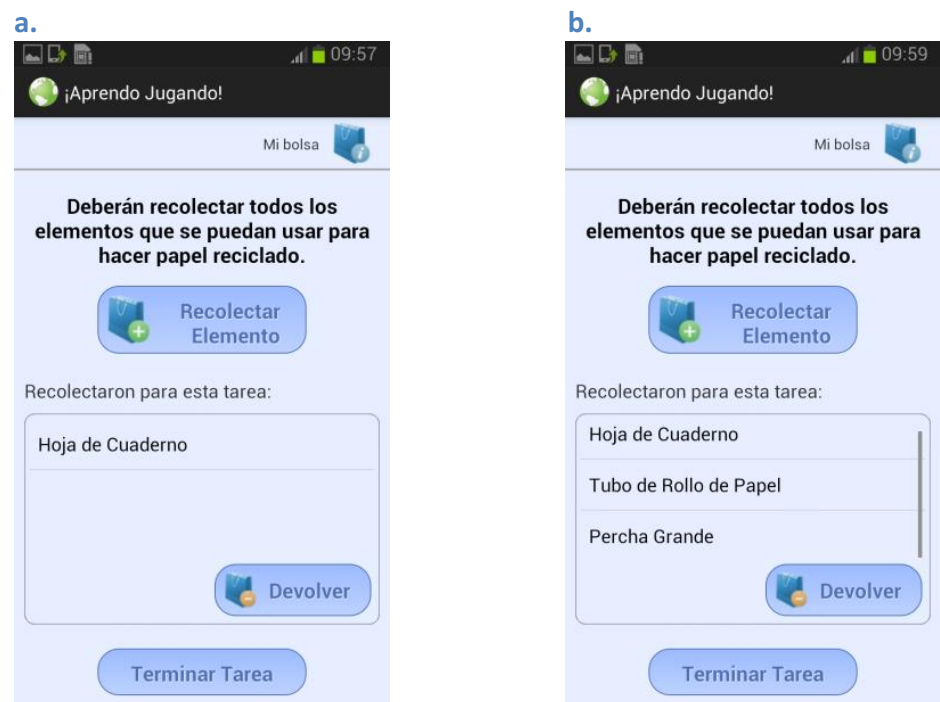

Figura 4.38: Listado de elementos concretos recolectados

Cuando el grupo decide devolver un elemento concreto previamente recolectado, se dispone de la posibilidad, de usar el botón "Devolver". Al presionar dicho botón, el grupo visualiza en una pantalla, la consigna recibida para la tarea que está realizando actualmente y la lista de elementos que recolectó hasta el momento. Esto se visualiza en Figura 4.39.a. De la lista de elementos concretos que se le muestra al grupo en dicha pantalla, el grupo deberá seleccionar los elementos que desea devolver (Figura 4.39.b) y luego presionar el botón "Devolver Elementos". Luego de esta acción, el elemento se elimina de la lista, el grupo saca el elemento de su canasta y lo regresa al lugar de la tarea posicionada para que quede disponible nuevamente. La pantalla visualizada en la Figura 4.32.c, muestra la lista de elementos concretos recolectados para la tarea posicionada a la cual se le eliminó el elemento "Percha Grande".
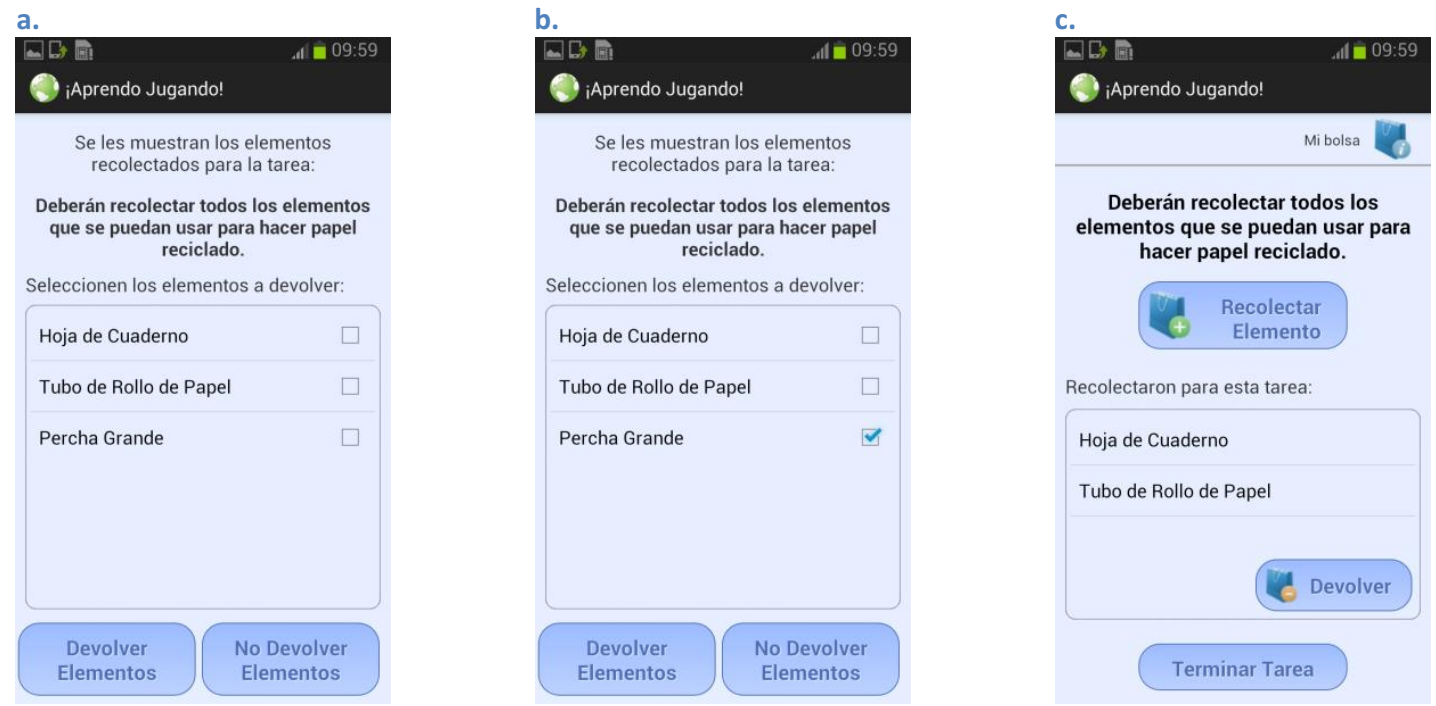

Figura 4.39: Devolver elementos concretos recolectados 
Cuando el grupo determina que ya no hay más elementos concretos para recolectar que respondan a la consigna recibida, presionará el botón de "Terminar Tarea" (presente en la Figura 4.39.c). Cuando se realiza esta acción, el prototipo le da la opción al grupo de realizar la siguiente tarea de recolección o bien realizar tareas de depósito. Esto se expresa en la pantalla visualizada en la Figura 4.40.a. En la Figura 4.40.b, se muestra la pantalla que visualiza el grupo, en caso de seleccionar que desea depositar elementos. En dicha figura, se muestra el mapa con el lugar al que deben dirigirse para depositar.

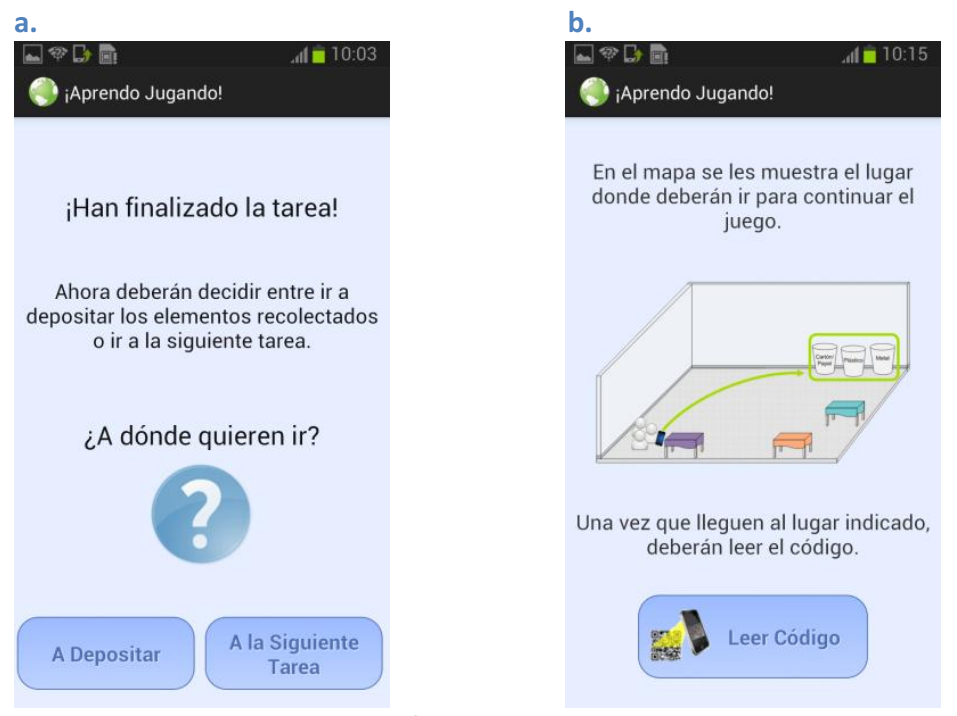

Figura 4.40: Elegir como continuar

Una vez que el grupo llega al área de depósitos indicada en el mapa y lee el código QR de una de las tareas de depositar, el grupo visualiza una pantalla como la presentada en la Figura 4.41.a. Dicha pantalla muestra la tarea de depositar "Cartón/Papel" junto con los elementos concretos que fueron recolectados hasta el momento por el grupo. En la Figura 4.41.b se muestran algunos de los elementos concretos seleccionados, indicando que son los que el grupo desea depositar. A medida que cada elemento concreto se selecciona en la lista, el grupo lo saca de la canasta y lo deja en el depósito. Una vez seleccionados todos los elementos concretos a depositar, se presiona el botón "Depositar Elementos", lo que internamente hace el prototipo, es eliminar los elementos seleccionados de la lista. Como resultado de haber presionado el botón "Depositar Elementos", se visualiza una pantalla como la que se muestra en la Figura 4.41.c. En dicha pantalla se puede decidir entre continuar con tareas de depositar o bien ir a la siguiente tarea de recolección. 

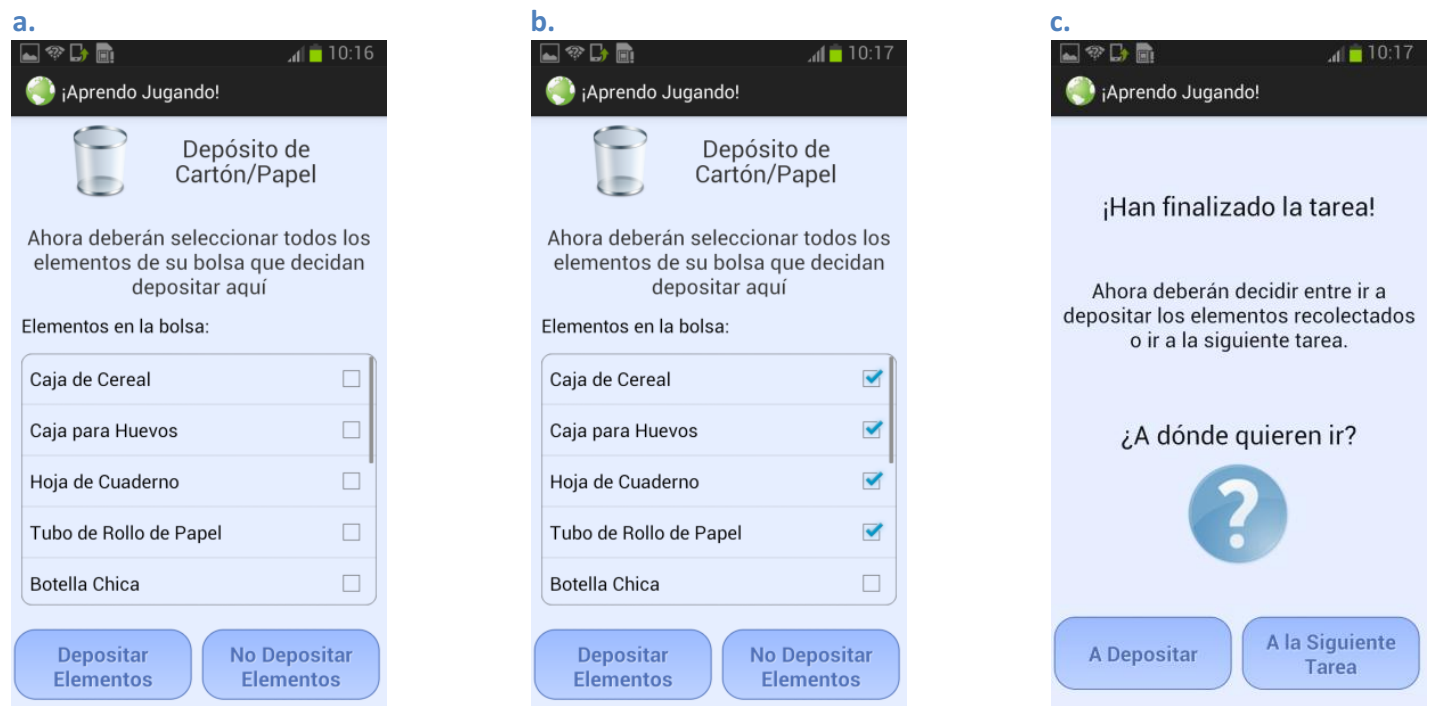

Figura 4.41: Depósito de elementos concretos

Una vez realizadas todas las tareas de recolección, se visualiza una pantalla como se muestra en la Figura 4.42. En dicha pantalla se da la opción para ir a depositar elementos o bien finalizar el juego.

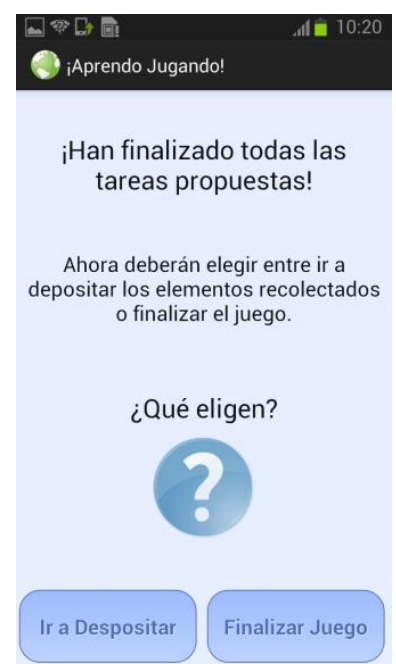

Figura 4.42: Decidir entre ir a depositar o finalizar el juego

Cuando el grupo decide "Finalizar el Juego", se visualizará una pantalla como que se presenta en la Figura 4.43.a, en donde el grupo podrá elegir entre ver su desempeño en el juego o bien, salir del mismo. En la Figura 4.43.b, se muestra la pantalla resultante de haber presionado el botón "Ver Desempeño". El grupo podrá ver su desempeño en las tareas de recolección y en las tareas de depósito. Notar que, en la pantalla de la Figura 4.43.b, se asume que el grupo no dejo ningún elemento concreto en el depósito de "Metal" y por este motivo, no aparece listado para ver el desempeño en el mismo. Para ver un desempeño en particular, se deberá seleccionar alguno de los ítems listados. 

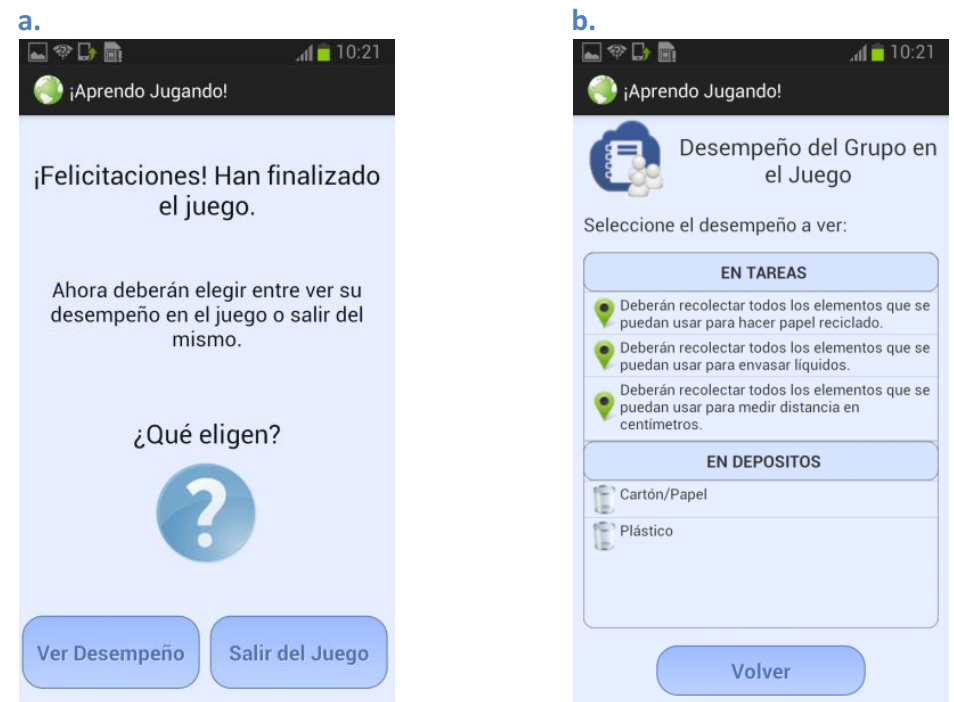

Figura 4.43: Ver desempeño del grupo

En la Figura 4.44.a, se visualiza el desempeño para la TPR1, mostrando el enunciado de la consigna recibida y los elementos concretos que el grupo recolectó correctamente, incorrectamente y aquellos que no recolectó. Cuando se presiona el botón de "Volver", se regresa a la pantalla que se visualiza en la Figura 4.44.b, desde la cual se puede continuar viendo el desempeño. En la Figura 4.44.c, se muestra la pantalla del desempeño en el depósito de "Cartón/Papel". Para las tareas de depositar, se indica el depósito en cuestión, lo que se depositó correctamente y lo que se depositó incorrectamente en él.
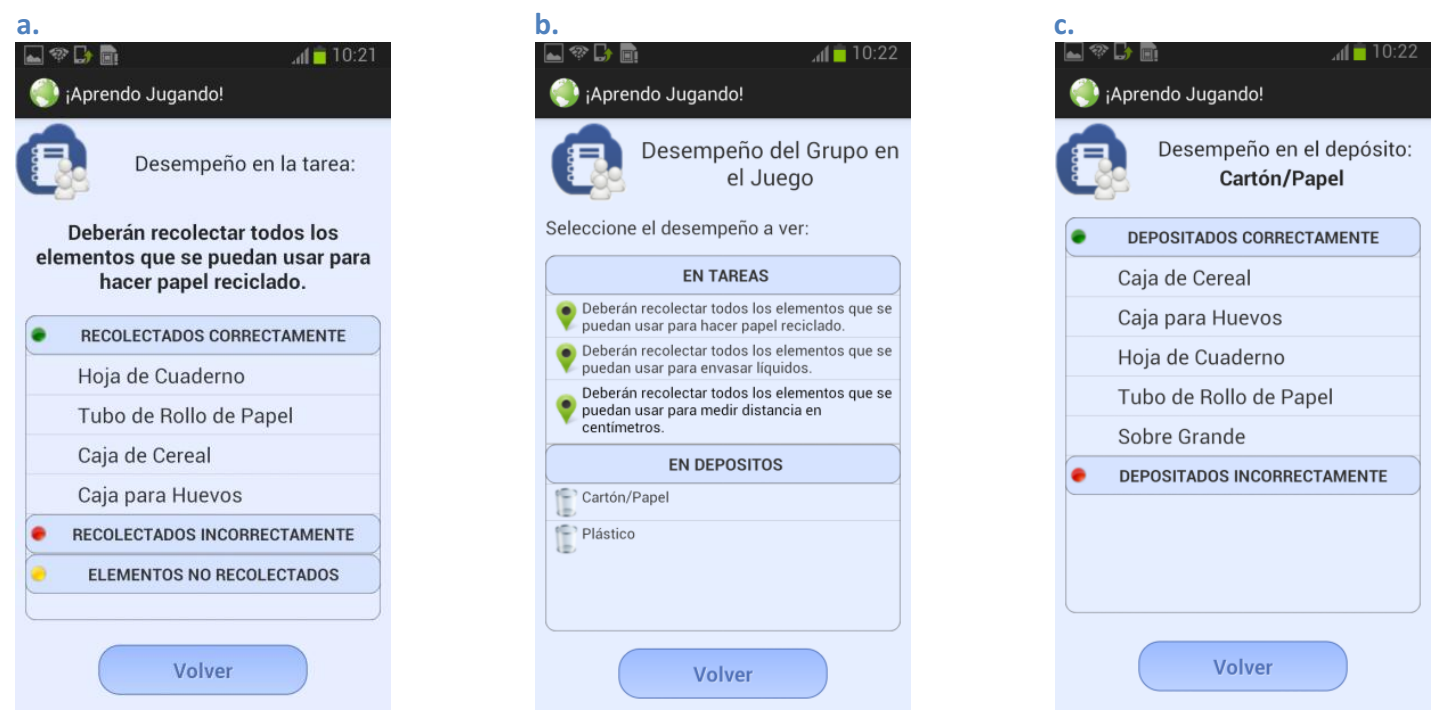

Figura 4.44: Visualización del desempeño

Una vez visualizado el desempeño en la tarea de depositar seleccionada (Figura 4.44.c), es posible presionar el botón "Volver", regresando a la pantalla anterior como se muestra en la Figura 4.45.a (notar que la Figura 4.44.b es igual a la pantalla 4.45.a). Una vez que el 
grupo decide dejar de ver su desempeño, selecciona el botón "Volver" de la pantalla mostrada en la Figura 4.45.a. y visualiza la pantalla que se muestra en la Figura 4.45.b. Desde dicha pantalla, podrá optar por ver nuevamente su desempeño o bien, "Salir del Juego".
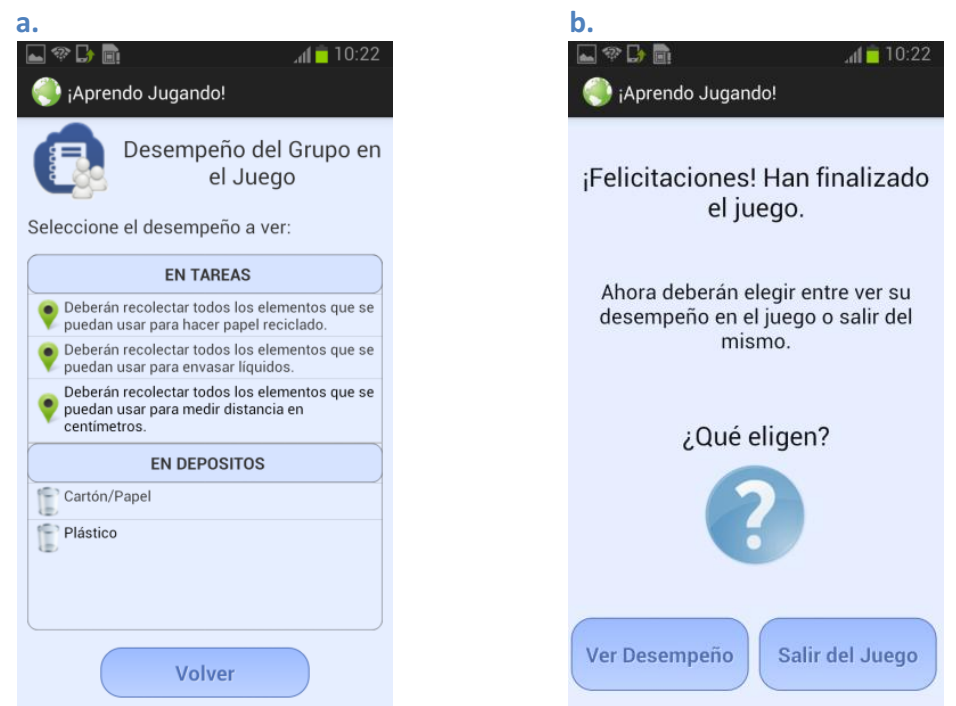

Figura 4.45: Terminar de ver desempeño y salir del juego

Cuando el grupo sale del juego, la información del desempeño queda disponible en el dispositivo móvil.

De esta manera, se presentaron algunas pantallas del prototipo ¡Aprendo Jugando! para mostrar la interacción del mismo.

\subsection{Cómo configurar el espacio físico para poner en práctica el prototipo}

Para poder poner en práctica el prototipo presentado en la Sección 4.2, se debe disponer de un espacio físico rectangular. En dicho espacio se identificarán tres lugares colocando una mesa en cada uno. Sobre dichas mesas se realizará cada tarea posicionada de recolección. Cada mesa será identificada con un color de acuerdo a la tarea posicionada de recolección (Ilamadas TPR1, TPR2 y TPR3) que se llevará a cabo en ella:

- TPR1: Naranja

- TPR2: Turquesa

- TPR3: Violeta

Se identificarán tres lugares para colocar los tres cestos en los cuales se realizarán las tareas de depositar. La disposición de las mesas y los cestos en el espacio seleccionado, debe respetar la distribución visualizada en la Figura 4.46. 


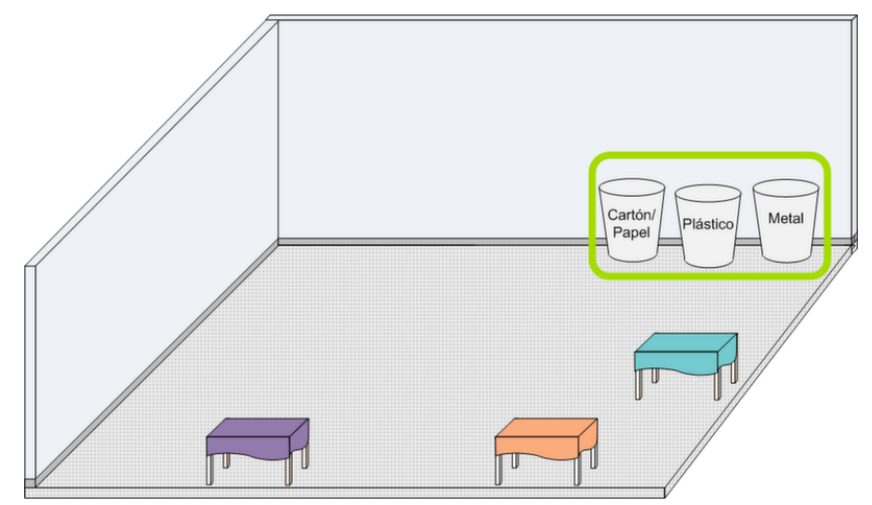

Figura 4.46: Distribución de las mesas y los cestos de depósito en el espacio físico

Colocar en cada mesa, el código QR de tarea de recolección correspondiente. En la Figura 4.47, se visualizan los códigos QR de cada tarea de recolección.
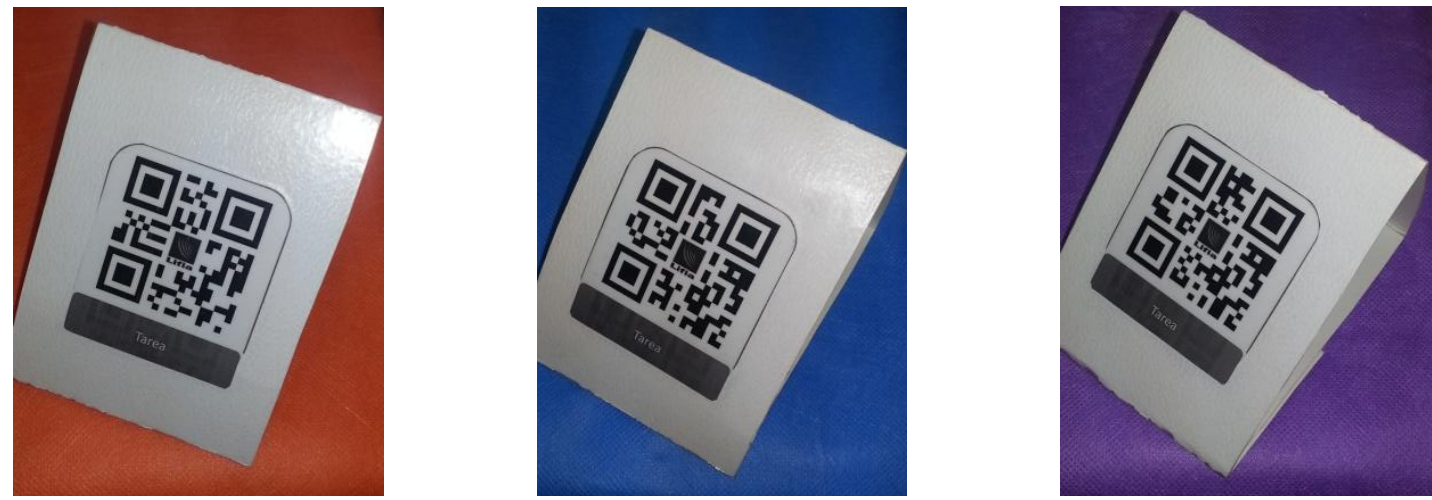

Figura 4.47: Códigos QR de tareas de recolección

Colocarle a los cestos de depósito el código QR correspondiente a cada tarea posicionada de depositar. En la Figura 4.48 se visualizan los tres cestos, donde cada uno de ellos ha sido identificado con el código QR correspondiente.

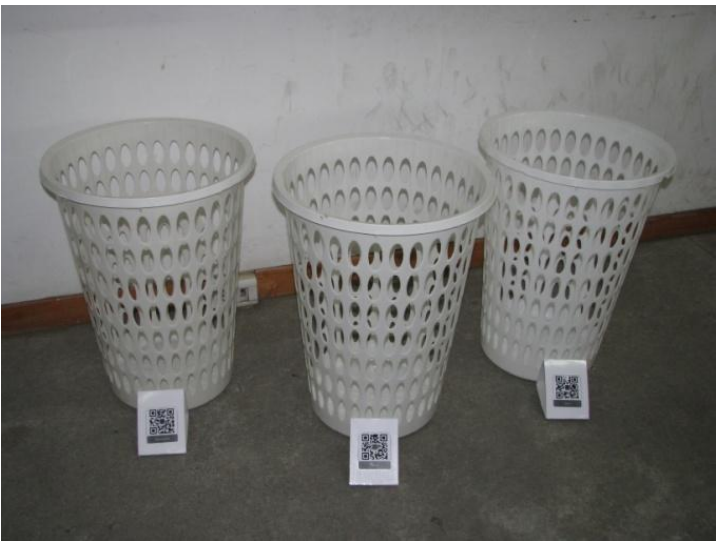

Figura 4.48: Códigos QR de tareas de depositar 
Se le debe colocar a cada elemento concreto el código QR correspondiente y se los debe ubicar sobre la mesa correspondiente a la tarea posicionada de recolectar para cual fueron definidos. En la Figura 4.49 se muestran las mesas sobre las que se colocaron los elementos concretos con su correspondiente código QR. En la Figura 4.49.a, se muestran los elementos concretos de la tarea posicionada de recolección TPR1, la cual se realiza en la mesa de color naranja. En la Figura 4.49.b, se presentan los elementos concretos para la tarea posicionada de recolección TPR2, mientras que en la Figura 4.49.c, se muestran los elementos concretos correspondientes a la tarea posicionada de recolectar TPR3. En la Figura 4.49.d, se muestran los tres lugares donde se realizan las tareas de recolección con los elementos concretos dispuestos en cada mesa.
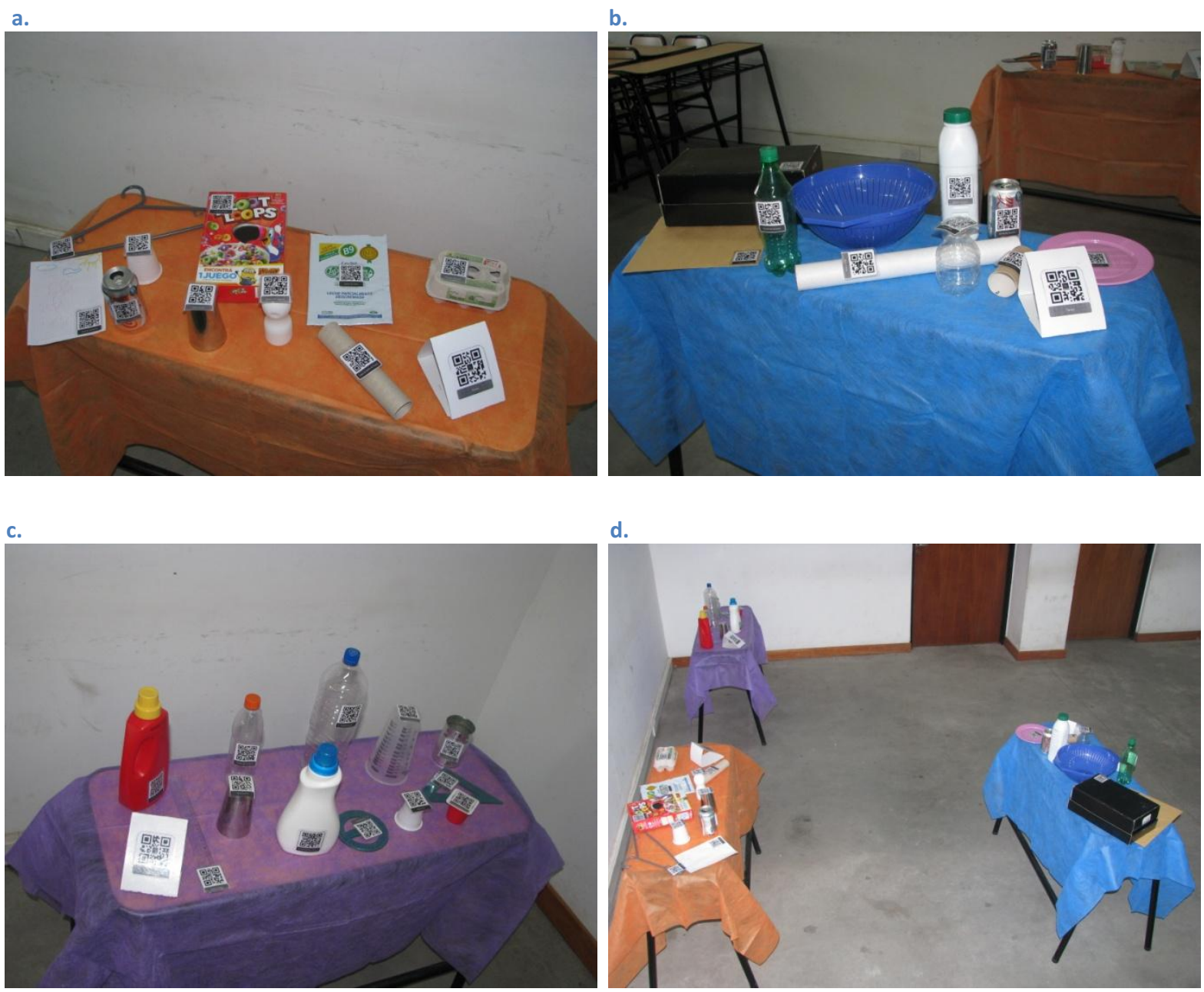

d.

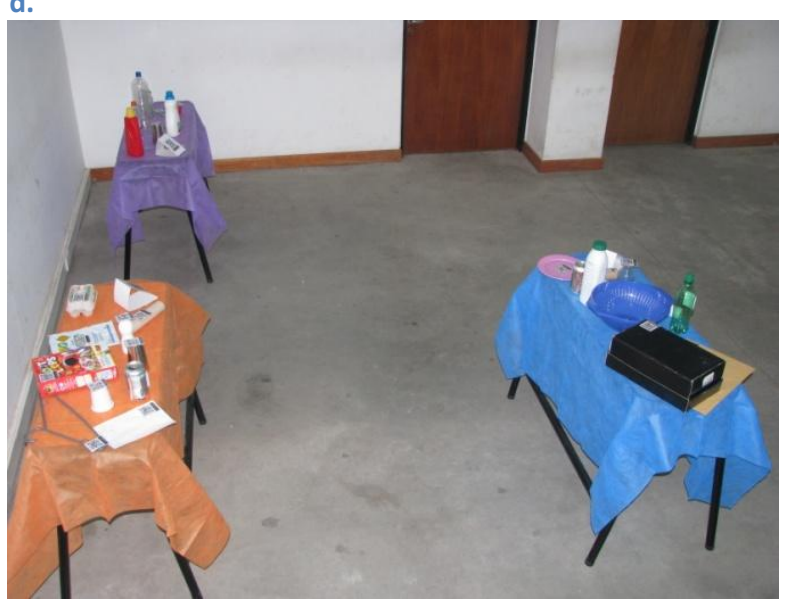

Figura 4.49: Disposición de las tareas de recolección y sus elementos concretos

Finalmente, se debe contar con una canasta para que el grupo transporte, dentro de ella, los elementos concretos que recolecta. Esta canasta deberá ser colocada en la posición en la que se asume, inicia la AEP-RD. En la Figura 4.50.a se muestra el lugar en el 
que se debe colocar la canasta para indicar el inicio de la AEP-RD. En la Figura 4.50.b, se muestra como vería el espacio físico el grupo desde la posición de inicio, hacia las mesas.
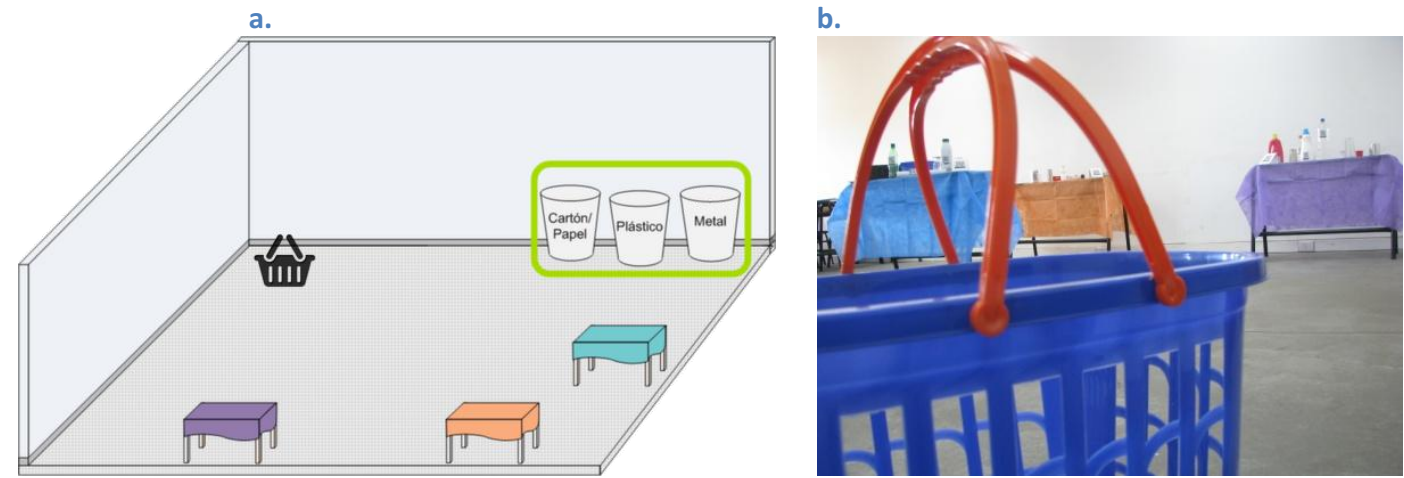

Figura 4.50: Disposición de la canasta para indicar el lugar de inicio de la AEP-RD

De este modo, el espacio físico, queda configurado para poner en práctica el prototipo ¡Aprendo Jugando!. 


\section{Casos de Estudio: Presentación, Análisis y Discusión}

En este capítulo, se presentan dos casos de estudio, en los que se realizaron diferentes puestas en práctica del prototipo presentado en el Capítulo 4, en ámbitos educativos. En particular, estos casos de estudio se llevaron a cabo en dos escuelas primarias distintas. De cada uno se realizará la presentación, análisis y discusión de aquellos aspectos relevantes que surgieron durante los mismos.

\subsection{Aspectos comunes para las puestas en práctica en los casos de estudio.}

En esta sección se describen las actividades realizadas en común para las puestas en práctica en ambos casos de estudio. Es importante destacar que estos aspectos comunes son aplicables para cualquier puesta en práctica del prototipo.

Se identificaron varios aspectos comunes para cualquier puesta en práctica que se lleve a cabo, estos son:

- Armado de códigos QR involucrados en el prototipo.

- Recolección de los datos de las pruebas.

- Precondición antes de las puestas en práctica.

- Armado del espacio físico para las puestas en práctica.

- Charla previa a las puestas en práctica.

- Dinámica planteada para los grupos.

A continuación se detallan cada uno de aspectos mencionados.

\section{- Armado de códigos QR involucrados en el prototipo}

Para las puestas en práctica, se armó un set de elementos concretos cada uno con su respectivo código $Q R$, se armaron los códigos $Q R$ identificadores de tareas de recolectar y los de las tareas de depositar. Estos elementos concretos, así como los códigos QR, pueden ser reutilizados para probar el prototipo en cualquier espacio físico.

- Recolección de los datos de las pruebas

Se realizó una planilla de observación ${ }^{23}$ de las puestas en práctica. Esta planilla sirvió para estructurar la observación durante el uso del prototipo por parte de cada grupo sin embargo, en dicha planilla se conto con un espacio para la toma de notas libres por parte

\footnotetext{
${ }^{23}$ Se uso la observación directa que, de acuerdo a [Tamayo, 2004], es aquella en la que el investigador puede observar y recoger datos mediante su propia observación. En particular, de acuerdo a la clasificación del autor mencionado, la observación realizada es no participante ya que se hizo uso de la observación directa sin ocupar un determinado nivel o función dentro de la comunidad en la cual se realizaron las puestas en práctica.
} 
del observador para registrar aspectos relevantes a su parecer. Adicionalmente, durante las puestas en práctica, se tomaron fotos, las que junto a las planillas de observación sirvieron como fuente de documentación del proceder de los miembros del grupo durante el uso del prototipo, sirviendo como material para la generación del análisis y discusión ya sea de la dinámica de los grupos como de aspectos de usabilidad del prototipo.

Luego de usada la planilla de observación para la puesta en práctica en la primer escuela, se decidió mejorarla en base a la experiencia de uso, habiéndose utilizado una nueva versión de la misma para las observaciones en la segunda escuela. Ambas planillas de observación se incorporaron en el Anexo C y Anexo D respectivamente.

Luego de cada puesta en práctica se realizó con cada grupo una charla a modo de entrevista informal sobre algunos aspectos, por ejemplo, de cómo incidió el color de las mesas para la comprensión del mapa recibido y la utilidad, al momento de recolectar o depositar, que cada elemento concreto contase, en el código QR, con su nombre escrito.

\section{Precondición antes de las puestas en práctica}

Como parte de la organización previa a las puestas en práctica, se seleccionaron grados en los que las temáticas relacionadas al prototipo ya hubiesen sido abordadas y para los que las edades de los alumnos, se correspondiesen con el rango de edad sugerido para la actividad educativa.

- Armado del espacio físico para las puestas en práctica

Tanto los elementos concretos como los códigos QR creados, se dispusieron en el espacio físico acorde a lo especificado en el Capítulo 4, Sección 4.3.

Cabe destacar que para cada grupo de alumnos, antes de iniciar cada puesta en práctica, se configuraba el espacio físico, de modo que todas las mesas dispusieran de los elementos concretos correspondientes y para que el espacio quedase configurado de idéntica manera para cada grupo (respetando lo enunciado en el Capítulo 4, Sección 4.3).

- Charla previa antes de las puestas en práctica

Antes de iniciar con las puestas en práctica para cada caso de estudio, se ingresó al aula de los alumnos y mientras ellos permanecían sentados en sus lugares habituales, los organizadores de las puestas en práctica dimos una charla respecto a los siguientes aspectos de importancia para el uso del prototipo:

- Características generales del juego y los conceptos de recolectar y depositar.

- Particularidades acerca del dispositivo móvil que usarían para la puesta en práctica.

- Como iniciar la aplicación desde el dispositivo móvil que les era facilitado.

- Qué era un código QR. 
- Cómo se leía un código QR, en particular mostrándole la diferencia entre los códigos QR para las tareas de recolección, de depositar y para elementos concretos.

- Se les contó la dinámica para recolectar un elemento concreto.

- Se les explicó la dinámica para depositar un elemento concreto.

- Se les contó qué les brindaba el juego al final del mismo para conocer cuál había sido su desempeño.

\section{- Dinámica planteada para los grupos}

A continuación se mencionan algunos aspectos relacionados a cómo fue usado el prototipo. Se planteo el uso del prototipo iAprendo Jugando! en grupos de tres personas, armados por afinidad entre ellos sin intervención del docente del grado ni la de las personas organizadoras de la puesta en práctica.

Cada grupo, fue independiente del resto ya que se plantearon las pruebas para que los alumnos que conformaban un grupo, al finalizar su puesta en práctica, aguardasen en un sector diferente al que se encontraban los grupos de alumnos que aun no habían participado en el uso del prototipo.

Si bien los grupos fueron conformados exclusivamente por alumnos, el docente podía ser consultado en caso de que así lo requiriesen los alumnos del grupo.

Cada grupo fue provisto con un celular Samsung Galaxy SIII (teléfono sin acceso a red de telefonía móvil, wireless, $3 G \circ 4 \mathrm{G}$ ), con el prototipo instalado y disponible en la primera pantalla de acceso mediante un ícono de acceso directo. Se les dirigió al lugar de inicio, indicado por la posición inicial para la canasta y se les daba la misma para que puedan colocar los elementos concretos a recolectar y depositar.

\subsection{Caso de Estudio: Escuela Nro. 76}

En esta sección se presenta la primera ${ }^{24}$ puesta en práctica realizada con el prototipo en un ámbito escolar. La misma se desarrolló en la Escuela Primaria Nro. 76 de la ciudad de La Plata, Pcia. de Buenos Aires, en el mes de noviembre de 2013. Escuela laica y pública de escolaridad simple.

A continuación se mencionan algunos detalles particulares de algunas puestas en práctica en el marco de este caso de estudio.

\footnotetext{
${ }^{24}$ Se realizaron pruebas no formalizadas previamente, lo que constituyo de ayuda para lograr introducir mejoras al prototipo antes de su uso con alumnos de escuelas primarias. Por ejemplo, el color en las mesas como ayuda adicional a la visualización del mapa, fue una mejora introducida a partir de estas pruebas iniciales.
} 


\section{Participantes}

Los participantes fueron alumnos de 4to. grado. Participaron en total 25 alumnos, en grupos de tres personas cada uno, excepto un grupo de cuatro personas por disparidad numérica. De los 25 alumnos, 15 eran de sexo masculino y 10 eran de sexo femenino, entre los 9 y 10 años de edad. En la Figura 5.1, se muestra el grupo de alumnos participantes de la puesta en práctica.

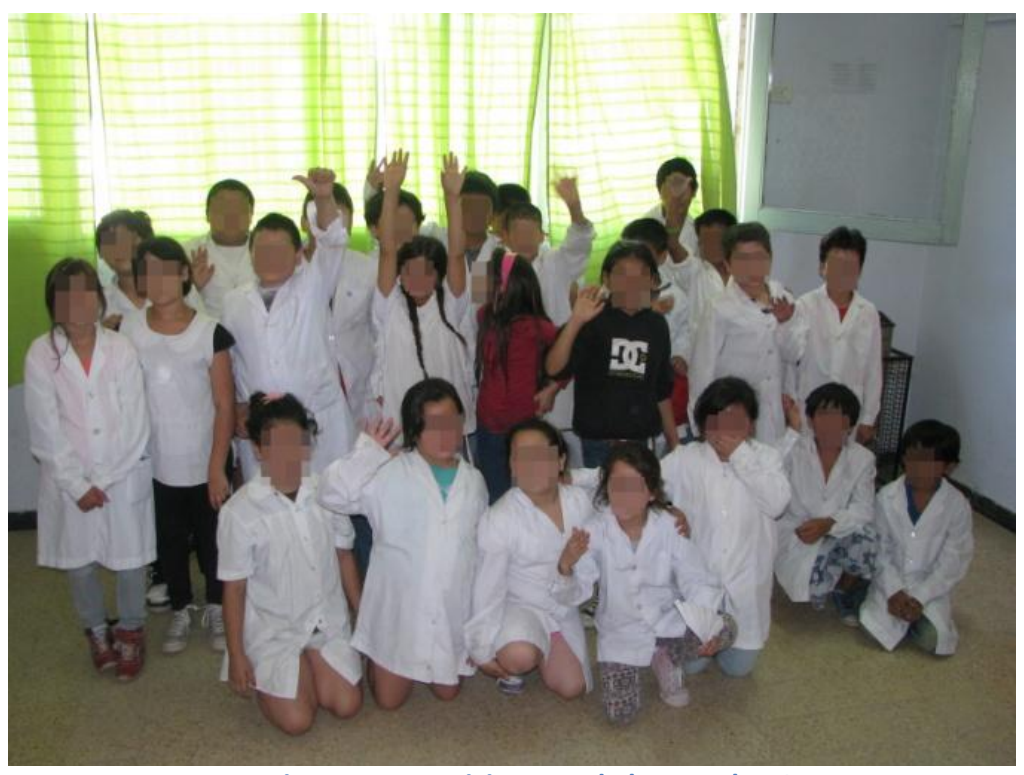

Figura 5.1: Participantes de la Escuela 76

\section{Armado de los grupos}

En la Tabla 5.1 se pueden apreciar los ocho grupos conformados, dos de ellos mixtos. El número de grupo determinó el orden en el que fueron realizadas las experiencias.

Tabla 5.1: Conformación de Grupos

\begin{tabular}{|c|c|c|}
\hline Grupo & Cantidad de nenas & Cantidad de nenes \\
\hline 1 & - & 3 \\
\hline 2 & 3 & - \\
\hline 3 & - & 3 \\
\hline 4 & 3 & - \\
\hline 5 & - & 3 \\
\hline 6 & - & 3 \\
\hline 7 & 2 & 2 \\
\hline 8 & 2 & 1 \\
\hline & 10 & 15 \\
\hline
\end{tabular}

\section{Puestas en práctica}

Página 102 de 167 
A continuación se mostrarán los momentos de recolectar y de depositar de dos grupos de alumnos de la escuela para poder visualizar estos aspectos en este caso de estudio. Cabe recordar que durante las puestas en práctica, los ocho grupos de alumnos realizaron el uso del prototipo a turnos disjuntos.

Una vez iniciada cada puesta en práctica y luego de leer el código QR de una tarea los alumnos del grupo recibían el enunciado de la consigna de la tarea en su dispositivo móvil. En particular, en la Figura 5.2, se muestra un grupo conformado por tres alumnas, en la que las mismas, están leyendo el código QR del elemento concreto "Caja de Cereal" como parte de su respuesta a la primera tarea de recolección propuesta.

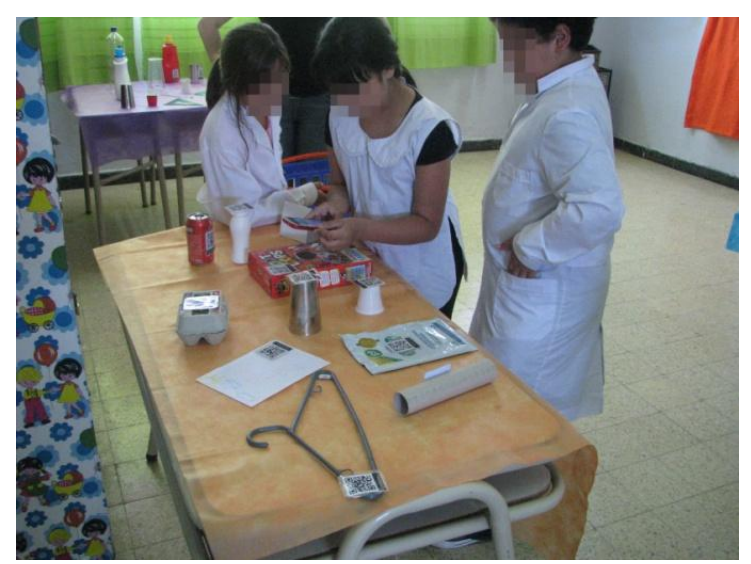

Figura 5.2: Grupo recolectando un elemento concreto

Cada grupo decidía luego de finalizada la tarea de recolección recibida, si pasaba a la siguiente tarea de recolección o si depositaba los elementos concretos recolectados. En particular en la Figura 5.3 se muestra un grupo formado por tres alumnos, el cual se encuentra realizando una tarea de depositar elementos concretos.

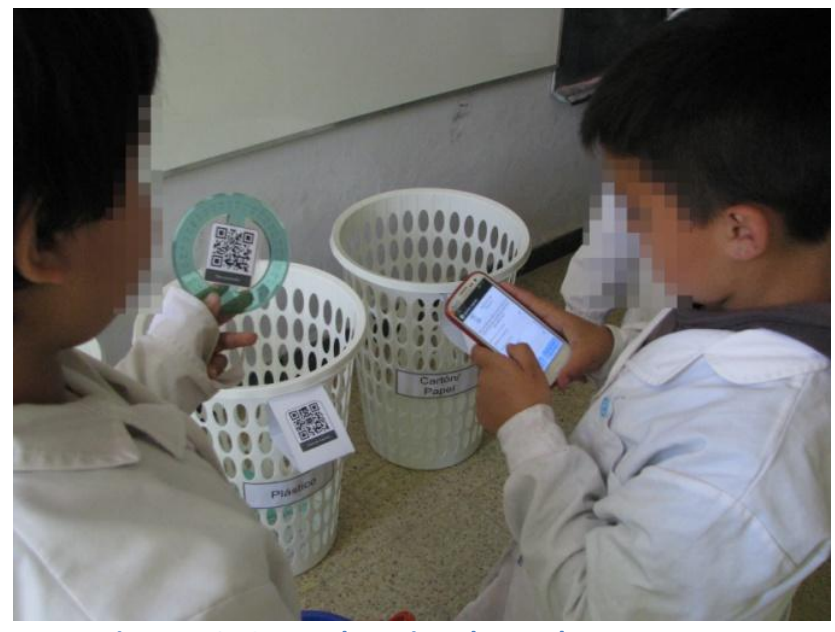

Figura 5.3: Grupo depositando un elemento concreto

\section{Recolección de Datos}


Una persona (de sexo femenino) ajena a la escuela, mayor de edad (33 años) y con formación Informática, realizó la observación de la experiencia llevada a cabo por cada grupo. El "observador" contó con una planilla para registrar aspectos particulares de la experiencia y con un área general para redactar apreciaciones de interés y relevantes a la tarea de observación. Esta planilla se adjunta en el Anexo C. Otras dos personas (de 21 años, de sexo masculino) participaron tomando fotos de las puestas en práctica del prototipo.

La recolección de los datos fue realizada durante la puesta en práctica de cada grupo.

\section{Análisis de Datos}

Acorde a los datos recolectados durante las puestas en práctica se presentan a continuación diagramas con las transiciones entre tareas realizadas por los grupos. Cada grupo fue eligiendo diferentes transiciones del prototipo, esto hizo que cada uno explorara dinámicas diferentes.

Tanto el Grupo 1 y 4 optaron por realizar las tres tareas de recolección y luego ir a depositar, primero al depósito de "Plástico", luego "Cartón/Papel" y por último al depósito de "Metal". Estas transiciones se pueden observar en la Figura 5.4.

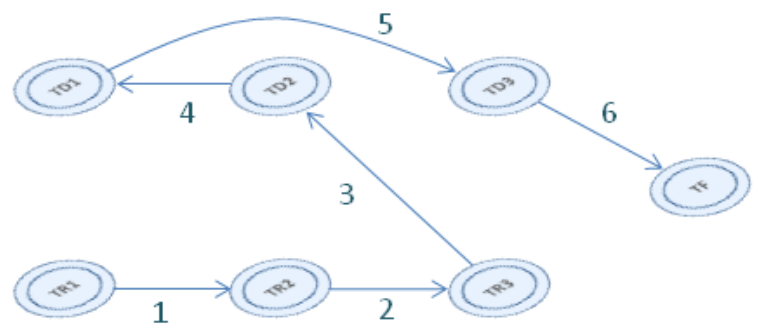

Figura 5.4: Diagrama con transiciones de los Grupos 1 y 4, Escuela 76

El Grupo 2, 5 y 8 optaron también por realizar primero las tareas de recolección, pero los depósitos los recorrieron de una manera distinta (a los Grupos 1 y 4), primero depositaron en el depósito de "Metal", luego en el depósito de "Plástico" y por último en el depósito de "Cartón/Papel". Estas transiciones se pueden observar en la Figura 5.5. 


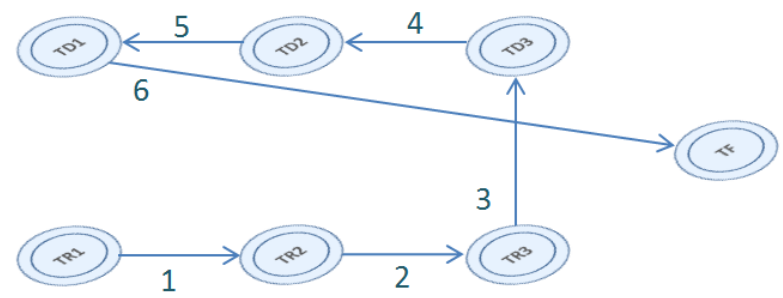

Figura 5.5: Diagrama con transiciones de los Grupos 2, 5 y 8, Escuela 76

El Grupo 3 optó también por realizar primero las tareas de recolección, pero en relación a las tareas de depositar, el orden seguido fue: primero el depósito de "Cartón/Papel", luego el depósito de "Plástico" y por último el depósito de "Metal". Estas transiciones se pueden observar en la Figura 5.6.

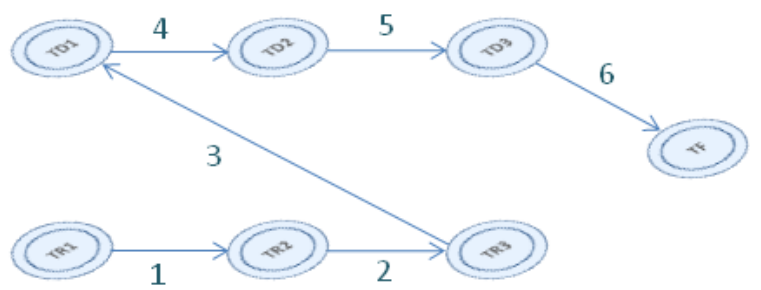

Figura 5.6: Diagrama con transiciones del Grupo 3, Escuela 76

El Grupo 6 y 7 fueron realizando de manera intercalada las tareas de recolección y las tareas de depositar. De la primera tarea de recolección, fueron a depositar en el depósito de "Cartón/Papel", luego realizaron la segunda tarea de recolección, al finalizarla pasaron al depósito de "Plástico", de allí se dirigieron al depósito de "Metal" y luego pasaron a realizar la tercera tarea de recolección. Una vez realizada esta tarea, fueron al depósito de "Plástico". Estas transiciones se pueden observar en la Figura 5.7.

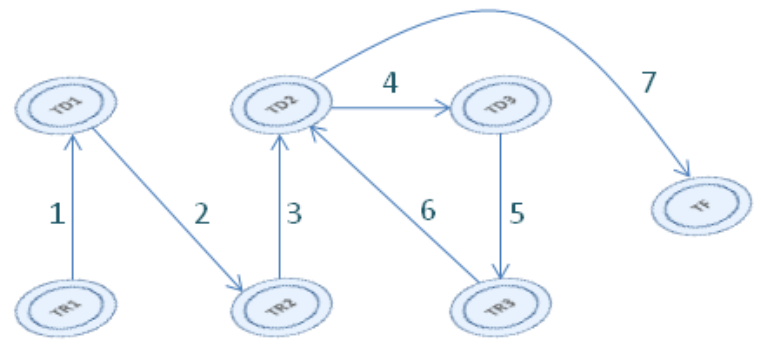

Figura 5.7: Diagramas con transiciones de los Grupos 6 y 7, Escuela 76

De las transiciones presentadas en la Figuras 5.4, 5.5, 5.6 y 5.7, se puede desprender lo siguiente:

- La mayoría de los grupos prefirió realizar primero las tres tareas de recolección y al finalizarlas, dirigirse a realizar tareas de depositar. Esto podría responder a 
la proximidad entre las tareas de recolectar en relación a las tareas de depositar.

- Cuando estos grupos llegaron al lugar donde los tres depósitos estaban colocados, tres grupos los visitó de derecha a izquierda, un grupo los visitó de izquierda a derecha y dos grupos lo hicieron desde el depósito central hacia la derecha y luego a la izquierda.

- Dos grupos intercalaron cada tarea de recolección con una tarea de depositar, en ambos casos, la elección estuvo directamente ligada al tipo de material de los elementos concretos recientemente recolectados.

- Al realizar las tareas de depositar se dejaron en cada depósito la totalidad de elementos concretos de cada tipo de material. No hubo depósitos parciales.

En base a las observaciones realizadas se obtiene la siguiente información:

- Predisposición de los alumnos a realizar la actividad. Los alumnos se mostraron receptivos a la actividad propuesta y les gusto participar de la misma, más allá de su desempeño. Muchos nos pidieron que regresáramos para hacer mas juegos con el dispositivo móvil y los elementos concretos.

- Resistencia al uso/manipulación del dispositivo móvil. Los alumnos no estaban familiarizados con el uso de dispositivos móviles y sólo cinco de ellos contaba con un dispositivo de este tipo para su uso personal fuera del ámbito escolar. Solamente un alumno de los 25 del grado, decidió no usar el dispositivo diciendo que no le gustaba hacerlo, sin embargo, participó entusiastamente de las otras responsabilidades como parte de la puesta en práctica (portar canasta y discutir con los compañeros de grupo ante cada consigna).

- Predisposición de la docente a que los alumnos participen de la actividad. La docente del aula le había contado a los alumnos de su grado que iríamos a hacer la experiencia y nos permitió realizar la misma, durante parte de sus horas curriculares.

- Predisposición del equipo de conducción y de las diferentes áreas disciplinarias para que la actividad sea llevada a cabo. En todo momento el equipo de conducción de la escuela, como el personal del gabinete psicopedagógico y de la biblioteca, se mostraron receptivos a la propuesta del juego.

- Factores distractores hallados durante la experiencia. Durante la puesta en práctica por parte de dos grupos (Grupos 7 y 8), se realizó un recreo en el patio central de la escuela, y la ventana del aula empleada como espacio físico era lindante al mismo. Esto sumo ruido al espacio que distrajo por momentos a los 
alumnos del grupo y además, aparecían niños de otros grados intrigados acerca de lo que se estaba haciendo en dicha aula. Esto incidió en el tiempo que les llevo realizar la puesta en práctica, sin registrar impacto en el desarrollo de la misma.

\subsection{Caso de Estudio: Escuela Manantialles}

En esta sección se presenta la segunda puesta en práctica realizada con el prototipo en un ámbito escolar. La misma se desarrolló en la escuela Manantiales de la ciudad de La Plata, Pcia. de Buenos Aires, en el mes de diciembre de 2013. Escuela laica y privada de escolaridad doble.

A continuación se mencionan algunos detalles particulares de las puestas en práctica de este caso de estudio.

\section{Participantes}

Los participantes fueron alumnos de 6to. grado. Participaron en total 30 alumnos, en grupos de tres personas cada uno. De los 30 alumnos, 17 eran de sexo masculino y 13 de sexo femenino, mayoritariamente de 11 años de edad. En la Figura 5.8, se visualiza el grupo de alumnos participantes, a una de las docentes del grado y a los organizadores de las puestas en práctica.

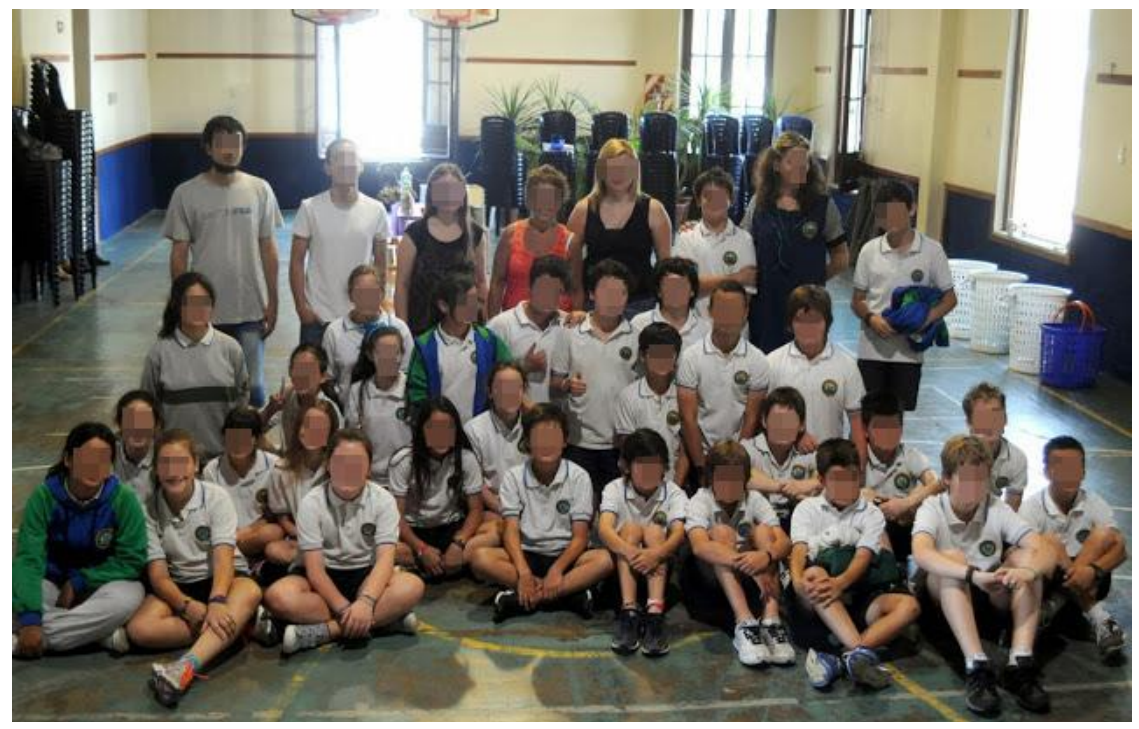

Figura 5.8: Participantes de la Escuela Manantiales

\section{Armado de los grupos}

En la Tabla 5.2 se pueden apreciar los diez grupos conformados, cinco de ellos mixtos. El número de grupo determinó el orden en el que fueron realizadas las experiencias. 


Tabla 5.2: Conformación de grupos
\begin{tabular}{|c|c|c|}
\hline Grupo & Cantidad de nenas & Cantidad de nenes \\
\hline 1 & 2 & 1 \\
\hline 2 & 1 & 2 \\
\hline 3 & 3 & - \\
\hline 4 & - & 3 \\
\hline 5 & - & 3 \\
\hline 6 & 2 & 1 \\
\hline 7 & 3 & - \\
\hline 8 & 1 & 2 \\
\hline 9 & 1 & 2 \\
\hline 10 & - & 3 \\
\hline & 13 & 17 \\
\hline
\end{tabular}

\section{Puesta en práctica}

Para esta escuela, se decidió configurar dos espacios físicos para que haya dos grupos realizando en simultaneo la puesta en práctica sin que se vieran entre ellos, ni pudieran interferir en sus respectivas experiencias. Esto se realizó a fines de reducir el tiempo total del caso de estudio (y que los docentes pudieran continuar con su espacio curricular), dado que ya se contaba con la experiencia del primer caso de estudio.

Durante las puestas en práctica, se realizaron las tareas propuestas. En particular, en la Figura 5.9, se muestra un grupo conformado por dos alumnos y una alumna, y se capta en el celular el momento en el que uno de los alumnos del grupo lee el código QR del elemento concreto "Caja para Huevos".

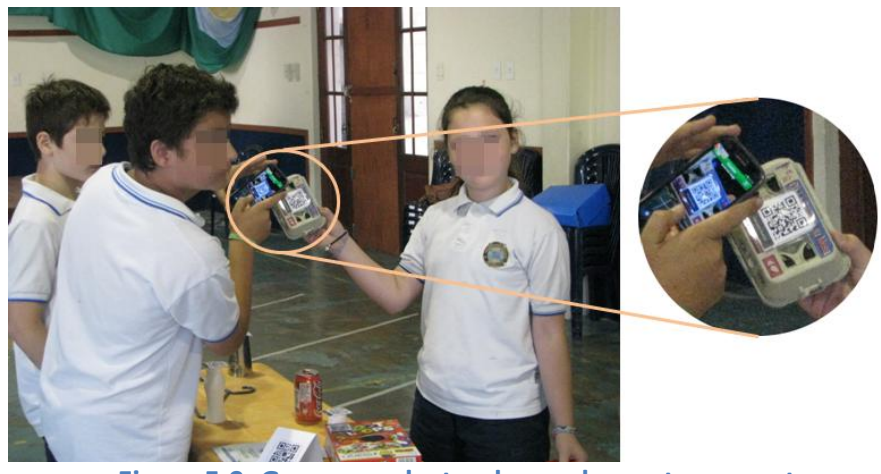

Figura 5.9: Grupo recolectando un elemento concreto

En la Figura 5.10 se puede apreciar a un grupo realizando una tarea de depositar, en particular uno de los alumnos está leyendo el código QR de uno de los depósitos. Se puede apreciar en la figura que otro de los alumnos posee la canasta con los elementos recolectados. 


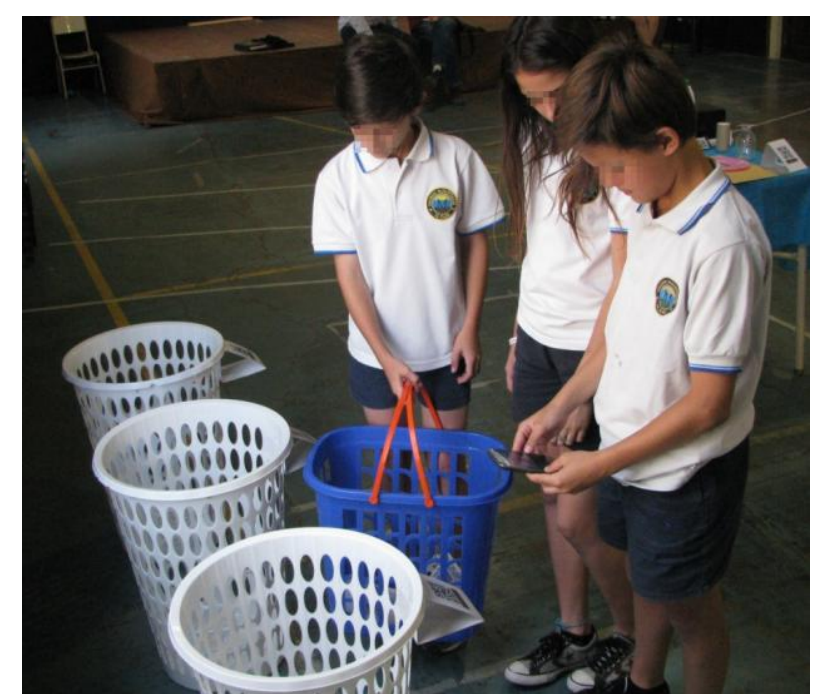

Figura 5.10: Grupo leyendo un código QR de un depósito

\section{Recolección de Datos}

En cada espacio físico había una persona (de sexo femenino) ajena a la escuela, mayor de edad (33 y 37 años respectivamente) y con formación Informática, quienes realizaron la observación de la experiencia llevada a cabo por cada grupo en cada espacio físico. Cada "observador" contó con una planilla, modificada en relación a la empleada en el primer caso de estudio, descripto en la Sección 5.2, para registrar aspectos particulares de la experiencia y con un área general para redactar apreciaciones de interés y relevantes a la tarea de observación. Esta planilla se adjunta en el Anexo D. Una persona (de sexo masculino) participó tomando fotos de las puestas en práctica del prototipo en uno de los dos espacios físicos configurados.

La recolección de los datos fue realizada durante la puesta en práctica de cada grupo.

\section{Análisis de Datos}

Acorde a los datos recolectados durante las puestas en práctica se presentan a continuación, diagramas con las transiciones entre tareas realizadas por los grupos. Cada grupo fue eligiendo diferentes transiciones del prototipo, esto hizo que cada uno explorara dinámicas diferentes.

Los Grupos 1 y 8 fueron realizando de manera intercalada las tareas de recolección y las tareas de depositar. De la primera tarea de recolección, pasaron a depositar en el depósito de "Cartón/Papel", luego realizaron la segunda tarea de recolección, al finalizarla pasaron al depósito de "Plástico, luego depositaron en el depósito de "Metal", para pasar a realizar la tercera tarea de recolección. Al finalizarla, se continuó por la tarea de depositar en el depósito de "Plástico" y para luego pasar a realizar la tarea final. Estas transiciones se pueden observar en la Figura 5.11. 


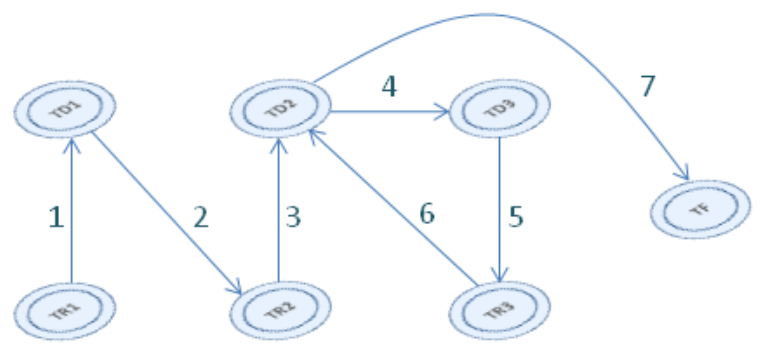

Figura 5.11: Diagrama con transiciones de los Grupos 1 y 8, Escuela Manantiales

Los Grupo 2, 5 y 6 optaron por realizar primero las tres tareas de recolección para luego pasar a realizar las tres tareas de depositar en el siguiente orden: primero en el depósito de "Cartón/Papel", y posteriormente en el depósito de "Plástico" y finalmente en el depósito de "Metal". Luego de esta última tarea realizaron la tarea final. Estas transiciones se pueden observar en la Figura 5.12.

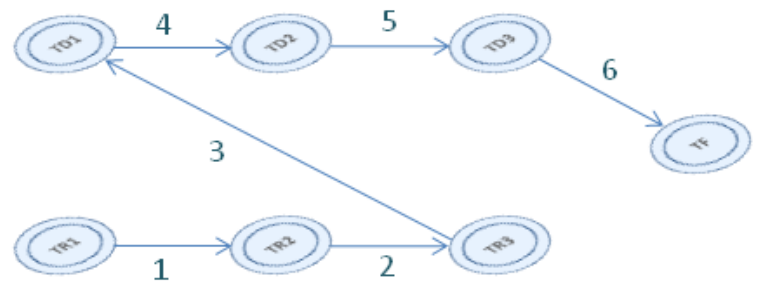

Figura 5.12: Diagrama con transiciones de los Grupos 2, 5 y 6, Escuela Manantiales

El Grupo 3, 4 y 10 optaron también por realizar primero las tareas de recolección y luego las tres tareas de depositar, sin embargo, a diferencia de los casos anteriores, los depósitos fueron recorridos de una manera distinta, el orden fue el que se detalla a continuación: primero el depósito de "Metal", luego el depósito de "Plástico" y por último el depósito de "Cartón/Papel". Luego realizaron la tarea final. Estas transiciones se pueden observar en la Figura 5.13.

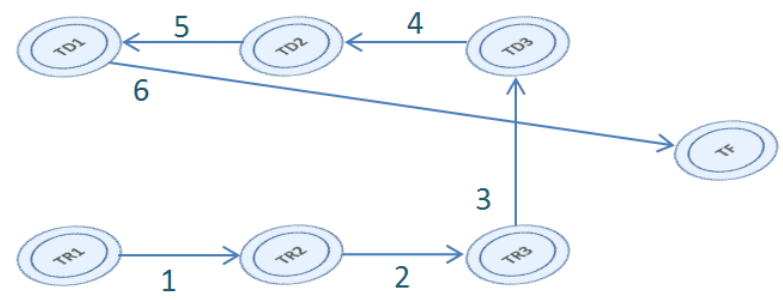

Figura 5.13: Diagrama con transiciones de los Grupos 3, 4 y 10, Escuela Manantiales

El Grupo 7 optó por iniciar en una tarea de recolección que no era la adecuada, luego fueron a realizar la primera tarea de recolección, pasaron a la segunda tarea de recolección, luego fueron a depositar en el depósito de "Cartón/Papel", luego depositaron en el depósito de "Plástico", luego en el depósito de "Metal". Luego de esto pasaron a realizar la tercera tarea de recolección para pasar a depositar en el siguiente orden: 
primero "Cartón/Papel" y luego "Plástico". Estas transiciones se pueden observar en la Figura 5.14.

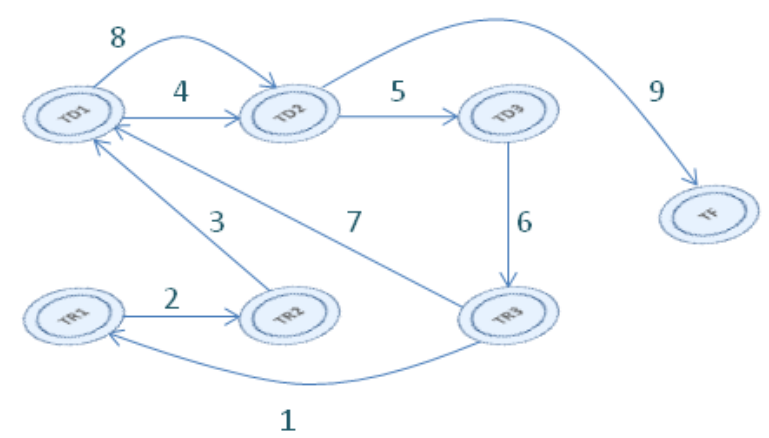

Figura 5.14: Diagrama con transiciones del Grupo 7, Escuela Manantiales

El Grupo 9 optó por realizar la primera tarea de recolección, luego depositaron en el depósito de "Cartón/Papel", pasaron a realizar la segunda tarea de recolección, para ir a depositar en el depósito de "Metal", luego a depositar en el depósito de "Plástico". Decidieron continuar realizando la tercera tarea de recolección y luego ir a depositar en el depósito de "Plástico", y de allí a la tarea final. Estas transiciones se pueden observar en la Figura 5.15.

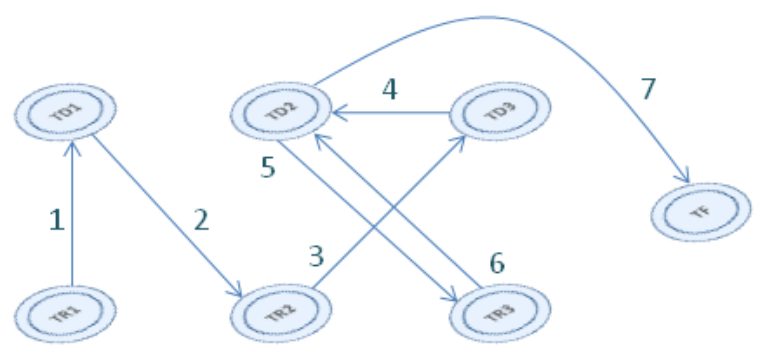

Figura 5.15: Diagrama con transiciones del Grupo 9, Escuela Manantiales

De las transiciones presentadas en la Figuras 5.11, 5.12, 5.13, 5.14 y 5.15, se puede desprender lo siguiente:

- Seis de los grupos prefirieron realizar primero las tres tareas de recolección y al finalizarlas, dirigirse a realizar tareas de depositar. Esto podría responder a la proximidad entre las tareas de recolectar en relación a las tareas de depositar.

- Cuando estos grupos llegaron al lugar donde los tres depósitos estaban colocados, tres grupos los visitó de derecha a izquierda, y los otros tres grupos lo hicieron de izquierda a derecha.

- Cuatro grupos intercalaron tareas de recolección con tareas de depositar.

- Se detectó solo en uno de los grupos (Grupo 7) la realización parcial de depósito (en particular en el depósito de "Cartón/Papel") . 
En base a las observaciones realizadas se obtiene la siguiente información:

- Predisposición de los alumnos a realizar la actividad. Los alumnos se mostraron receptivos a la actividad propuesta y les gusto participar de la misma, más allá de su desempeño.

- Resistencia al uso/manipulación del dispositivo móvil. Los alumnos estaban ampliamente familiarizados con el uso de dispositivos móviles y la gran mayoría contaba con un dispositivo de este tipo para su uso personal fuera del ámbito escolar.

- Predisposición de la docente a que los alumnos participen de la actividad. La docente del aula le había contado a los alumnos de su grado que iríamos a hacer la experiencia y nos permitió realizar la misma, durante parte de sus horas curriculares.

- Predisposición del equipo de conducción y de las diferentes áreas disciplinarias para que la actividad sea llevada a cabo. En todo momento el equipo de conducción de la escuela y la docente de tecnología se mostraron receptivos a la propuesta del juego. Siendo observadoras pasivas durante las puestas en práctica.

- Factores distractores hallados durante la experiencia. Durante las puestas en práctica en uno de los espacios físicos (Grupos 6, 7, 8, 9 y 10) había personas de prensa gráfica tomando fotos durante las mismas, esto impacto en el tiempo de cada puesta en práctica ya que muchas veces se le pedía a los alumnos que mostraran lo que estaban haciendo para registrarlo con la cámara fotográfica.

\subsection{Discusión}

En esta sección se presentan algunos aspectos a discutir respecto de los casos de estudio presentados en las Secciones 5.2 y 5.3 .

Para ambos casos de estudio, en todas las puestas en práctica los grupos recolectaron al menos un elemento concreto de cada tarea de recolección propuesta. Todos los elementos concretos recolectados, fueron recolectados del modo indicado, es decir, primero se leyó su código QR y posteriormente se lo colocó dentro de la canasta.

Se observó, en ambos casos de estudio, que para la tercera tarea de recolección el elemento concreto "Transportador" fue el elemento que más confusión generó al momento de la recolección.

Solo un grupo de los 18 grupos totales (Grupo 7 de la Escuela Manantiales), tuvo problemas para interpretar el mapa para llegar a una tarea de recolección. En ambos 
casos de estudio, cuando los alumnos no podían orientarse con el mapa mencionaron que los colores en las mesas les fueron de ayuda.

Las puestas en práctica incluyeron el depósito de todos los elementos recolectados antes de acceder a la tarea final (desempeño). Al finalizar las mismas, la canasta de todos los grupos estaba vacía.

Para ambos casos de estudio se detectó, que algunos grupos intentaron depositar elementos concretos con la misma dinámica con la que los habían recolectado, es decir, mediante la lectura del códigos QR de los elementos concretos. Una vez que realizaron el primer depósito comprendieron la dinámica de los mismos. En relación a esto, el hecho de que el código QR del elemento concreto, incluyera además el nombre del mismo, favoreció a su reconocimiento al momento de sacarlo de la canasta y seleccionarlo de la lista visible en el dispositivo móvil al momento de depositar (esto también se observó al momento de devolver elementos concretos en las tarea de recolección).

Se detectó que hubo rotación de equipamiento por parte de los miembros del grupo, estando, en la mayoría de las puestas en práctica, el dispositivo móvil al menos una vez en poder de un miembro diferente del grupo. Los varones se mostraban reticentes a tomar la canasta, sin embargo adoptaron esa función dentro del grupo.

Se pudo comprobar con el Grupo 7 de la Escuela 76 que la conformación por parte de cuatro alumnos en un grupo, no es conveniente, ya que la dinámica en el prototipo propuesto plantea realizar tres tareas de recolección y tres tareas de depósito. Y no todos los integrantes del grupo pudieron realizar, al menos una vez, ambas clases de tareas.

Se repitieron patrones de transiciones en ambos casos de estudios obteniendo el mismo diagrama de transición en ambos casos. Esto implica que hubo experiencias similares en ambos casos de estudio. A continuación se detallan las figuras con transiciones coincidentes entre sí:

- La Figura 5.5 (tres grupos) es igual a la Figura 5.13 (tres grupos).

- La Figura 5.6 (un grupo) es igual a la Figura 5.12 (tres grupos).

- La Figura 5.7 (dos grupos) es igual a la Figura 5.11 (dos grupos).

- En ambos casos de estudio, todos los grupos visualizaron su desempeño y lo discutieron con el docente del grado, pudiendo así trabajar sobre las recolecciones o depósitos incorrectos (u omitidos) detectados.

- En ambos casos de estudio se reusaron los mismos códigos QR tanto de elementos concretos como de tareas, sin que estos sufrieran roturas o deterioro. 
En ambas Escuelas, si bien el uso de dispositivos móviles personales no estaba permitido para los alumnos, se mostraron receptivos a la propuesta y valoraron al prototipo como un recurso positivo para las actividades curriculares.

En ambos casos de estudio se contó con la presencia de personal de prensa gráfica registrando la experiencia, en el primer caso de estudio el registro no se dio en simultáneo con las puestas en práctica lo que no actuó como factor distractor, a diferencia de lo sucedido en el segundo caso de estudio. 


\section{Conclusiones y Trabajos Futuros}

En este capítulo se presentan las conclusiones obtenidas en relación al trabajo presentado y se mencionan posibles trabajos futuros.

\subsection{Conclusiones}

En el presente trabajo se presentó un enfoque de modelado extensible y flexible para actividades educativas posicionadas que contempla el desacoplamiento de los aspectos de posicionamiento, actividades educativas e información relevante de los usuarios (su actividad, respuestas brindadas, etc.) para facilitar el reuso de cada uno de ellos. Para lograr esto, se propusieron tres modelos:

- Modelo de Actividades Educativas.

- Modelo de Actividades Educativas Posicionadas.

- Modelo de Usuario.

Dentro de cada uno de estos modelos se presentaron los conceptos más relevantes, como por ejemplo:

- En el Modelo de Actividades Educativas, los conceptos de actividad educativa, planificación, tarea, consigna, enunciado (modelando, entre otros conceptos el lugar y el elemento).

- En el Modelo de Actividades Educativas Posicionadas, los conceptos de actividad educativa posicionada, tarea posicionada, elemento concreto, lugar posicionado.

- En el Modelo del Usuario, los conceptos de grupo, roles de participantes, respuestas y actividades del usuario.

En caso de que una actividad educativa, tenga tareas cuyos enunciados están ligados a particularidades del espacio físico en el que deben ser realizadas, las mismas no podrán ser reusadas en diferentes tareas posicionadas en otros espacios físicos.

Estos modelos pueden ser extendidos para diferentes dominios, en particular esto se mostró para la extensión de los modelos del enfoque para el dominio presentado en el Capítulo 4, en donde se presenta un dominio particular en el cual se contemplan actividades educativas posicionadas en la que las tareas posicionadas involucran elementos concretos que el alumno debe recolectar y posteriormente depositar de acuerdo a un criterio (en particular, relacionado el tipo de material). A partir de este análisis se decidió extender los modelos propuestos en el Capítulo 3. De este modo los conceptos introducidos en cada modelo son los siguientes: 
- En el Modelo de Actividades Educativas, los conceptos de componente de manipulación, tanto de recolectar como de depositar, lugar de depósito y el tipo de material.

- En el Modelo de Actividades Educativas Posicionadas, el concepto de lugar de depósito posicionado.

- En el Modelo del Usuario, el concepto de respuesta de manipulación.

Esta extensión, fue usada para implementar el prototipo ¡Aprendo Jugando! (para Android) propuesto en la Sección 4.2. Dicha extensión fue instanciada con tres tareas de recolección, tres tareas de depositar y una tarea de finalización. Es importante notar que, tanto los modelos propuestos en el Capítulo 3, como los modelos extendidos en el Capítulo 4, pueden ser instanciados para diferentes prototipos, por ejemplos para diferentes plataformas (Android, IPhone, etc). Estos modelos no se limitan a ningún programa educativo en particular, sino que, quien los instancie deberá recibir los criterios pedagógicos necesarios para hacerlo.

En el Capítulo 5, se presentaron dos casos de estudio en los cuales se puso en práctica el prototipo ¡Aprendo Jugando!. Durante las puestas en práctica se realizaron observaciones que sirvieron para la recolección de datos para un análisis y discusión sobre los mismos.

Cabe mencionar que en la implementación del prototipo, se decidió contemplar dos dinámicas diferentes para recolectar elementos que para depositarlos. En la primera, se debe leer el código QR del elemento concreto y de esta manera se incorpora a una lista, debiendo el alumno ingresarlo a una canasta, mientras que en el caso de depositar elementos concretos, estos se marcan en una lista del dispositivo, se elige una opción para depositarlos y manualmente, el alumno los saca de la canasta y los deja en un cesto.

En este trabajo se usaron los códigos QR como mecanismo de identificación tanto de tareas posicionadas como de elementos concretos. Esto influye en la forma en la que los alumnos deben interactuar con éstos ya que debe haber una acción explícita de lectura del código QR. En el caso de contar con un mecanismo de sensado automático, como por ejemplo RFID, la canasta y los depósitos podrían detectar automáticamente los elementos concretos que se coloquen dentro de ellos o se quiten (al incluir etiquetas RFID en los elementos concretos, depósitos y canasta). Esto impacta en la implementación del prototipo ya que se debe tener alguna comunicación entre estos RFID que detectan el ingreso de un elemento (a la canasta o depósito) con la aplicación móvil. Desde el punto de vista del alumno, pasa a ser transparente la recolección y el depósito de elementos concretos. Y desde el punto de vista de los modelos, esto no tiene impacto.

Realizar este tipo de actividades educativas posicionadas en espacios físicos fuera de la escuela, impactan en la motivación de los alumnos ya que permitirían realizar trabajos de 
campo educativos con el apoyo de la tecnología móvil. En los dos casos de estudio, no fue posible realizar las puestas en práctica fuera de la escuela por una cuestión de permisos para salidas de los alumnos.

Cuando se estaba finalizando con la escritura de esta tesis, fueron aceptados dos trabajos relacionados. Estos trabajos son [Alconada Verzini et al., 2015a] y [Alconada Verzini et al., 2015b]. El primero de estos trabajos presenta una herramienta visual para la construcción de experiencias sensibles a la posición. La misma está basada en una generalización de los conceptos de separación de concerns empleados en esta tesis. Como trabajo futuro se particularizará esta herramienta para definir actividades educativas posicionadas. Por otro lado, en [Alconada Verzini et al., 2015b] se presenta un enfoque de modelado para aplicaciones sensibles a la posición. Este mismo concepto es el usado en esta tesis, pero particularizándolo para actividades educativas posicionadas, donde la posición queda desacoplada de las actividades educativas.

\subsection{Trabajos Futuros}

En esta sección se presentan posibles trabajos futuros en diferentes aspectos relacionados al trabajo propuesto. Los mismos se plantean con respecto a:

- Extender los modelos del enfoque

- Para que en la planificación se puedan incorporar transiciones condicionales para pasar a una siguiente tarea.

- Para contar con la lógica necesaria para la creación de tareas dinámicas en base, por ejemplo, al desempeño actual, historial del alumno o respuestas brindadas. Este tipo de tareas permitiría reforzar, de forma dinámica, las tareas propuestas en la planificación original. Esto requiere un análisis exhaustivo de cómo plantear las estrategias de creación teniendo en cuenta en que momentos de la actividad educativa posicionada y en qué lugares, se brindarán las mismas.

- Para sumar el concepto de mensajes entre grupos para resolver tareas de manera colaborativa.

- Para contemplar puntos de encuentro de los grupos para su colaboración en la resolución de tareas.

- Para soportar mensajes desde los tutores u observadores hacia los alumnos o entre ellos.

- Para incorporar el concepto de monitoreo de la actividad de los alumnos para que un tutor pueda intervenir en caso de ser necesario, enviándole mensajes al dispositivo y registrar la comunicación que, por este medio, se dé entre las partes 
- Incorporar otro tipos de consignas que puedan ser evaluadas durante la puesta en práctica por parte de un docente o tutor, valiéndose de la modelización del envío de respuestas generadas por los alumnos a estos roles y la recepción de mensajes en consecuencia por parte de los alumnos.

- Instanciación de los modelos

- Se podría trabajar en la definición y creación de un repositorio de instancias de clases pertenecientes a los modelos de actividades educativas y actividades educativas posicionadas, con el objetivo de poder compartirlas en una comunidad de uso. Esto permitiría el reuso de estos objetos para diferentes espacios físicos, así como la facilidad al momento de prototipar.

\section{- Creación de prototipos}

- Proveer la opción de deshacer o rehacer tareas

- Por ejemplo, incluir la posibilidad de volver a realizar una tarea de recolección ya visitada, de modo que el alumno puede regresar a recolectar o devolver elementos concretos de una tarea de recolección o bien, poder incluir la posibilidad de extraer un elemento concreto de un depósito y registrar su depósito en otro diferente.

- Considerar características de accesibilidad en diferentes aspectos del prototipo

- Utilizar diferentes tipos de sensado

- Para los elementos concretos y las tareas: Esto implica analizar otras formas de interacción en base a cada tipo de sensado determinando cuál de ellas genera más transparencia para los usuarios

- Para los participantes: contemplar sensado permanente de los participantes para poder brindarle asistencia en la movilidad, por ejemplo asistirlo para que siga un camino asignado.

- Herramienta de autor

- Creación de una herramienta de autor para que los docentes puedan desde la misma, instanciar los modelos, crear los mapas de los espacios físicos y generar una aplicación prototípica ejecutable desde un dispositivo móvil para diferentes plataformas (por ejemplo, Android o IPhone). Por ejemplo, se 
trabajará en realizar una extensión de la herramienta presentada en [Alconada Verzini et al., 2015a].

Los listados previamente, son algunos de los posibles trabajos futuros derivables de la tesis presentada. 
Página 120 de 167 


\section{Referencias}

[Al Hamdani, 2013] Al Hamdani, D. S. Mobile Learning: A Good Practice. Procedia-Social and Behavioral Sciences, 103, 665-674. 2013

[Alconada Verzini et al., 2015a] Alconada Verzini, A.M. Tonelli, J.I., Challiol, C., Lliteras, A.B., \& Gordillo S.E. Authoring Tool for Location-Aware Experiences. In Proceeding of 2015 Narrative and Hypertext Workshop. ACM, ISBN 978-1-4503-3797-7/15/09, DOI: http://dx.doi.org/10.1145/2804565.2804570. 21-25. 2015.

[Alconada Verzini et al., 2015b] Alconada Verzini, A.M., Tonelli, J.I., Challiol, C., Lliteras, A.B., \& Gordillo S.E. Combing Location-Aware Applications with in-situ Actors Performances. In Proceeding of 2015 Narrative and Hypertext Workshop. ACM, ISBN 978-1-4503-37977/15/09, DOI: http://dx.doi.org/10.1145/2804565.2804571. 27-31. 2015.

[Ali et al., 2012] Ali, A., Ouda, A., \& Capretz, L. F. A Conceptual Framework for Measuring the Quality Aspects of Mobile Learning. Bulletin of the IEEE Technical Committee on Learning Technology, 14(4), 31. 2012

[Anderson et al., 2001] Anderson, L. W., Krathwohl, D. R., \& Bloom, B. S. A taxonomy for learning, teaching, and assessing: A revision of Bloom's taxonomy of educational objectives. Allyn \& Bacon. 2001

[Bamberger and Tal, 2007] Bamberger, Y., \& Tal, T. Learning in a personal context: levels of choice in a free choice learning environment in science and natural history museums. Science Education, 91(1), 75-95. 2007

[Bäumer et al., 1998] Bäumer, D., Riehle, D., Siberski, W., \& Wulf, M. The role object pattern. In Washington University Dept. of Computer Science. 1998

[Beckman, 1990] Beckman, M. Collaborative learning: Preparation for the workplace and democracy?. College teaching, 38(4), 128-133. 1990

[Bloom and Krathwohl, 1956] Bloom, B. S., \& Krathwohl, D. R. Taxonomy of Educational Objectives: The Classification of Educational Goals. Handbook I: Cognitive Domain. 1956

[Britain, 2004] Britain, S. A review of learning design: concept, specifications and tools. A report for the JISC E-learning Pedagogy Programme, 2006. 2004

[Brown et al., 2010a] Brown, E., Sharples, M., Clough, G., Tangney, B., Wishart, J., Wijers, M., \& Polmear, G. Education in the wild: contextual and location-based mobile learning in action. Learning Sciences Research Institute. 2010

[Brown et al., 2010b] Brown, E., Börner, D., Sharples, M., Glahn, C., De Jong, T., \& Specht, M. Location-based and contextual mobile learning. A STELLAR Small-Scale Study. 2010

[Brown, 2010] Brown, E. Introduction to location-based mobile learning. In: Brown, Elizabeth ed. Education in the wild: contextual and location-based mobile learning in action. A report from the STELLARAlpine Rendez-Vous workshop series. Nottingham, UK: Learning Sciences Research Institute, University of Nottingham, pp. 7-9. 2010

[Bruner, 1996] Bruner, J. S. Toward a theory of instruction .(Vol. 59). Harvard University Press. 59. 1996 
[Camilloni et al., 2001] Camilloni, A., Carretero, M., Castorina, J. A., Lenzi, A., \& Litwin, E. Debates constructivistas. Aique. 2001

[Carretero, 1993] Carretero, M. Constructivismo y educación. Editorial Progreso. 1993

[Carretero, 1997] Carretero, M. ¿Qué es el constructivismo?. Constructivismo y educación, Desarrollo cognitivo y aprendizaje. México: Ed. Progreso, pp. 39-71. 1997

[Challiol et al., 2012] Challiol, C., Rossi, G., Gordillo, S. E., \& Fortier, A. Separation of concerns in mobile hypermedia: architectural and modeling issues. Handbook of Research on Mobile Software Engineering: Design, Implementation and Emergent Applications, 1, 211-233. 2012

[Chan et al., 2006] Chan, T. W., Roschelle, J., Hsi, S., Kinshuk, Sharples, M., Brown, T., \& Hoppe, U. One-to-one technology-enhanced learning: An opportunity for global research collaboration. Research and Practice in Technology Enhanced Learning, 1(01), 3-29. 2006

[Chu et al., 2010] Chu, H. C., Hwang, G. J., Tsai, C. C., \& Tseng, J. C. A two-tier test approach to developing location-aware mobile learning systems for natural science courses. Computers \& Education, 55(4), 1618-1627. 2010

[Cochrane and Bateman, 2010] Cochrane, T., \& Bateman, R. Smartphones give you wings: Pedagogical affordances of mobile Web 2.0. Australasian Journal of Educational Technology, 26(1). 2010

[Cole and Engeström, 2001] Cole, M., \& Engeström, Y. Enfoque histórico-cultural de la cognición distribuida. Cogniciones distribuidas: Consideraciones psicológicas y educativas. 2001

[Conole, 2008] Conole, G. Capturing practice: the role of mediating artefacts in learning design. In: Lockyer, L., Bennett, S., Agostinho, S. and Harper, B. (eds) Handbook of Research on Learning Design and Learning Objects: Issues, Applications and Technologies. Hershey, Pennsylvania: Information Science Reference, part of IGI. 2008.

[Costabile et al., 2008] Costabile, M. F., De Angeli, A., Lanzilotti, R., Ardito, C., Buono, P., \& Pederson, T. Explore! possibilities and challenges of mobile learning. In Proceedings of the SIGCHI Conference on Human Factors in Computing Systems, AMC, (pp. 145-154). ACM. 2008

[Daniels, 2003] Daniels, H. Vygotsky y la pedagogía (G. Sánchez Barberán, trad.). 2003

[Devedžić et al., 2007] Devedžić, V., Jovanović, J., \& Gašević, D. The pragmatics of current elearning standards. Internet Computing, IEEE, 11(3), 19-27. 2007

[Dey, 2001] Dey, A.K. Understanding and using context. Personal and ubiquitous computing, 5(1), 4-7. 2001

[Dodds and Thropp, 2006] Dodds, P., \& Thropp, S.E. Sharable Content Object Reference Model (SCORM) 2004. Version 1.0. Advanced Distributed Learning. 2006

[Engeström and Escalante, 1996 ] Engeström, Y., \& Escalante, V. Mundane tool or object of affection? The rise and fall of the postal buddy. Context and consciousness: Activity theory and human-computer interaction, 325-374. 1996

[Engeström et al., 1999] Engeström, Y., Miettinen, R., \& Punamäki, R. L. (1999). Perspectives on activity theory. Cambridge University Press. 1999 
[Engeström, 1987] Engeström, Y. Learning by expanding: An activity-theoretical approach to developmental research. 1987

[Engeström, 2001] Engeström, Y. Expansive learning at work: Toward an activity theoretical reconceptualization. Journal of education and work, 14(1), 133-156. 2001

[Facer et al., 2004] Facer, K., Joiner, R., Stanton, D., Reid, J., Hull, R., \& Kirk, D. Savannah: mobile gaming and learning?. Journal of Computer Assisted Learning, 20(6), pp. 399-409. 2004

[Frohberg et al., 2009] Frohberg, D., Göth, C., \& Schwabe, G. Mobile learning projects-a critical analysis of the state of the art. Journal of Computer Assisted Learning, 25(4), 307-331. 2009

[Gamma et al., 1994] Gamma, E., Helm, R., Johnson, R., \& Vlissides, J. Design patterns: elements of reusable object-oriented software. Pearson Education. 1994.

[Gomez et al., 2014] Gómez, S., Zervas, P., Sampson, D. G., \& Fabregat, R. Context-aware adaptive and personalized mobile learning delivery supported by UoLmP. Journal of King Saud University-Computer and Information Sciences, 26(1), 47-61. 2014

[González, 2012] González, M. J. C. Las consignas como enunciados orientadores de los procesos de escritura en el aula. Enunciación, 15(2), 58-67. 2012

[González-Tejero, 2011] Serrano González-Tejero, J.M., \& Pons Parra, R.M. El constructivismo hoy: enfoques constructivistas en educación. Revista electrónica de investigación educativa, 13(1), 1-27. 2011

[Hafedh et al., 2004] Hafedh, M., Amel, E., \& Hamid, M. Understanding Separation of Concerns. In Proceedings of Aspect-Oriented Software Development (AOSD), pp. 76-85. 2004

[Hansen and Bouvin, 2009 ] Hansen, F. A., \& Bouvin, N. O. Mobile learning in context-contextaware hypermedia in the wild. International Journal of Interactive Mobile Technologies, 3(1), 6-21. 2009

[Hansen et al., 2012] Hansen, F. A., Kortbek, K. J., \& Grønbæk, K. Mobile urban drama: interactive storytelling in real world environments. New Review of Hypermedia and Multimedia, 18(12), 63-89. 2012

[Hatakka et al., 2007] Hatakka, M., Avdic, A., \& Andersson, A. SCORM: from the perspective of the course designer: a critical review. In ECEL 2007: 6th European Conference on E-Learning: Copenhagen Business School, p. 307. Academic Conferences Limited. 2007

[Huang et al., 2012] Huang, R., Zhang, H., Li, Y., \& Yang, J. A framework of designing learning activities for mobile learning. In Hybrid Learning, (pp. 9-22). Springer Berlin Heidelberg, pp. 9-22. 2012

[Hyo-Jeong et al., 2008] Hyo-Jeong, S. O., Insu, K. I. M., \& Chee-Kit, L. O. O. I. Seamless mobile learning: Possibilities and challenges arising from the Singapore experience. Educational Technology International, 9(2), 97-121. 2008

[IMS, 2003] IMS, S. IMS Simple Sequencing Best Practice and Implementation Guide. Version 1.0 Final Specification. IMS Global Learning Consortium. 2003

[IMS, 2006] IMS. IMS question \& test interoperability specification v2.0/v2.1. 2006. Disponible en: http://www.imsglobal.org/question/index.html. Último acceso: Agosto de 2015.

Página 123 de 167 
[IMS-LD, 2003] IMS Learning Design Specification. IMS-LD. 2003. http://www.imsglobal.org/learningdesign/index.html. Último acceso: Agosto de 2015.

[Ivić, 1994] Ivić, I. Lev s. vygotsky. Prospects, 24(3-4), 761-785. 1994

[Jesse and Chang, 2012] Jesse, R., \& Chang, M. Using IMS learning design to author authentic learning examples in mobile context. In Proceeding of 2012 IEEE Seventh International Conference on Wireless, Mobile and Ubiquitous Technology in Education (WMUTE), 2012 IEEE Seventh International Conference on (IEEE, pp. 167-171). IEEE. 2012

[Kadirire, 2009] Kadirire, J. Mobile Learning DeMystified. In R. Guy (Ed) The Evolution of Mobile Teaching and Learning. Informing Science Press. 2009

[Kato et al., 2010] Kato, H., Chai, D., \& Tan, K. T. Barcodes for mobile devices. Cambridge: Cambridge University Press. 2010

[Kennedy, 2006] Kennedy, D. Writing and using learning outcomes: a practical guide. University College Cork. 2006

[Keskin and Metcalf, 2011] Keskin, N., \& Metcalf, D. The Current Perspectives, Theories and Practicies of Mobile Learning. The Turkish Online Journal of Educational Technology, 10(2), pp. 202-208. 2011

[Kjeldskov and Paay, 2004] Kjeldskov, J., \& Paay, J. Augmenting the City with fiction: fictional requirements for mobile guides. MIRW/MGuides 2007, 15. 2004

[König and Paramythis, 2012] König, F., \& Paramythis, A. Adaptive Collaboration Scripting with IMS LD. In Intelligent Adaptation and Personalization Techniques in Computer-Supported Collaborative Learning, Springer Berlin Heidelberg, pp. 47-84. 2012

[Kukulska-Hulme et al., 2007] Kukulska-Hulme, A., Traxler, J., \& Pettit, J. Designed and usergenerated activity in the mobile age. Journal of Learning Design, 2(1), 52-65. 2007

[Kukulska-Hulme et al., 2011] Kukulska-Hulme, A., Sharples, M., Milrad, M., Arnedillo-Sanchez, I., \&and Vavoula, G. The genesis and development of mobile learning in Europe. In: Parsons, David ed. Combining E-Learning and M-Learning: New Applications of Blended Educational Resources. Hershey, PA: Information Science Reference (an imprint of IGI Global), pp. 151177. 2011

[Lallerana and McGrinn, 1981] Lallerana, R., \& McGinn, N. Definición del campo temático de planeación educativa. In Documento base del Congreso Nacional de Investigación Educativa. México. 1981

[Larkin and Simon, 1987] Larkin, J. H., \& Simon, H. A. Why a diagram is (sometimes) worth ten thousand words. Cognitive science, 11(1), 65-100. 1987

[Lave and Wenger, 1991] Lave, J., \& Wenger, E. Situated Learnig Legitimate Peripheral Participation. Cambridge University Press. 1991

[Lehman, 1996] Lehman, M. M. Laws of software evolution revisited. In Software process technology, Springer Berlin Heidelberg, (pp. 108-124). 1996

[Leonhardt, 1998] Leonhardt, U. Supporting location-awareness in open distributed systems (Doctoral dissertation, Imperial College). 1998

[Leontev, 1978] Leont, E.V. Activity, consciousness, and personality. Moscow: Progress. 1978 
[Liu et al., 2014] Liu, T. C., Lin, Y. C., \& Paas, F. Effects of prior knowledge on learning from different compositions of representations in a mobile learning environment. Computers \& Education, 72, 328-338. 2014

[Lliteras et al., 2011] Lliteras, A. B., Challiol, C., Mostaccio, C., \& Gordillo, S. Representaciones enriquecidas para la navegación indoor-outdoor en aplicaciones móviles. In XVII Congreso Argentino de Ciencias de la Computación. 2011

[Lliteras et al., 2012] Lliteras, A.B., Challiol, C. y Gordillo, S. Juegos Educativos Móviles Basados en Posicionamiento: Una Guía para su Conceptualización . 41 JAllO. Agosto de 2012. Facultad de Informática, UNLP. Con referato. In Proceedings of ASSE 2012 Argentine Symposium on Software Engineering. ISSN: 1850-2792, pp. 164-175. 2012

[Lliteras et al., 2013] Lliteras, A.B., Challiol, C. y Gordillo, S. Juegos Educativos Móviles: Aspectos Involucrados. In XVIII Congreso Argentino de Ciencias de la Computación, pp. 671-680. 2013

[Lompscher, 1999] Lompscher, J. Motivation and activity. European Journal of psychology of education, 14(1), 11-22. 1999

[Loomis and Lederman, 1986] Loomis, J. M., \& Lederman, S. J. Tactual perception. Handbook of perception and human performances, 2, (2). 1986

[Lu et al., 2010] Lu, C., Chang, M., Echo Huang, K., Chen, C.: Usability of Context-Aware Mobile Educational Game. Knowledge Management \& E-Learning, 3(3), pp. 448-477. 2010

[Luckin, 2010] Luckin, R. Re-designing learning context: Technology-rich, learner-centred ecologies. Routledge. 2010

[Madhavji et al., 2006] Madhavji, N. H., Fernandez-Ramil, J., \& Perry, D. (Eds.). Software evolution and feedback: Theory and practice. John Wiley \& Sons. 2006.

[Malone and Lepper, 1987] Malone, T.W., Lepper, M.R.: Making learning fun: A taxonomy of intrinsic motivations for learning. In: Snow, R.E., Farr, M.J. (eds.). Aptitude, Learning and Instruction III: Cognitive and affective Process Analyses, vol. 3, pp. 223-253. 1987

[Manches and O'Malley, 2012] Manches, A., \& O'Malley, C. Tangibles for learning: a representational analysis of physical manipulation. Personal and Ubiquitous Computing, 16(4), 405-419. 2012

[McNeil and Jarvin, 2007] McNeil, N., \& Jarvin, L. When theories don't add up: disentangling the manipulatives debate. Theory into Practice, 46(4), 309-316. 2007

[Millard et al., 2013] Millard, D. E., Hargood, C., Jewell, M. O., \& Weal, M. J. Canyons, deltas and plains: towards a unified sculptural model of location-based hypertext. In Proceedings of the 24th ACM Conference on Hypertext and Social Media (pp. 109-118). ACM, pp. 109-118. 2013

[Miller, 1956] Miller, G.A. The magical number seven, plus or minus two: some limits on our capacity for processing information. Psychological review, 63(2), 81. 1956

[Montessori, 1964] Montessori, M. The Montessori method. Ney York; Schocken. 1964

[Moreira et al., 2005] Moreira, A., Araujo, J., \& Rashid, A. A Concern-oriented Requirement Engineering Model. In Proceedings of Conference on Advanced Information Systems Engineering (CAISE'05), Springer, LNCS 3520, pp. 293-308. 2005

Página 125 de 167 
[Moreno and Mayer, 2000] Moreno, R., \& Mayer, R.E. A coherence effect in multimedia learning: The case for minimizing irrelevant sounds in the design of multimedia instructional messages. Journal of Educational Psychology, 92(1), 117. 2000

[Moreno and Mayer, 2001] Moreno, R., \& Mayer, R.E. Designing for understanding: A learnercentered approach to multimedia learning. In Proceedings Human-Computer Interaction, 248-250. 2001

[Neumann et al., 2009] Neumann, S., Klebl, M., Griffiths, D., Hernández-Leo, D., De la FuenteValentin, L., Hummel, H., \& Oberhuemer, P. Report of the results of an IMS learning design expert workshop. 2009

[Ng, 2013] Ng, W. Conceptualising mLearning literacy. International Journal of Mobile and Blended Learning (IJMBL), 5(1), 1-20. 2013

[Ng, 2015] Ng, W. Mobile Learning: BYOD and Personalised Learning. In New Digital Technology in Education. Springer International Publishing. pp. 171-189. 2015

[O'Malley et al., 2003] O'Malley, C., Vavoula, G., Glew, J., Taylor, J., Sharples, M., \& Lefrere, P. Guidelines for learning/teaching/tutoring/ in a mobile environment. Mobilearn project deliverable. 2003

[Ossher and Tarr, 2000] Ossher, H. and Tarr, P.: Multi-Dimensional Separation of Concerns andthe Hyperspace Approach. In Proceedings of the Symposium on Software Architecturesand Component Technology: The State of the Art in Software Development, 2000, pp. 293-323. 2000

[Paramythis, 2008] Paramythis, A. Adaptive support for collaborative learning with ims learning design: Are we there yet. In Proceedings of the Workshop on Adaptive Collaboration Support, held in conjunction with the 5th International Conference on Adaptive Hypermedia and Adaptive Web-Based Systems, pp. 17-29. 2008

[Parnas, 1972] Parnas, D. L. On the criteria to be used in decomposing systems into modules. Communications of the ACM, 15(12), 1053-1058. 1972.

[Parsons, 2014] Parsons, D. The future of mobile learning and implications for education and training. Increasing Access, 217. 2014

[Piaget and Szeminska, 1995] Piaget, J. and Szeminska, A. "The child's conception of number (C. Gattegno \& F. M Hodgson, Trans.)". In The essential Piaget, Edited by: Gruber, HE and Voneche, JJ 298-341. Northvale, NJ: Jason Aronson. (Original work published 1941). 1995

[Piaget, 1952] Piaget, J. The origins of intelligence in children. International Universities Press. 8(5), 18.1952

[Piaget, 1965] Piaget, J. The stages of the intellectual development of the child. Educational psychology in context: Readings for future teachers, 98-106. 1965

[Piaget, 1972] Piaget, J. Intellectual evolution from adolescence to adulthood. Human development, 15(1), 1-12. 1972

[Powell and Kalina, 2009] Powell, K.C., \& Kalina, C.J. Cognitive and social constructivism: Developing tools for an effective classroom. Education, 130(2), 241. 2009

[Prensky, 2001] Prensky, M.: Digital Game-based Learning. McGraw-Hill, New York. 2001 
[Quinn, 2000] Quinn, C. mLearning: Mobile, Wireless, In-Your-Pocket Learning. LineZine, Fall. 2000

[Raessens, 2007] Raessens, J.: Playing history. Reflections on mobile and location-based learning. In T. Hug (Ed.), Didactics of microlearning. Concepts, discourses, and examples, 2007, pp. 200-217. 2007

[Reigeluth, 2007] Reigeluth, C. M. Order, first step to mastery: An introduction to sequencing in instructional design. In order to learn: How the sequence of topics influences learning, 1940. 2007

[Riestra, 2004] Riestra, D. Las consignas de trabajo en el espacio socio-discursivo de la enseñanza de la lengua. Les consignes de travail dans l'espace socio-discursif de l'enseignement de la langue. Université de Genève: Doktorego tesia. 2004

[Rogers et al., 2005] Rogers, Y., Price, S., Stanton Fraser, D., Randell, C., Weal, M., \& Fitzpatrick, G. Ubi-learning integrates indoor and outdoor experiences. Communications of the ACM, 48 (1), 55-59, Shih, J.L. 2005

[Rumbaugh et al., 1991] Rumbaugh, J., Blaha, M., Premerlani, W., Eddy, F., \& Lorensen, W. E. (1991). Object-oriented modeling and design, Englewood Cliffs: Prentice-hall, (Vol. 199, No. (1). 1991

[Ryu and Parson, 2009] Ryu, H., \& Parsons, D. Designing learning activities with mobile technologies. IGI Global. 2009

[Santos et al., 2011] Santos, P., Pérez-Sanagustín, M., Hernández-Leo, D., \& Blat, J. QuesTInSitu: From tests to routes for assessment in situ activities. Computers \& Education, 57(4), 25172534. 2011

[Santos et al., 2014] Santos, P., Hernández-Leo, D., \& Blat, J. To be or not to be in situ outdoors, and other implications for design and implementation, in geolocated mobile learning. Pervasive and Mobile Computing, 14, 17-30. 2014

[Sarrab et al., 2012] Sarrab, M., Elgamel, L., \& Aldabbas, H. Mobile learning (m-learning) and educational environments. International journal of distributed and parallel systems, 3(4), 31-38. 2012

[Scanlon, 2014] Scanlon, E. Mobile learning: location, collaboration and scaffolding inquiry. Increasing Access, 85. 2014

[Sharples et al., 2005] Sharples, M., Taylor, J., \& Vavoula, G. Towards a theory of mobile learning. In Proceedings of mLearn 2005, 1(1), 1-9. 2005

[Sollervall et al., 2012] Sollervall, H., Otero, N., Milrad, M., Johansson, D., \& Vogel, B. Outdoor activities for the learning of mathematics: Designing with mobile technologies for transitions across learning contexts. In 2012 IEEE Seventh International Conference on Wireless, Mobile and Ubiquitous Technology in Education (WMUTE), 2012 IEEE Seventh International Conference on IEEE., (pp. 33-40). 2012

[Sutton and Rouvellou, 2002] Sutton, S.M., \& Rouvellou, I. Modeling of Software Concerns in Cosmos. In Proceedings of the 1st international conference on Aspect-Oriented Software Development (AOSD '02), ACM Press, pp. 127-133. 2002

[Sweller, 1988] Sweller, J. Cognitive load during problem solving: Effects on learning. Cognitive science, 12(2), 257-285. 1988

Página 127 de 167 
[Tamayo, 2004] Tamayo, M. El proceso de la investigación científica. Editorial Limusa. 2004

[Tarr et al., 1999] Tarr, P., Ossher, H., Harrison, W., \& Sutton, S.M. N Degrees of Separation MultiDimensional Separation of Concerns. In Proceedings of the 21st international conference on Software engineering, ACM Press, pp. 107-119. 1999

[Traxler, 2005] Traxler, J. Defining mobile learning. In Proceedings, IADIS international conference on mobile learning, Malta. 2005

[Traxler, 2009] Traxler, J. Learning in a mobile age. International Journal of Mobile and Blended Learning (IJMBL), 2009, vol. 1, no( 1), p. 1-12. 2009

[Uden, 2007] Uden, L. Activity theory for designing mobile learning. International Journal of Mobile Learning and Organization, 1(1), 81-102. 2007

[UML] UML. Unified Modeling Language. URL: http://www.uml.org/. Fecha de última visita: 201505-08

[UML_DC] UML, Diagrama de Clases. URL: http://www.uml-diagrams.org/class-diagrams.html. Fecha de última visita: 2015-05-08

[UML_DP] UML, Diagrama de Paquetes. URL: http://www.uml-diagrams.org/packagediagrams.html. Fecha de última visita: 2015-05-08

[UML_DS] UML, Diagrama de Secuencia. URL: http://www.uml-diagrams.org/sequencediagrams.html. Fecha de última visita: 2015-06-28

[Vogel et al., 2010] Vogel, B., Spikol, D., Kurti, A., \& Milrad, M. Integrating mobile, web and sensory technologies to support inquiry-based science learning. In Proceeding of , Paper presented at the 6th IEEE International Conference on Wireless, Mobile, and Ubiquitous Technologies in Education, Kaohsiung, Taiwan. 2010

[Vygotsky, 1978] Vygotsky, L. S. Mind and society: The development of higher mental processes. 1978

[Vygotsky, 2012] Vygotsky, L.S. Thought and language. MIT press. 2012

[Wadsworth, 1996] Wadsworth, B.J. Piaget's theory of cognitive and affective development: Foundations of constructivism. Longman Publishing. 1996

[Wexler et al., 2007] Wexler, S., Schlenker B., Brown J., Metcalf D., Quinn C., Thor E., Van Barneveld A., \& Wagner E. $360^{\circ}$ Research Report Mobile Learning: What It Is, Why It Matters, and How to Incorporate It into Your Learning Strategy. The eLearning Guild. 2007

[Wijers et al., 2010] Wijers, M., Jonker, V., Drijvers, P.. MobileMath: exploring mathematics outside the classroom. In ZDM Mathematics Education, 2010, Vol. 42(, № 7), pp. 789-799. 2010

[Woodill, 2012] Woodill, G. Moving from e-learning to m-learning. The Canadian Learning Journal, 16(2), 34-35. 2012

[Woolf, 1997] Woolf, B. The null object pattern. Pattern Languages of Program Design, 3. 1997

[Yen et al., 2012] Yen, J. C., Lee, C. Y., \& Chen, I. The effects of image-based concept mapping on the learning outcomes and cognitive processes of mobile learners. British Journal of Educational Technology, 43(2), 307-320. 2012 
[Ying et al., 2009] Ying, K., Wu, S., Chang, M., \& Heh, J.S. Narrative Elements Analysis for Educational Mobile Game Development. In: Technology Enhanced Learning Conference, 26. 2009

[Zacharia and Olympiou, 2011] Zacharia, Z. C., \& Olympiou, G. Physical versus virtual manipulative experimentation in physics learning. Learning and Instruction, 21(3), 317-331. 2011

[Zervas and Sampson, 2014] Zervas, P., \& Sampson, D. G. Supporting Mobile Access to Online Courses: The ASK Mobile SCORM Player and the ASK Mobile LD Player. Increasing Access, 125. 2014

[Zhang, 1997] Zhang, J. The nature of external representations in problem solving. Cognitive science, 21(2), 179-217. 1997 
Página 130 de 167 


\section{Anexo A: Cómo instalar el prototipo ¡Aprendo Jugando! en un dispositivo móvil}

En este anexo se describen los requerimientos básicos necesarios para instalar el prototipo iAprendo Jugando!, cómo instalar un lector de códigos QR para ser usado desde el prototipo y por último cómo instalar el prototipo

Los requerimientos básicos para instalar el prototipo iAprendo Jugando! son: contar con un dispositivo móvil (Android versión 4.0 o superior) con cámara de fotos y alguna aplicación para la lectura de código QR.

A continuación, en las siguientes secciones, se describirá la instalación de un posible lector de códigos QR, así como también la instalación del prototipo.

Las pantallas incluidas en la documentación de este anexo, fueron tomadas con un dispositivo Samsung Galaxy SIII con Android 4.0 Ice Cream Sandwich. Para mostrar cómo copiar el archivo del prototipo en una computadora, se tomó como base el sistema operativo Windows 7.

\section{A.1 Instalación de un Lector de QR}

En esta sección se muestra como instalar el lector de QR "QRDroid" desde el "PlayStore" de "Google Play". Notar que este lector es a modo de ejemplo, podría instalarse cualquier otro lector de códigos QR.

A continuación se describen los pasos para la instalación. Los mismos asumen que el dispositivo móvil posee conexión a internet.

En primer lugar, se deberá seleccionar la opción "Menú" de la pantalla de inicio del dispositivo móvil, esta opción se encuentra destacada en la Figura A.1. Una vez en dicha opción, se deberá seleccionar la opción "PlayStore". Esta opción aparece destacada en la Figura A.1.b 


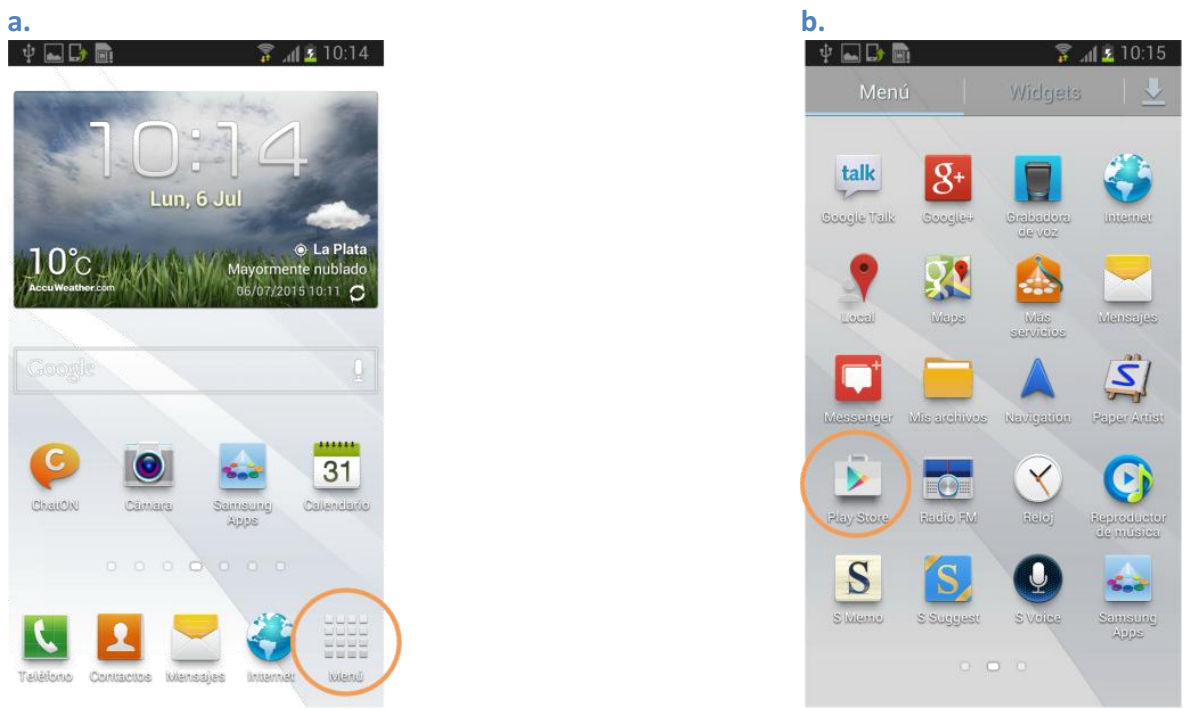

Figura A.1: Primeros pasos para la instalación de un Lector de códigos QR

Desde el "Google Play" en el casillero destacado en la Figura A.2.a, se deberá escribir el término " $q r$ ", como se muestra en la Figura A.2.b, al buscar con este término aparecen listados lectores de QR disponibles en la tienda. En particular, en la Figura A.2.c, se muestra resaltado el lector de códigos $Q R$, que vamos a instalar para este anexo.
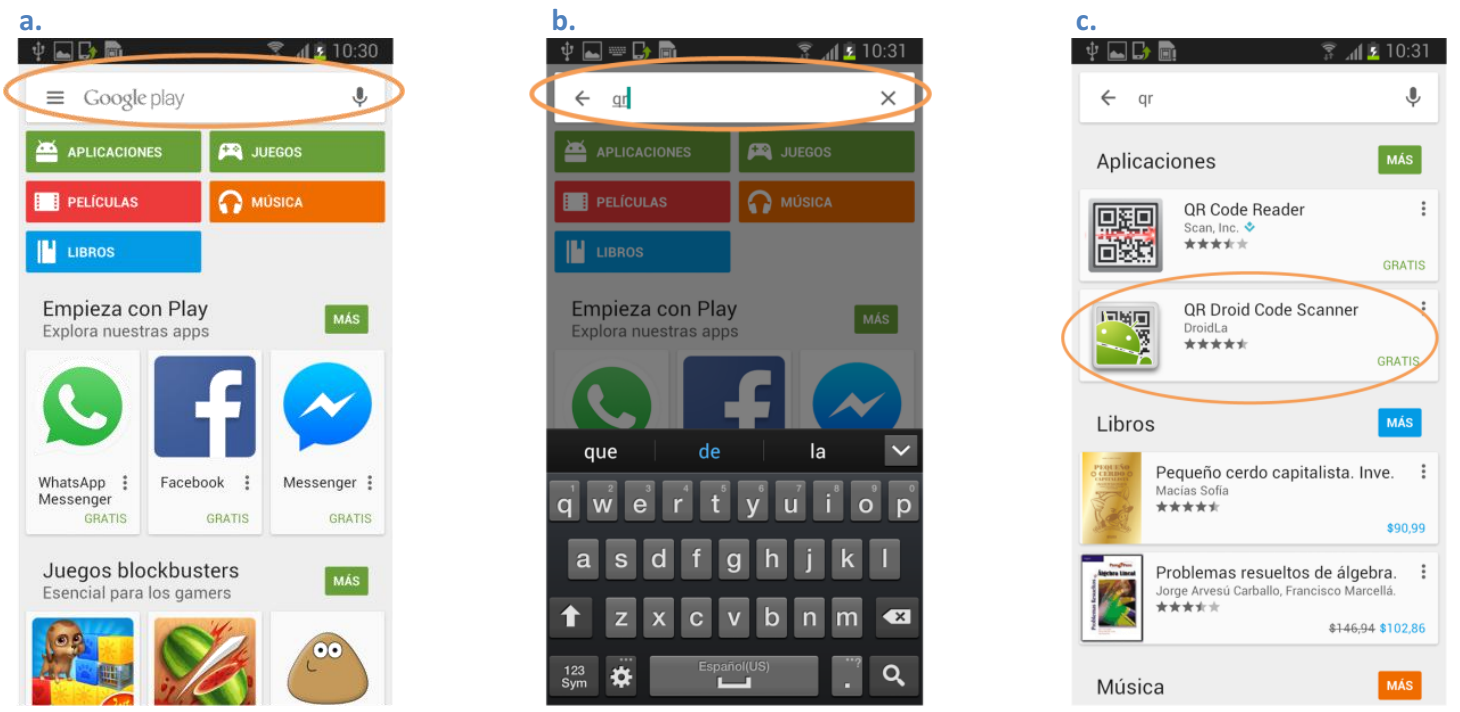

Figura A.2: Selección de un lector de códigos QR desde el PlayStore de Google Play

Al seleccionar el lector de códigos QR destacado en la Figura A.2.c, se visualiza la pantalla que se muestra en la Figura A.3.a, al presionar el botón "Instalar" destacado en dicha figura, se visualiza la pantalla mostrada en la Figura A.3.b, mostrando los permisos que son necesarios aceptar para que el lector de códigos QR, se instale en el dispositivo. De dicha ventana, se deberá seleccionar el botón "Aceptar". 


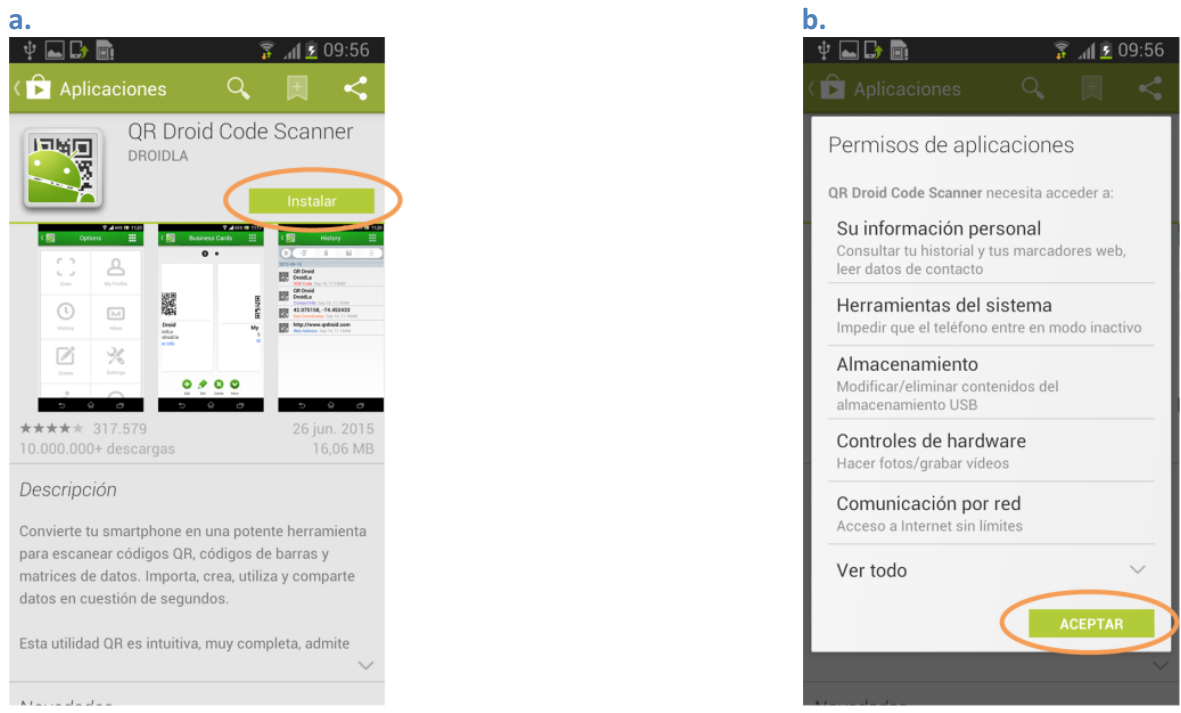

Figura A.3: Instalación del lector de códigos QR, llamado QRDroid

Una vez aceptados los permisos solicitados, se procederá a la descarga de la aplicación como se visualiza en la Figura A.4.a. Cuando finaliza la descarga, el lector de códigos QR se instala y se pasa a visualizar la pantalla que se muestra en la Figura A.4.b. Desde esta ventana se puede abrir el lector recién instalado o bien desinstalarlo. Una vez finalizados los pasos de instalación, el lector de códigos QR queda disponible desde el "Menú" del dispositivo como se muestra en la Figura A.4.c.
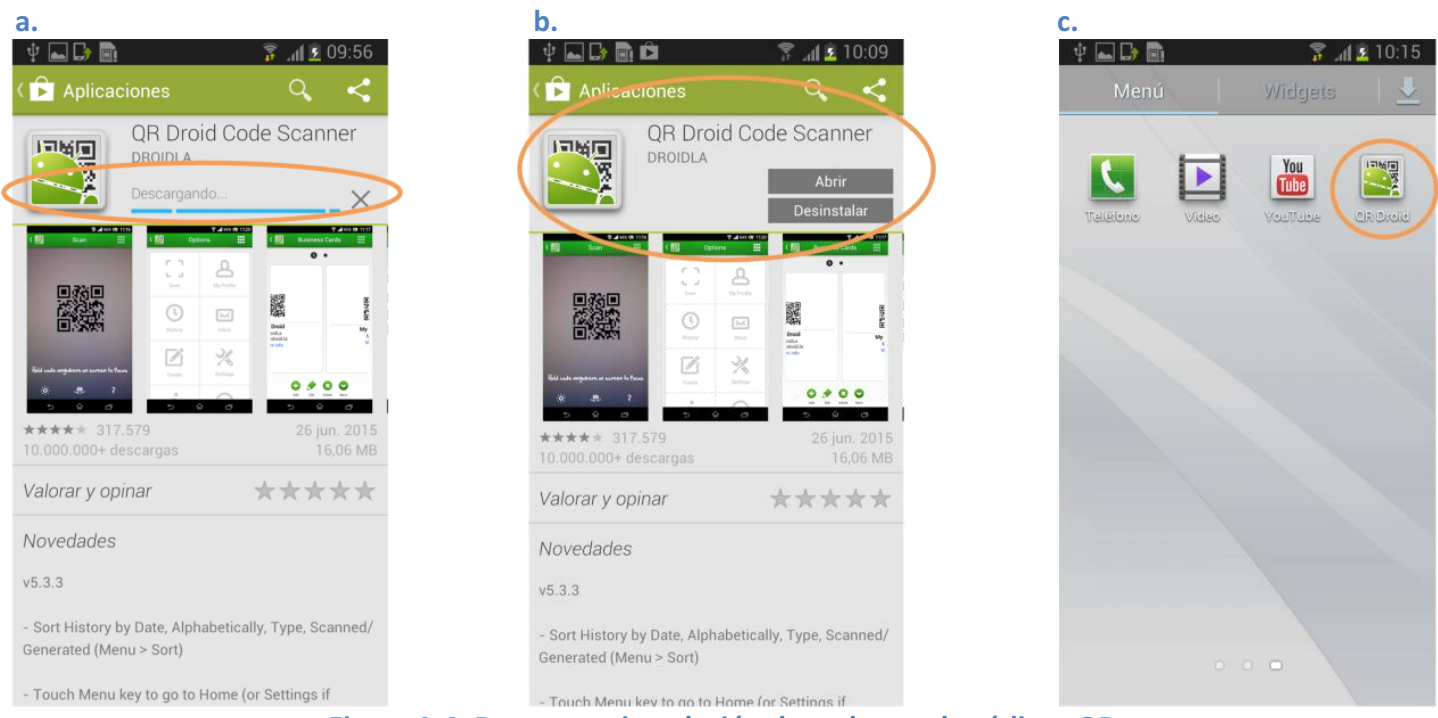

Figura A.4: Descarga e instalación de un lector de códigos QR 


\section{A.2 Instalación del prototipo ¡Aprendo Jugando!}

El prototipo ¡Aprendo Jugando! es una aplicación Android, por ello, el archivo posee extensión ".apk". A continuación se describen los pasos necesarios para copiar el archivo llamado "aprendo.apk" a su dispositivo móvil:

- Asumiendo que ya tiene en su computadora el archivo llamado "aprendo.apk", conecte su dispositivo móvil a la misma.

- Luego acceda a su dispositivo móvil, desde el explorador de Windows, como si este fuese un disco más de su computadora.

- Navegue la estructura de carpetas y en el lugar que decida, cree una carpeta, por ejemplo, llamada "AprendoJugando". En la Figura A.5 se muestra esta carpeta creada en el dispositivo móvil.

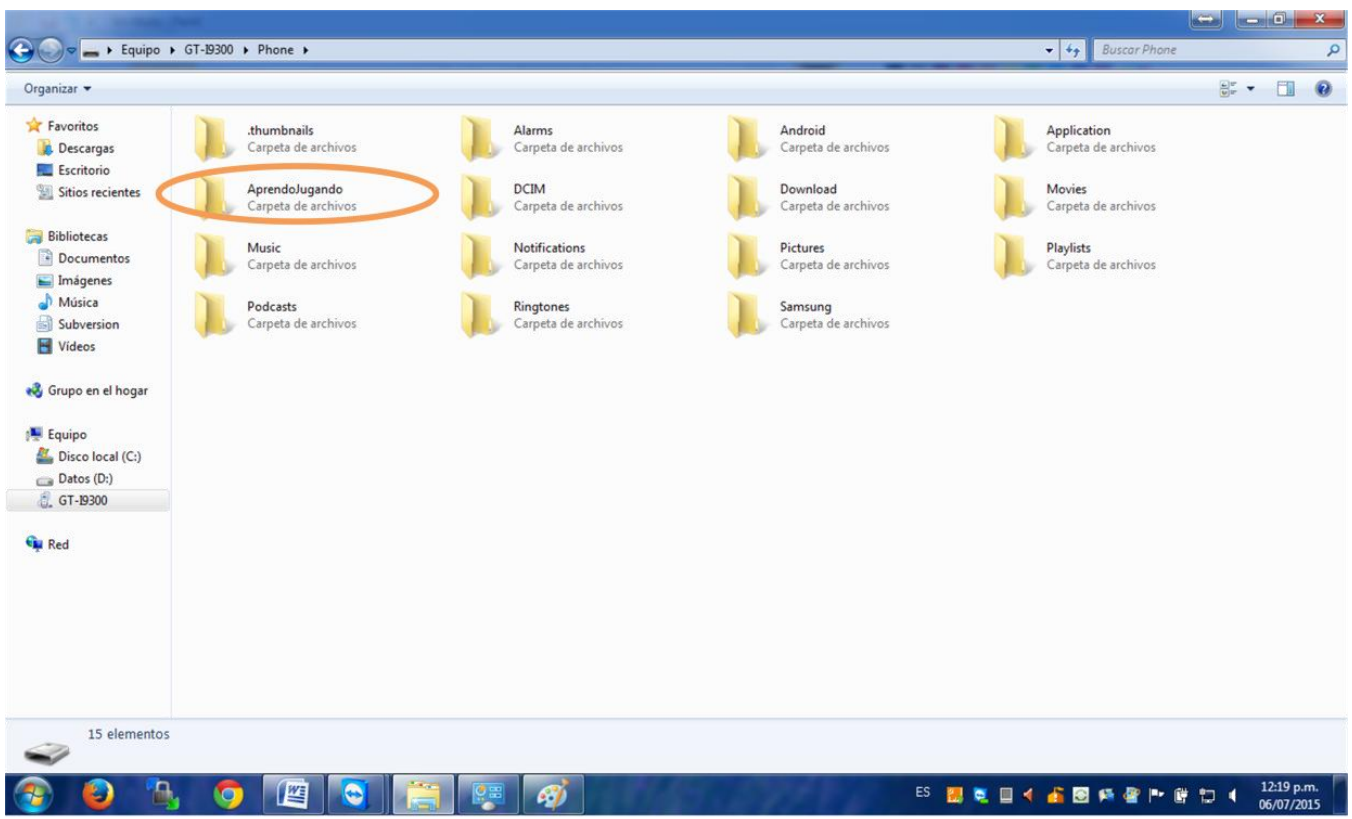

Figura A.5: Creación de una carpeta en el dispositivo

- En la carpeta creada, copie el archivo "aprendo.apk" desde su computadora al dispositivo móvil. En la Figura A.6, se muestra dicho archivo copiado en el dispositivo. 


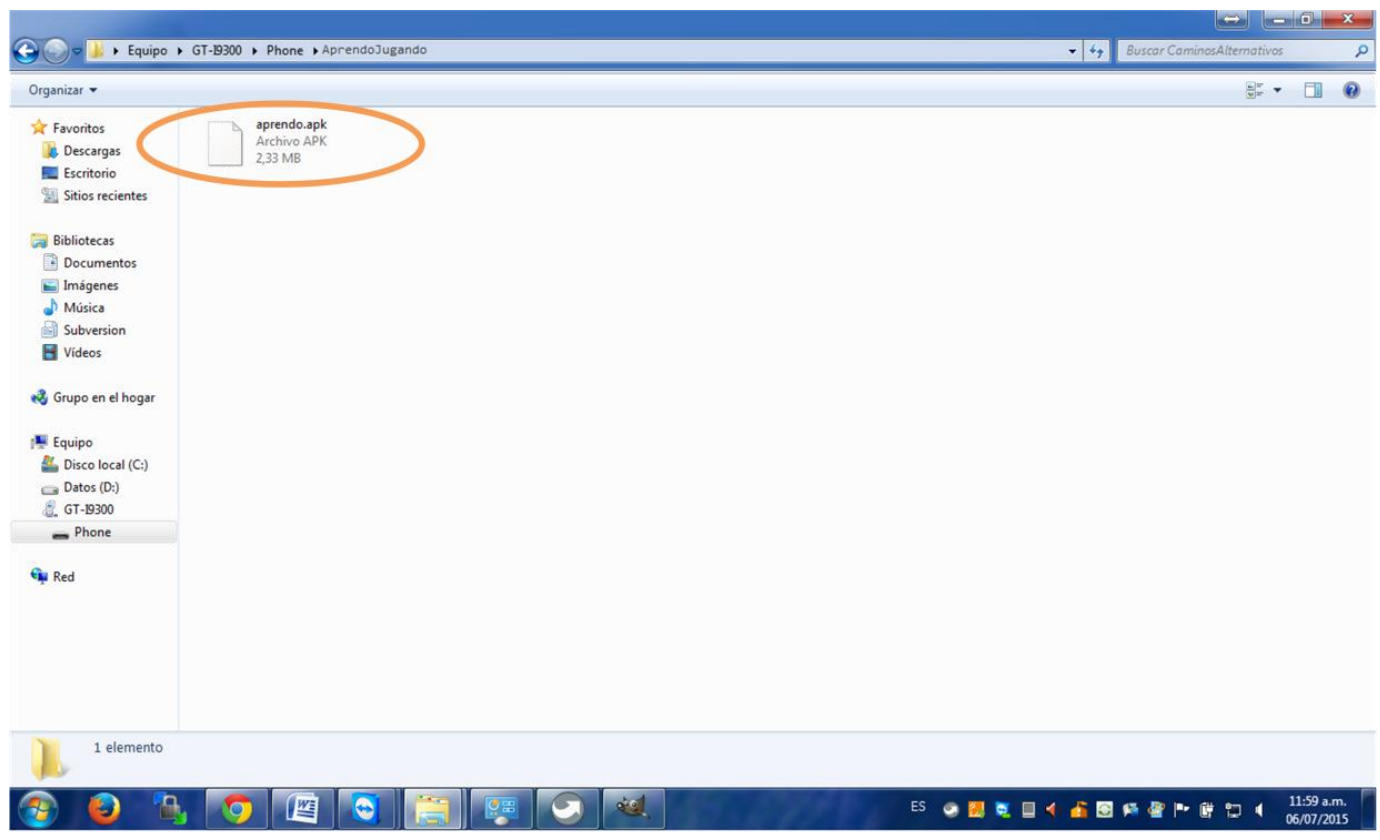

Figura A.6: Archivo .apk copiado al dispositivo

Una vez copiado el archivo apk en una computadora, se describirán los pasos necesarios para la instalación en el dispositivo móvil.

Desde la pantalla inicial del dispositivo móvil, se deberá seleccionar la opción "Menú", esta opción esta destacada en la Figura A.7.a. Una vez ingresado al menú, se deberá acceder a la opción "Ajustes". Esta opción se muestra destacada en la Figura A.7.b.
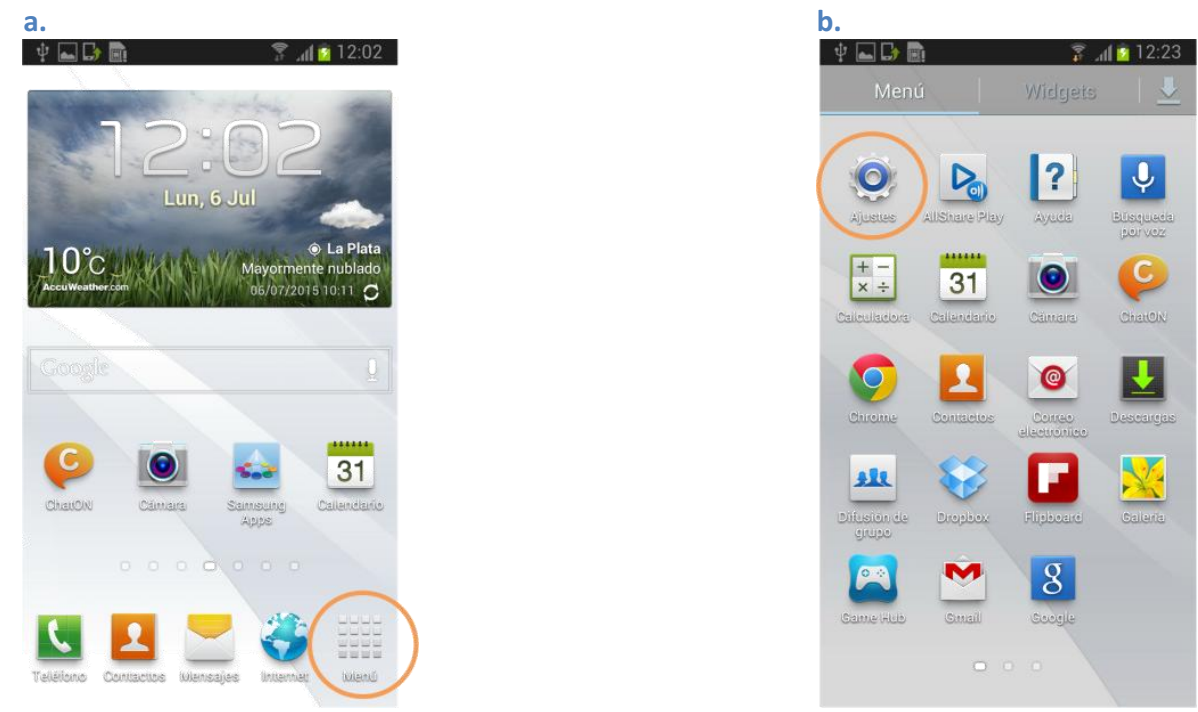

Figura A.7: Iniciando ajuste del dispositivo móvil

De opciones de ajuste disponibles, se debe seleccionar la opción de "Seguridad". Esta opción se muestra resaltada en la Figura A.8.a. Una vez ingresada a dicha opción, se debe 
buscar la opción denominada "Fuentes desconocidas", la cual se destaca en la Figura A.8.b.
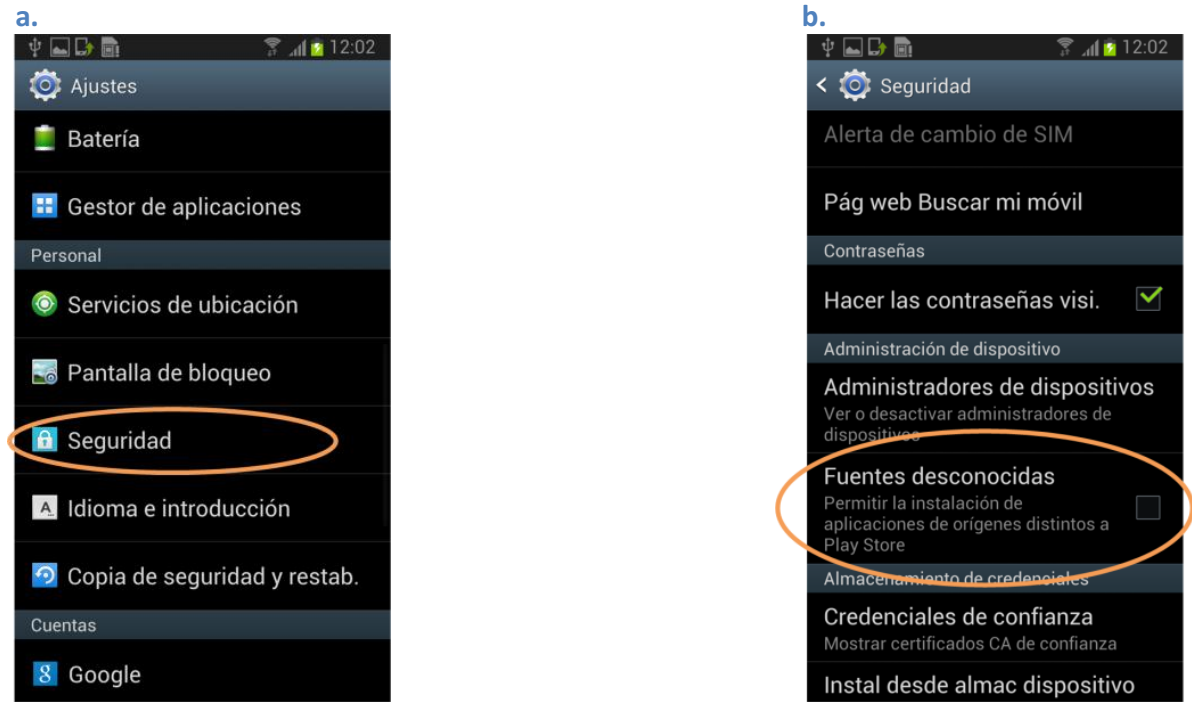

Figura A.8: Ajustes de Seguridad

Se deberá habilitar dicha opción marcando en el casillero disponible, esto se visualiza en la Figura A.9.a. Al hacerlo aparecerá un cartel de advertencia, el cual se deberá "Aceptar". Esto se muestra en la Figura A.9.b.
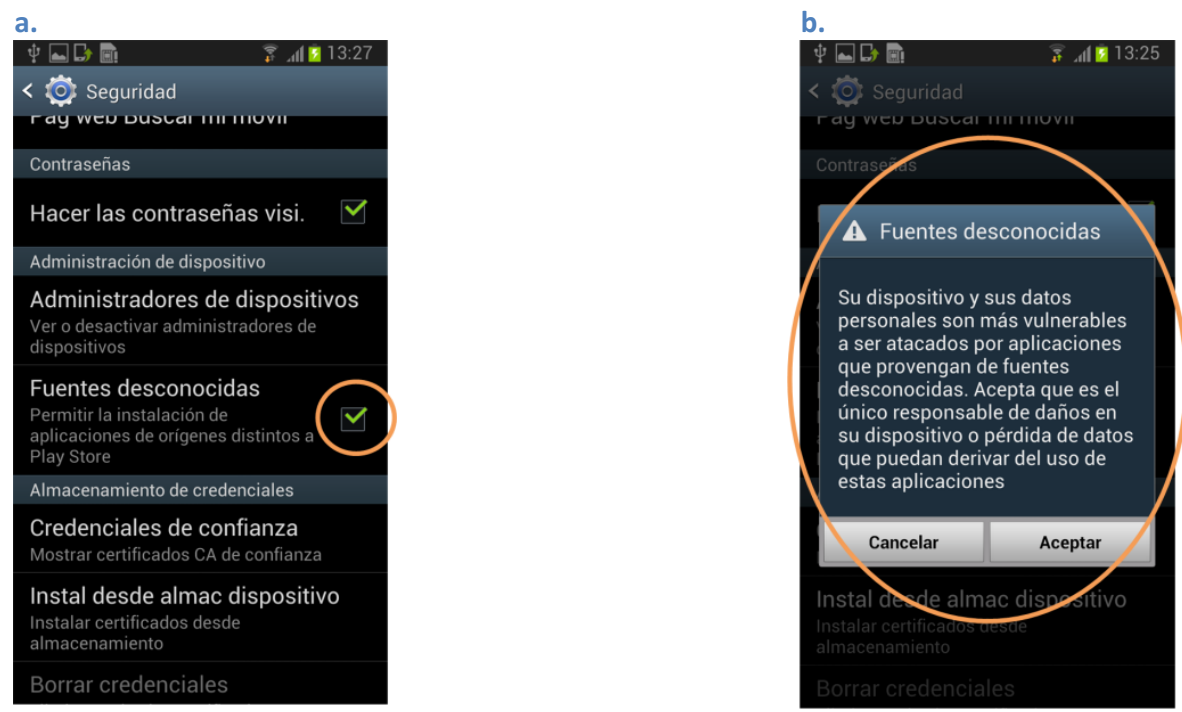

Figura A.9: Permiso para Fuentes desconocidas

Luego de aceptar el cartel de advertencia de la Figura A.9.b, se volverá a la pantalla principal del dispositivo, desde la cual se deberá seleccionar la opción de "Menú", como se muestra en la Figura A.10.a. Una vez ingresado a esta opción, se debe elegir la opción "Mis archivos". Esta opción se muestra destacada en la Figura A.10.b. 


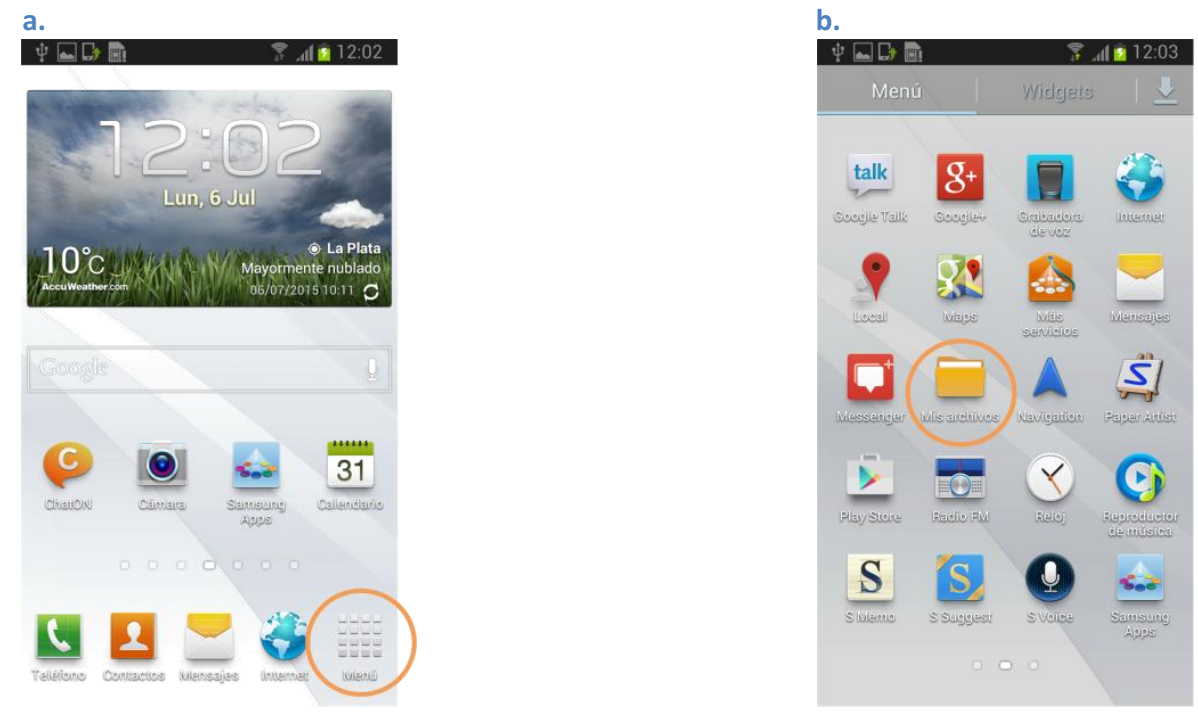

Figura A.10: Iniciando la búsqueda del archivo .apk

Al acceder a la opción "Mis archivos", se mostrará una pantalla como la que se visualiza en la Figura A.11.a, de la cual se deberá elegir nuevamente la opción llamada "Mis archivos" de la mencionada figura. Luego de esto, se debe elegir la opción de carpeta "sdcard0", la cual se muestra destacada en la Figura A.11.b. Una vez seleccionada dicha carpeta, se visualizará una pantalla similar a la que se muestra en la Figura A.11.c, desde la cual se debe seleccionar la carpeta "AprendoJugando". Esta carpeta se destaca en la figura mencionada.

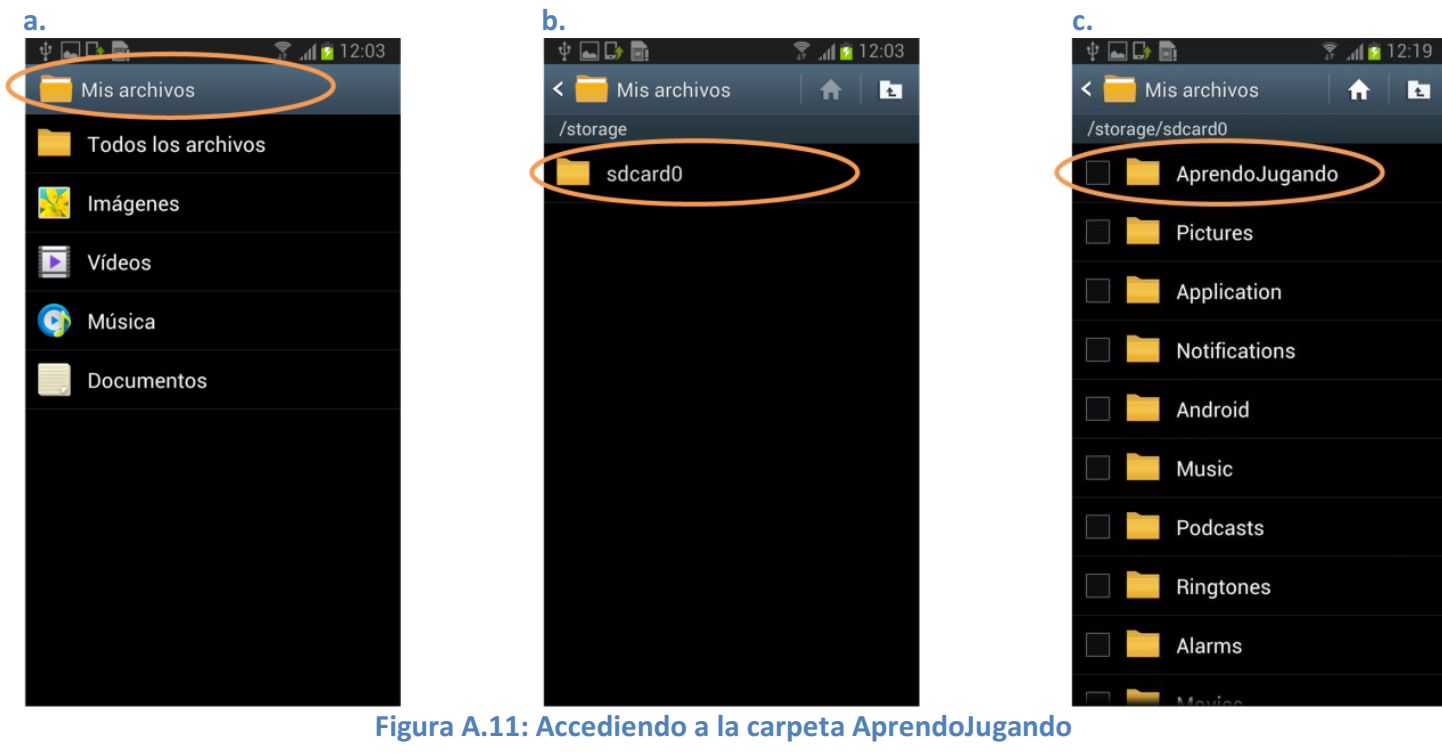

Al acceder a la carpeta "AprendoJugando", se visualizará el archivo "aprendo.apk", esto se muestra destacado en la Figura A.12.a. Se deberá seleccionar dicho archivo, al hacerlo se pasará a visualizar la pantalla que se muestra en la Figura A.12.b. En dicha figura, se 
debe elegir la opción de "Instalar". Una vez elegida esta opción, se abrirá un cartel de "Uso de acciones completas" para definir de qué modo se desea realizar la instalación. Este cartel se visualiza en la Figura A.12.c.
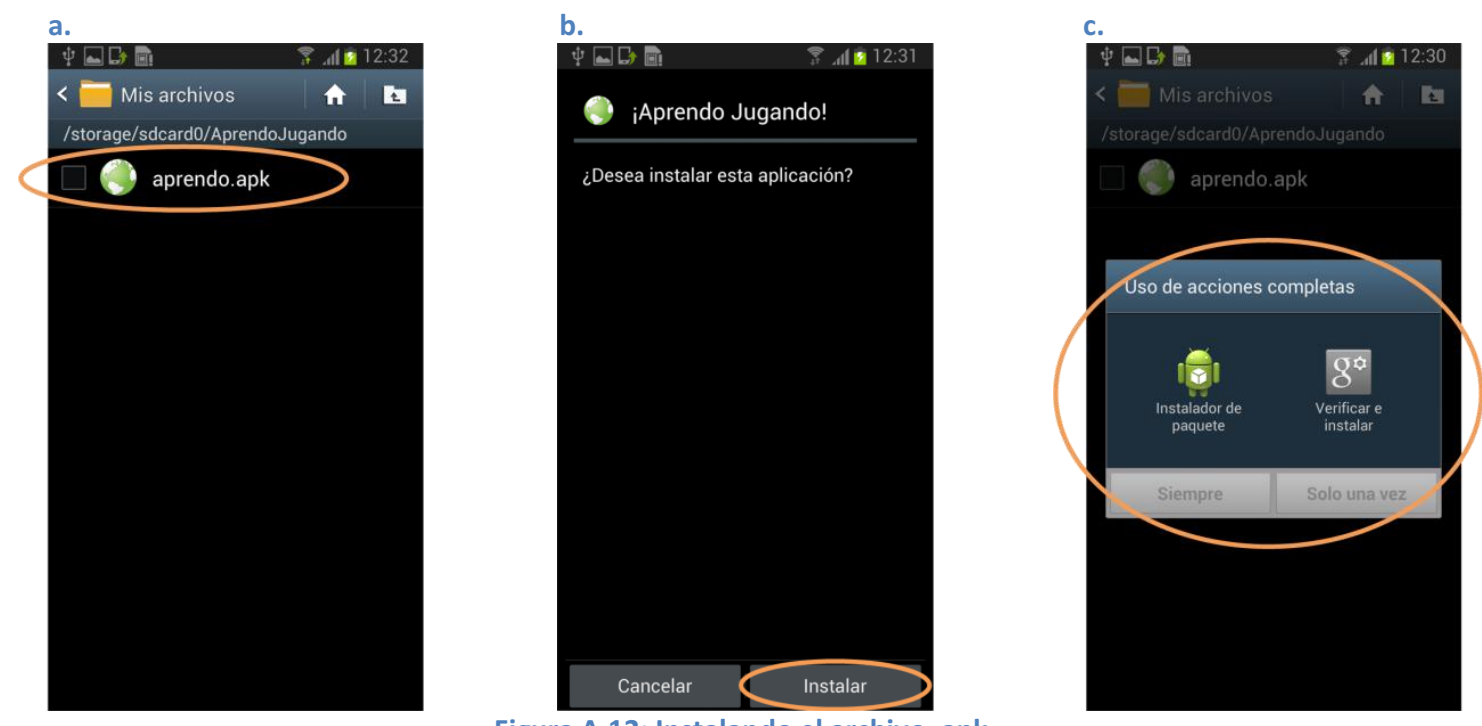

Figura A.12: Instalando el archivo .apk

Del cartel "Uso de acciones completas", se debe seleccionar la opción "Instalador de paquetes" y decidir, como usuario del dispositivo móvil, si este tipo de acciones desea que se realice "Siempre" de este modo o "Solo una vez". La opción "Instalador de paquetes" se muestra destacada en la Figura A.13.a. Una vez realizado esto, se pasa a visualizar la pantalla que se muestra en la Figura A.13.b. Una vez instalado el prototipo, éste queda disponible desde la opción de menú. La opción de acceso al prototipo "AprendoJugando" se destaca en la Figura A.13.c.

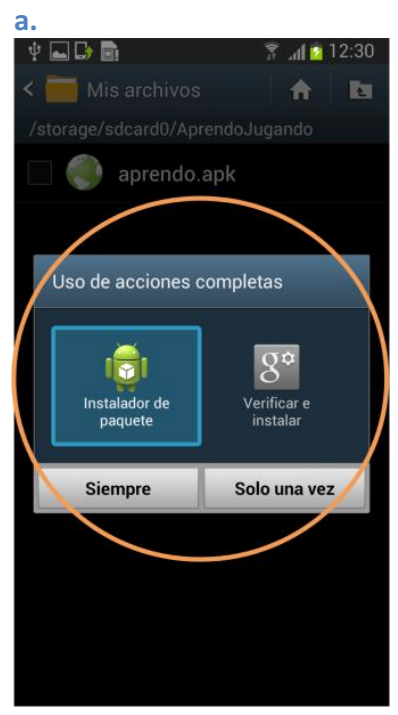

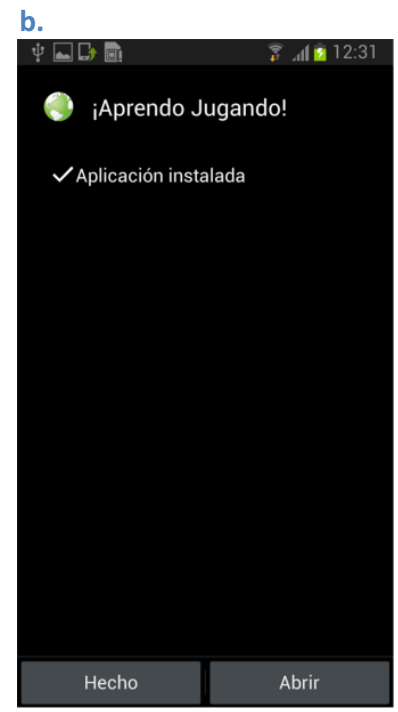

Figura A.13: ¡AprendoJugando! instalado

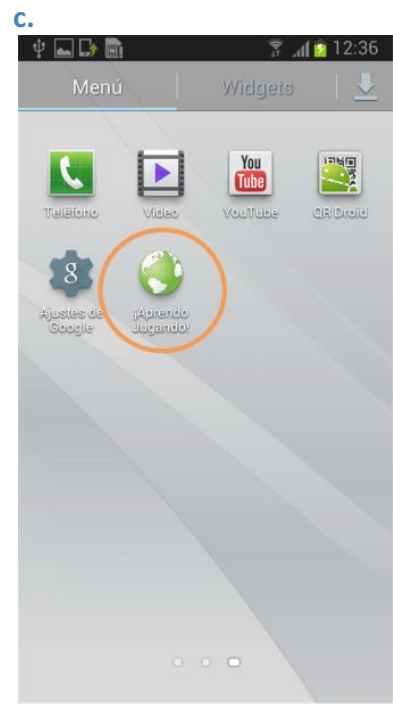

Página 138 de 167 
De este modo, se presentaron los pasos necesarios para dejar instalado el prototipo "AprendoJugando" en el dispositivo móvil y un lector de códigos QR.

Notar que las pantallas, así como los pasos previamente descriptos podrían variar de acuerdo a la versión de Android del dispositivo móvil. El lugar desde donde se accede el archivo del prototipo, también podría diferir. 
Página 140 de 167 


\section{Anexo B: Simulación de uso del prototipo ¡Aprendo jugando!}

En este anexo se mostrará una simulación particular de uso del prototipo que se presentó en el Capítulo 4. Previo a la simulación realizada, se configuró el espacio físico de acuerdo a lo definido en dicho capítulo.

A continuación en la Figura B.1 se muestra el espacio físico configurado. Por un lado en la Figura B.1.a se muestra el sector donde se ubicaron las mesas con los elementos concretos de cada tarea posicionada de recolección del prototipo y en la Figura B.1.b, se muestran los tres lugares de depósito donde se realizarán las tareas posicionadas de depositar. En la Figura B.1.C se muestra la canasta posicionada en el lugar de inicio del prototipo.

a.

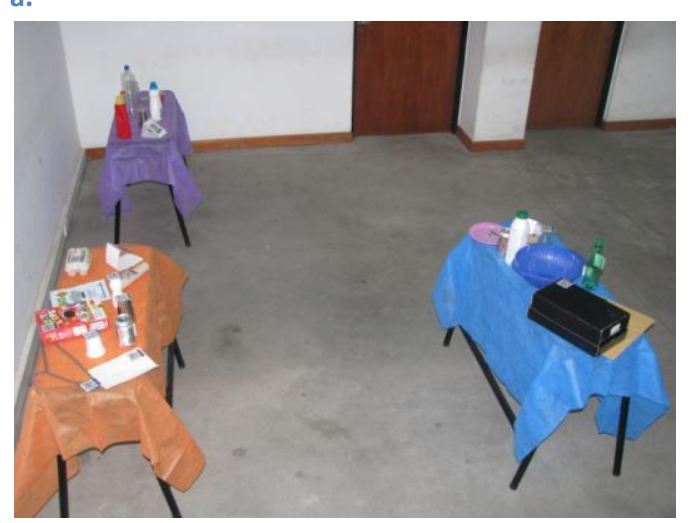

c. b.

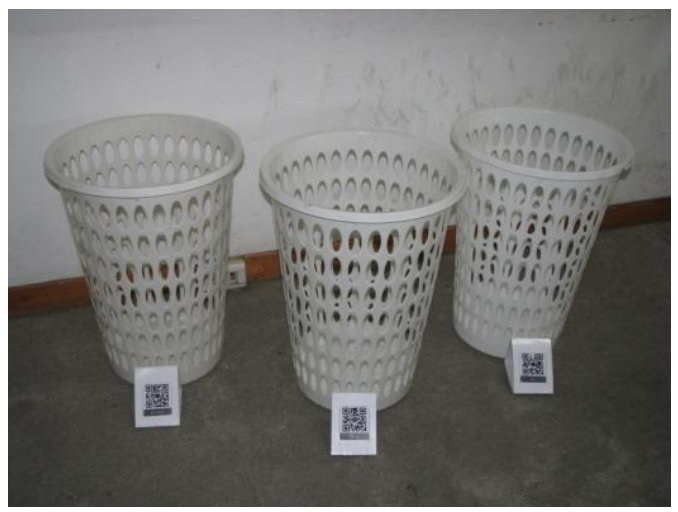

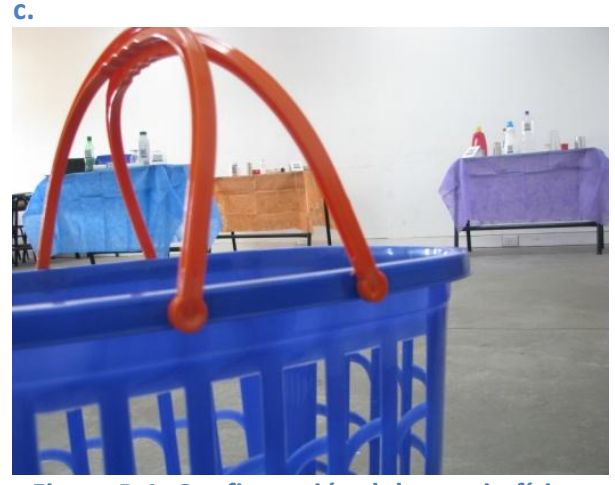

Figura B.1: Configuración del espacio físico

En particular, para la simulación de uso se adoptará el orden de visita de tareas que se muestra en la Figura B.2. Notar que la simulación se inicia con la lectura del código QR de la tarea posicionada TPR3 (posicionada en la mesa de color violeta), la cual no es la tarea inicial en el prototipo. Pero se consideró de esta manera en la simulación para mostrar de 
que manera el prototipo contempla esta posibilidad para brindar asistencia en consecuencia.

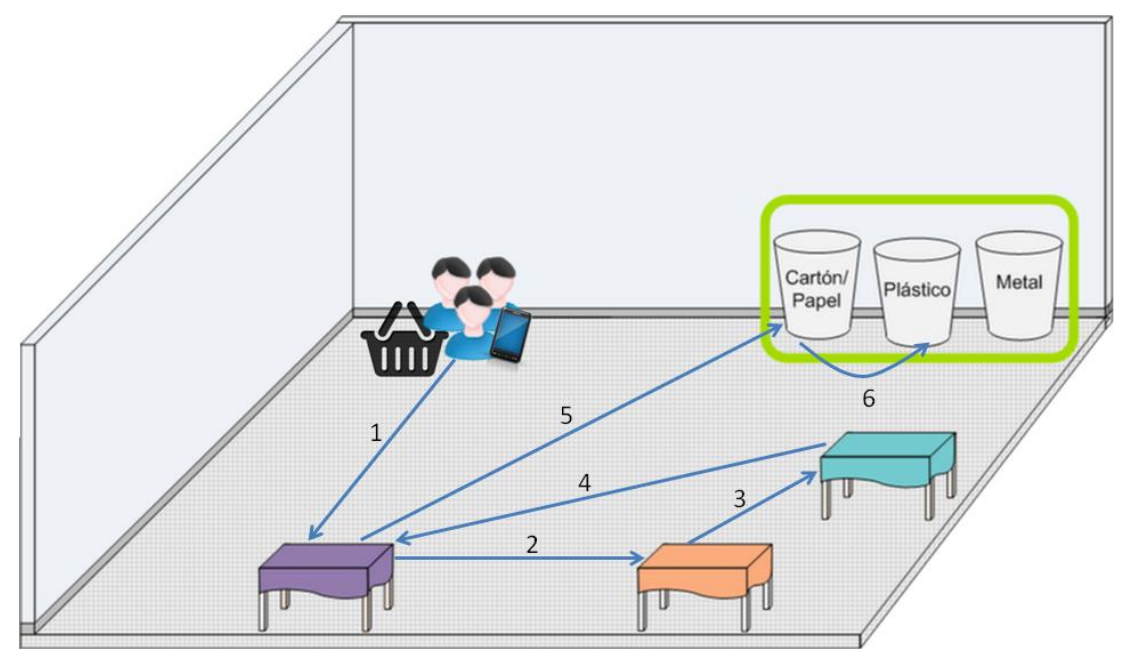

Figura B.2: Secuencia de tareas visitadas para la simulación

El orden de visitas de tareas visualizada en la Figura B.2, para la simulación de uso del prototipo se describe a continuación:

1. Se camina hacia la TPR3, se lee el código QR de dicha tarea que no es la primera en el juego.

2. Se camina hacia la mesa de la TPR1. Se lee el código QR de la tarea. Se recolectan elementos concretos y se finaliza la tarea.

3. Se camina hacia la mesa de la TPR2. Se lee el código QR de la tarea. Se recolectan elementos concretos y se finaliza la tarea.

4. Se camina hacia la mesa de la TPR3. Se lee el código QR de la tarea. Se recolectan elementos concretos y se finaliza la tarea.

5. Se camina hacia los lugares de depósitos. Se lee el código QR de la tarea para depositar "Cartón/Papel". Se depositan elementos concretos y se finaliza la tarea.

6. Se decide continuar depositando. Se lee el código QR de la tarea para depositar "Plástico". Se depositan elementos concretos y se finaliza la tarea.

A continuación se describe la secuencia de visitas de tareas desde la perspectiva de uso del prototipo. La simulación se inicia ejecutando el prototipo desde la posición de inicio mostrada en la Figura B.1.c. En ese momento se visualiza la pantalla de bienvenida visualizada en a Figura B.3.a. Luego de leer el objetivo del juego, al presionar el botón "iA Jugar!", se pasa a la pantalla que se visualiza en la pantalla de la Figura B.3.b, en la que se muestra el lugar al que hay que dirigirse para realizar la primera tarea de recolección. 
Todas las tareas de recolectar y de depositar, se reciben mediante la lectura de un código QR. Esto también se usa para la acción de recolectar un elemento concreto. Cada vez que en el prototipo se visualice la acción de "Leer Código", "Seguir Depositando" o bien la de "Recolectar Elemento", la misma implicará que al activarse la acción, se pasará a visualizar el lector de código QR abierto y que desde dicha aplicación se procederá a la "lectura" del mismo para proceder en consecuencia. Por una cuestión de simplicidad, en este anexo, solamente nombraremos las acciones "Leer Código", "Seguir Depositando" y "Recolectar Elemento" asumiendo que todo el mecanismo descripto previamente, esta implícito en el nombre de cada acción.

Para iniciar con la lectura de códigos QR de tareas, en esta simulación se decidió iniciar por la tercera tarea de recolección. Al hacerlo, el prototipo detecta que no es el código QR que espera, por lo que se obtiene la pantalla que se visualiza en la Figura B.3.c. En dicha figura, se muestra la pantalla en la que se indica que no es el código QR esperado, indicándose nuevamente mediante un mapa el lugar donde se encuentra la tarea a realizar.

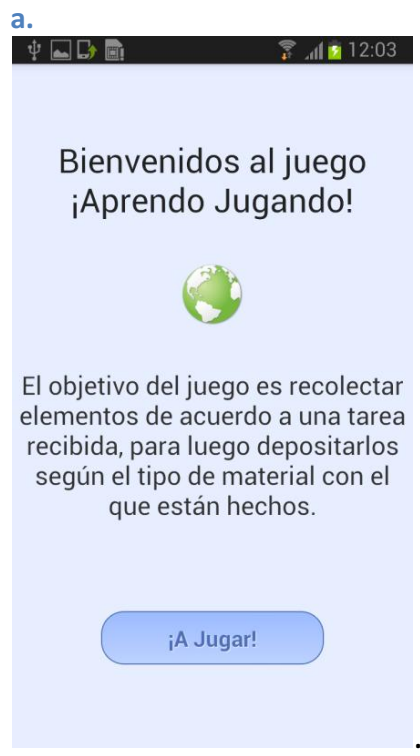

b.

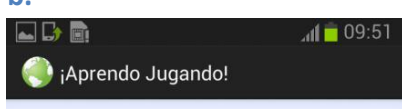

En el mapa se les muestra el lugar donde deberán ir para continuar e juego.

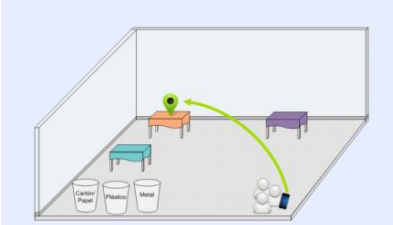

Una vez que lleguen al lugar indicado, deberán leer el código.

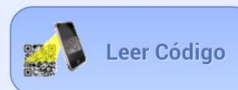

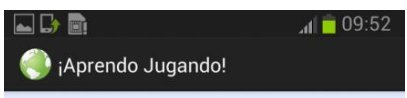

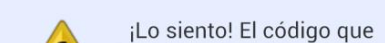

¡Lo siento! El código que En el mapa les mostramos donde deberán ir.

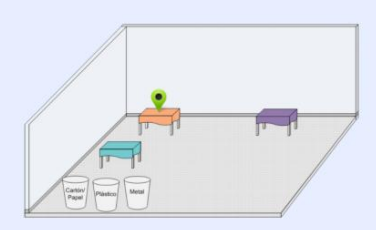

Una vez que lleguen al lugar indicado deberán leer el código.

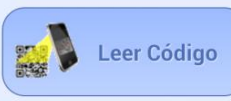

Figura B.3: Pantalla de bienvenida e inicio del prototipo

Luego de presionar el botón "Leer Código" en la pantalla de la Figura B.3.c, se visualiza la pantalla mostrada en la Figura B.4.a. En dicha pantalla se visualiza el enunciado de la consigna de la primera tarea de recolección a realizar. Al presionar el botón "Recolectar Elemento", y al leer el código QR de un elemento concreto de la mesa de la tarea en curso, por ejemplo "Hoja de Cuaderno", éste será incorporado a la lista de elementos concretos recolectados para la tarea (Figura B.4.b). Al presionar nuevamente el botón "Recolectar Elemento" y al leer el código QR del elemento concreto "Tubo de Rollo de Papel", este elemento se suma la lista como se visualiza en la Figura B.4.c. 

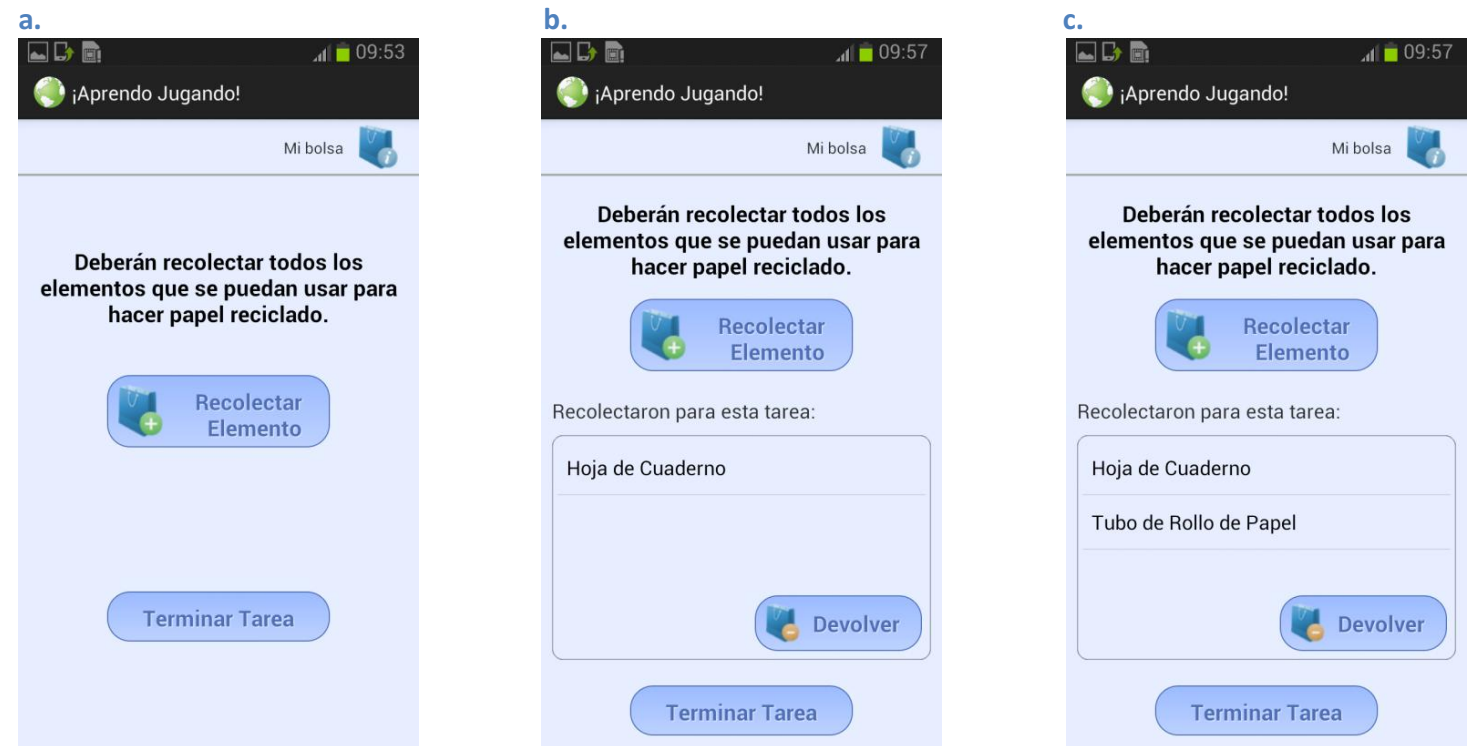

Figura B.4: Recolectar elementos concretos para la primera tarea de recolección

Luego de presionar nuevamente el botón "Recolectar Elemento", y leer el código QR del elemento concreto "Percha Grande", dicho elemento se suma a la lista como se visualiza en la Figura B.5.a. A continuación se decide devolver un elemento de la lista de elementos recolectados, para ello, se presiona el botón "Devolver". Al hacerlo, una pantalla como la que se muestra en la Figura B.5.b será visualizada. En ella, se pueden seleccionar los elementos que se desean devolver. En la Figura B.5.c, se muestra el elemento concreto "Percha Grande", seleccionado para ser devuelto.
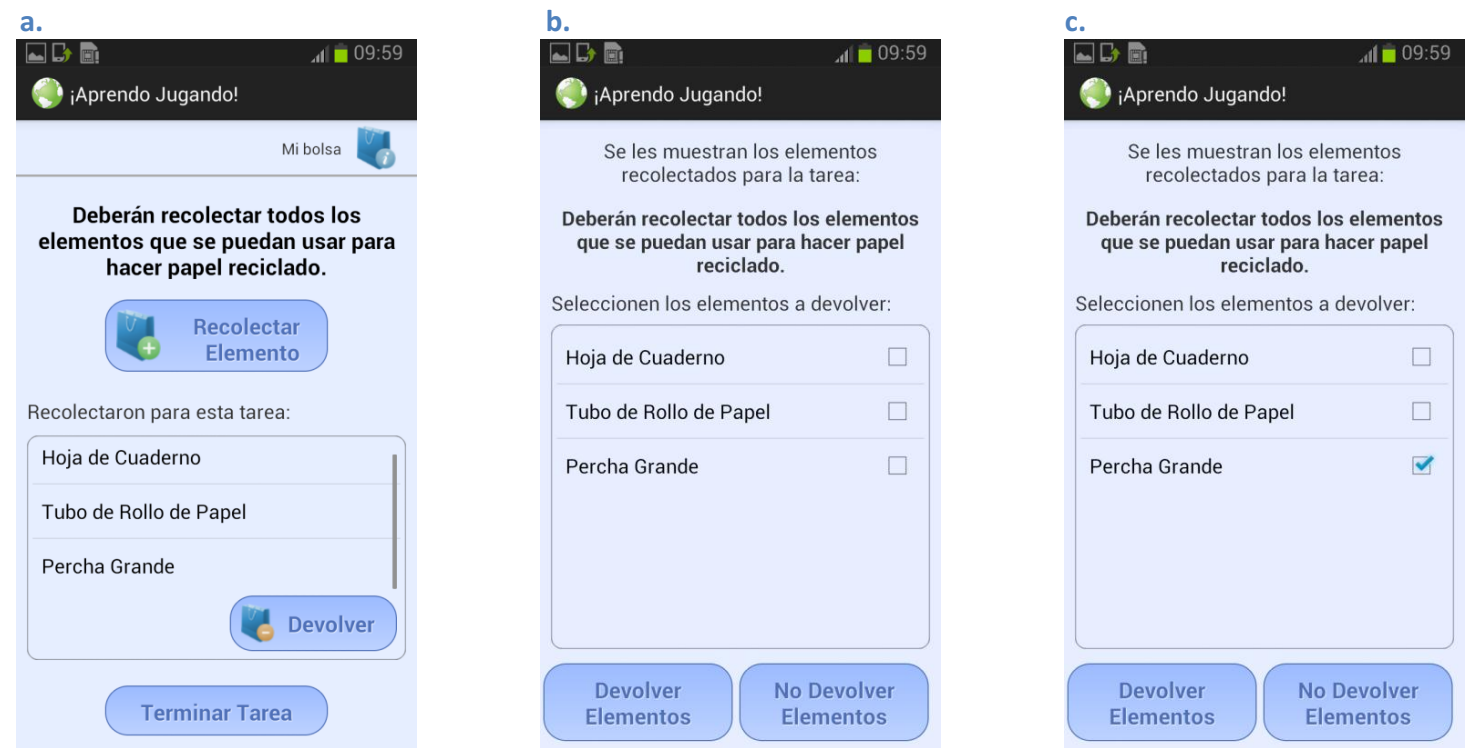

Figura B.5: Devolver elementos concretos previamente recolectados 
Al presionar el botón "Devolver Elementos" en dicha pantalla, el elemento concreto se quita de la lista y se visualiza la pantalla de la Figura B.6.a. A continuación, se presiona el botón "Recolectar Elemento" y se lee el código QR del elemento concreto "Caja de Cereal". Este elemento se agrega a la lista como se visualiza en la Figura B.6.b. Luego de esto, se presiona nuevamente el botón "Recolectar Elemento" y se lee el código QR del elemento concreto "Caja para Huevos", sumándose a la lista como se visualiza en la Figura B.6.c.
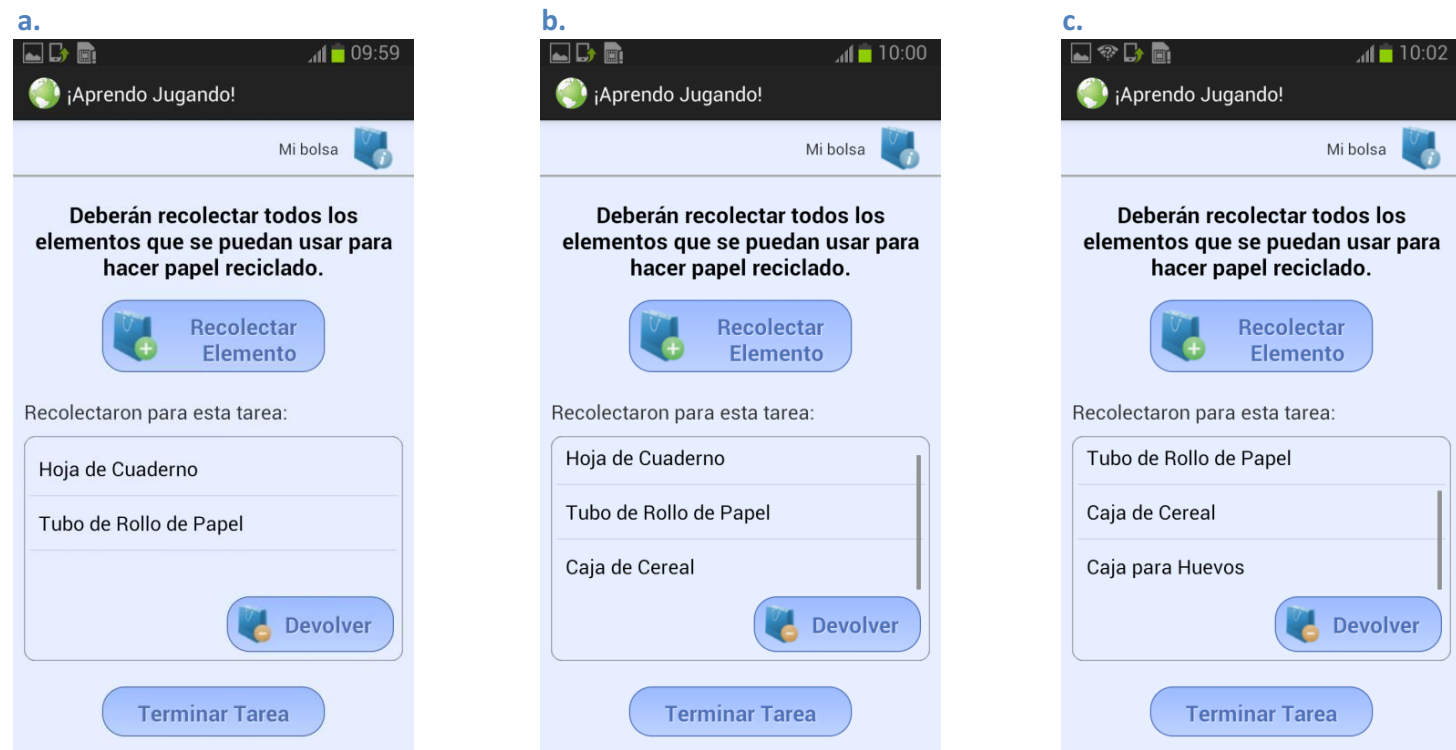

Figura B.6: Recolección de elementos concretos para la primera tarea posicionada

Al decidir no seguir recolectando elementos concretos, se presiona el botón "Terminar Tarea", visualizándose la pantalla que se muestra en la Figura B.7.a. En dicha figura, se anuncia la finalización de la tarea y se brinda la opción entre realizar la siguiente tarea de recolección o bien una tarea de depositar. En la simulación, se decide presionar el botón "Siguiente Tarea" (tarea de recolección), al hacerlo se visualiza la pantalla que se muestra en la Figura B.7.b. En dicha pantalla, se muestra el mapa indicando la posición de la próxima tarea de recolección a realizar. 

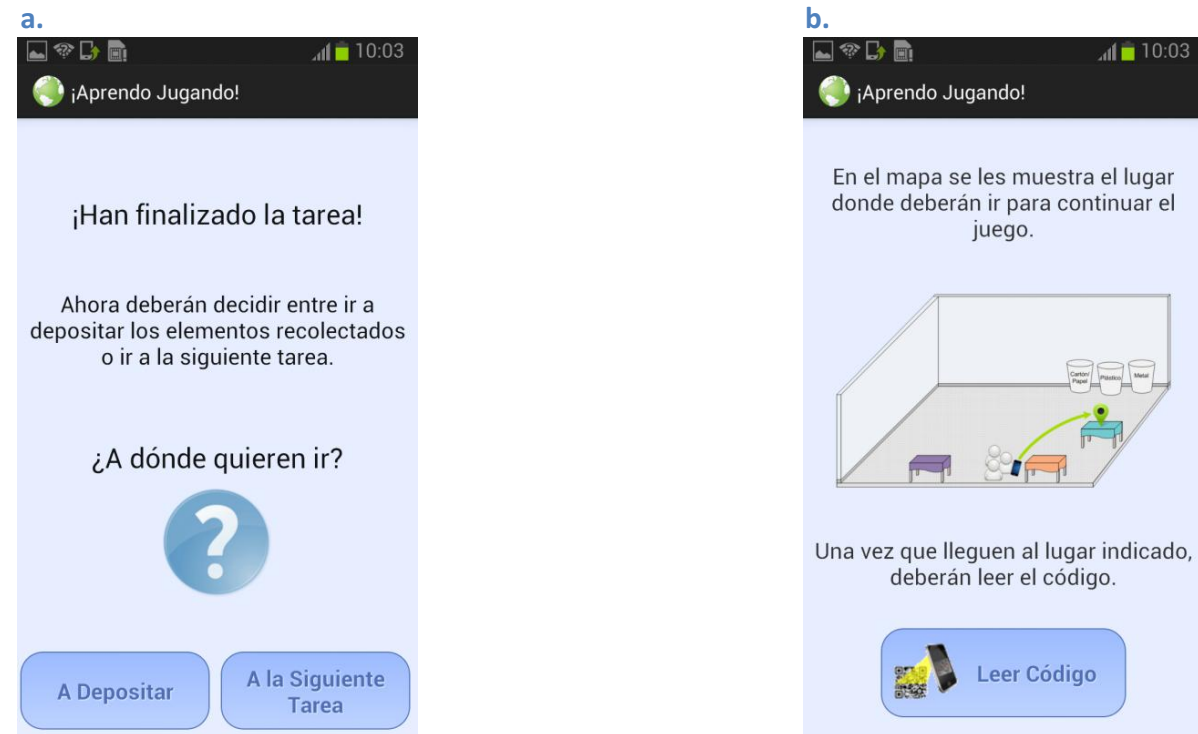

Figura B.7: Finalización de la primera tarea de recolección e ir a la siguiente tarea de recolección

A continuación se lee el código de la segunda tarea de recolección y se visualiza la pantalla de la Figura B.8.a. En dicha pantalla se visualiza el enunciado de la consigna para la segunda tarea de recolección. Al presionar el botón "Recolectar Elemento" y leer el código QR del elemento "Botella de Gaseosa", este se suma a la lista de elementos recolectados para la tarea. Esto se visualiza en la Figura B.8.b. Al presionar nuevamente el botón "Recolectar Elemento" y leer el código QR del elemento concreto "Botella de Leche", se agrega a la lista. Esto se observa en la Figura B.8.c.
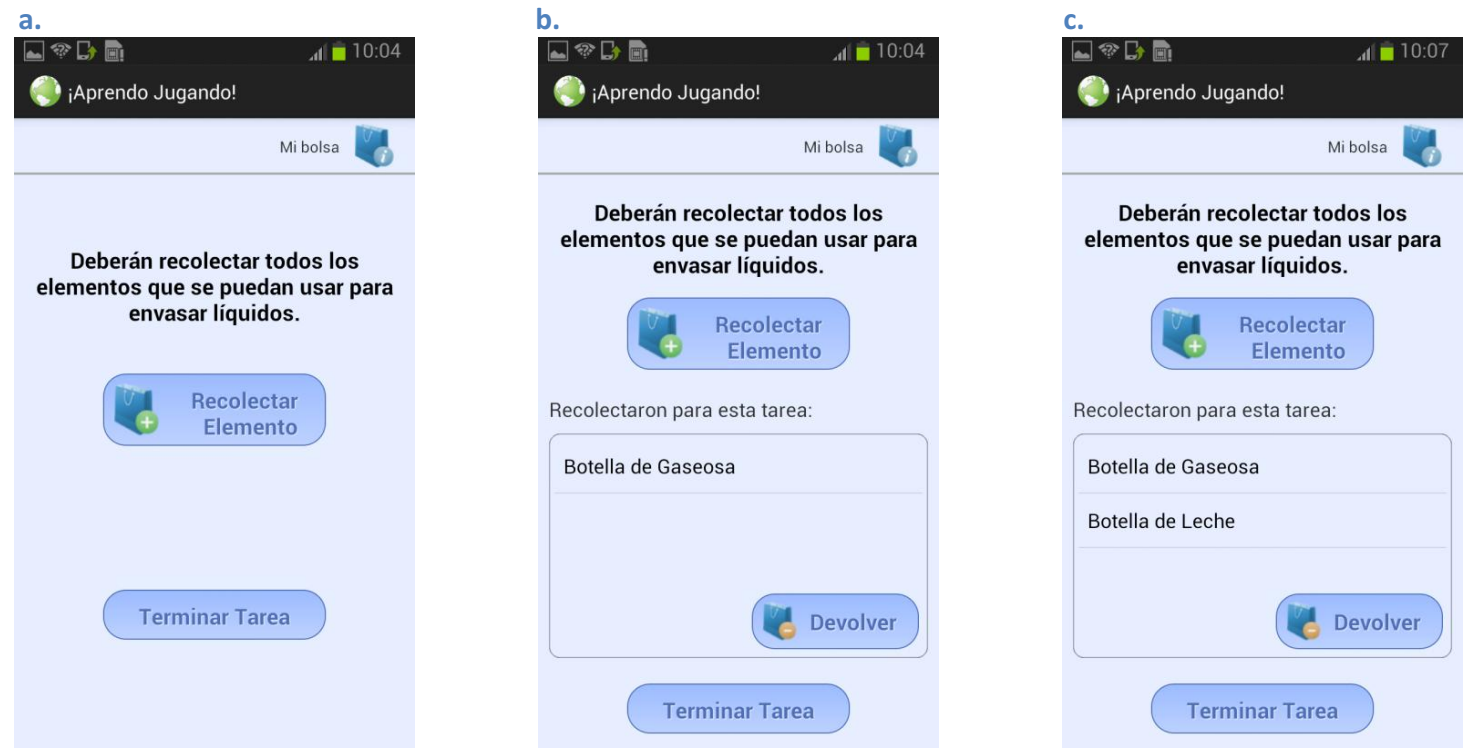

Figura B.8: Segunda tarea de recolección 
A continuación se presiona nuevamente el botón de "Recolectar Elemento" y se lee el código QR del elemento concreto "Botella Chica", el que se agrega a la lista de elementos, esto se visualiza en la pantalla de la Figura B.9.a. Nuevamente se presiona el botón "Recolectar Elemento" y se lee el código QR del elemento concreto "Sobre Grande" incorporándose el elemento a la lista como se visualiza en la Figura B.9.b.
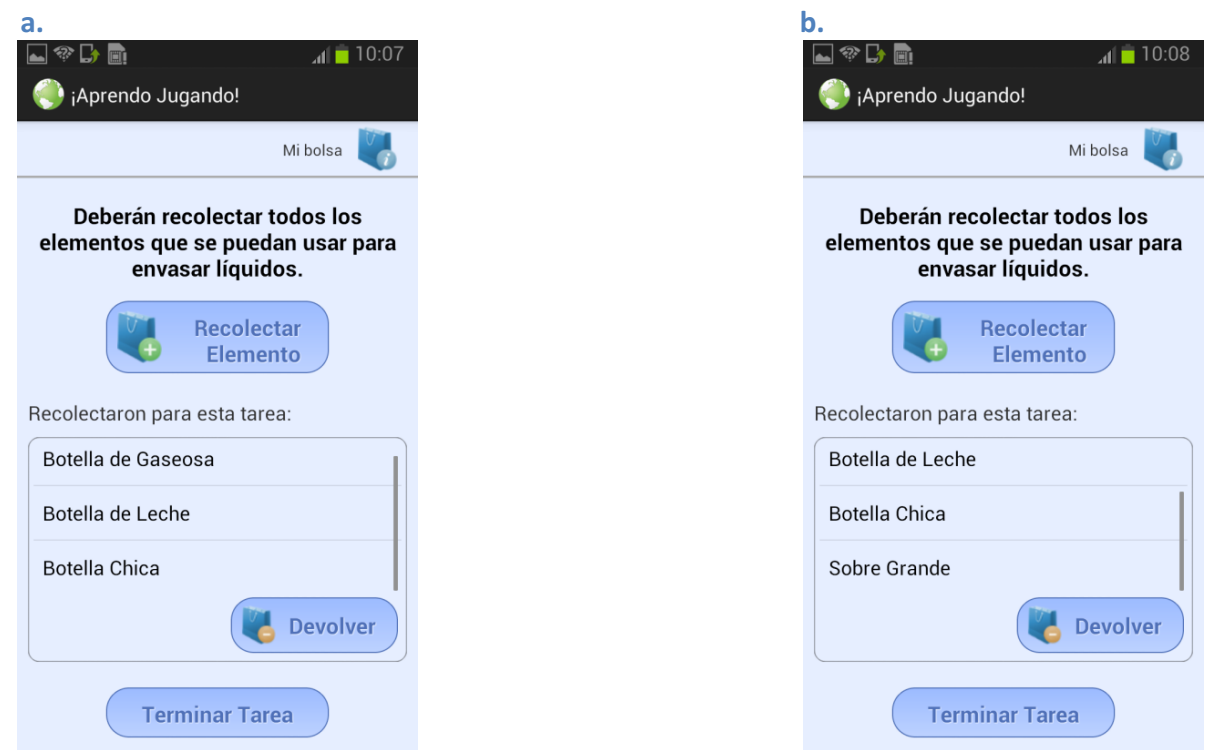

Figura B.9: Recolección de elementos concretos de la segunda tarea de recolección

El prototipo cuenta con una opción de visualización de los elementos que se han recolectado (agrupados por la tarea para la cual se ha recolectado cada uno) y no se han devuelto. Esta opción está disponible seleccionando "Mi bolsa" de la Figura B.9.b. Al seleccionar esta opción, se visualiza una pantalla como la que se muestra en la Figura B.10.a.

Al acceder a la opción "Mi bolsa", se muestran los diferentes elementos concretos recolectados en cada tarea de recolección realizada hasta el momento. En la Figura B.10.a, se muestran todos los elementos concretos recolectados para la primera tarea de recolección y en la Figura B.10.b, se muestra la misma pantalla que se ha desplazado hacia abajo para continuar con la lectura de los elementos concretos recolectados para la segunda tarea de recolección. Una vez visualizados los elementos listados en la bolsa, se presiona la opción "Volver", visualizándose la pantalla de la Figura B.10.c. En dicha pantalla se visualizan los elementos concretos recolectados para la tarea actual (segunda tarea de recolección). 

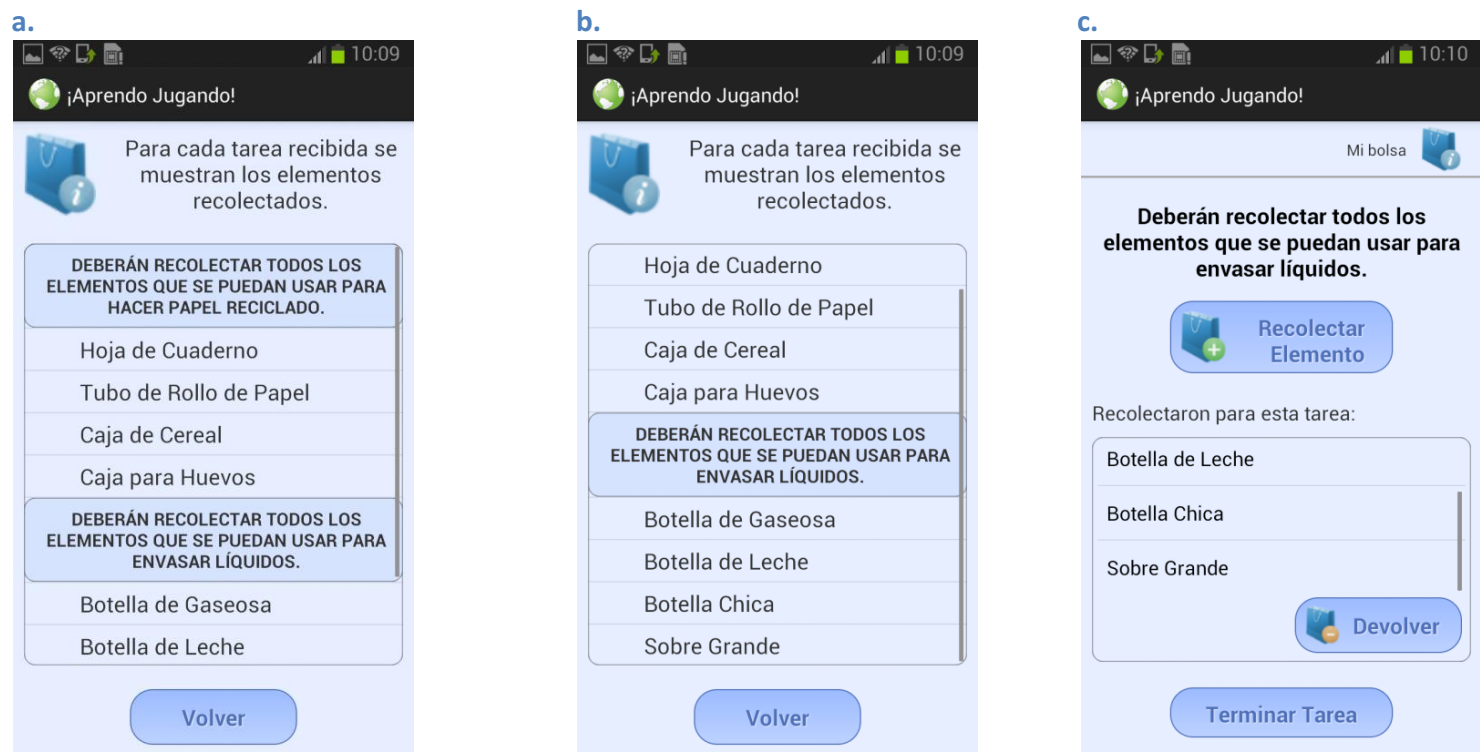

Figura B.10: Visualización de Mi bolsa

Notar que si bien solo se visualizan tres elementos, la barra deslizante de la lista está habilitada mostrando que hay más elementos concretos. Se decide finalizar la tarea y para ello se presiona el botón "Terminar Tarea". Pasándose a visualizar la pantalla de la Figura B.11.a. Esta figura muestra que se ha finalizado la tarea y se debe optar entre ir a la siguiente tarea de recolección, o bien dirigirse a depositar elementos concretos recolectados previamente. En particular, para la simulación propuesta, se presiona el botón "Siguiente Tarea" y se visualiza la pantalla de la Figura B.11.b, en la cual se muestra en el mapa, la posición de la tercera tarea de recolección.
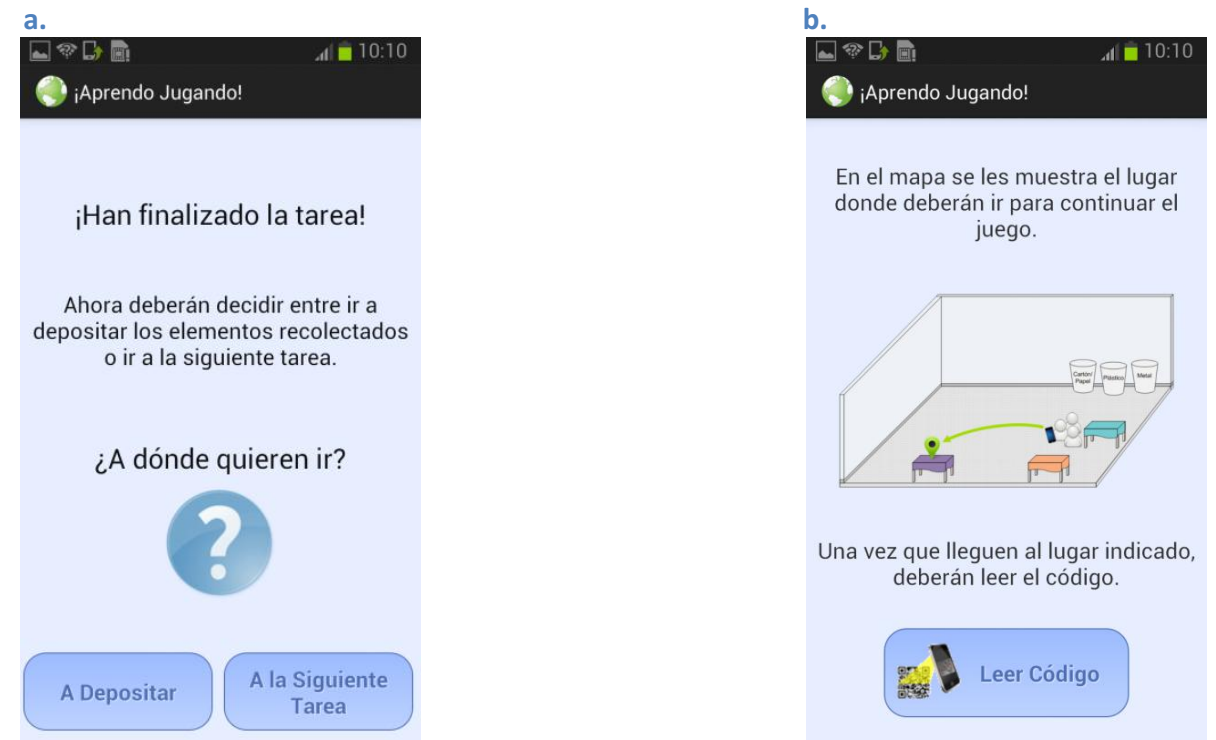

Figura B.11: Finalización de la segunda tarea de recolección e ir a la siguiente tarea de recolección 
Al presionar, el botón "Leer Código" de la Figura B.11.b, y al leer el código QR de la tercera tarea de recolección, se visualiza la pantalla mostrada en la Figura B.12.a. En dicha ventana se muestra el enunciado de la consigna de la tercera tarea de recolección. Al presionar el botón "Recolectar Elemento" y al leer el código QR del elemento concreto "Regla Grande", éste se suma a la lista de los elementos recolectados para la tarea como se visualiza en la pantalla de la Figura B.12.b. Al presionar en dicha figura el botón "Recolectar Elemento" y leer el código QR del elemento concreto "Escuadra", éste se suma a la lista y se visualiza en la pantalla como se muestra en la Figura B.12.c.
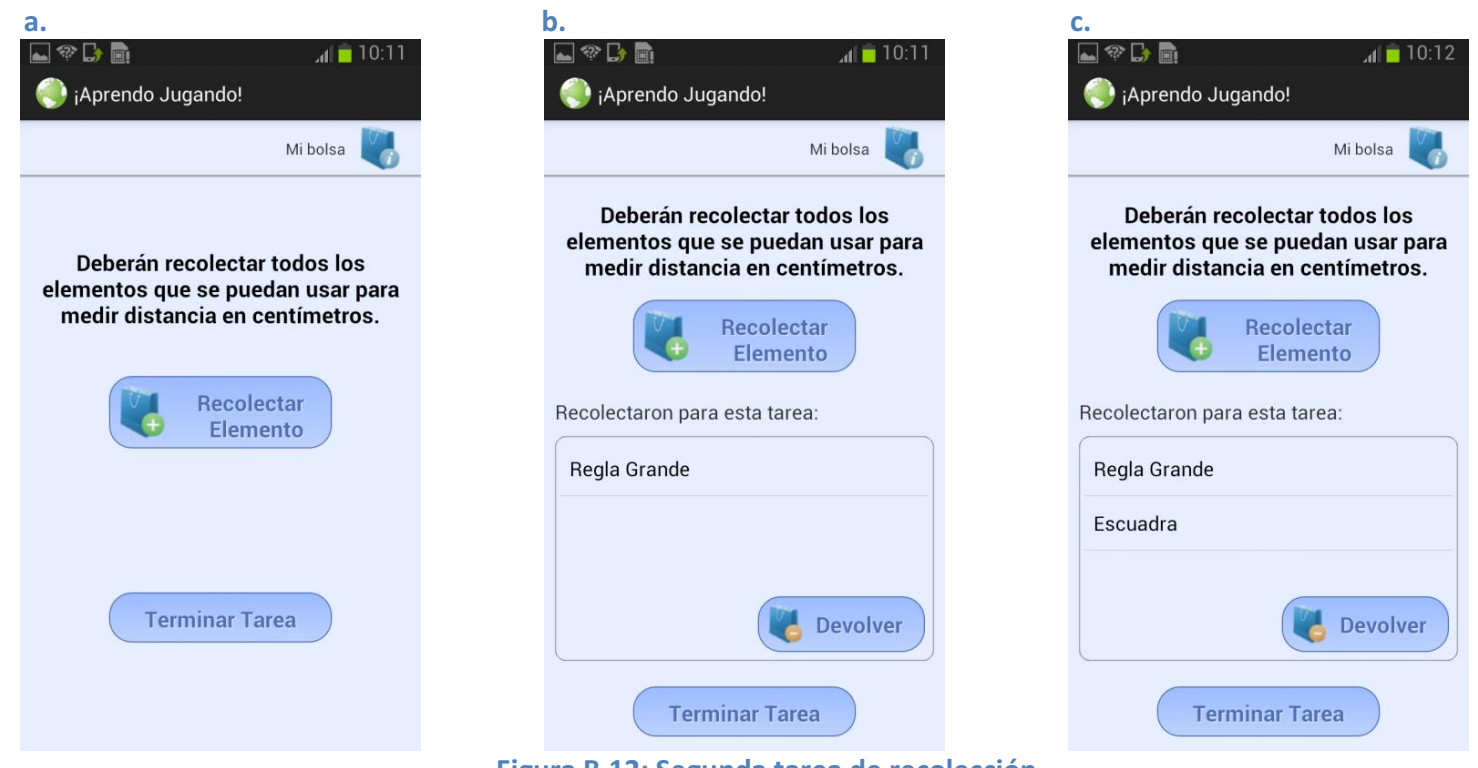

Figura B.12: Segunda tarea de recolección

Se presiona nuevamente el botón "Recolectar Elemento" y se lee el código QR del elemento "Vaso Medidor Grande", el cual se adiciona a la lista de elementos recolectados para la tarea. Esto se visualiza en la Figura B.13. 


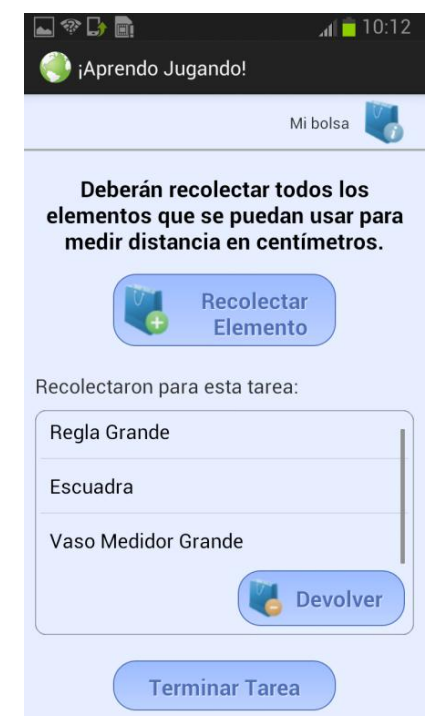

Figura B.13: Elementos concretos recolectados

Se decide finalizar de recolectar elementos concretos para la tarea actual y se presiona el botón "Terminar Tarea". Luego de esto se visualiza la pantalla que se muestra en la Figura B.14.a. En dicha pantalla, como ya no quedan tareas de recolección para realizar, se visualizan las opciones para ir a depositar o bien para finalizar el juego. En la simulación, se decide presionar el botón "Ir a Depositar". A continuación se visualiza la pantalla que se muestra en la pantalla de la Figura B.14.b, donde en un mapa se destacan los lugares de los depósitos para dirigirse a realizar las tareas de depositar.
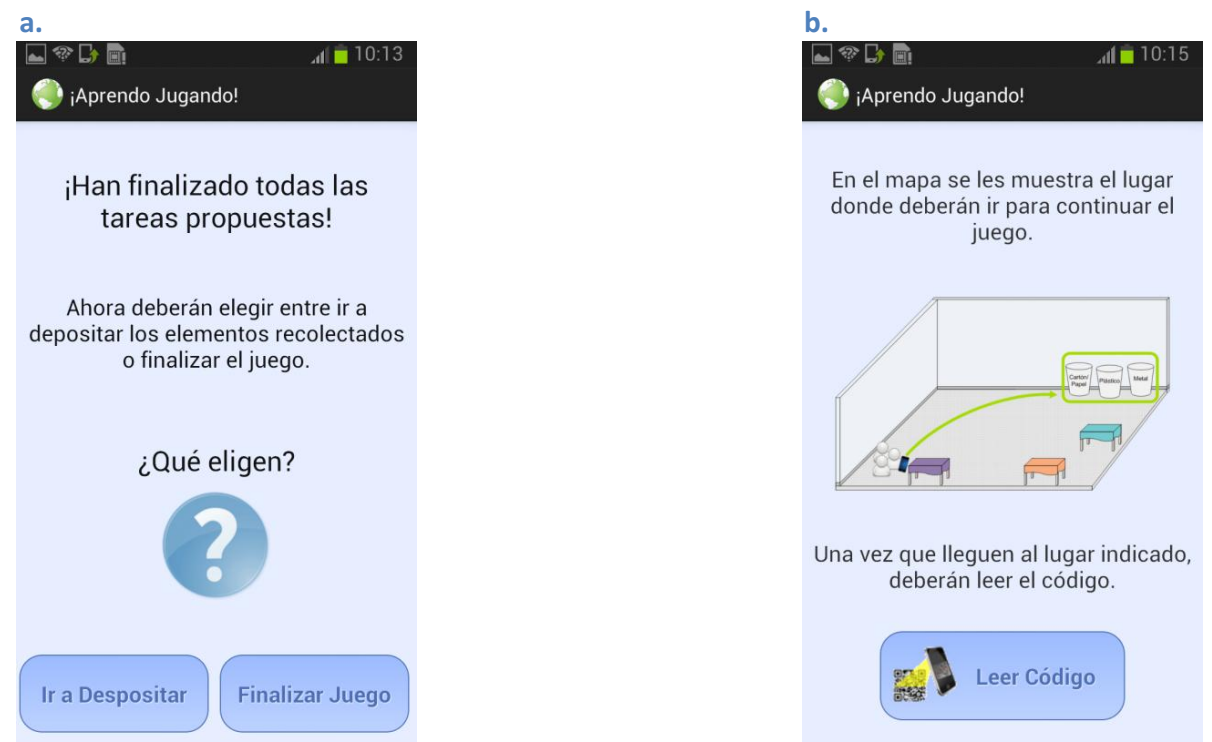

Figura B.14: Finalización de la tercera tarea de recolección e ir a depositar

Al leer el código QR de la tarea de depositar "Cartón/Papel", se visualiza la pantalla que se muestra en la Figura B.16.a. En esta pantalla, se muestra el enunciado de la consigna de 
esta tarea y se listan todos los elementos concretos recolectados para ser seleccionados y posteriormente depositados. En la Figura B.16.b, se muestran los elementos concretos "Caja de Cereal", "Caja para Huevos", "Hoja de Cuaderno" y "Tubo de Rollo de Papel" seleccionados.
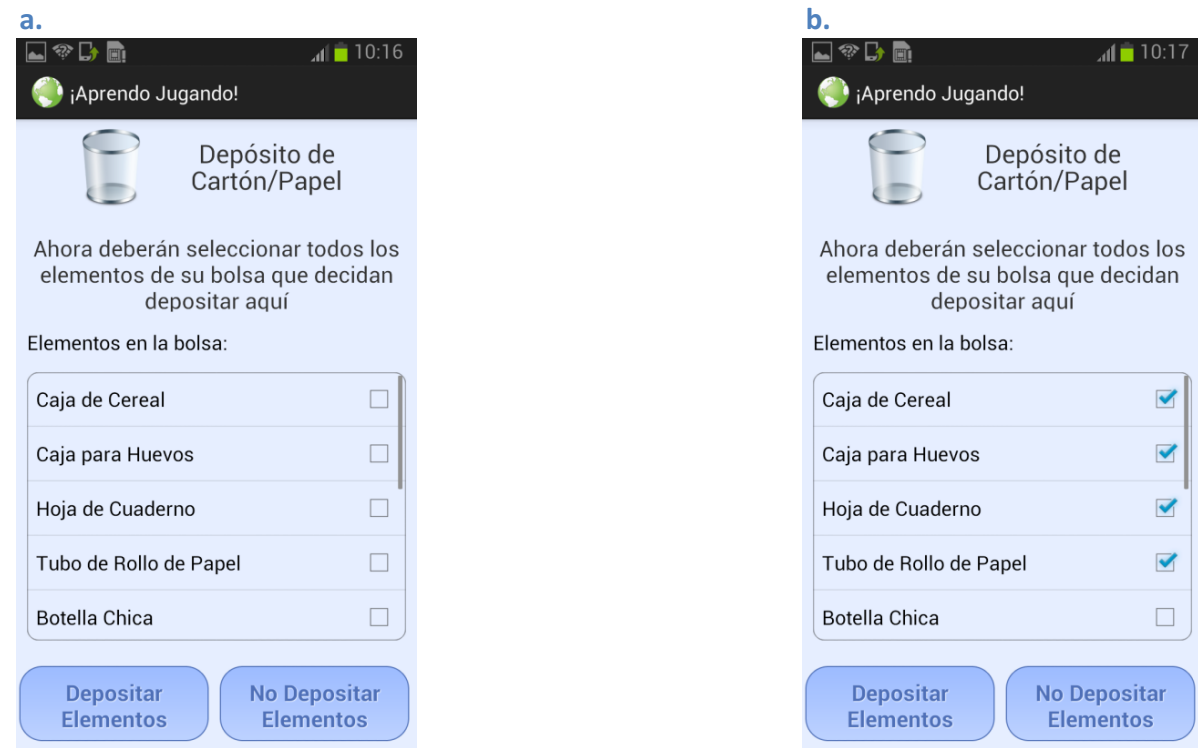

Figura B.15: Tarea de depositar "Cartón/Papel"

Para poder analizar la lista de elementos, se la desplaza hacia abajo y se selecciona el elemento "Sobre Grande" de la lista. Esto se visualiza en la Figura B.16.a. Se decide terminar de depositar y se presiona el botón "Depositar Elementos". Luego de esto, se visualiza la pantalla que se muestra en la Figura B.16.b. En este caso, se informa que los elementos concretos seleccionados han sido depositados, lo que implica que en el prototipo se eliminan de la lista de elementos concretos, y se debe optar entre seguir depositando o bien, finalizar el juego. Se decide presionar el botón "Seguir Depositando". 

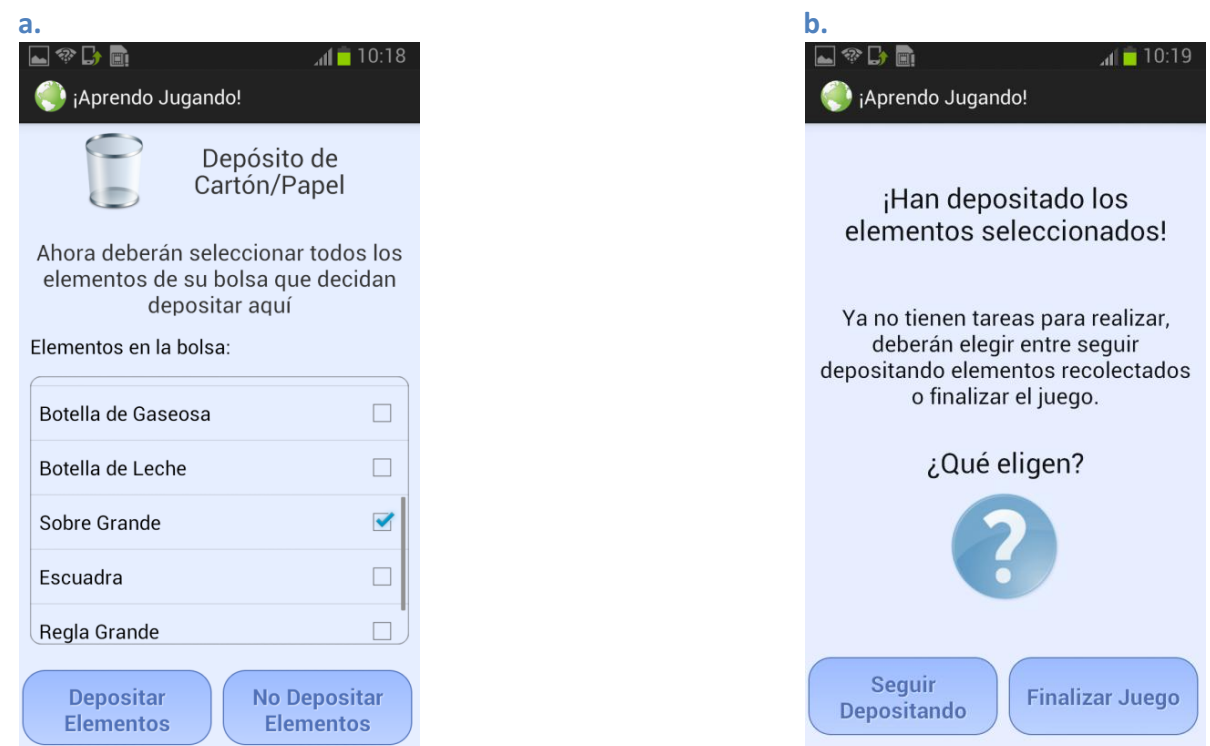

Figura B.16: Finalización de la tarea de depositar "Cartón/Papel" y Seguir Depositando

Al presionar el botón "Seguir Depositando", como en el prototipo se asumen los tres depósitos uno al lado del otro, se omite la visualización del mapa, puesto que el usuario se asume en ese lugar al venir de realizar una tarea de depositar. Se lee el código QR correspondiente a la tarea de depositar "Plástico", se recibe el enunciado de su consigna y se visualiza el listado de elementos concretos disponibles para depositar. Esto se muestra en la Figura B.17.a. En la Figura B.17.b, se muestran los elementos concretos "Botella Chica", "Botella de Gaseosa", "Botella de Leche", "Escuadra" y "Regla Grande" seleccionados en la lista de los elementos de la bolsa. En la Figura B.17.c, se muestra la lista desplazada hacia abajo y el elemento concreto "Vaso Medidor Grande" seleccionado. Una vez seleccionados los elementos concretos a depositar, se presiona el botón "Depositar Elementos". 

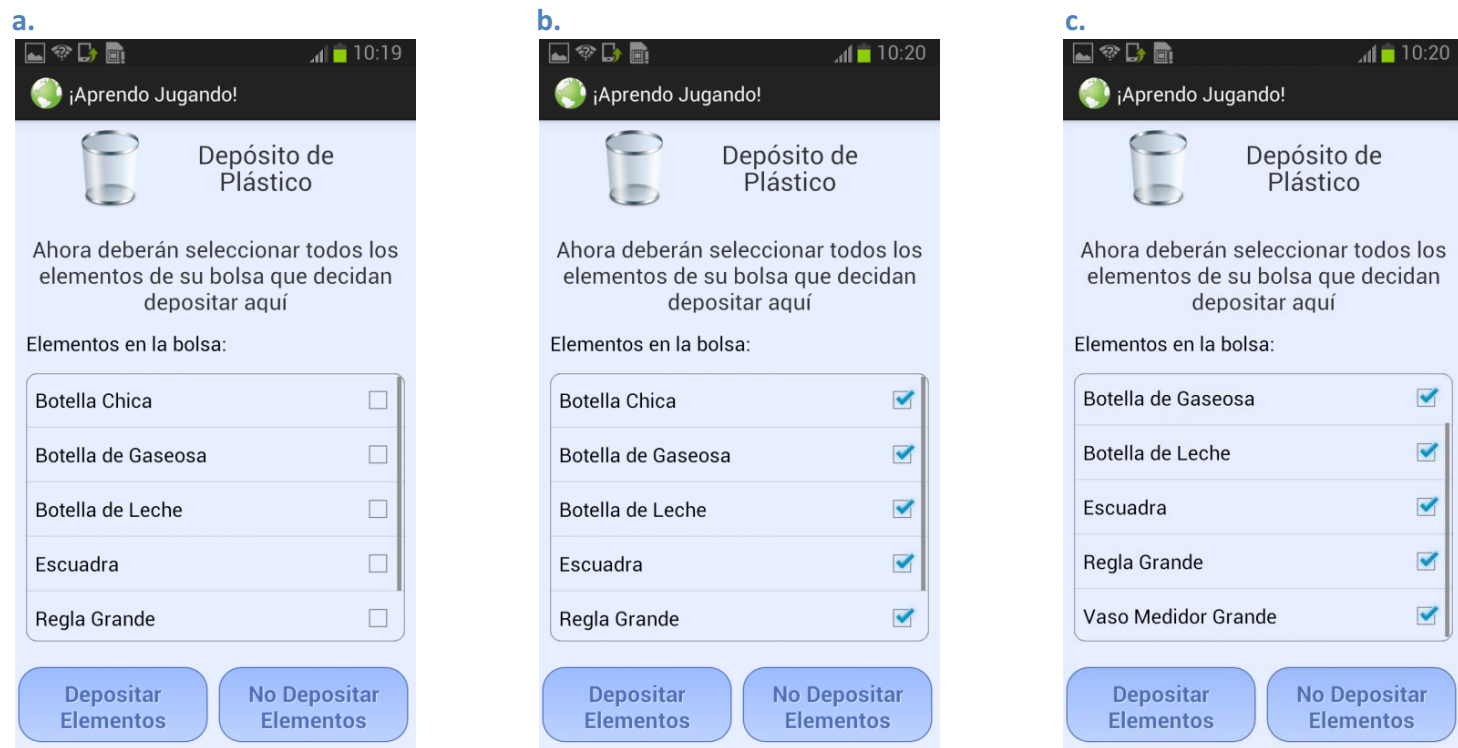

Figura B.17: Tarea de depositar "Plástico"

Luego de presionar el botón "Depositar Elementos" de la Figura B.17.c, se visualiza la pantalla mostrada en la Figura B.18.a, en la que dado que se depositaron todos los elementos de la bolsa y que ya se habían realizado todas las tareas de recolección, el juego ha finalizado, debiéndose optar entre ver el desempeño o bien salir del juego. Se decide presionar el botón "Ver Desempeño". Luego de esto se visualiza la pantalla que se muestra en la Figura B.18.b. En esta pantalla el desempeño se agrupa por un lado para las tareas de recolección (Ilamadas "En Tareas") y por otro lado para las tareas de depositar (llamadas "En Depósitos"). Notar que, como en la simulación no se han depositado elementos concretos en el depósito de "Metal", este no aparece listado. 

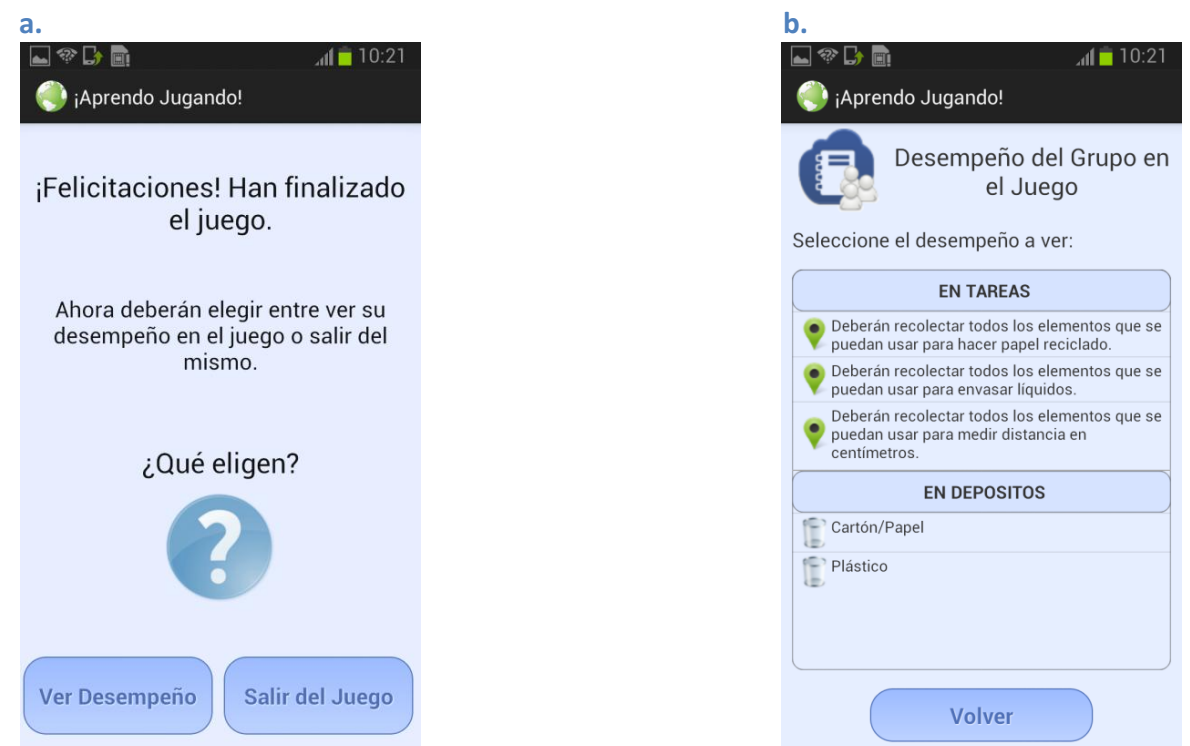

Figura B.18: Finalización del juego optar entre ver desempeño y salir

De la pantalla visualizada en la Figura B.18.b, se decide ver el desempeño en la primera tarea de recolección. Al seleccionarla, se visualiza la pantalla mostrada en la Figura B.19.a. En dicha pantalla, se visualiza el enunciado de la consigna de la tarea, y se muestran los elementos concretos recolectados clasificados en correctamente o incorrectamente recolectados y se indican los elementos concretos que faltaron recolectar en la tarea realizada (se considera que un elemento faltó ser recolectado si constituía una opción válida a la consigna y no se lo recolectó). Notar que, en este caso particular, todos los elementos concretos recolectados son correctos y no restó recolectar ningún elemento concreto. Al finalizar de ver este desempeño, se presiona el botón "Volver" y se visualiza la pantalla de la Figura B.19.b. 

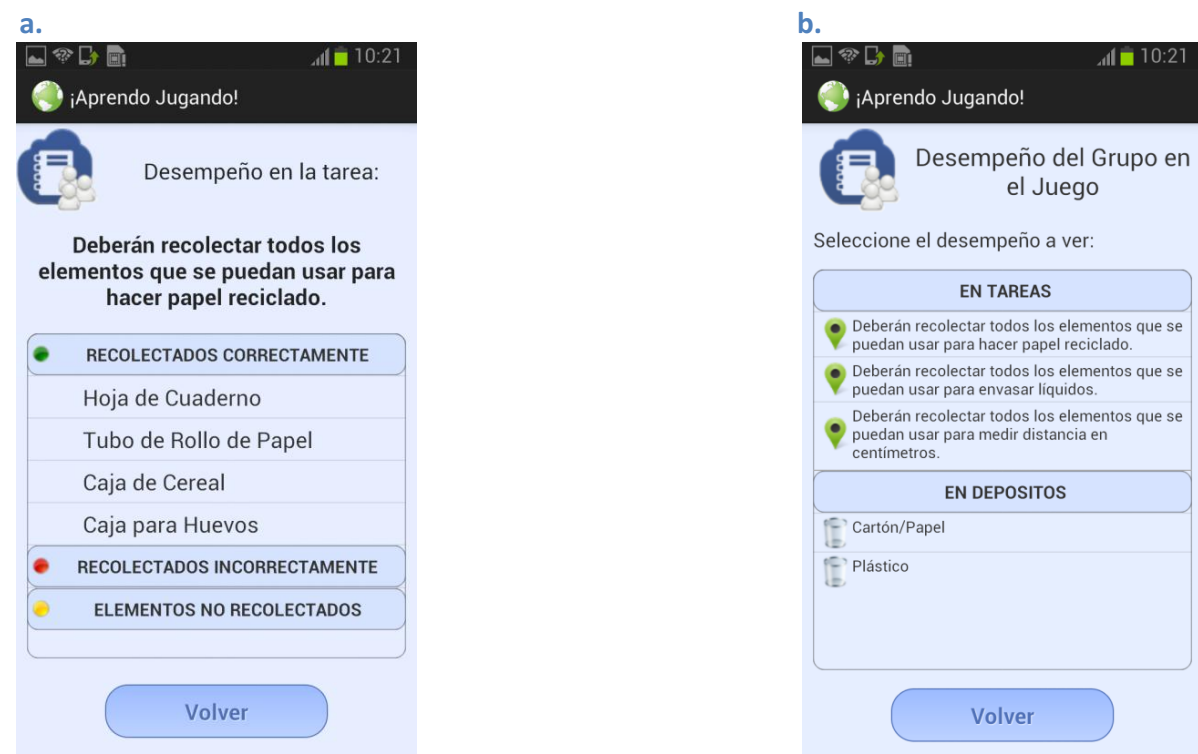

Figura B.19: Desempeño en la primera tarea de recolección

De la pantalla visualizada en la Figura B.19.b, se decide ver el desempeño en la segunda tarea de recolección. Al seleccionarla, se visualiza la pantalla mostrada en la Figura B.20.a. En dicha pantalla, se visualiza el enunciado de la consigna de la tarea, y se muestran los elementos concretos recolectados clasificados en correctamente 0 incorrectamente recolectados y se indican los elementos concretos que faltaron recolectar en la tarea realizada. Notar que en esta tarea, faltó recolectar el elemento concreto "Envase de Gaseosa" y se recolectó incorrectamente el elemento concreto "Sobre Grande". Al finalizar de ver este desempeño, se presiona el botón "Volver" y se visualiza la pantalla mostrada en la Figura B.20.b.
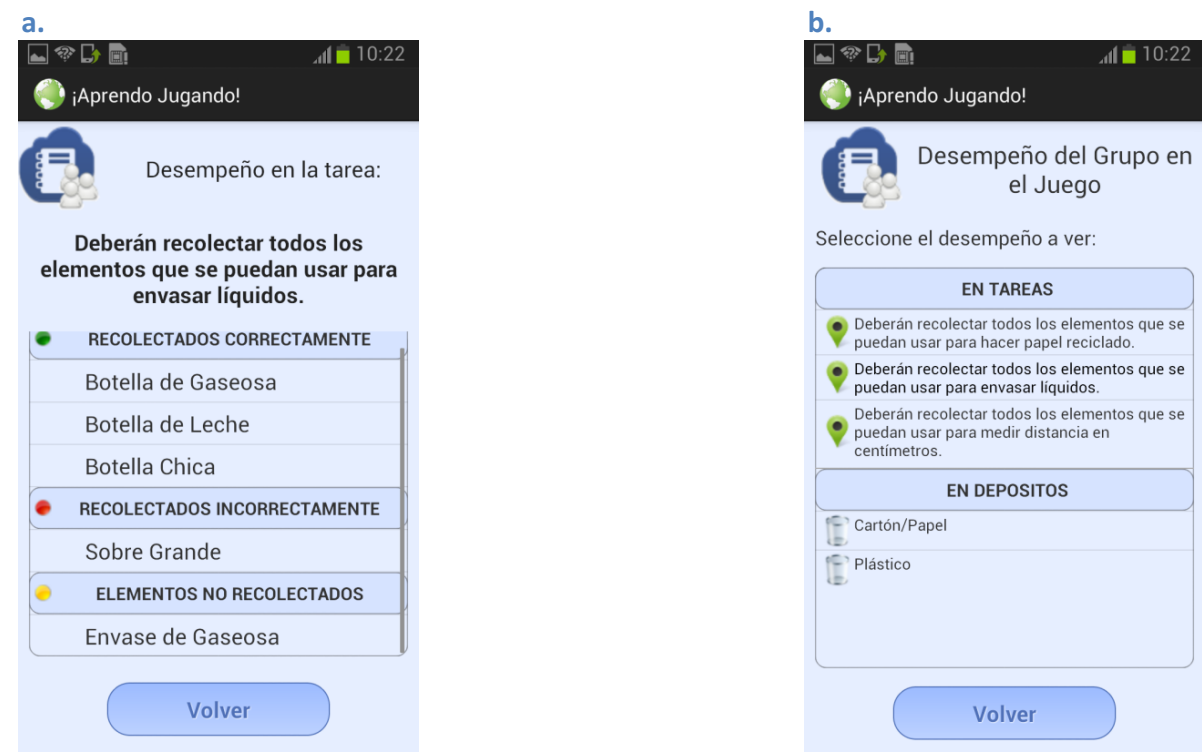

Figura B.20: Desempeño en la segunda tarea de recolección 
De la pantalla visualizada en la Figura B.20.b, se decide ver el desempeño en la tercera tarea de recolección. Al seleccionarla, se visualiza la pantalla mostrada en la Figura B.21.a. En dicha pantalla, se visualiza el enunciado de la consigna de la tarea, y se muestran los elementos concretos recolectados clasificados en correctamente o incorrectamente recolectados y se indican los elementos concretos que faltaron recolectar en la tarea realizada, siendo que los mismos eran correctos de recolección. Notar que en esta tarea se recolectó incorrectamente el elemento concreto "Vaso Medidor Grande". Al finalizar de ver este desempeño, se presiona el botón "Volver" y se visualiza la pantalla mostrada en la Figura B.21.b.

a.

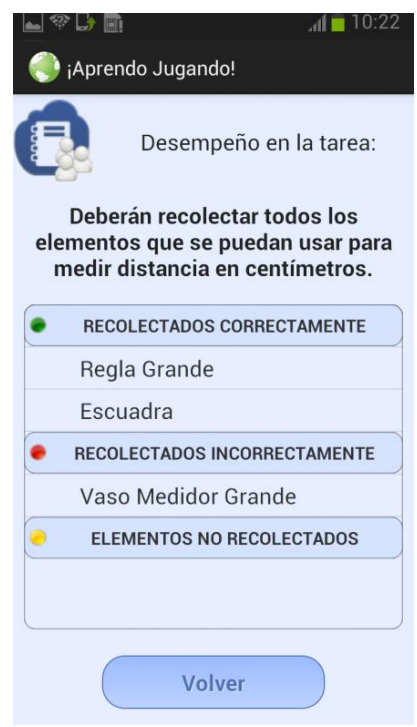

b.

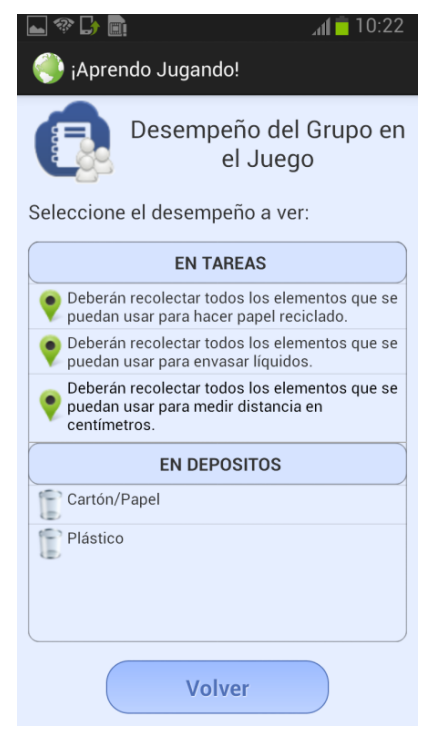

Figura B.21: Desempeño en la tercera tarea de recolección

De la pantalla visualizada en la Figura B.21.b, se decide ver el desempeño en la tarea de depositar en el depósito de "Cartón/Papel". Al seleccionarla, se visualiza la pantalla mostrada en la Figura B.22.a. En dicha pantalla, se visualiza el nombre del depósito, el enunciado de la consigna de la tarea, y se muestran los elementos concretos depositados clasificados en correctamente o incorrectamente depositados. Notar que en esta tarea se depositaron correctamente todos los elementos concretos. Al finalizar de ver este desempeño, se presiona el botón "Volver" y se visualiza la pantalla mostrada en la Figura B.22.b. En dicha pantalla se decide ver el desempeño en la tarea de depositar en el depósito de "Plástico". Al seleccionarla, se visualiza la pantalla mostrada en la Figura B.22.c. En dicha pantalla, se visualiza el nombre del depósito, el enunciado de la consigna de la tarea, y se muestran los elementos concretos depositados clasificados en correctamente o incorrectamente depositados. Notar que en esta tarea, también se depositaron correctamente todos los elementos concretos. 

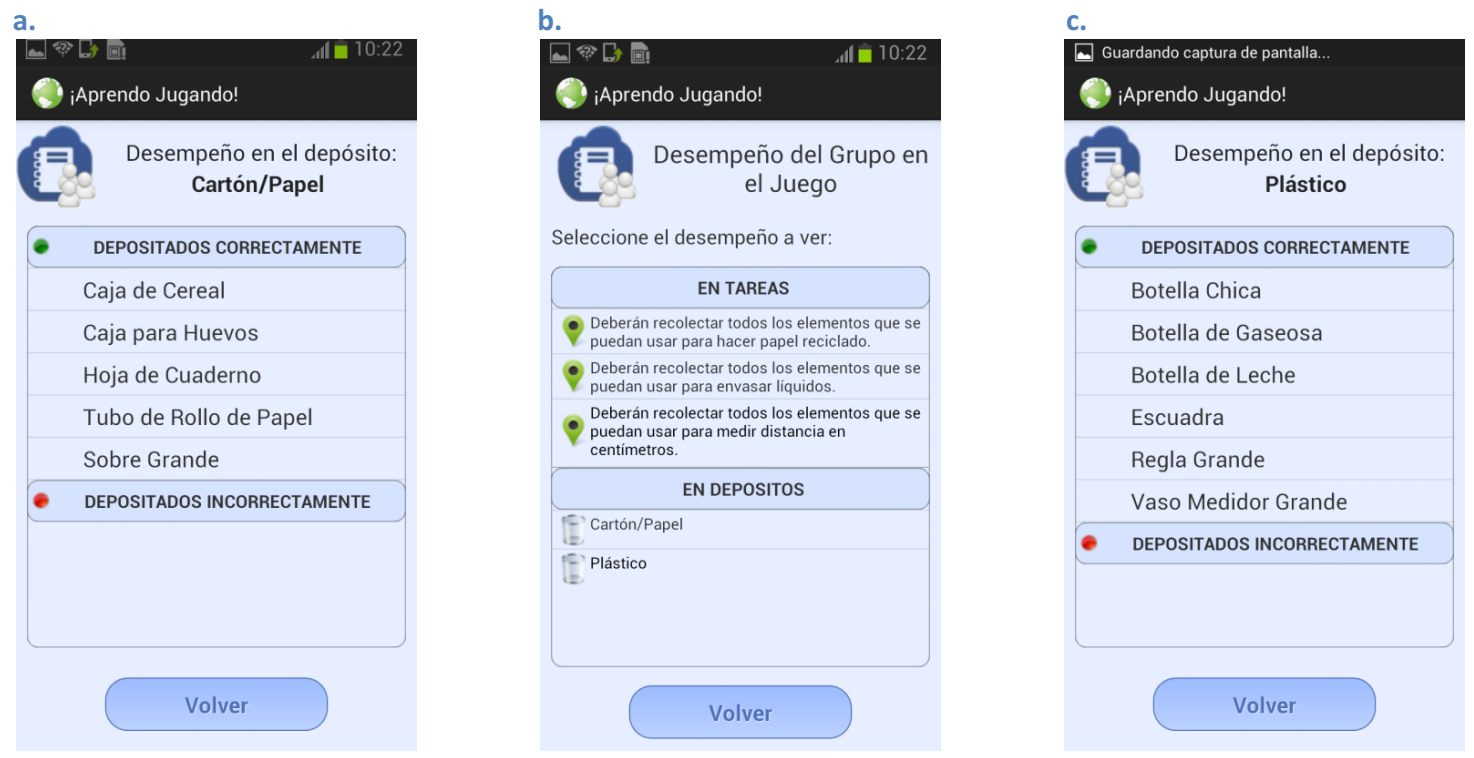

Figura B.22: Desempeño en las tareas de depositar

Al presionar el botón "Volver" en la pantalla visualizada en la Figura B.22.c, se visualiza la pantalla mostrada en la Figura B.23.a. En dicha pantalla se decide finalizar de ver desempeños y se presiona el botón "Volver". Como resultado, se visualiza la pantalla mostrada en la Figura B.23.b, en la cual se puede optar entre volver a ver el desempeño en el jugo o bien salir del mismo. En esta simulación se optó por presionar el botón "Salir del Juego". Al realizar esto, se visualiza una pantalla como se muestra en la Figura B.23.c, donde se pide confirmación para cerrar el juego realmente. Notar que los desempeños obtenidos, quedan almacenados en el dispositivo.

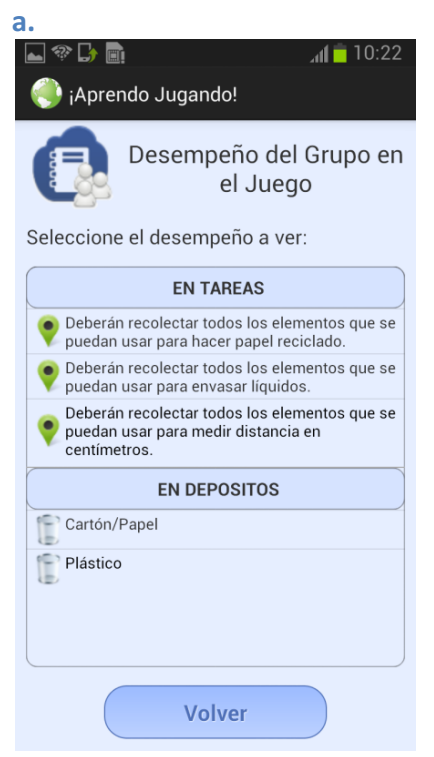

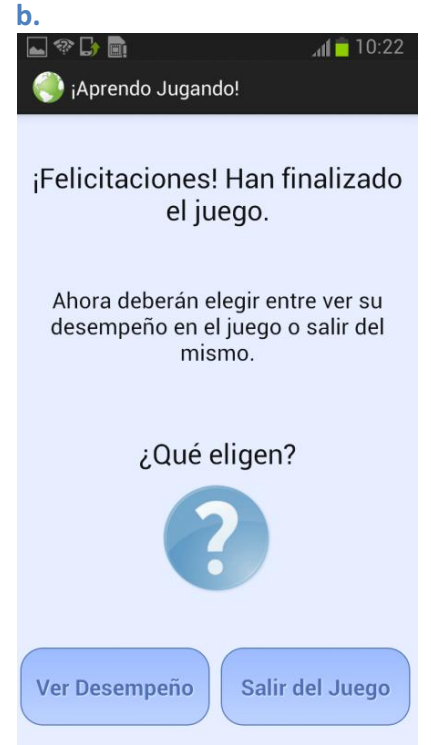

Figura B.23: Salir del juego

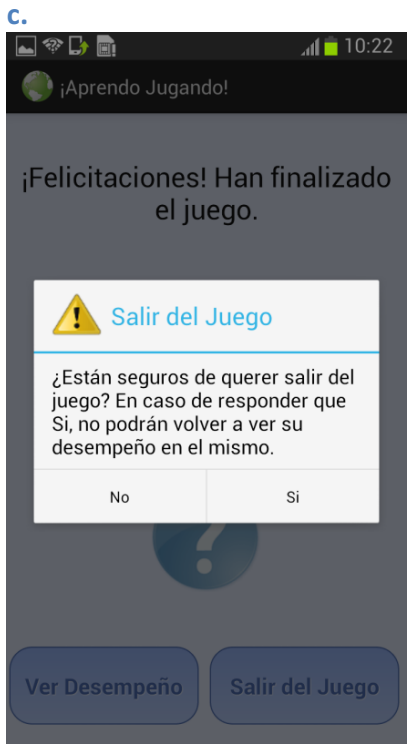

Página 157 de 167 
De este modo, se presentó una simulación de uso del prototipo de acuerdo a la secuencia de visitas a tareas propuesta en la Figura B.2. 


\section{Anexo C: Planilla de observación para la Escuela Nro. 76}

En este anexo se presenta la planilla de observación realizada para cada puesta en práctica realizada en la Escuela Nro. 76. Los datos obtenidos a partir de la observación, son presentados en el Capítulo 5, Sección 5.2.

Se puede apreciar que la Planilla C.1, cuenta con los siguientes ítems que se fueron completando para cada una de las tareas.

- Comprendieron el mapa que recibieron para llegar a:

- Lectura de códigos QR de tarea

- Al recibir la tarea, y leerla la comprendieron (desde el enunciado y no la solución)

- Lectura de códigos QR de los elementos concretos

- Observaron los elementos concretos mientras lo sostenían

- Debatieron en grupo que recolectar

- Debatieron en grupo que actividad realizar a continuación

- Lectura de códigos QR de depósitos

- Debatieron en grupo que depositar

Cabe destacar que los ítems relacionados a los depósitos podían ser completados al final de todas las tareas o cuando se iba realizando cada tarea, esto dependía de cómo los alumnos elegían continuar su experiencia.

Además, se puede apreciar en la Planilla C.1, que se van a ir completando las transiciones realizadas por los alumnos como así también las observaciones generales detectadas en cada puesta en práctica. 


\section{Planilla C.1}

\section{iAPRENDO JUGANDO! Escuela Nro. 76 -4to. Grado-}

Cant. de nenas

Nomenclatura a usar:

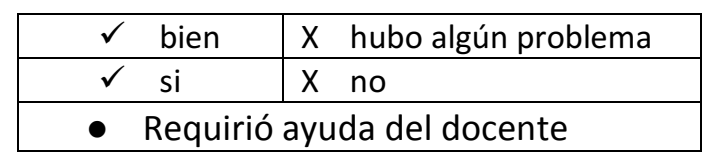

\begin{tabular}{|c|c|c|c|c|c|c|c|c|c|}
\hline & $\begin{array}{l}\text { Comprendieron } \\
\text { el mapa que } \\
\text { recibieron para } \\
\text { llegar a: }\end{array}$ & $\begin{array}{l}\text { Lectura } \\
\text { de } \\
\text { códigos } \\
\text { QR de } \\
\text { tarea }\end{array}$ & $\begin{array}{l}\text { Al recibir la } \\
\text { tarea, y leerla la } \\
\text { comprendieron } \\
\text { (desde el } \\
\text { enunciado y no } \\
\text { la solución) }\end{array}$ & $\begin{array}{l}\text { Lectura de } \\
\text { códigos QR } \\
\text { de los } \\
\text { elementos } \\
\text { concretos }\end{array}$ & $\begin{array}{l}\text { Observaron los } \\
\text { elementos } \\
\text { concretos } \\
\text { mientras lo } \\
\text { sostenían }\end{array}$ & $\begin{array}{l}\text { Debatieron } \\
\text { en grupo que } \\
\text { recolectar }\end{array}$ & $\begin{array}{l}\text { Debatieron } \\
\text { en grupo que } \\
\text { actividad } \\
\text { realizar a } \\
\text { continuación }\end{array}$ & $\begin{array}{l}\text { Lectura de } \\
\text { códigos QR } \\
\text { de depósitos }\end{array}$ & $\begin{array}{l}\text { Debatieron } \\
\text { en grupo que } \\
\text { depositar }\end{array}$ \\
\hline Tarea 1 & & & & & & & & & \\
\hline Tarea 2 & & & & & & & & & \\
\hline Tarea 3 & & & & & & & & & \\
\hline
\end{tabular}

\begin{tabular}{|l|l|}
\hline Flujo seguido en el uso del juego & Observaciones Generales: \\
\hline
\end{tabular}




\section{Anexo D: Planilla de observación para la Escuela Manantiales}

En este anexo se presenta la planilla de observación realizada para cada puesta en práctica realizada en la Escuela Manantiales. Los datos obtenidos a partir de la observación, son presentados en el Capítulo 5, Sección 5.2.

Se puede apreciar que la Planilla D.1, cuenta con los siguientes ítems que se fueron completando para cada una de las tareas.

- Comprendieron el mapa que recibieron para llegar a:

- Identificaron cuál es el código QR de tarea

- Al recibir y leer la tarea, comprendieron la consigna

- Lectura de códigos QR de los elementos concretos (a nivel de software del lector de código QR y uso de botones del aprendo)

- Leyeron código QR de elementos concretos y dejaron en la canasta

- Pusieron en la canasta elementos concretos que no leyeron

- Leyeron código QR de elementos concretos y no lo pusieron en la canasta

- Observaron los elementos concretos mientras lo sostenían

- Debatieron en grupo que recolectar

- Debatieron en grupo que actividad realizar a continuación

En relación a los depósitos:

- Llegaban a los depósitos sin acceder al mapa que les indica donde están

- Depositar sin leer el código QR del depósito

- Lectura de códigos QR de depósitos

- Debatieron en grupo que depositar

- Al momento de depositar: Quisieron leer nuevamente el código QR del elemento concreto

- Depositaron sin tildar en la lista del juego

Cabe destacar que los ítems relacionados a los depósitos podían ser completados al final de todas las tareas o cuando se iba realizando cada tarea, esto dependía de cómo los alumnos elegían continuar su experiencia. 
Además, se puede apreciar en la Planilla D.1, que se van a ir completando las transiciones realizadas por los alumnos como así también las observaciones generales detectadas en cada puesta en práctica. 


\section{Planilla D.1}

\section{¡APRENDO JUGANDO! 2013-12-12}

Escuela Manantiales 6to. Grado Cant. de nenas

Cant. de nenes

\begin{tabular}{|c|c|c|c|}
\hline & TAREA 1 & TAREA 2 & TAREA3 \\
\hline \multicolumn{4}{|l|}{ Comprendieron el mapa que recibieron para llegar a: } \\
\hline \multicolumn{4}{|l|}{ Identificaron cual es el código QR de tarea a leer } \\
\hline \multicolumn{4}{|l|}{ Lectura de códigos QR de tarea } \\
\hline \multicolumn{4}{|l|}{ Al recibir y leer la tarea, comprendieron la consigna } \\
\hline \multicolumn{4}{|l|}{$\begin{array}{l}\text { Lectura de códigos QR de los elementos concretos (a nivel de } \\
\text { software de lector de QR y uso de botones del aprendo) }\end{array}$} \\
\hline \multicolumn{4}{|l|}{$\begin{array}{l}\text { Leyeron código QR de elementos concretos y } \\
\text { dejaron en la canasta (si-no) }\end{array}$} \\
\hline \multicolumn{4}{|l|}{$\begin{array}{l}\text { Pusieron en la canasta elementos concretos que no } \\
\text { leyeron (si-no) }\end{array}$} \\
\hline \multicolumn{4}{|l|}{$\begin{array}{l}\text { Leyeron QR de elementos concretos y no lo } \\
\text { pusieron en la canasta(si-no) }\end{array}$} \\
\hline \multicolumn{4}{|l|}{ Observaron los elementos concretos mientras lo sostenían } \\
\hline \multicolumn{4}{|l|}{ Debatieron en grupo que recolectar } \\
\hline Debatieron en grupo que actividad realizar a continuación & & & \\
\hline
\end{tabular}

\begin{tabular}{|l|l|}
\hline & \multicolumn{1}{|c|}{ DEPÓSITOS } \\
\hline $\begin{array}{l}\text { Llegaban a los depósitos sin acceder al mapa que les } \\
\text { indica donde están } \\
\text { (De difícil observación) }\end{array}$ & \\
\hline Depositar sin leer el código QR del depósito & \\
\hline Lectura de códigos QR de depósitos & \\
\hline Debatieron en grupo que depositar & \\
\hline $\begin{array}{l}\text { Al momento de depositar: Quisieron leer nuevamente } \\
\text { el código QR del elemento concreto }\end{array}$ & \\
\hline Depositaron sin tildar en la lista del juego & \\
\hline
\end{tabular}

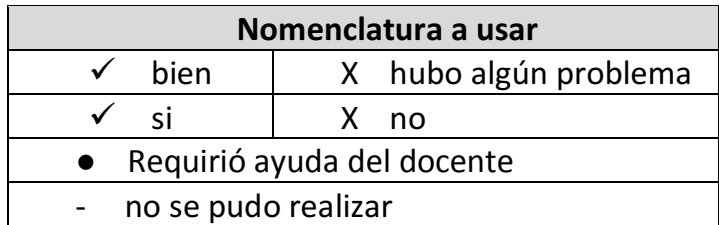

Flujo de acciones del grupo

\section{Observaciones:}


Página 164 de 167 


\section{Publicaciones realizadas relacionadas a la temática de la tesis}

A continuación se listan los trabajos publicados que se relacionan con la temática de la tesis realizada, se detalla de cada uno de estos trabajos un resumen del mismo y los aspectos relacionados a la tesis.

- Juegos Educativos Móviles Basados en Posicionamiento: Una Guía para su Conceptualización [Lliteras et al., 2012]

Resumen: Los Juegos Educativos Móviles basados en posicionamiento constituyen un tipo particular de Aplicación Móvil y cuentan con características propias que los identifican. Son creados con objetivos educativos y se emplean como una herramienta en el proceso de aprendizaje por considerarse un elemento motivador para el alumno en dicho proceso. En este trabajo se propone una Guía para la Conceptualización de Juegos Educativos Móviles basados en posicionamiento. Esta conceptualización contempla dos capas, la capa de contenido educativo y la capa de movilidad, a fin de lograr el reuso de las mismas brindando flexibilidad en su composición.

Relación con la tesis presentada:

- Esta publicación fue usada como base para desacoplar los conceptos de actividades educativas y posicionamiento, en particular se identificaron tres capas conceptuales: Actividades Educativas, Actividades Educativas Posicionadas y Usuario. De esta manera, se aprovecha las ventajas ya planteada en la publicación para cualquier tipo de contenido educativo posicionado en general, y se lo aplica a actividades educativas posicionadas.

- Las estructuras mencionadas en esta publicación fueron usadas para la estructuración de actividades educativas, ya que las mismas se definieron en general para cualquier contenido educativo. En el caso particular de esta tesis serían tareas y actividades educativas. Es decir, la generalidad presentada en dicha publicación, permite beneficiarse de las ventajas de la solución propuesta para contenido educativo y aplicarlo, en esta tesis, en las actividades educativas y tareas.

- Juegos Educativos Móviles: Aspectos Involucrados [Lliteras et al., 2013]

Resumen: Los Juegos Educativos Móviles son creados con objetivos educativos y se emplean como una herramienta en el proceso de aprendizaje por considerarse un elemento motivador para los alumnos. En este trabajo se presentan tres aspectos

Página 165 de 167 
de este tipo de juegos: el contenido, la movilidad y la presentación (que se le brinda al alumno de los dos aspectos anteriores). El objetivo de este trabajo, es presentar estos aspectos de manera desacoplada entre sí, para poderlos combinar, al momento de la creación de estos juegos, fomentando de este modo, el reuso de cada aspecto.

Relación con la tesis presentada:

- De esta publicación, se tomo el concepto de separación del contenido educativo de la presentación visual de los mismos, y se lo particularizo para definir los componentes de enunciando de una manera independiente de cómo los mismos son visualizados. En el prototipo presentado se define una posible visualización de las actividades educativas, podrían crearse otras visualizaciones a partir de las mismas.

- Authoring Tool for Location-Aware Experiences [Alconada Verzini et al., 2015a]

Resumen: In this paper, we present an approach to create location-aware experiences. We use the concept of separation of concerns to represent the content layer and the location layer. This separation allows reusing the layers independently one of each other. The focus of this paper is to provide an end-user tool to create location-aware applications in-situ. By using our tool, the locationaware experiences can be defined in both indoor and outdoor spaces. We present an example of how our tool is used and we describe some discussion points that have occurred to us while defining a tool with these characteristics.

Relación con la tesis presentada:

- En esta publicación se presenta una herramienta visual para la construcción de experiencias sensibles a la posición. La misma está basada en una generalización de los conceptos de separación de concerns definidos en esta tesis. Como trabajo futuro se particularizará esta herramienta para definir actividades educativas posicionadas.

- Combing Location-Aware Applications with in-situ Actors Performances [Alconada Verzini et al., 2015b]

Resumen: In this paper we present a model to define location-aware experiences having its different aspects (contents, location, etc) decoupled one from another. We have created an application following this model, which is also combined with actors' performances. This application defines three relevant locations inside a specific building. By reading a QR-code the user indicates that he/she has arrived at one of those locations. In that moment, the application triggers some questions 
related to the actors' performances. Hence, the user is required to see all the plays in order to be able to answer such questions. The application assists the user in moving throughout the different locations. We present the evaluation of this application and then we discuss interesting aspects that have shown up as a result of the in-situ evaluation of this application.

Relación con la tesis presentada:

- En esta publicación se presenta un enfoque de modelado para aplicaciones sensibles a la posición. Este mismo concepto es el usado en esta tesis, pero particularizándolo para actividades educativas posicionadas, donde la posición queda desacoplada de las actividades educativas. 